\author{
Universidade de São Paulo \\ Instituto de Química \\ Instituto de Física \\ Instituto de Biociências \\ Faculdade de Educação
}

Simone Alves de Assis Martorano

\title{
A TRANSIÇÃO PROGRESSIVA DOS MODELOS DE ENSINO SOBRE CINÉTICA QUÍMICA A PARTIR DO DESENVOLVIMENTO HISTÓRICO DO TEMA
}

São Paulo

2012 


\author{
Universidade de São Paulo \\ Instituto de Química \\ Instituto de Física \\ Instituto de Biociências \\ Faculdade de Educação
}

\title{
A TRANSIÇÃO PROGRESSIVA DOS MODELOS DE ENSINO SOBRE CINÉTICA QUÍMICA A PARTIR DO DESENVOLVIMENTO HISTÓRICO DO TEMA
}

\section{Simone Alves de Assis Martorano}

\author{
Tese apresentada ao Instituto de Física, ao \\ Instituto de Química, ao Instituto de \\ Biociências e à Faculdade de Educação da \\ Universidade de São Paulo, para obtenção do \\ título de Doutor em Ensino de Ciências, \\ modalidade Química. \\ Orientadora: Profa. Dra. Maria Eunice Ribeiro \\ Marcondes
}

São Paulo

2012 
Autorizo a reprodução e divulgação total ou parcial deste trabalho, por qualquer meio, convencional ou eletrônico, para fins de estudo e pesquisa, desde que citada a fonte.

\section{FICHA CATALOGRÁFICA Preparada pelo Serviço de Biblioteca e Informação do Instituto de Física da Universidade de São Paulo}

Martorano, Simone Alves de Assis

A transição progressiva dos modelos de ensino sobre cinética química a partir do desenvolvimento histórico do tema. - São Paulo, 2012.

Tese (Doutorado) - Universidade de São Paulo.

Faculdade de Educação, Instituto de Física, Instituto de Química e Instituto de Biociências

Orientador: $\operatorname{Prof}^{\mathrm{a}} \mathrm{Dr}^{\mathrm{a}}$ Maria Eunice Ribeiro Marcondes

Área de Concentração: Ensino de Química

Unitermos: 1. História da Ciência; 2.Formação continuada do professor; 3.Cinética química. 
Para

Eábio, men marido, Sabriel e Rafael, meus filhos, amor e gratidão pelo apoio incondicional e compreensão as longo dessa jornada. 


\section{Agradecimentos}

Aos professores que participaram de todo processo, por sua disposição, envolvimento e interesse em tornar o ensino de química melhor

À professora Maria Eunice, que com sua sabedoria guiou meus passos nesta jornada do doutorado, orientando-me a fazer as melhores escolhas durante este percurso.

Às minhas queridas amigas, Angella, Miriam e Mara que me incentivaram e ajudaram de diversas maneiras na realização deste trabalho.

A toda a minha família que me apoiou o tempo todo, em especial a minha querida sogra Maria Julia.

A todos meus amigos do GEPEQ, que contribuíram enormemente para o meu aprendizado.

Aos meus amigos do programa por este tempo de convívio, troca de experiências e amizade. 
Martorano, S.A.A.; A transição progressiva dos modelos de ensino sobre cinética química a partir do desenvolvimento histórico do tema. Tese (Doutorado) - Instituto de Química, faculdade de Educação.Universidade de São Paulo. São Paulo, 2012.

\section{Resumo}

Atualmente, no ensino médio brasileiro, o tema cinética química tem sido apontado por professores do ensino médio como sendo de difícil abordagem devido ao caráter empírico como também abstrato dos conhecimentos envolvidos. Levando em consideração essas dificuldades, o objetivo desta pesquisa foi o de identificar como uma abordagem com foco na história da ciência pode contribuir para uma transição progressiva de professores de química do ensino médio no que se refere ao modelo de ensino de cinética química, considerando os conteúdos e as estratégias de ensino utilizadas. Para alcançar esse objetivo foi oferecido um curso de formação continuada para 20 professores de química, em que foi apresentado o tema cinética química na perspectiva do desenvolvimento histórico desse tema (reconstrução histórica), permitindo assim uma melhor compreensão do contexto no qual esses conceitos foram desenvolvidos. Baseando-se na perspectiva de Lakatos, foram construídos modelos de ensino de cinética química a partir das ideias dos professores, procurando-se verificar se esses modelos formam sequências de transição progressiva, similares ao que Lakatos, na História da Ciência, se refere a "problemática" que aumenta o poder explanatório/heurístico do modelo. A evolução dos modelos, que geralmente consiste em transições progressivas e que variam em grau, está relacionada ao entendimento manifestado pelos professores dos conteúdos específicos de cinética química, do entendimento da natureza da ciência e à compreensão do desenvolvido histórico desse tema. Inicialmente, os modelos de ensino dos professores estavam baseados principalmente nos aspectos macroscópicos da cinética química, como, por exemplo, nos fatores que influem na velocidade de uma reação química, sendo que poucos professores possuíam modelos em que estavam presentes aspectos microscópicos. Percebeu-se, pela análise dos modelos de ensino dos professores, que houve transição progressiva principalmente no que se refere ao entendimento do papel da Historia da Química no ensino como também na construção de imagem de ciência mais coerente com a perspectiva racionalista.

Palavras Chave: História da Química, Formação continuada do professor, Cinética Química. 
Martorano, S.A.A.; Progressive transitions in models on chemical kinetics from the historical development of the subject. Tese (Doutorado) - Instituto de Química, faculdade de Educação.Universidade de São Paulo. São Paulo, 2012.

Abstract

Chemical kinetics in high school is regarded, by teachers, as a complex topic to be taught since it comprehends explanatory theoretical models (including mathematical models) besides descriptive empirical approaches. Considering these difficulties the aim of this study is to investigate how a historical approach can facilitate teaching, taking into account their decisions about the content selection and teaching strategies. An in-service course on chemical kinetics focused on its historical development (historical reconstruction) was offered to 20 chemistry teachers. The course aimed to promote the understanding of the historical context in which the kinetic concepts were developed. Based on Lakatos science program perspective, models for chemical kinetics teaching were built and they were based on the teachers' conceptions raised during the course activities as an attempt to verify if they represented sequences of progressive transitions similar to what Lakatos has referred as "progressive problemshifts" in the history of science. The evolution of the teachers' models were related to the understanding manifested by them of specific content on chemical kinetics, understanding the nature of science, as well as the comprehension of the historical development of chemical kinetic concepts and models. At the beginning of the course, the teaching models were mainly based on macroscopic aspects of chemical kinetics, for instance, the factors that affect the rate of chemical reactions. Analyzing teaching models of teachers, we noted that there was a progressive transition, especially on the understanding of the role of the History of Science in education, but also in building of the image of science, more consistent with the rationalist perspective.

Keywords: History of Chemistry, Professor of Continuing Education, Chemical Kinetics. 


\section{Sumário}

Introdução

Capítulo 1. Revisão de estudos sobre o ensino e aprendizagem do tema Cinética Química e do papel da História e Filosofia da Ciência no ensino de Química. .22

1.1. O ensino e aprendizagem do tema Cinética Química ..................................22

1.2. A História e Filosofia da Ciência e o Ensino de Química.................................41

Capítulo 2. A Reconstrução Histórica do Desenvolvimento da Cinética Química .....56

Texto 1: O desenvolvimento Histórico da Cinética Química: Os estudos iniciais uma breve tentativa de sinalizar o contexto (1850-1862)

Texto 2: Os estudos sobre a influência da temperatura e da concentração na velocidade de uma Transformação Química no período de 1862 a 1888. .65

Texto 3: O desenvolvimento da teoria das colisões e o conceito de energia de ativação (1889-1918)

Texto 4: O desenvolvimento da teoria do estado de transição (1918-1935) ..............77

Capítulo 3. Caminhos metodológicos

3.1 Primeira Etapa: Curso de formação continuada para professores de química....81

3.1.1 Descrição dos encontros .88

Primeiro encontro .88

Segundo encontro: Os estudos iniciais da cinética química .89

Terceiro encontro: O reconhecimento da cinética química como campo da química (1850 a 1867) .92

Quarto encontro: O uso do conceito de energia para explicar a velocidade de uma reação (1872 a 1888) .94

Quinto encontro: As primeiras teorias de colisões entre molécula (1889-1918)........98

Sexto encontro: A teoria do Estado de Transição (1918 - 1935) 100

Sétimo encontro: Os Programas de Investigação Científica (Lakatos) 102

Oitavo encontro 103 
3.2.Segunda Etapa: Acompanhamento da aplicação dos planos de ensino pelos

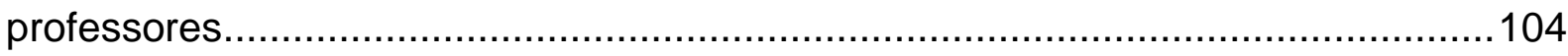

3.3. Instrumentos de análise dos dados da pesquisa...........................................105

Capítulo 4. A transição progressiva dos modelos de ensino de cinética química ...113

4.1 Transição progressiva dos modelos de ensino durante o curso de formação continuada.

4.2 Transição progressiva das duas professoras após a aplicação do plano de ensino 290

Conclusões e Considerações ...............................................................................

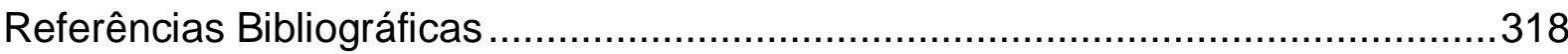

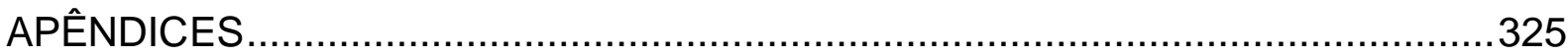

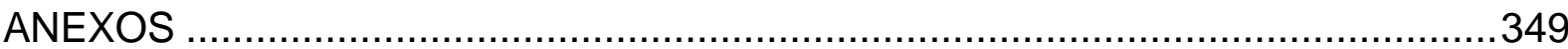




\section{ÍNDICE DE QUADROS}

\section{Capítulo 1}

Quadro 1. Estratégias de ensino para uma aprendizagem como investigação (Gil Peréz p.203, 1993)

\section{Capítulo 3}

Quadro 3.1 Temas, conteúdos e atividades de cada um dos encontros do curso de formação continuada

Quadro 3.2 Perfil e experiência profissional de cada professor. Nota: 1Professores Coordenadores das Oficinas Pedagógicas das diretorias de Ensino da Rede Pública de São Paulo

Quadro 3.3. Categorias para a identificação da perspectiva filosófica dos professores (Martorano, 2007)

\section{Capítulo 4}

Quadro 4.1 Habilidades e competências indicadas no plano de ensino da professora P1.

Quadro 4.2 Modelos de ensino de cinética química do professor P1, em relação aos três aspectos analisados (cinética química, Historia da Química e imagem da ciência) nas diferentes etapas do curso de formação.

Quadro 4.3 Habilidades e competências indicadas no plano de ensino da professora P2.

Quadro 4.4. Modelos de ensino de cinética química do professor P2, em relação aos três aspectos analisados (cinética química, Historia da Química e imagem da ciência) nas diferentes etapas do curso de formação.

Quadro 4.5 Habilidades e competências indicadas no plano de ensino da professora P3.

Quadro 4.6 Modelos de ensino de cinética química do professor P3, em relação aos três aspectos analisados (cinética química, Historia da Química e imagem da ciência) nas diferentes etapas do curso de formação.

Quadro 4.7 Habilidades e competências indicadas no plano de ensino da professora P4.

Quadro 4.8 Modelos de ensino de cinética química do professor P4, em relação aos três aspectos analisados (cinética química, Historia da Química e imagem da ciência) nas diferentes etapas do curso de formação.

Quadro 4.9 Habilidades e competências indicadas no plano de ensino do professor P5.

Quadro 4.10 Modelos de ensino de cinética química do professor P5, nas diferentes etapas do curso de formação.

Quadro 4.11 Habilidades e competências indicadas no plano de ensino do professor P6.

Quadro 4.12 Modelos de ensino de cinética química do professor P6, nas diferentes etapas do curso de formação.

Quadro 4.13 Habilidades e competências indicadas no plano de ensino da 
professora P7

Quadro 4.14 Modelos de ensino de cinética química do professor P7, nas diferentes etapas do curso de formação

Quadro 4.15 Habilidades e competências indicadas no plano de ensino do professor P8

Quadro 4.16 Modelos de ensino de cinética química do professor P8, nas diferentes etapas do curso de formação

Quadro 4.17 Habilidades e competências indicadas no plano de ensino da professora P9

Quadro 4.18 Modelos de ensino de cinética química do professor P9 nas diferentes etapas do curso de formação

Quadro 4.19 Habilidades e competências indicadas no plano de ensino da professora P10

Quadro 4.20 Modelos de ensino de cinética química do professor P10 nas diferentes etapas do curso de formação

Quadro 4.21 Habilidades e competências indicadas no plano de ensino da professora P1

Quadro 4.22 Modelos de ensino de cinética química do professor P11 nas diferentes etapas do curso de formação

Quadro 4.23 Habilidades e competências indicadas no plano de ensino da professora P12

Quadro 4.24 Modelos de ensino de cinética química do professor P12 nas diferentes etapas do curso de formação

Quadro 4.25 Habilidades e competências indicadas no plano de ensino da professora P13

Quadro 4.26 Modelos de ensino de cinética química do professor P13 nas diferentes etapas do curso de formação

Quadro 4.27 Habilidades e competências indicadas no plano de ensino do professor P14

Quadro 4.28 Modelos de ensino de cinética química do professor P14 nas diferentes etapas do curso de formação

Quadro 4.29 Habilidades e competências indicadas no plano de ensino da professora P15

Quadro 4.30 Modelos de ensino de cinética química do professor P15 nas diferentes etapas do curso de formação

Quadro 4.31 Habilidades e competências indicadas no plano de ensino da professora P16

Quadro 4.32 Modelos de ensino de cinética química do professor P16 nas diferentes etapas do curso de formação

Quadro 4.33 Habilidades e competências indicadas no plano de ensino da professora P17

Quadro 4.34 Modelos de ensino de cinética química do professor P17 nas 
diferentes etapas do curso de formação

Quadro 4.35 Modelos de ensino de cinética química da professora P18 nas diferentes etapas do curso de formação

Quadro 4.36 Habilidades e competências indicadas no plano de ensino da professora P19

Quadro 4.37 Modelos de ensino de cinética química da professora P19 nas diferentes etapas do curso de formação

Quadro 4.38 Habilidades e competências indicadas no plano de ensino da professora P20

Quadro 4.39 Modelos de ensino de cinética química da professora P20 nas diferentes etapas do curso de formação

Quadro 4.40 Questão da avaliação final elaborada da professora P11

Quadro 4.41 Modelos de ensino de cinética química da professora P11 nas diferentes etapas do curso de formação e na aplicação de seu plano de ensino

Quadro 4.42 Modelos de ensino de cinética química da professora P15 nas diferentes etapas do curso de formação e na aplicação de seu plano de ensino 


\section{ÍNDICE DE FIGURAS}

\section{Capítulo 1}

Figura 1.1 A relação entre o fenômeno químico e as teorias/modelos (Cakmakci et al, p.484, 2005). (Tradução nossa)

Figura 1.2 Questão 1 do Instrumento (Taştan et al ,p. 50, 2010). 38

Figura 1.3 Respostas dos professores por questão (Taştan et al ,p. 52, 2010).

Figura 1.4 Caráter interdisciplinar da Educação em ciências (Cachapuz et al, p. 365, 2002)

\section{Capitulo 2}

Figura 2.1 Extrato do "Poggendorf's Annalen der Physik und chemie, The law by the action of acids on cane sugar occurs", onde Wilhelmy estuda a influência do tempo na velocidade da hidrólise da sacarose.

Figura 2.2 Extrato do "Poggendorf's Annalen der Physik und chemie, The law by the action of acids on cane sugar occurs", onde Wilhelmy estuda a influência da quantidade de açúcar na velocidade da hidrólise da sacarose

Figura 2.3. Extrato do "Poggendorf's Annalen der Physik und chemie, The law by the action of acids on cane sugar occurs", onde Wilhelmy estuda a independência do valor de $\mathrm{M}$ da quantidade de açúcar.

Figura 2.4 Esquema da aparelhagem que van't Hoff (1898) utilizou para estudar a marcha da reação de decomposição do gás arsina. (Études de Dynamique Chimique, pág.190,1898)

Figura 2.5 Dados experimentais obtidos por van't Hoff na decomposição do gás arsina a $310^{\circ} \mathrm{C}$ (Études de Dynamique Chimique, pág.190,1898).

Figura 2.6 Superfície de energia potencial de uma reação (Schor, 1994).

Figura 2.7 Representação de Evans e Polanyi (1935) para indicar o estado de transição. (Schor, 1994).

\section{Capítulo 4}

Figura 4.1 A variação da velocidade de uma reação em função do tempo segundo P1.

Figura 4.2 Mapa conceitual sobre a imagem da ciência elaborado pela professora P1.

Figura 4.3 Transição progressiva da professora $\mathrm{P} 1$ nas três fases da pesquisa, em relação aos seguintes aspectos de seu modelo de ensino: CQ: cinética química, HQ: História da Química e IC: imagem da ciência.

Figura 4.4 A variação da velocidade de uma reação em função do tempo segundo P2.

Figura 4.5 Transição progressiva da professora P2 nas três fases da pesquisa, em relação aos seguintes aspectos de seu modelo de ensino: $C Q$ : cinética química, HQ: História da Química e IC: imagem da ciência

Figura 4.6 Mapa conceitual sobre a imagem da ciência elaborado pela professora P3. 
Figura 4.7 Mapa conceitual sobre o tema cinética química elaborado pela professora P3.

Figura 4.8 Transição progressiva da professora P3 nas três fases da pesquisa, em relação aos seguintes aspectos de seu modelo de ensino: $C Q$ : cinética química, HQ: História da Química e IC: imagem da ciência.

Figura 4.9 A variação da velocidade de uma reação em função do tempo segundo P4.

Figura 4.10 Mapa conceitual, sobre a imagem da ciência, elaborado pela professora P4.

Figura 4.11 Transição progressiva da professora $P 4$ nas três fases da pesquisa, em relação aos seguintes aspectos de seu modelo de ensino: $C Q$ : cinética química, HQ: História da Química e IC: imagem da ciência.

4.12 Mapa conceitual sobre a imagem da ciência elaborado pelo professor P5.

Figura 4.13 Transição progressiva do professor P5 nas três fases da pesquisa, em relação aos seguintes aspectos de seu modelo de ensino: $C Q$ : cinética química, HQ: História da Química e IC: imagem da ciência.

Figura 4.14 A variação da velocidade de uma reação em função do tempo segundo P6.

Figura 4.15 Mapa conceitual sobre a imagem da ciência elaborado pelo professor P6.

Figura 4.16 Transição progressiva do professor P6 nas três fases da pesquisa, em relação aos seguintes aspectos de seu modelo de ensino: $C Q$ : cinética química, HQ: História da Química e IC: imagem da ciência.

Figura 4.17 A variação da velocidade de uma reação em função do tempo segundo P7.

Figura 4.18 Mapa conceitual sobre imagem da ciência elaborado pela professora P7.

Figura 4.19 Transição progressiva da professora P7 nas três fases da pesquisa, em relação aos seguintes aspectos de seu modelo de ensino: $C Q$ : cinética química, HQ: História da Química e IC: imagem da ciência.

Figura 4.20 A variação da velocidade de uma reação em função do tempo segundo P8

Figura 4.21 Mapa conceitual sobre a imagem da ciência elaborado pelo professor P8.

Figura 4.22 Transição progressiva do professor P8 nas três fases da pesquisa, em relação aos seguintes aspectos de seu modelo de ensino: CQ: cinética química, HQ: História da Química e IC: imagem da ciência.

Figura 4.23 A variação da velocidade de uma reação em função do tempo segundo P9

Figura 4.24 Transição progressiva do professor P9 nas três fases da pesquisa, em relação aos seguintes aspectos de seu modelo de ensino: $C Q$ : cinética química, HQ: História da Química e IC: imagem da ciência.

Figura 4. 25 Mapa conceitual sobre a imagem da ciência elaborado pela professora 
P10.

Figura 4.26 Transição progressiva da professora P10 nas três fases da pesquisa, em relação aos seguintes aspectos de seu modelo de ensino: $C Q$ : cinética química, HQ: História da Química e IC: imagem da ciência.

Figura 4.27 Transição progressiva da professora P11 nas três fases da pesquisa, em relação aos seguintes aspectos de seu modelo de ensino: $C Q$ : cinética química, HQ: História da Química e IC: imagem da ciência

Figura 4.28 A variação da velocidade de uma reação em função do tempo segundo P12

Figura 4.29 Mapa conceitual sobre a imagem da ciência elaborado pela professora P12..

Figura 4.30 Transição progressiva da professora $\mathrm{P} 12$ nas três fases da pesquisa, em relação aos seguintes aspectos de seu modelo de ensino: $C Q$ : cinética química, HQ: História da Química e IC: imagem da ciência.

Figura 4.31 Mapa conceitual sobre a imagem da ciência elaborado pela professora P13.

Figura 4.32 Transição progressiva da professora P13 nas três fases da pesquisa, em relação aos seguintes aspectos de seu modelo de ensino: $C Q$ : cinética química, $\mathrm{HQ}$ : História da Química e IC: imagem da ciência

Figura 4.33 A variação da velocidade de uma reação em função do tempo segundo P14.

Figura 4.34 Mapa conceitual sobre a imagem da ciência elaborado pelo professor P14.

Figura 4.35 Transição progressiva do professor P14 nas três fases da pesquisa, em relação aos seguintes aspectos de seu modelo de ensino: CQ: cinética química, HQ: História da Química e IC: imagem da ciência.

Figura 4.36 A variação da velocidade de uma reação em função do tempo segundo P15.

Figura 4.37 Mapa conceitual da professora P15 sobre a visão de ciência que ela espera que seus alunos construam.

Figura 4.38 Transição progressiva da professora P15 nas três fases da pesquisa, em relação aos seguintes aspectos de seu modelo de ensino: $C Q$ : cinética química, $H Q$ : História da Química e IC: imagem da ciência.

Figura 4.39 Transição progressiva da professora P16 nas três fases da pesquisa, em relação aos seguintes aspectos de seu modelo de ensino: $C Q$ : cinética química, $\mathrm{HQ}$ : História da Química e IC: imagem da ciência.

Figura 4.40 Mapa conceitual da professora P17 sobre a visão de ciência que ela espera que seus alunos construam.

Figura 4.41 Transição progressiva da professora $\mathrm{P} 17$ nas três fases da pesquisa, em relação aos seguintes aspectos de seu modelo de ensino: $C Q$ : cinética química, $H Q$ : História da Química e IC: imagem da ciência.

Figura 4.42 A variação da velocidade de uma reação em função do tempo segundo P18.

Figura 4.43 Mapa conceitual da professora P18 sobre a visão de ciência que ela 
espera que seus alunos construam.

Figura 4.44 Transição progressiva da professora P18 nas três fases da pesquisa, em relação aos seguintes aspectos de seu modelo de ensino: $C Q$ : cinética química, HQ: História da Química e IC: imagem da ciência.

Figura 4.45 Mapa conceitual sobre a imagem da ciência elaborado pela professora P19.

Figura 4.46 Transição progressiva da professora $\mathrm{P} 19$ nas três fases da pesquisa, em relação aos seguintes aspectos de seu modelo de ensino: $C Q$ : cinética química, $\mathrm{HQ}$ : História da Química e IC: imagem da ciência.

Figura 4.47 A variação da velocidade de uma reação em função do tempo segundo P20.

Figura 4.48 Mapa conceitual sobre a imagem da ciência elaborado pela professora P20.

Figura 4.49 Transição progressiva da professora P20 nas três fases da pesquisa, em relação aos seguintes aspectos de seu modelo de ensino: $C Q$ : cinética química, HQ: História da Química e IC: imagem da ciência.

Figura 4.50 Questionário elaborado pela professora P11 para levantamento das ideias iniciais dos alunos sobre cinética química.

Figura 4.51 Imagens do experimento decomposição da matéria orgânica.

Figura 4.52 Imagem do experimento dissolução de comprimido efervescente.

Figura 4.53 Imagens da pesquisa feita pelos alunos: "FATOS HISTÓRICOS DA CINÉTICA QUÍMICA".

Figura 4.54 Texto sobre a História da Cinética química incluído pela professora P11 na avaliação.

Figura 4.55 Transição progressiva da professora $\mathrm{P} 11$ nas quatro fases da pesquisa, em relação aos seguintes aspectos de seu modelo de ensino: $C Q$ : cinética química, HQ: História da Química e IC: imagem da ciência.

Figura 4.56 Imagem de alguns alunos durante a realização da primeira atividade (instrumento 2, Apêndice VII).

Figura 4.57 Imagem de alguns alunos respondendo as questões do texto sobre a história da cinética química.

Figura 4.58 Imagem da aula experimental, difusão gasosa.

Figura 4.59 Transição progressiva da professora $P 15$ nas quatro fases da pesquisa, em relação aos seguintes aspectos de seu modelo de ensino: $C Q$ : cinética química, HQ: História da Química e IC: imagem da ciência.

Figura 4.60 Transição progressiva dos professores nas 3 fases da pesquisa, em relação aos seguintes aspectos de seu modelo de ensino: $\mathrm{CQ}$ : cinética química.

Figura 4.61 Transição progressiva dos professores nas 3 fases da pesquisa, em relação aos seguintes aspectos de seu modelo de ensino: Imagem da natureza da ciência (IC).

Figura 4.62 Transição progressiva dos professores nas 3 fases da pesquisa, em relação aos seguintes aspectos de seu modelo de ensino: História da Química (HQ). 


\section{Introdução}

Comumente os professores de química, do ensino médio, consideram que seus alunos não conseguem aprender determinados conceitos químicos porque acreditam que eles iniciam o ensino médio com muitas falhas e lacunas de aprendizagem, como, por exemplo, dificuldades em interpretar gráficos, tabelas, dados experimentais, enunciados e exercícios.

Essas dificuldades são relatadas em muitas pesquisas (Justi e Ruas, 1997; van Driel, 2002; Kaya e Geban ,2012; Cakmakci et al, 2005 e 2010) e, junte-se a elas, a dificuldade no entendimento de conceitos, como, por exemplo, em interpretar o comportamento da matéria em termos submicroscópicos (Pozo e Crespo, 2009). Segundo os autores, muitos indivíduos enfrentam dificuldades em entender a matéria como descontínua e de aplicar espontaneamente, o modelo corpuscular em suas explicações, independentemente do grau de instrução recebida.

Contudo, o entendimento da natureza descontínua da matéria, como também o uso de um modelo corpuscular, são de fundamental importância para que os indivíduos compreendam e interpretem muitos fenômenos que ocorrem no mundo em que vivem.

Atualmente, no ensino médio, o tema cinética química tem sido apontado pelos professores como sendo de difícil abordagem, por causa do caráter empírico, tanto como abstrato deste tema. A compreensão da velocidade de uma reação química envolve a interpretação de dados experimentais e o entendimento do caráter dinâmico das partículas. Assim, o aluno tem de transitar entre o mundo macroscópico e o submicroscópico, o que exige um entendimento mais complexo da natureza da matéria.

Escolheu-se como foco de estudo, o tema cinética química, por considerá-lo um conteúdo imprescindível para a formação básica em química do aluno do ensino médio. O conhecimento desse assunto proporciona ao aluno o entendimento da velocidade de uma reação química, dos fatores que a determinam ou a modificam, mas, além disso, leva ao entendimento do mecanismo (ou caminho) de uma reação. 
Este conhecimento também pode proporcionar ao aluno o entendimento de diversos processos que estão presentes no seu cotidiano, como, por exemplo, a conservação de alimentos, o uso de catalisadores nos veículos, em nossas indústrias, entre outros.

Contudo, percebe-se que somente essas justificativas para o aprendizado de cinética química não têm sido suficientes para que os professores superem as dificuldades no seu ensino.

Pesquisas atuais no ensino de ciências, voltadas para a o ensino e aprendizagem de conceitos científicos, têm enfatizado a importância da História e Filosofia da Ciência (HFC) no processo de ensino e aprendizagem (Gil-Pérez, 1993; González, 1994; Justi,1997; Cachapuz, 1994; Cachapuz et al, 2002, 2004; Níaz, 2008, 2009; Porto, 2010).

A História da Química poderia então ajudar a superar as dificuldades encontradas no entendimento do tema cinética química. Segundo Porto (2010), o estudo e discussão de episódios históricos podem propiciar aos estudantes a superação de visões inadequadas sobre a natureza do conhecimento científico, como por exemplo, a ideia de que existe um único "método científico".

Portanto, este trabalho tem como foco investigar como a História da Química, mas especificamente o desenvolvimento histórico da cinética química, pode contribuir para o processo de ensino dos conceitos envolvidos no tema cinética química, como também na construção de uma visão de ciência alinhada à uma perspectiva atualmente aceita da filosofia da ciência.

A ideia de se de desenvolver esta investigação com professores, do ensino médio, surgiu a partir da pesquisa de mestrado da autora deste trabalho, que tratou da análise de livros didáticos e, para tal, foram elaborados quatro programas de investigação cientifica (Lakatos,1998) a partir da reconstrução histórica, de um determinado período de tempo, do desenvolvimento da cinética química. A partir dessa análise, percebeu-se que nos livros didáticos pouco o quase nenhuma História da Química era abordada no capitulo de cinética química e que a imagem sobre a natureza da ciência que poderia ser construída, a partir da leitura desse livro, era predominantemente empirista e indutivista. 
Assim, a partir de reflexões, sobre esses resultados, surgiu a ideia de se investigar como os professores de química, do ensino médio abordam o tema cinética química em suas aulas. Na busca desse objetivo foi elaborado um curso de formação continuada, dirigido aos professores de química, que teve como tema o estudo do desenvolvimento histórico da cinética química, de um determinado período de tempo (1850-1935).

Segundo Schnetzler (2002), existem várias razões para incentivar ações e programas de formação continuada visando à melhoria do ensino de ciências. A autora aponta as três principais razões, que são apresentadas a seguir:

Necessidade de contínuo aprimoramento profissional e de reflexões críticas sobre a prática pedagógica" (Schnetzler, p.15, 2002)

A formação continuada de professores tem o papel não só de garantir a atualização dos professores, como também de suprir deficiências do curso de formação.

\begin{abstract}
Necessidade de superar o distanciamento das pesquisas em ensino e sua utilização por professores. Em muitas pesquisas, o professor é considerado apenas como objeto de investigação por parte de professores universitários, que se utilizam dessa relação para esboçar novos projetos de pesquisa e deles derivarem novas prescrições, procedimentos, competências ou fazeres e saberes que os professores devem dominar. (Schnetzler, p.15, 2002)
\end{abstract}

Segundo Schnetzler (2002), não se deve conceber o professor como um mero técnico ou aplicador do que outros dizem, mas sim reconhecer e valorizar o professor como produtor de saberes pedagógicos, tão importantes ou mais do que muitas prescrições que a pesquisa educacional universitária já produziu.

"Superar as visões simplistas dos professores sobre a atividade docente." (Schnetzler, p.15, 2002)

Por essa visão, segundo a autora, entende-se que para ensinar química basta que o professor conheça o conteúdo químico e use algumas estratégias pedagógicas para controlar ou entreter os alunos. Contudo, a autora aponta que os cursos de reciclagem ou capacitação docente têm tido pouca efetividade devido aos objetivos, tempo, falta de grupos de discussões após o curso, ausência de discussões de cunho epistemológico e psicopedagógico sendo que muitas vezes 
esses cursos são realizados fora do contexto de trabalho do docente.

Portanto, a partir dessas considerações pretendeu-se, nesta pesquisa, alcançar os seguintes objetivos:

Objetivos Gerais:

- Contribuir para a formação continuada do professor de química.

- Contribuir para a melhoria do processo de ensino de cinética química.

- Contribuir para a construção de uma imagem da ciência coerente com a perspectiva racionalista contemporânea.

Objetivos específicos:

- Analisar o processo de incorporação, pelos professores, dos aspectos relacionados à História da Química no planejamento de seu ensino de cinética química.

- Caracterizar as concepções sobre a natureza da ciência dos professores de química do ensino médio.

- Analisar os planos de ensino baseados na História da Química, elaborados pelos professores para o ensino-aprendizagem de conceitos da cinética química, bem como a aplicação de tais planos.

Assim, a questão que guiou esta pesquisa é: Como professores de química, do ensino médio, se apropriam de ideias sobre a natureza da ciência e o desenvolvimento histórico da cinética química e as refletem no planejamento do ensino a partir da participação de um curso de formação continuada?

Partiu-se da seguinte hipótese: A transição progressiva dos modelos de ensino de cinética química dos professores pode ser facilitada pela participação desses em curso de formação continuada, voltado para a abordagem histórica desse tema.

Esta pesquisa foi desenvolvida nas seguintes etapas:

No capitulo um é apresentada fundamentação teórica que aborda uma pequena revisão bibliográfica de pesquisas desenvolvidas com o foco no tema cinética química e no papel da História e Filosofia da Ciência no ensino de química. 
No capítulo dois está a reconstrução histórica do desenvolvimento da cinética química, elaborada a partir das ideias de Imre Lakatos (1998).

No capítulo três está descrita a metodologia dessa pesquisa, com a descrição dos encontros do curso de formação continuada.

No capítulo quatro encontra-se a análise da transição progressiva dos professores de química no que diz respeito aos seus modelos de ensino de cinética química.

No final são apresentadas algumas considerações sobre a transição progressiva desse grupo de professores, a conclusão desse trabalho e algumas sugestões para a formação continuada de professores de química. A intenção aqui, é a de que as reflexões feitas nessa tese possam ser um ponto de partida para outros estudos voltados para a formação continuada de professores de ciências

No Apêndice, encontram-se informações sobre as atividades realizadas durante o curso de formação continuada que foram elaboradas pela autora dessa pesquisa.

No anexo encontram-se informações sobre as atividades realizadas elos professores que participaram do curso de formação continuada e que aplicaram seus planos de ensino nas suas respectivas escolas. 


\section{Capítulo 1. Revisão de estudos sobre o ensino e aprendizagem do tema Cinética Química e do papel da História e Filosofia da Ciência no ensino de Química.}

Procurou-se nesse capítulo fazer uma síntese das principais ideias dos pesquisadores da área de ensino de ciências, que desenvolveram seus estudos com o foco no tema cinética química como também no papel da História e Filosofia da Ciência no ensino de química. O Objetivo dessa pequena revisão é o de fornecer um suporte teórico para a análise das atividades que os professores realizaram, incluindo o plano de ensino, durante o curso de formação continuada.

\subsection{O ensino e aprendizagem do tema Cinética Química}

O tema cinética química proporciona ao aluno do ensino médio 0 entendimento de que as reações químicas podem ocorrer em diferentes velocidades e que certos fatores, como por exemplo, a temperatura e pressão, podem influenciar essas velocidades, acelerando-as ou não, conforme a necessidade do processo.

Para 0 entendimento da influência desses fatores, em termos submicroscópicos, são necessários modelos cinéticos que possibilitem descrever como se dá a interação entre as partículas reagentes de uma transformação química.

Contudo, percebe-se no ensino médio que o conhecimento sobre a velocidade das reações químicas não está relacionado a um modelo teórico, focando-se muitas vezes somente a influência dos fatores na velocidade, com explicações do tipo "como o aumento da temperatura acarreta o aumento da velocidade de uma reação", não se levando em conta os motivos porque isso ocorre.

Em relação ao ensino de cinética química, no texto da Proposta Curricular do Estado de São Paulo, espera-se que os professores de química, do ensino médio, proporcionem oportunidades para que seus alunos desenvolvam as seguintes competências (São Paulo (Estado), p.54, 2011): 
- Reconhecer as variáveis (estado de agregação, temperatura, concentração e catalisador) que podem modificar as velocidades (rapidez) de transformações químicas.

- Representar energia de ativação em diagramas de energia e reconhecê-la, assim como a orientação de colisão entre partículas, como fatores determinantes para que ocorra uma colisão efetiva.

- Fazer previsões qualitativas, usando modelos explicativos, sobre como composições de variáveis podem afetar as velocidades de transformações químicas.

- Reconhecer que transformações químicas podem ocorrer em mais de uma etapa e identificar a etapa lenta de uma reação química como a determinante da velocidade com que esta ocorre.

Pode-se supor que um professor que pretenda desenvolver essas competências tenha que abordar, em suas aulas sobre o tema cinética química, os seguintes conteúdos:

-Conceito de velocidade de reação.

-Variáveis que podem modificar a velocidade de uma reação química (concentração, temperatura, pressão, estado de agregação, catalisador),

-Modelos explicativos das velocidades das transformações químicas.

Alguma vezes, o professor ao abordar os fatores que podem influenciar a velocidade de uma reação química utiliza experimentos para que o aluno consiga observar esse comportamento (foco no procedimento empírico). Contudo, para o entendimento dos dados experimentais, o aluno necessita de explicações que envolvam entidades abstratas e modelos, como o choque entre moléculas, partículas, modelo atômico, quebra e formação de ligações químicas, entre outros.

Segundo Justi e Ruas (1997), para a aprendizagem do tema cinética química é necessário o entendimento integrado de muitos conceitos fundamentais, como, o da natureza particular da matéria e o caráter interativo e dinâmico das reações químicas. A integração desses conhecimentos para o entendimento da velocidade de uma reação química pode ser difícil para o aluno do ensino médio, criando-se 
assim um obstáculo que o professor terá que enfrentar no planejamento das suas atividades.

Outro ponto que o professor pode levar em consideração no seu planejamento de ensino é que os alunos, muitas vezes, já possuem concepções sobre velocidade, que podem ou não ser adequadas.

Algumas concepções alternativas apresentadas pelos alunos em relação à cinética química são (Justi e Ruas, 1997):

-Os alunos atribuem às substâncias participantes da reação, ou a uma delas, a responsabilidade pela velocidade do processo.

-Em suas explicações sobre a dinâmica de uma reação química existe a coexistência da teoria das colisões com uma visão contínua de matéria.

-A questão do movimento das partículas envolvidas em uma reação química não é considerada pelos alunos em suas explicações sobre a interação entre essas partículas.

No nível submicroscópico as maiores dificuldades estão relacionadas ao entendimento do caráter dinâmico de uma reação química. Segundo Beltran (1997), os fenômenos químicos são explicados com base em modelos atômico-iônicomoleculares envolvendo movimento e interação entre as partículas, e isso exige do aluno:

\begin{abstract}
"Muitas vezes a compreensão desses modelos (atômico-iônicomoleculares) exige de nossos alunos abstrações muito difíceis, principalmente para iniciantes do ensino médio. Porém, cada vez que um aluno consegue compreender como o modelo explica 0 fenômeno, e perceber as limitações de um determinado modelo, ele estará dando passos seguros em direção à aquisição de uma autonomia de raciocínio altamente desejável no estudante em geral e no de química em particular." (Beltran,p.14,1997)
\end{abstract}

Em sua pesquisa sobre o tema cinética química, Beltran (1997), ao propor a seguinte questão aos seus alunos: "Explique, usando a teoria das colisões e o conceito de complexo ativado, por que a velocidade de uma reação química aumenta com a elevação da temperatura do sistema", o autor constatou que muitos desses alunos, do terceiro ano do ensino médio, manifestavam a ideia de que em uma reação química todos os choques entre as moléculas ocorreriam com a mesma 
energia e ao se elevar a temperatura do sistema, todos os choques ocorreriam com maior energia, alcançando a energia do complexo ativado simultaneamente, apresentando assim, a concepção de simultaneidade.

Em relação ao movimento das moléculas, Beltran (1997) encontrou que os alunos, em suas representações, só indicavam apenas o movimento de translação, aproximando as moléculas umas das outras. As moléculas, na representação dos alunos, não apresentam movimento de rotação. Todas se movem em sincronia.

Segundo van Driel (2002), a introdução de ideias sobre a cinética das reações químicas, apresenta desafios às concepções iniciais dos estudantes. A noção de velocidade de reação requer que os alunos entendam que é preciso tempo para uma reação química ocorrer, e que esse tempo é influenciado por fatores como a temperatura do sistema e as concentrações das substâncias reagentes. Para o autor, um modelo simples de colisão entre partículas pode ser útil para explicar essas influências observáveis em termos corpusculares.

Para investigar as ideias sobre a natureza corpuscular da matéria no estudo da velocidade de uma reação, o autor utilizou uma série de experimentos e questões, nas quais os alunos eram convidados a explicar suas observações usando suas ideias corpusculares. Nessa atividade, a introdução de cinética química estava centrada em um entendimento básico do conceito de velocidade de reação, tanto em nível macroscópico como corpuscular.

Analisando as respostas, encontrou que a maioria dos alunos foi capaz de utilizar um modelo simples de movimento e de colisões de partículas para explicar o efeito da concentração sobre a velocidade de reação. No entanto, quando solicitado a explicar o efeito da temperatura sobre a velocidade da reação, muitos alunos usando esse modelo, chegaram à conclusão errada: eles diziam que as colisões entre partículas que se movem rapidamente seriam menos eficazes, porque as partículas podiam "voltar para trás" (como uma analogia a choques entre bolas de bilhar).

Esse problema, segundo o autor, foi devido às limitações do modelo simples de colisão entre partículas que não envolvia noções de energia de ativação, estruturas espaciais e de orientações das partículas, conceitos que fazem parte de 
um modelo mais avançado, baseado na teoria do estado de transição, que incluiria a quebra e formação de ligações entre as moléculas. O autor, não incluiu esses conceitos no modelo que os alunos iriam usar para explicar a velocidade das reações, pois achava que esse fosse muito complicado para os alunos neste nível.

Apesar de o autor estar ciente das limitações dos estudantes de raciocinar em termos corpusculares, que os obrigam a argumentar a partir de uma hipótese que não se baseia em observações empíricas, ele acredita que esses alunos podem aprender a tornar-se mais eficientes na utilização de modelos corpusculares como ferramentas explicativas.

Segundo Kaya e Geban (2012), o conceito de velocidade de reação é um tópico central no currículo de Química, assim, a compreensão dos conceitos com respeito à velocidade de reação e os fatores que a afetam têm um papel chave na aprendizagem de química. Contudo, devido à natureza abstrata do tema, os alunos enfrentam dificuldades e também possuem algumas ideias equivocadas sobre 0 conceito de velocidade de reação. Os alunos são obrigados a pensar sobre partículas, realizar cálculos matemáticos e pensar nas inter-relações entre eles, a fim de melhorar a sua compreensão dos conceitos de velocidade de reação. Além disso, este conceito é um pré-requisito essencial para outros tópicos de química, especialmente o estado de equilíbrio químico.

Kaya e Geban (2012) apontam que, embora tenha havido substancial investigação sobre a compreensão dos estudantes a respeito do conceito de equilíbrio químico, pouco se investigou sobre a compreensão deles e relação ao conceito de velocidade de reação.

Os autores realizaram um estudo, cujo objetivo foi investigar os efeitos de uma instrução orientada para a mudança conceitual por meio de demonstrações (IOMCAD) na compreensão dos alunos do conceito de velocidade de reação quando comparado a uma instrução tradicional.

Participaram desse estudo 69 alunos do 11․ Ano de escolaridade (27 do sexo masculino e 42 do sexo feminino) de duas classes de química do mesmo professor em uma escola pública. Os dois métodos de ensino foram aleatoriamente designados para os grupos. O grupo experimental que foi instruído com as 
demonstrações orientadas para a mudança conceitual era constituído de 34 alunos (15 homens e 19 mulheres), enquanto o grupo de controle instruído pelo ensino de química tradicional era constituído de 35 estudantes (12 homens e 23 mulheres). As idades dos alunos, de ambos os grupos, variou de 16 a 17 anos.

Para esse estudo foi elaborado um teste de múltipla escolha que tinha por objetivo medir o entendimento dos alunos sobre o conceito de velocidade de reação. Nele foram considerados os objetivos instrucionais do tema cinética química seguindo-se o livro didático do $11 \%$. Ano. As questões estão relacionadas a concepções alternativas (equívocos) sobre velocidade de reação, encontradas na literatura (por exemplo, Bozkoyun, 2004; Cakmakci et al, 2003;. Calik et al ., 2010; Van Driel, 2002).

Alguns dos itens do teste são (Kaya e Geban, 2012):

- A velocidade de reação é o tempo entre o início e o final de uma reação.

- Velocidade de reação é o número de átomos que colidem numa unidade de tempo.

- Para ocorrer uma reação química as partículas na colisão devem estar na fase gasosa.

- Todas as colisões na fase gasosa produzem uma reação química.

- Quando a concentração de uma substância aumenta, há aumento de energia cinética, assim, aumenta a velocidade da reação.

- Quando a concentração aumenta, aumenta a superfície, assim, aumenta a velocidade da reação.

- A velocidade de reação é independente da concentração de reagentes.

- Enquanto uma reação ocorre, a concentração de produtos aumenta com o tempo, assim, a velocidade de reação aumenta.

- A diminuição da concentração de um dos reagentes aumenta a concentração do outro reagente, portanto a velocidade da reação é constante.

- Mudança de temperatura não altera a velocidade da reação.

- Quando a temperatura aumenta, a velocidade da reação diminui.

- Quando o tamanho de partícula de reagente é diminuída, o seu volume é reduzido e por isso, velocidade da reação aumenta. 
- Substâncias com partículas grandes se movem mais lentamente do que aquelas com partículas pequenas, assim a sua velocidade de reação é menor.

- Quando a energia de ativação de uma reação diminui, a velocidade de reação diminui também.

O teste sobre o conceito de velocidade de reação foi aplicado a ambos os grupos como um pré-teste e pós-teste para avaliar a compreensão dos alunos sobre esse conceito.

A estratégia de ensino foi projetada pelos autores considerando-se as quatro condições para a mudança conceitual (Posner et al., 1982), que são: insatisfação, inteligibilidade, plausibilidade e fertilidade. O professor iniciou a aula fazendo algumas perguntas relacionadas ao tema, a fim de ativar seus conhecimentos prévios e equívocos ligados ao assunto.

Segundo Kaya e Geban (2012), os alunos tiveram dificuldades em justificar as suas respostas às perguntas do professor por causa de seu conhecimento anterior. Quando eles perceberam que suas concepções existentes eram insuficientes para a explicação dos fenômenos, tornaram-se insatisfeitos com essas concepções (insatisfação). Por exemplo, enquanto o efeito da temperatura sobre a velocidade da reação era ensinado, no início da aula, o professor perguntou aos alunos: o que aconteceria se aumentassem a temperatura do ambiente em que uma reação química estivesse ocorrendo?. Os alunos deram diferentes respostas para esta questão. Algumas de suas respostas foram: "a energia de ativação da reação vai aumentar, assim, a velocidade dessa reação irá diminuir", e "como as partículas vão se mover mais rápido, a possibilidade de colisão entre as essas partículas e a ocorrência de uma reação irá diminuir" (Kaya e Geban, p.220, 2012).

Em seguida, os conceitos foram explicados através da utilização de uma demonstração relacionada ao assunto. Por exemplo, a fim de explicar a relação entre temperatura e velocidade de uma reação, o professor realizou uma demonstração envolvendo a reação entre o bicarbonato de sódio $\left(\mathrm{NaHCO}_{3}\right.$, hidrogenocarbonato de sódio) e vinagre $\left(\mathrm{CH}_{3} \mathrm{COOH}\right.$, ácido acético). No final de cada demonstração, era realizada uma sessão de discussão com o objetivo de incentivar os alunos a estabelecer uma ligação entre novos conceitos e as suas observações 
sobre o que estava ocorrendo nos experimentos. Assim, os alunos podiam relacionar exemplos de eventos aos conceitos fornecidos durante a aula pelo professor. Segundo os autores, o objetivo era fazer com que esses conceitos se tornassem mais inteligíveis para os alunos (inteligibilidade).

Depois disso, novos exemplos, especialmente da vida cotidiana, relacionadas a esse tema foram dados aos alunos para melhorar a sua compreensão do conceito de velocidade. Por exemplo, depois de explicar o efeito do aumento da temperatura na velocidade de uma reação, o professor mencionou que alguns dos nossos alimentos são mantidos na geladeira e pediu que os alunos explicassem. Segundo os autores, uma vez que os alunos utilizaram os novos conceitos na solução de problemas, esses conceitos ficaram mais plausíveis para os alunos (plausibilidade).

$\mathrm{Na}$ parte final desse estudo os alunos foram convidados a utilizar o novo conceito para explicar uma nova situação.

Quando as proporções de respostas corretas para as questões do pós-teste, para ambos os grupos, foram examinadas percebeu-se que havia uma diferença estatisticamente significativa na proporção de respostas corretas em algumas questões entre o grupo experimental e o de controle. Por exemplo, em uma das perguntas os alunos foram convidados a escolher a propriedade que não era dependente da temperatura durante a reação. No Pré-teste, a maioria dos alunos, tanto no grupo experimental $(61,8 \%)$ como no grupo controle $(60 \%)$ escolheu a alternativa "o número de moléculas que têm energia de ativação". Após o tratamento, enquanto que $91,2 \%$ dos estudantes no grupo experimental responderam corretamente a esta questão, selecionando a energia de ativação como sendo independente da temperatura durante a reação, somente $48,6 \%$ dos estudantes do grupo controle respondeu corretamente a esta pergunta.

Em outra questão, os alunos foram convidados a escolher uma alternativa indicando o fator e o seu efeito sobre a velocidade de uma determinada reação química. No Pré-teste, a alternativa mais selecionada para esta questão era de que um catalisador aumenta a energia de ativação da reação. Por exemplo, 50\% dos estudantes do grupo experimental e $34,3 \%$ dos estudantes no grupo de controle selecionaram essa alternativa. No entanto, no pós-teste, a porcentagem dos 
estudantes do grupo experimental que ainda continuou com este equívoco foi somente de $2,9 \%$ enquanto a percentagem dos alunos do grupo de controle foi de $25,7 \%$.

Os autores apontam que, os resultados mostram que o processo de ensino realizado proporcionou uma aquisição significativamente melhor dos conceitos científicos relacionados à velocidade de reação, quando comparada com o ensino tradicional de química. Comparando-se os processos de ensino é relatado que no grupo experimental, os alunos participaram ativamente das atividades. Foram consideradas as concepções alternativas dos alunos para promover a mudança conceitual sobre o conceito de velocidade de reação. No entanto, o ensino de química pelo método tradicional, que foi utilizado no grupo de controle, o método mais utilizado pelo professor foram palestras sem a participação dos alunos. 0 professor resolveu problemas numéricos para que os alunos praticassem o uso dos conceitos. No entanto, o professor não considerou as concepções alternativas dos alunos e conhecimentos anteriores. Os alunos eram principalmente passivos durante a instrução (Kaya e Geban, p. 222, 2012).

Segundo os autores, o melhor entendimento do conceito de velocidade de reação mostrado pelo o grupo experimental foi devido principalmente, a terem sido consideradas as concepções alternativas dos alunos para promover a mudança conceitual.

No ensino de cinética química, o desenvolvimento de habilidades relacionadas à leitura de tabelas e elaboração de gráficos é essencial para que o aluno possa interpretar os diferentes dados cinéticos que são obtidos experimentalmente, para poder entender, por exemplo, o efeito da concentração na velocidade de uma reação química.

Cakmakci, Leach e Donnelly (2005) apontam que pesquisas em outras áreas das ciências mostram que os estudantes possuem dificuldades em fazer transformações com e através de diferentes formas de representação, por exemplo transformar uma equação química em seu respectivo gráfico. Isso ocorre porque, segundo os autores, o entendimento sobre a estrutura da cinética química é complexo, pois envolve duas linhas distintas, mas complementares de 
desenvolvimento, o "empírico" e o "teórico". Os autores mostram a relação entre o fenômeno químico teórico/empírico na figura 1.1.

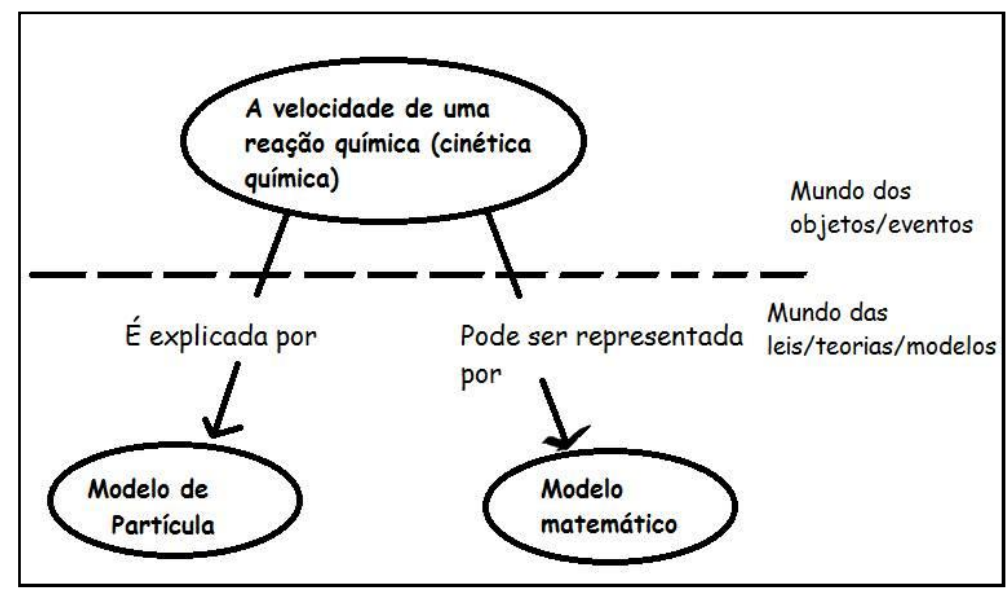

Figura 1.1 A relação entre o fenômeno químico e as teorias/modelos (Cakmakci, Leach e Donnelly p.484, 2005). (Tradução nossa)

Assim, os autores apontam que a cinética química pode ser explicada pelo modelo de partícula e também pode ser representada/quantificada em termos de modelagem matemática. Esse aspecto matemático geralmente é trabalhado na graduação.

Cakmakci, Leach e Donnelly (2005) investigaram o desenvolvimento do entendimento de alunos do nível secundário e universitário da Turquia sobre os conceitos envolvidos em fenômenos da cinética química. Esse estudo foi baseado, principalmente, nas respostas dadas por 191 alunos a um questionário aberto de 11 questões envolvendo conceitos relacionados ao tema. A amostra incluiu 108 alunos do ensino secundário (idades entre 15-16 anos) de três diferentes escolas, 48 alunos do primeiro ano (maiores de 17 anos) e 35 alunos do terceiro ano (maiores de 19 anos) do curso de licenciatura. Os dados foram coletados, em diferentes momentos, no ensino secundário 5 a 6 semanas após os alunos terem passado pelo ensino de cinética química, e imediatamente após o ensino no caso dos alunos universitários. O mesmo diagnóstico foi usado para todos os alunos.

Esse estudo focou as respostas dos alunos a dois problema. O primeiro, relacionado a uma situação do cotidiano, tinha por objetivo verificar o entendimento dos alunos sobre o fator concentração do reagente. O segundo problema, relacionado ao entendimento da variação da velocidade de uma reação química 
através do tempo, pedia aos alunos que construíssem um gráfico que representasse essa variação, justificando a sua construção.

Em relação ao problema relacionado à variação da velocidade com o tempo, as respostas foram categorizadas pela comparação entre as semelhanças e diferenças nas respostas de todos os estudantes. Foram identificadas sete categorias que representam modelos mutuamente excludentes do problema "velocidade de reação-tempo". Os modelos são:

- Modelo científico (MC): A velocidade da reação é descrita através de sua natureza dinâmica. A relação entre concentração dos reagentes/produtos e a velocidade é descrita em termos de modelo de colisão ou em termos de modelo matemático. Esta categoria inclui respostas como: "a velocidade da reação deve cair, por causa da alta concentração de moléculas no início, quando é maior o número de colisões por unidade de tempo e por isso a reação é rápida. Os reagentes são consumidos, suas concentrações caem, as colisões ocorrem com menor frequência, e a velocidade da reação diminui" ou "a velocidade da reação é diretamente proporcional à concentração dos reagentes, portanto, a velocidade da reação diminui”.

Para a surpresa dos autores, dos 35 alunos universitários do terceiro ano, somente $9(26 \%)$ usaram o modelo científico e no grupo de estudantes do primeiro ano a porcentagem foi alta.

- O modelo de aumento (MA): de acordo com esse modelo a reação é concebida como tendo um inicio lento e depois disso ocorre rapidamente. Os alunos podem usar modelos macroscópicos, de partícula e matemáticos para as suas justificativas.

Este modelo é usado respectivamente pelos estudantes do nível secundário (23\%), pelos alunos do primeiro ano (13\%) e do terceiro ano da graduação (3\%). Os autores observaram que alguns estudantes confundem velocidade de reação com quantidade de reagente ou produto.

- Modelo de aumento-constante (MAC): Nesse modelo a reação se inicia com velocidade igual a zero e vai aumentando até atingir um valor onde este permanece constante até o final da reação. 
$8 \%$ dos alunos do secundário, $25 \%$ dos alunos do primeiro ano da graduação e para a surpresa dos autores, metade dos alunos do terceiro ano da graduação, usaram esse modelo.

- Modelo constante (MCE): Nesse modelo a reação se inicia com um determinado valor de velocidade que é mantido constante até o final da reação. Neste modelo é comum os alunos usarem os termos "se....quando" no seu raciocínio. "Se a temperatura ou concentração é alterada, a velocidade de reação pode mudar, caso contrário a velocidade permanece constante durante a reação". Muitos dos estudantes assumem que, enquanto alguns fatores (por exemplo, temperatura, concentração catalisador) não são alterados, a velocidade de reação mantém-se constante durante a reação.

- Modelo de aumento-constante-decréscimo (MACD): Nesse modelo, a reação se inicia com velocidade igual a zero e vai aumentando ate atingir um valor máximo; a partir desse valor sofre um decréscimo gradual até atingir zero quando o reagente limitante é consumido.

- Modelo de decréscimo (MD): Esse modelo é baseado principalmente na ideia de que "uma reação lenta leva um longo tempo e uma reação rápida ocorre em um tempo menor" ou "a velocidade de reação é inversamente proporcional ao tempo". Os sujeitos possuem uma imagem geral de como diferentes reações tendem a ocorrer, contudo eles não dão ou não conseguem explicar como a velocidade da reação muda conforme o progresso da reação. A relação entre a velocidade da reação e o tempo é representada graficamente como o modelo científico, contudo seu raciocínio e interpretação são diferentes do estabelecido pela perspectiva química.

- Indeterminado (I): nessa categoria estão as respostas que não foram representadas em nenhuma das categorias anteriores.

Segundo os autores, os resultados sugerem que ambos os grupos de estudantes, do ensino secundário e da graduação, usam concepções que não são consistentes com o modelo científico e que possuem dificuldades para explicar como a velocidade de uma reação muda durante o progresso dessa reação. Muitos estudantes têm dificuldade em entender que a velocidade da reação é alta no inicio e que é mais baixa no final; Em vez disso, eles manifestam a ideia de que a reação 
se inicia lentamente. Somente $33 \%$ dos alunos da escola secundária, $44 \%$ dos alunos universitários do primeiro ano e $26 \%$ dos alunos universitários do terceiro ano usaram o "modelo científico" (MC).

Os resultados, segundos os autores, sugerem que os estudantes conseguem um mínimo de progresso entre o nível secundário e o nível universitário. Muitos estudantes apresentam dificuldades em encontrar uma explicação satisfatória para um fenômeno ou evento. Muitos deles, particularmente os do nível secundário, inspiram-se em um modelo macroscópico para explicar os fenômenos. Enquanto o modelo macroscópico diz pouco sobre a natureza da velocidade da reação e é essencialmente descritivo, os modelos de partículas e matemáticos permitem que muito mais seja explicado, quantificado, e predito. Contudo, os modelos de partículas e matemáticos não são frequentemente usados pelos estudantes e na maioria dos casos quando usados, não estão efetivamente e apropriadamente em concordância com o aceito no currículo de química (Cakmakci, Leach e Donnelly, 2005).

Isso, segundo os autores, não é surpreendente: o ensino geralmente não proporciona aos alunos oportunidades para se mover através de representação verbal, matemática e simbólica na química. Uma recomendação possível para a reestruturação do ensino seria apoiar o aluno no uso de diversas representações alternadamente.

Em outro estudo Cakmakci, Leach e Donnelly (2006) identificaram as principais dificuldades conceituais apresentadas pelos alunos do ensino médio e da licenciatura em química, da Turquia, sobre o tema velocidade de uma reação química. Para o levantamento dessas ideias foram usadas uma série de atividades e entrevistas individuais.

A amostra para o estudo principal incluiu 108 estudantes do ensino médio (idades 15-16) em três turmas de duas escolas, universidades 48 alunos universitários do primeiro ano e 35 alunos universitários do terceiro ano. Os dados foram coletados após o ensino formal, em sala de aula, de cinética química. Dois testes de diagnóstico foram utilizados para a coleta de dados e cada teste diagnóstico foi projetado para durar aproximadamente 45 a 50 min. 
A seguir são apresentada as ideias dos alunos relacionadas com a velocidade de reação onde a sua relação com a concentração ou pressão foi discutida:

- Os estudantes tendem a usar uma modelagem "macroscópica" em vez de usar "partículas" ou uma modelagem "matemática".

Segundo os autores, as explicações dos estudantes do ensino médio tendem a ser mais restrita a aspectos macroscópicos de um fenômeno. Depois de mais instrução, os alunos tendem a mover-se de uma modelagem macroscópica de partículas para uma modelagem matemática. A esse respeito, uma progressão na aprendizagem envolve o aluno a tornar-se capaz de usar mais modos científicos em suas explicações.

- Os estudantes do ensino médio estavam mais propensos a fornecer explicações baseadas em modelos teóricos e entidades de conceitos químicos já estabelecidos. No entanto, eles tinham dificuldades conceituais em fazer transformação dentro e através de diferentes modelos teóricos.

- Os estudantes do ensino médio geralmente não usam um conceito cientificamente aceitável de velocidade de reação em diferentes contextos. Embora um conceito aceitável pode ter sido usado em um determinado contexto, ideias erradas podem, no entanto, ser utilizadas em outros contextos.

- Muitos estudantes do ensino médio possuem dificuldades em compreender que a reação tinha a velocidade mais elevada no início da reação e a velocidade mais baixa no final: ao invés disso, eles tendem a pensar o contrário.

Segundo Cakmakci, Leach e Donnelly (2006), a compreensão dos estudantes pode ser restringida por experiências perceptivas de suas vidas diárias (por exemplo, um pedaço de madeira queima lentamente no início e depois vai mais rápido) ou do laboratório de química (por exemplo, a reação de magnésio com ácido diluído).

Outra razão apontada pelos autores, para a falta de conhecimento dos estudantes ou ideias incorretas, seria a abordagem que é empregada pelos autores dos livros didáticos, que geralmente enfatiza o estado inicial e final de uma reação, 
negligenciando os processos que ocorrem entre estes dois estados. Especificamente, as diferenças entre a noção de "velocidade inicial", "a velocidade instantânea", e "a velocidade média ao longo de um intervalo de tempo" são negligenciadas nos livros didáticos. De fato, os resultados que os autores encontraram sugerem que esses termos não foram diferenciados por muitos estudantes, e o termo "velocidade de reação" foi usado por eles de maneira diferente em diferentes contextos.

\begin{abstract}
$\mathrm{Na}$ verdade, quando educadores de ciências usam a terminologia em cinética, as palavras são usadas com significados diferentes em contextos diferentes. Por exemplo, quando pedimos aos alunos "como um aumento na temperatura afetaria a velocidade de reação", assume-se que os alunos compreendam o que estamos falando (na verdade, estamos perguntando "como é que um aumento da temperatura afeta a velocidade média de reação?"). Outro exemplo é quando pedimos aos alunos "como é a alteração da velocidade de reação durante a reação?", que realmente significa "como é a alteração da velocidade instantânea durante a reação?" (Cakmakci, Leach e Donnelly, p.1812,2006).
\end{abstract}

- As respostas graduandos foram menos afetadas pelo contexto. Várias dificuldades conceituais expostos por alunos do ensino médio persistiu entre universitários.

Segundo os autores, foi possível notar que, em geral, os alunos eram mais propensos a usar modelos teóricos a fim de responder questões conceitualmente enquadradas, no entanto, eles tendem a recorrer a modelagem macroscópica ao interpretar questões fenomenologicamente emolduradas. Em outras palavras, quando é dado uma dica teórica, os alunos são mais propensos a usar termos científicos e modelos teóricos em suas explicações. Estes resultados sugerem que a conduta dos alunos para explicações podem significativamente depender dos contextos sociais e culturais das perguntas e métodos utilizados. Assim, a fim de avaliar os conhecimentos dos alunos de uma área de conteúdo específico, os autores apontam que deve ser feita uma avaliação cuidadosa do instrumento de sondagem e é necessário investigar as ideias dos alunos em uma variedade de contextos.

Justi (1997) investigou as concepções de professores de química, do ensino médio, por meio de um instrumento com questões relacionadas à reação química e 
velocidade de reação. Pela análise das respostas foi possível identificar a teoria das colisões como a única base teórica das ideias dos professores. Contudo, a maneira com que os professores entendem a teoria das colisões e a usam para explicar alguns fenômenos e conceitos, varia muito. A maioria dos professores apontou que a colisão efetiva deve ocorrer para que uma reação química ocorra. Eles caracterizaram essas colisões como aquelas que ocorrem quando há energia suficiente e uma orientação apropriada. Eles também associam colisões com ligações sendo quebradas e formadas. Contudo, alguns professores indicaram que as moléculas devem colidir em uma dada posição (desenhada por eles) a fim de obter uma colisão eficaz.

Peréz (2006), em seus estudos sobre as concepções de professores colombianos em formação inicial sobre cinética química, identificou algumas dificuldades no entendimento da velocidade de uma reação química. Por exemplo, embora os professores identifiquem a necessidade de o sistema ser fechado, alguns não identificam essa informação como condição central para definir o conceito de velocidade e de reação. Também, alguns dos professores consideram que à medida que a reação avança, diminuem as concentrações dos reagentes e a dos produtos.

Quanto à diferenciação e representação matemática do conceito de velocidade de uma reação química, o autor encontrou uma alta porcentagem de respostas incorretas. Os professores em formação consideram que somente pode representar-se a velocidade de reação em termo de variação da concentração dos reagentes por unidade de tempo. Contudo, eles não contemplam a possibilidade de expressá-la em termos de variação da concentração de produtos em função do tempo.

O autor acredita que essa dificuldade evidencia que os professores não entendem o avanço da reação em termos da variação da concentração de reagentes e produtos por unidade de tempo. Para o autor, essas concepções alternativas que os professores em formação inicial apresentam foram construídas a partir dos processos de ensino e aprendizagem pelo qual estes passaram durante a sua vida escolar. Assim, em relação à representação matemática da velocidade de uma reação química, embora o professor tenha se apropriado da linguagem formal, tal 
como faria um especialista, a lógica de seu raciocínio está associada ao pensamento simplista que usualmente está presente no cotidiano.

Para o autor, uma estratégia que visa favorecer a apropriação de conceitos de cinética química pelos professores em formação deveria promover a articulação entre os níveis macroscópico, submicroscópico e simbólico da química, para que estes avancem na construção de expressões matemáticas que lhes permitam compreender os conceitos de velocidade de reação desde o ponto de vista teórico e experimental.

Segundo Taştan et al (2010), a cinética química é um tema importante para os estudantes de química entenderem a ocorrência de uma reação química por meio da teoria da colisão, os mecanismos de reações, a importância de catalisadores na cinética química e também entender muitas aplicações industriais como a fabricação de remédios e a síntese de compostos orgânicos e inorgânicos.

Os autores realizaram um estudo cujo objetivo foi o de examinar as concepções sobre os mecanismos de reação para determinadas situações de 49 futuros professores turcos de química, 40 alunos do quarto ano da universidade e nove alunos do quinto ano da universidade, de duas universidades na Turquia. As Ideias dos participantes foram obtidas através de questões abertas e entrevistas semi-estruturadas relacionadas ao mecanismo de reação.

O questionário era composto por três questões abertas sobre o mecanismo de reação. O objetivo da questão 1 (fig. 1.2) foi avaliar a compreensão dos professores da etapa determinante da velocidade (ou etapa limitante da velocidade) para um mecanismo de várias etapas.

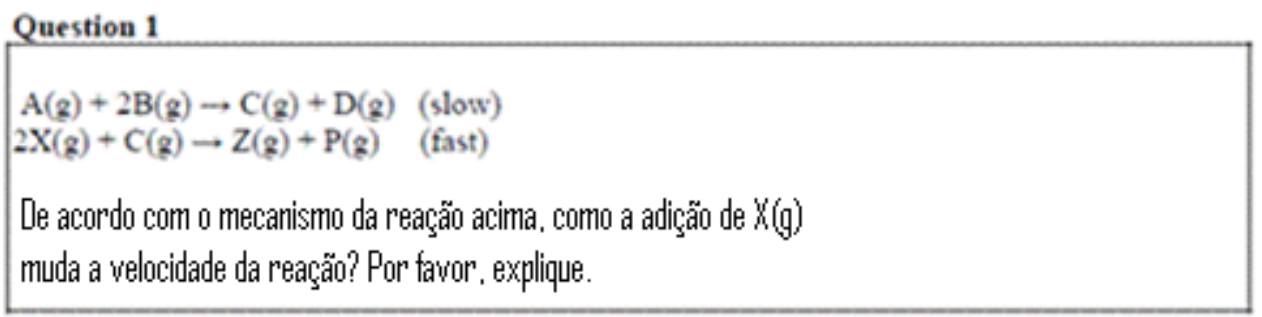

Figura 1.2 Questão 1 do Instrumento para avaliar o entendimento dos professores sobre o mecanismo de uma reação química (Taştan et al ,p. 50, 2010). (tradução nossa). 
Para a análise dos dados, foram elaboradas quatro categorias principais: respostas corretas, respostas parcialmente corretas, respostas incorretas e ausência de respostas. Na figura 1.3 os autores apontam as categorias formadas de acordo com as respostas escritas dos professores a cada questão:

\begin{tabular}{|c|c|c|c|c|}
\hline Questions & Correct answers & Partially correct answers & Incorrect answers & No response \\
\hline 1 & $32(65 \%)$ & $5(10 \%)$ & $12(25 \%)$ & 0 \\
\hline $2 \mathrm{a}$ & $6(12 \%)$ & $21(43 \%)$ & $15(31 \%)$ & $7(14 \%)$ \\
\hline $2 \mathrm{~b}$ & $8(17 \%)$ & $7(14 \%)$ & $28(57 \%)$ & $6(12 \%)$ \\
\hline
\end{tabular}

Figura 1.3 Respostas dos professores por questão (Taştan et al ,p. 52, 2010).

Segundo Taştan et al (2010), várias dificuldades conceituais foram expostas pelos futuros professores de química. Os resultados do estudo revelaram que alguns dos futuros professores não estavam cientes de que a etapa lenta é a etapa determinante do mecanismo da reação. Os autores também perceberam que os professores de química tiveram dificuldades de entender o mecanismo de uma reação a partir da interpretação de uma curva de energia potencial (questão 2, fig. 1.2). Além disso, a maioria dos participantes não conseguiu fazer diferenciação entre complexo ativado da reação e intermediários.

A partir dos resultados do estudo, os autores apontam que velocidade de reação e equilíbrio químico são conceitos que estão emaranhados e confusos nas mentes dos alunos do ensino de química. Segundo eles:

Compreender o conceito de velocidade de reação pode muito bem ajudar os alunos a compreender mais facilmente o equilíbrio químico. Sugerimos que ao discutir equilíbrio químico na sala de aula, o professor deve consultar os pontos relacionados a lei de velocidade e no tempo certo, ele deve fazer uma distinção entre as partes que são, na sua maioria, confusas. Além disso, efeito da concentração na velocidade de reação e o conceito de equilíbrio químico precisam ser discriminados (Taştan et al ,p. 58, 2010).(Tradução nossa)

Bektasli e Cakmakci (2011) realizaram um estudo que consistia em investigar as ideias de alunos sobre "taxa" (velocidade) em dois diferentes contextos: na física em que o termo velocidade também é usado e na química (velocidade de reação). Participaram desse estudo 200 alunos do 11‥ Ano do ensino secundário (idade entre 16-17 anos) de três escolas públicas na Turquia. 
Segundo os autores, existem muitos conceitos que não são isolados e exclusivos de uma única disciplina. Um desses conceitos é o conceito de "taxa" (velocidade) que é usado em muitas áreas da ciência. O termo "taxa" (velocidade) é frequentemente usado para descrever uma mudança de quantidade que ocorre por unidade de tempo. Basicamente o termo "velocidade" tem um significado similar na física e na química, mas o uso e a terminologia deste conceito são diferentes para cada domínio. Assim, na química o termo "taxa" (velocidade) pode ser definida como a mudança da concentração de um reagente em particular, ou produto por unidade de tempo. Por outro lado na física "velocidade" é usado para a quantidade de deslocamento em certo período de tempo (Bektasli e Cakmakci, 2011).

Portanto, nesse estudo os termos "taxa" e "velocidade" são usados, algumas vezes, alternadamente pelos autores. A meta desse estudo é apresentada através das seguintes questões: Qual é o tipo de dificuldade conceitual que os alunos experimentam nos conceitos de "taxa" (velocidade) na química e na física? E quão bem os alunos usam o conceito de velocidade em uma variedade de contextos como a química e a física?

Os dados desse estudo foram obtidos por meio das respostas dos alunos a seis questões. Três questões são sobre velocidade na química que foram usadas em estudos anteriores (Cakmakci et al, 2006; Cakmakci, 2011) e três sobre velocidade na cinemática. Inicialmente, cada questão foi analisada e três categorias de respostas foram criadas e usadas para relatar os resultados: (1) respostas correspondentes a ideias com o significado científico incorreto, (2) respostas correspondentes a ideias com o significado científico aceito, (3) todas as outras respostas. Seis estudantes desse estudo foram entrevistados.

Em relação às questões que abordavam a ideia de velocidade para a química, os autores encontraram que, apesar de os alunos passarem pela instrução formal desse conceito, muitos não responderam de acordo com as ideias aceitas cientificamente. As dificuldades mais comuns foram, segundo Bektasli e Cakmakci, (p.279, 2011):

-A reação é entendida como iniciando-se lentamente e aumentando a velocidade em seguida. 
-Confusão entre velocidade na formação e quantidade de produtos (ou a velocidade de consumo de reagentes e a quantidade de reagentes) durante a reação. Desde que a quantidade de produto aumenta durante a reação, os estudantes também podem concluir que a velocidade também aumenta, ou desde que a quantidade de reagente diminui durante a reação, estudantes podem também concluir que a velocidade diminui.

-Enquanto certos fatores (por exemplo, catalisadores) não são alterados, a velocidade da reação permanece constante, ou permanece a mesma durante a reação. Portanto, os estudantes não levam em consideração os dados experimentais. Por exemplo, eles não levam em consideração a mudança da concentração de um reagente em particular ou de um produto por unidade de tempo.

As ideias discutidas nesse capitulo apontam que o caminho para o ensino de cinética química não é algo simples, contudo, poderia ser facilitado se o professor em seu planejamento, levasse em consideração as dificuldades dos alunos principalmente no entendimento na natureza dinâmica e particular da matéria.

\subsection{A História e Filosofia da Ciência e o Ensino de Química}

Segundo Porto (2010), recomendações para a inclusão da História da Ciência nos currículos de ciência, em especial no currículo dos cursos para a formação de professores, podem ser observadas em diferentes países. Especificamente no Brasil a recomendação para a inclusão da História da Ciência no ensino já pode ser observada no texto da reforma Francisco Campos de 1931:

Ao professor ainda compete referir, abreviadamente, a propósito das descobertas mais notáveis da Química, a evolução dos conceitos fundamentais através dos tempos, revelando aos alunos os grandes vultos da História, a cuja tenacidade e intuição deve a civilização contemporânea, além da satisfação espiritual de dilatar o conhecimento do mundo objetivo, o concurso dos processos químicos em benefício da saúde, das comodidades da vida, da defesa e do desenvolvimento das nações (Porto, p.160, 2010 citando Campos, 1942). 
Atualmente, em relação à formação inicial, nas diretrizes curriculares para o curso de química há um forte compromisso com a necessidade da abordagem histórica. Segundo Porto (2010):

A concepção subjacente ao texto é a de que a História da Ciência não deve ser apenas um ornamento curricular: é a própria natureza do processo de elaboração da Ciência que impõe a presença de sua História. (Porto, p.162,2010).

Ainda em relação ao licenciado de química, em outro documento oficial aparece a orientação para inclusão da Historia da Ciência no ensino de química, assim como a imagem sobre a natureza da ciência que se espera que os alunos construam:

$\mathrm{Na}$ interpretação do mundo através das ferramentas da Química é essencial que se explicite seu caráter dinâmico. Assim, o conhecimento químico não deve ser entendido como um conjunto de conhecimentos isolados, prontos e acabados, mas sim uma construção da mente humana, em contínua mudança. A História da Química, como parte do conhecimento socialmente produzido, deve permear todo o ensino de Química, possibilitando ao aluno a compreensão do processo de elaboração desse conhecimento, com seus avanços, erros e conflitos. A consciência de que 0 conhecimento científico é assim dinâmico e mutável ajudará o estudante e o professor a terem a necessária visão crítica da ciência. Não se pode simplesmente aceitar a ciência como pronta e acabada e os conceitos atualmente aceitos pelos cientistas e ensinados nas escolas como "verdade absoluta". Tampouco deve o aluno ficar com impressão de que existe uma "ciência" acima do bem e do mal, que o cientista tenta descobrir. A ciência deve ser percebida como uma criação do intelecto humano e, como qualquer atividade humana, também submetida a avaliações de natureza ética. (PCNEM, p.3132,1999)

Cachapuz et al (2002) apontam, na forma de uma rede conceitual (fig.1.4) exemplos de articulações possíveis entre as diferentes disciplinas e áreas disciplinares. Percebe-se nessa rede, que a História e a Filosofia de ciência estão interligadas a outras áreas de conhecimento para a construção da educação em ciências. Assim, na sua formação, para o ensino de ciências, os professores teriam que incorporar os saberes de referência dessa área de conhecimento. Segundo os autores, as abordagens interdisciplinares devem estar no centro da promoção de uma cultura científica dos cidadãos, e daí a sua importância: "É precisamente com base nestes saberes de referência que as orientações para o Ensino das Ciências 
ganham (tentativamente) o seu sentido, unidade e coerência". (Cachapuz et al; p.365,2002)

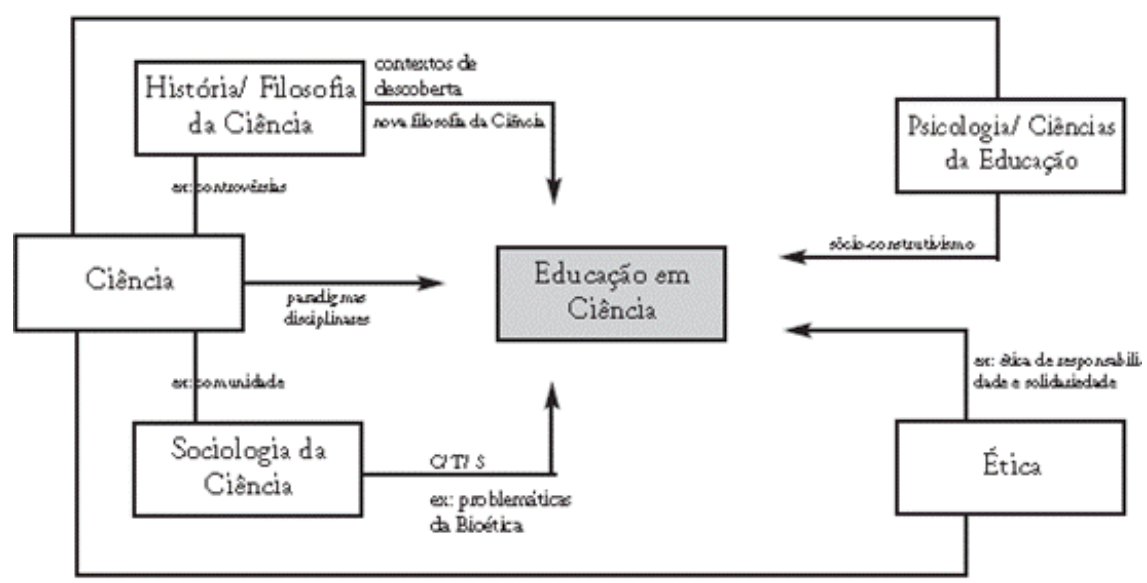

Figura 1.4 Caráter interdisciplinar da Educação em ciências (Cachapuz et al, p. 365, 2002)

Apesar dessas orientações, tem-se observado em diferentes pesquisas (Saito et al, 2010; Martins e Rosa, 2007; Oki e Moradillo, 2009), que esse processo de inclusão não é algo simples de ser realizado. Muitas dificuldades são apontadas pelos professores em relação à inclusão da História da Ciência no ensino. As principais delas estão relacionadas, à falta de conhecimento específico (História da Química), ao desconhecimento de fontes, matérias e estratégias, como também à visão inadequada desses professores sobre a natureza da ciência.

Porto (2010), aponta que uma das razões dessas dificuldades é a falta de discussões das diretrizes oficiais por parte dos professores. É importante que o professor compreenda qual visão sobre a História da Ciência, os documentos oficiais (propostas curriculares, parâmetros curriculares nacionais) abordam para o ensino e aprendizagem dos conhecimentos científicos.

Outro problema, ligado à formação dos professores, que Porto (2010) aponta, é a questão da qualidade das fontes de informação sobre a História da Ciência. Embora atualmente o professor tenha acesso a diversas fontes de pesquisa, através de livros didáticos, revistas especializadas, internet, entre outros, o autor chama a atenção para qual História da Ciência está vinculada por essas fontes, ou seja, em qual concepção historiográfica os autores desses materiais se basearam ao escrevêlos. 
Como estratégias, para que durante a sua formação o professor tenha a oportunidade de vivenciar debates a respeito da História da Ciência, além da leitura de artigos de historiadores da ciência e artigos originais dos próprios cientistas (fontes primárias), Porto (2010) indica para essa finalidade o estudo de caso:

Definimos estudo de caso como a análise, com certa profundidade, de algum episódio bem delimitado da História da Ciência. Trabalhar com estudo de caso é essencialmente diferente de empregar a História da Ciência apenas para "ilustrar" algum conteúdo que está sendo estudado,..... estudo de caso pressupõe alguma profundidade, em que o contexto das ideias seja apresentado, bem como os problemas surgidos na época que levaram um químico a determinada ideia, as hipóteses discutidas, os fatores que levaram ao abandono ou aceitação desta ou daquela hipótese, os debates contemporâneos, enfim, um relato que permita ao aluno vislumbrar a natureza do empreendimento científico. (Porto, p.174, 2010)

Admitindo-se a importância da História da Ciência como fomentadora de estratégias para o ensino e aprendizagem, Saito et al (2010), apresentam as seguintes questões: de que forma introduzi-la em um curso que visa a formação de professores? Quais as melhores abordagens para a inserção da História da Ciência nas aulas de Química no Ensino Médio?

As autoras apontam que não é tarefa fácil responder a estas questões, visto ser um grande desafio integrar duas áreas do conhecimento com objetos de estudos tão diferentes como são os da educação e os da História da Ciência. O primeiro desafio é definir qual visão sobre a história da ciência deseja-se abordar nessas estratégias: "...diferentemente do que pensa o senso comum, não basta juntar História e Ciência para que o resultado final seja provavelmente História da Ciência (Alfonso-Goldfarb, p.8,1994)."

As autoras colocam que ainda a perspectiva histórica dominante que permeia o material didático para o ensino não só da Química, mas também de outras áreas da ciência, continua ainda a valorizar os feitos dos "grandes homens da ciência", dando ênfase ao progresso contínuo do pensamento científico.

Segundo Saito et al (2010), as tendências historiográficas atuais da História da Ciência não mais se baseiam na ideia de que o conhecimento científico seja construído por meio do acúmulo e aprimoramento de antigas ideias, ou de 
revoluções que romperam radicalmente com o passado, tal como abordam as vertentes historiográficas mais tradicionais.

A abordagem contemporânea dos historiadores da ciência, denominada pelos historiadores de a nova historiografia da ciência, volta-se para a análise pontual e minuciosa dos estudos de caso, buscando identificar a especialidade de episódios e documentos. Nesse processo contempla-se a contextualização das ideias, procurando-se seu significado no seio do pensamento característico do período estudado (Porto, 2010).

Assim, segundo Saito et al (2010), os mesmos documentos históricos, agora analisados sob essa perspectiva historiográfica, revelam-se muito mais ricos na medida em que a análise histórica leva em consideração tanto a lógica interna do texto, quanto o contexto social da época em que foi escrito.

Para as autoras Martins e Rosa (2007), as discussões de História e Filosofia da Ciência (HFC) são importantes na formação do professor. Por isso, elas consideram relevante investigar como a inserção dessas discussões é feita em sala de aula. Para isso, realizaram entrevistas semiestruturadas com docentes da instituição (Universidade Federal da Bahia), com o objetivo de verificar qual a percepção que esses professores de Física apresentam em relação à HFC.

Quando foi solicitada a opinião desses docentes sobre HFC no Ensino Médio e Superior (O que você pensa sobre a utilização de História e Filosofia da Ciência no ensino de física em nível médio? E no superior?), as autoras apontam que apenas 1 professor (do total de 10 que participaram da pesquisa) não foi favorável à inserção de HFC no ensino e que $60 \%$ dos entrevistados consideraram a HFC fundamental ou imprescindível para a formação do professor. Nenhum docente manifestou-se contrário à discussão do tema na Licenciatura.

Em relação ao uso da HFC em sala de aula, coerentemente com as respostas obtidas na questão acima em que os docentes se mostraram favoráveis à discussão de HFC na formação do licenciado, segundo as autoras, 90\% afirmaram que utilizaram HFC nas disciplinas que ministram. 
As autoras apontam que apesar de observarem um movimento para ampliar a inserção de HFC na Licenciatura, não existem ainda pesquisas para avaliar o desempenho deste novo currículo, além disso, pareceu haver uma falta de divulgação de experiências de outras universidades, ou mesmo a inexistência de outras experiências, o que reforça tanto a necessidade de se desenvolver pesquisas quanto á de compartilhá- las.

O estudo de caso realizado por Oki e Moradillo (2009) em uma disciplina da História da Química, que teve como objetivo explorar as potencialidades de aproximação entre História e Filosofia da Ciência da educação científica, as autoras pretendiam auxiliar os alunos na compreensão da natureza da ciência como também no aprendizado de conceitos químicos.

Segundo as autoras, ainda que a valorização desses campos na formação profissional tenha crescido, a inclusão desses temas nos currículos ainda segue um modelo tradicional, em que, geralmente disciplinas específicas abordam os conteúdos e a articulação com a didática é extremamente frágil. Tradicionalmente, o ensino da História das Ciências por disciplinas específicas não busca fazer uma ampla articulação com conteúdos da Filosofia da Ciência (Oki e Moradillo, p.69,2009).

Esse estudo envolveu a intervenção de uma professora/investigadora numa disciplina de História da Química e teve caráter exploratório, com abordagem de pesquisa qualitativa. Para a análise dos resultados utilizou-se um modelo misto, com categorias analíticas definidas a priori, que nortearam as dimensões epistemológicas de análise e a identificação de categorias emergentes, construídas a partir das respostas dos alunos a questionários abertos.

Foram encontrados os seguintes resultados:

- O trabalho realizado na disciplina História da Química, fundamentado numa abordagem explícita de conteúdos da Filosofia da Ciência, possibilitou algum ganho em relação aos conhecimentos epistemológicos detectados inicialmente entre os alunos pesquisados. 
- Concepções mais elaboradas e menos ingênuas foram identificadas nos momentos posteriores ao trabalho didático realizado em cada aula, uma vez que detectou-se o aparecimento de novas categorias que refletiam posições mais racionalistas e contextualizadas sobre o conhecimento científico e a ciência.

- A abordagem de controvérsias científicas na disciplina foi avaliada positivamente, considerando-se que ela possibilitou, em especial, o reconhecimento da ciência como uma atividade humana sujeita a erros e conflitos, além da percepção do caráter provisório do conhecimento científico e da complexidade envolvida no contexto da justificação de novas teorias científicas.

Segundo Oki e Moradillo (2009), a disciplina História da Química é um espaço privilegiado no currículo para discussões sobre a natureza da ciência com os alunos, durante a formação inicial.

Resende et al (2010) realizaram um estudo onde um dos objetivos era o de conhecer as ideias dos estudantes universitários (Bacharelado em Química) a respeito da natureza do trabalho científico, após a aplicação de uma estratégia de ensino baseada na História da Química. Para isso, realizaram o trabalho em duas etapas, na primeira etapa foi produzido um guia de estudos no qual a história do desenvolvimento da química estrutural foi usada como base para a discussão de aspectos importantes a respeito da produção do conhecimento científico. $\mathrm{Na}$ segunda etapa, esse guia de estudos foi aplicado em um curso de nível superior em química.

O referido guia de estudos teve, segundo os autores, o intuito de apresentar e analisar uma série de acontecimentos que se constituíram em pilares para o desenvolvimento dos conhecimentos sobre a estrutura dos compostos químicos. Este guia era composto por textos e questões.

No final do processo, solicitou-se aos estudantes a produção de um texto sobre as suas ideias a respeito da natureza do trabalho científico. As ideias por eles expressas foram categorizadas qualitativamente com relação ao entendimento sobre as características essenciais do trabalho científico e as visões deformadas da ciência. 
Os autores analisaram os episódios selecionados no texto e nos relatos escritos dos estudantes, através de três categorias consideradas por eles como essenciais para a atividade científica:

1․ Categoria: A ciência vista como atividade humana, ressaltando quais seus interesses, aspectos sociais e relações com ciência, tecnologia, sociedade e ambiente.

2ª . Categoria: O caráter provisório do conhecimento científico, reconhecendo a existência de crises importantes e remodelações profundas na evolução histórica dos conhecimentos, as limitações dos conhecimentos atuais.

3a . Categoria: Visão histórica e problemática da ciência e da construção do conhecimento, colocando quais os problemas geraram tais construções, as dificuldades, contextualizando-os historicamente apresentando melhor os aspectos da história da ciência.

As características do trabalho científico mais destacado pelos alunos nos seus textos foram o "caráter social do desenvolvimento científico" e a "recusa de um empirismo que concebe os conhecimentos como resultados da inferência indutiva a partir de "dados puros". O entendimento da "procura de coerência global" na construção do conhecimento científico foi também detectado em um número considerável de textos produzidos. Em contrapartida, o entendimento do "papel atribuído pelo pensamento divergente" na construção da ciência não se deu como seria desejável. Da mesma forma, poucos alunos fizeram referência a diferenças existentes entre teorias, leis e hipóteses e ao papel de cada uma delas na construção do conhecimento científico, sugerindo um baixo grau de "recusa da ideia de 'Método Cientifico'” (Resende et al 2010).

Segundo os autores, os resultados evidenciaram a possibilidade do uso do guia de estudos como um eficiente instrumento para auxiliar os estudantes no desenvolvimento de um entendimento adequado acerca da natureza da ciência.

Embora existam importantes motivos e justificativas para a inclusão da Historia e filosofia da Ciência no ensino, Níaz (2009) aponta que, dada à complexidade da natureza da ciência, mesmo para filósofos da ciência, algumas das 
controvérsias entre os pesquisadores na área de ensino de ciências, estão centradas na questão do que deve ser incluído e em que nível de complexidade. Deve-se, portanto, levar em consideração que ideias sobre a ciência o professor espera que seu aluno construa e se está preparado para abordar esse tema em suas aulas.

Segundo Níaz (2009), apesar de controvérsias, certo grau de consenso foi alcançado dentro da comunidade de pesquisadores. As ideias consideradas importantes e que deveriam ser incluídas no ensino são:

- O conhecimento científico baseia-se fortemente, mas não totalmente, na observação, evidência experimental, argumentos racionais e ceticismo.

- As observações estão carregadas de teoria.

- A ciência é tentativa/ erro.

- Não há uma maneira de fazer ciência e, portanto, não há passo-a-passo universal, um método científico que pode ser seguido.

- Leis e teorias possuem diferentes funções no domínio da ciência e, portanto, as teorias não se tornam leis com provas adicionais.

- O progresso científico é caracterizado por uma concorrência entre teorias rivais.

- Diferentes cientistas podem interpretar os mesmos dados experimentais em mais de um caminho.

- O desenvolvimento de teorias científicas, às vezes é baseado em fundamentos inconsistentes.

- Os cientistas são criativos e muitas vezes recorrem à imaginação e à especulação.

- As ideias científicas são afetadas por seu meio social e histórico.

Como justificativa à inclusão dessas ideias sobre a natureza da ciência no ensino, Níaz (2009) aponta que uma revisão da literatura mostra que para a maioria dos professores, em muitas partes do mundo, falta uma compreensão adequada de alguns ou de todos os diferentes aspectos sobre a natureza da ciência descritos anteriormente. Ainda, para ele foi surpresa que em sua análise dos currículos de 
ciências e manuais escolares, verificou que esses são fortemente inclinados para uma postura totalmente empírica e positivista.

Assim, ao enfocar a natureza e a dinâmica da ciência, o professor estaria discutindo aspectos relativos ao campo da filosofia da ciência. Ao abordar como o conhecimento cientifico é construído estaria discutindo também a filosofia da ciência, mas, com um enfoque internalista, ou seja, estaria discutindo as metodologias de cada perspectiva filosófica. O enfoque externalista da construção do conhecimento científicos seria abordado através da historia da ciência, onde seriam consideradas as influências dentro de um contexto mais amplo (social, econômico e político).

Níaz (2009) realizou um estudo cujo objetivo era o de facilitar a transição progressiva dos professores de química da compreensão sobre a natureza da ciência no contexto das controvérsias históricas. O autor selecionou controvérsias (embora não discutidas nos livros didáticos) que se referem a episódios que fazem parte do currículo de química (essas controvérsias referem-se aos modelos atômicos de Thomson, Rutherford, Bohr e da carga elétrica elementar). Para isso, elaborou um curso denominado "Investigação no Ensino de Química", que era parte de um programa de mestrado em educação, para 17 professores em serviço.

Este grupo de professores tinha vários aspectos em comum e formaram um grupo coerente, partilhando as mesmas preocupações e dificuldades. Quase todos os professores foram formados nas proximidades da universidade e tinham uma formação educacional muito semelhante, que não incluía qualquer exposição a novas tendências no ensino das ciências ou da filosofia das ciências.

O autor aponta que durante o curso as interações entre os professores participantes deste estudo facilitaram a transição progressiva da compreensão sobre a natureza da ciência nos seguintes pontos:

- Problemática da natureza do método científico, a objetividade e a base empírica da ciência.

- Mitos associados com relação à natureza da ciência e do ensino de Química.

- O papel da especulação e controvérsia na construção do conhecimento baseado em episódios do currículo de química. 
- A ciência não se desenvolve apelando à objetividade, em um sentido absoluto, a criatividade e os pressupostos também desempenham um papel fundamental.

- A diferenciação entre a lei científica idealizada e as observações é crucial para a compreensão da complexidade da ciência.

Esse estudo mostrou que, dada à oportunidade de refletir, discutir e participar de uma série de atividades do curso com base em vários episódios controversos diretamente relacionados ao currículo de química, a compreensão dos professores sobre a natureza da ciência pode ser melhorada.

Apesar dos resultados encontrados, Níaz (2009) aponta que uma palavra de cautela é necessária porque a relação entre diferentes tópicos do currículo de química e HFC é complexa:

Dada a complexidade de entender a natureza da ciência, mesmo para os pesquisadores em ensino de ciências, é plausível sugerir que os participantes neste estudo podem não ter entendido a natureza da ciência em toda sua complexidade. Além disso, é essencial entender que o nível de complexidade em que pode ser introduzida a natureza da ciência (NOS - nature of 51ortale) irá variar a partir do secundário até ao universitário. No entanto, é importante que esses cursos possam motivar os professores a questionar a "sabedoria convencional sobre a natureza empírica da química" e prosseguir estudos na natureza da ciência dentro de uma perspectiva HFC. (p. 62) (tradução nossa)

Considerando-se a necessidade dos professores de ciências incluírem a História e Filosofia da Ciência no seu ensino, quais seriam as estratégias que facilitariam essa abordagem?

Segundo Del Pino et al (2006), a apropriação dos papéis da história das ciências pelo professor pode se dar em diferentes estratégias:

- Enfocar o paralelismo entre as ideias ou pré-concepções dos estudantes e as concepções vigentes ao longo da história das ciências. Extrair da história das ciências informações sobre as resistências e obstáculos que se manifestam ao longo do trabalho do cientista e relacioná-las com as dificuldades dos estudantes, (Del Pino et al;p.70, 2006).

Por exemplo, ao abordar as dificuldades na aceitação de uma nova teoria, tanto o professor quanto o aluno podem verificar que este processo, às vezes, pode 
durar longos anos. Se a aceitação de uma nova teoria foi tão difícil para os próprios cientistas, maior atenção deveria ser dada a ela, principalmente por parte do professor ao planejar as suas estratégias de ensino.

Contudo, isso não significa postular um paralelismo ente a História da Ciência e o desenvolvimento do conhecimento individual. Segundo Gagliardi (1988), a história pode dar "pistas", porém, o aluno atual vive em um contexto diferente daquele em que o conhecimento científico foi desenvolvido.

Levando-se essa ideia em consideração, nesse trabalho procurou-se discutir o processo de aceitação de uma teoria científica pela comunidade científica, por exemplo, discutir com os professores o processo de aceitação do modelo atômico de Dalton, que foi motivo de controvérsias no século dezenove.

- Permitir extrair da história das ciências os problemas significativos e colocar o aluno em condições de abordá-los, promovendo situações de aprendizagem que permitam aos alunos vivenciar a construção de conhecimentos científicos. É possível evitar delineamentos experimentais de cunho empirista como aqueles propostos pelo Método da Descoberta (Del Pino et al;p.70, 2006).

O estudo de ciências através de problemas, retirados da HC pode, então, proporcionar ao aluno a oportunidade de utilizar procedimentos que sejam próximos aos que utiliza um cientista em suas pesquisas (formular e comprovar hipóteses, medir, contrastar modelos, etc), mas também de utilizar outros procedimentos específicos já não da ciência, mas da aprendizagem escolar, para ler e compreender os textos científicos, decodificar os gráficos, comunicar suas ideias e conhecimentos, como apontam os autores Pozo e Crespo (2009).

- Mostrar o caráter hipotético, tentativo da ciência e mostrar as limitações das teorias, os problemas pendentes de solução, apresentando para os alunos a aventura da criação científica evitando visões dogmáticas, de como se acumula o conhecimento científico, e a produção coletiva do mesmo. As discussões sobre a história das ciências podem ser ao mesmo tempo uma discussão sobre o que é conhecer e como se conhece. Ao mostrar que cada conhecimento atual é o resultado de um longo processo, que não bastam algumas experiências para mudar 
uma teoria, que os fatores sociais tem muito peso, pode-se começar a desmitificar a imagem da ciência na população (Del Pino et al; p.70-71,2006).

Considerou-se nesse trabalho a importância de se discutir sobre o caráter provisório das leis e teorias, evidenciando assim o caráter dinâmico da ciência.

Pode-se mostrar a ciência como uma construção humana, coletiva, fruto do trabalho de muitas pessoas, para evitar a ideia de uma ciência feita basicamente por gênios, em sua maioria homens.

Mas a questão que apresentamos nessa pesquisa é como se pode proporcionar ao aluno a oportunidade de construir uma visão mais realista da ciência e do trabalho científico, durante as aulas de ciências?

Essa tarefa não é fácil, um dos primeiros obstáculos que pode-se encontrar é que dificilmente o professor tem consciência de que quando está ensinando, além do conteúdo, está também passando ao aluno uma determinada imagem sobre a natureza da ciência.

Cachapuz et al ( 2002) apontam que a construção do conhecimento científico exige mudanças profundas e que só uma mudança conceitual, metodológica e atitudinal ajudaria a ultrapassar, nisso a História da Ciência é um importante instrumento ao alcance do professor, que pode ajuda-lo:

- A criar oportunidades para que os alunos se conscientizem da natureza do conhecimento cientifico como sendo não definitivo e também como os conceitos e as teorias mudam;

- No questionamento da exigência de princípios objetivos e únicos, centrados apenas numa racionalidade lógica;

- A evidenciar o papel relevante que a comunidade científica possui na legitimação do conhecimento científico, bem como as resistências que, quase sempre, os cientistas colocam á mudança de paradigma.

Para Gil-Pérez (1993), no campo da didática de ciências, deve-se dar uma maior atenção às abordagens propostas da HFC para o ensino de ciências e utilizálas explicitamente na fundamentação de suas propostas. 
Contudo, o autor aponta que essa aproximação não se refere a fazer do aluno um pequeno cientista, nem tão pouco se refere à aprendizagem por descoberta, mas que a História e Filosofia da Ciência tenham um papel nas palavras do autor:

De um autêntico fio condutor - mesmo que nem sempre explícito- na transformação do ensino de ciências. Um fio condutor que tem se mostrado frutífero inclusive através dos erros cometidos e que se vê reforçado tanto pelas orientações construtivistas como pelas implicações da epistemologia contemporânea no ensino (GilPérez,1993).(tradução nossa)

Portanto, a HFC não seria mais um aspecto do ensino ou outro conteúdo que o professor deveria levar em consideração em seu planejamento do ensino, mas sim ser o eixo que integra os conhecimentos científicos.

O autor propõe uma estratégia de ensino, esquematizada em quatro fases, onde tenta integrar os aspectos que considera como essenciais relativos a atividade científica e que têm sido reiteradamente ressaltados pela HFC, mas que muitas vezes não são levados em consideração no ensino de ciências. Gil Peréz (1993) refere-se concretamente aos problemas de contextualização do trabalho científico (relações CTS, tomada de decisões) e aos componentes afetivos (interesse pela tarefa, clima de trabalho). O quadro 1 apresenta um resumo dessa estratégia.

1. Levantar situações problemáticas, tendo em conta as ideias, visões de mundo, habilidades e atitudes dos alunos, gerar interesse e proporcionar uma concepção preliminar da tarefa.

2. Os estudantes propõem um estudo qualitativo das situações problemáticas levantadas e decisões, com a ajuda das buscas da literatura necessária para reduzir problemas específicos (oportunidade de começar a explicar a funcionalidade de suas ideias)

3. Orientar o tratamento científico dos problemas propostos, o que implica:

- A invenção de conceitos e emissão hipóteses (ocasião para as ideias anteriores serem usadas para fazer previsões).

- O desenvolvimento de estratégias de resolução (incluindo, se for caso, os projetos experimentais) para a verificação da hipótese, à luz do corpo de conhecimento disponível.

- A resolução e análise dos resultados, comparando-os com os obtidos por outros grupos de estudantes e da comunidade científica. Isso pode se tornar uma oportunidade para o conflito cognitivo entre os vários projetos (todos eles considerados como uma hipótese) e forçado a elaborar novas hipóteses.

4. Propor o uso repetido dos novos conhecimentos numa variedade de situações para permitir o aprofundamento e fortalece-los, com ênfase e especial destaque para a relação entre ciência / tecnologia / sociedade, que emolduram o desenvolvimento científico (através do incentivo a este respeito, fazendo decisões) e direcionar todo esse tratamento para mostrar o caráter do corpo coerente que tem toda a ciência. 
Incentivar, em especial, as atividades de sínteses (diagramas, relatórios, mapas), o desenvolvimento de produtos (sujeito a quebrar abordagens excessivamente escolar e reforçar o interesse na tarefa) e a concepção de novos problemas.

Quadro 1. Estratégias de ensino para uma aprendizagem como investigação (Gil-Peréz p.203, 1993) (tradução nossa)

A estratégia proposta pelo autor baseia-se no modelo de aprendizagem por investigação:

A ideia central do modelo de aprendizagem de ciência como investigação que propomos é, como vimos anteriormente, lidar com questões não resolvidas de situações de interesse através do qual os alunos podem participar na construção do conhecimento. Uma primeira questão que se levanta é: até que ponto os alunos podem (re)construir conhecimentos que levaram muito tempo e esforço pela maioria dos notáveis cientistas? (Gil-Peréz p.204, 1993)(tradução nossa)

Para o autor, o aluno nessa estratégia deve ser considerado como um "cientista novato" e o professor como um especialista capaz de dirigir a investigação dos alunos (que, de fato, vão replicar obras bem conhecidas pelo professor).

Portanto, isso implica uma mudança completa da estrutura curricular pois, a partir da abordagem histórica, outros conceitos seriam trabalhados além do conhecimento científico, como, por exemplo, aqueles relacionados a natureza da ciência.

A abordagem histórica do tema cinética química, principalmente a partir das ideias de Níaz (2009), ou seja, a partir de discussões sobre o desenvolvimento de alguns conceitos que foram importantes para o entendimento da velocidade de uma reação, poderia criar oportunidades para se explorar as principais características do desenvolvimento da ciência que são: o processo de construção das teorias científicas pelos cientistas, o papel da comunidade científica na aceitação ou rejeição destas teorias, e o processo da troca de uma teoria por outra., além de facilitar o entendimento da velocidade de uma reação química. 


\section{Capítulo 2. A Reconstrução Histórica do Desenvolvimento da Cinética Química}

Para esse trabalho elaborou-se um texto sobre o desenvolvimento histórico da cinética química do período que vai do ano de 1850 até o ano de 1935. Esse período foi escolhido, porque é o que abrange o desenvolvimento dos conceitos da cinética química que são abordados no ensino médio. Estes são: a ideia de velocidade de uma reação química, os fatores que influem nessa velocidade (principalmente a concentração e a temperatura) e os modelos microscópicos que explicam tanto a velocidade como esses fatores e a teoria da colisão e do estado de transição.

O texto foi escrito levando-se em consideração as ideias do filósofo da ciência Imre Lakatos $(1998,1999)$. Essas ideias fazem parte de uma nova corrente filosófica denominada nova filosofia da ciência surgida a partir da metade do século XX, como resultado de várias críticas ao positivismo, visão filosófica até então dominante. De acordo com essa nova filosofia, o que o cientista observa e investiga é uma "construção" da realidade que está em acordo com a sua formação, marco teórico e até valores sociais, portanto não existem observações neutras.

\section{Breve introdução das ideias de Imre Lakatos}

A metodologia dos programas de investigação científica, segundo Lakatos (1998), constitui, como qualquer outra metodologia, um programa de investigação historiográfico, sendo que o historiador que aceita essa orientação procurará na história programas de investigação rivais, alterações progressivas e degenerativas de problemáticas.

Cada reconstrução racional produz um padrão característico do desenvolvimento racional do conhecimento científico, mas às vezes, segundo Lakatos (1998), essas reconstruções normativas podem ter necessidade de ser completadas por teorias externas empíricas que explicam os fatores residuais não racionais. Mas a reconstrução racional ou história interna é primária, a história externa só tem uma importância secundária. 
Segundo Lakatos (1998), seja qual for o problema que o historiador da ciência pretende resolver, é necessário, em primeiro lugar, reconstruir a parte concernente ao desenvolvimento do conhecimento científico objetivo, ou seja, a parte relativa "história interna".

É importante ressaltar que, segundo Lakatos (1998), o que para um historiador da ciência constitui a história interna depende da sua filosofia, quer ele esteja ciente disso ou não. Para explicar como é a elaboração da história interna Lakatos (1998) aponta que:

Assim, ao construir a história interna, o historiador será muito seletivo: omitira tudo que é irracional à luz da sua teoria da racionalidade. Mas essa seleção normativa ainda não permite uma reconstrução racional completamente livre. Não é somente o êxito (interno) ou fracasso (interno) de um programa que unicamente podem ser avaliados de modo retrospectivo: é também frequentemente 0 seu conteúdo. A história interna não é simplesmente uma seleção de fatos metodologicamente interpretados, ela pode ser ocasionalmente a sua versão radicalmente melhorada (Lakatos, p.41,1998).

Portanto, o historiador pode incluir na sua versão alguma explicação teórica que pode ajudar a entender melhor o que está sendo estudado.

Segundo Lakatos (1998), muitos historiadores manifestam a sua aversão à ideia de qualquer reconstrução racional por ela não levar em consideração a história externa:

Um dos problemas mais interessantes da história externa consiste em especificar as condições psicológicas e, na verdade, sociais, que são necessárias (mas, como é evidente, nunca suficientes) para tornar possível o progresso científico; mas na própria formulação desse problema " externo" tem forçosamente de intervir uma teoria metodológica, uma definição de ciência. A história da ciência é uma história de acontecimentos que são selecionados e interpretados de uma maneira normativa. (Lakatos,1998,p.43).

A reconstrução histórica apresentada neste trabalho foi feita a partir de pesquisas de historiadores da ciência, artigos de pesquisadores e artigos originais dos cientistas que estiveram envolvidos no estudo da cinética química. Foram utilizados os estudos dos pesquisadores Laidler (1984, 1987, e 1993) e Justi (1997, 1999), que desenvolveram trabalhos tendo como foco o estudo da cinética química. 
Esse texto foi desenvolvido durante o mestrado da autora desse trabalho e foi melhorado no período do desenvolvimento doutorado.

Procurou-se nos textos indicar qual o problema que o cientista estava investigando, quais as razões para escolher uma determinada linha de trabalho e não outra como também identificar, quando necessário, o contexto histórico em que determinado conhecimento científico foi desenvolvido. Neste texto, pretendeu-se apresentar aos professores, principalmente, as mudanças das teorias e dos métodos utilizados pela comunidade científica, na sua tentativa de entender a velocidade de uma reação química.

O texto apresentado a seguir, representa a reconstrução histórica que serviu como base para a discussão sobre o desenvolvimento da cinética química durante o curso de formação continuada.

\section{Texto 1: O desenvolvimento Histórico da Cinética Química: Os estudos iniciais - uma breve tentativa de sinalizar o contexto (1850-1862)}

Segundo Laidler (1993), até 1900 a cinética química era quase que inteiramente um assunto empírico, havia pequeno entendimento sobre como a velocidade de uma reação química poderia ser interpretada em termos de movimentos moleculares.

Mais quais seriam as ideias sobre as reações químicas que eram discutidas nesse período de tempo? Na metade do século XIX já se tinha o conhecimento do modelo para a estrutura da matéria proposto por John Dalton (1808), contudo, podese notar que nesses estudos iniciais não estavam presentes discussões sobre a constituição da matéria, ou mais precisamente discussões sobre o modelo atômico de Dalton. Segundo Oki (2009):

Durante o século $\mathrm{XIX}$, a ideia de átomo foi considerada por grande parte da comunidade científica como uma hipótese fundamental para uma interpretação quantitativa de dados empíricos, mesmo existindo dúvidas e especulações sobre a realidade dos átomos que, em parte eram de ordem filosófica. O grande desafio a ser enfrentado pelos atomistas para tornar a hipótese atômica amplamente aceitável era concretizar a necessária articulação entre as dimensões macroscópica e submicroscópica. (Oki, 2009. P.1072) 
Sabe-se que a ideia de átomo não era aceita pela maior parte dos físicos químicos dessa época, pois, para estes cientistas o conhecimento científico verdadeiro era aquele que só poderia ser provado pela experimentação.

A seguir serão apresentados e discutidos alguns aspectos dos estudos originais de Ludwig Ferdinand Wilhelmy (1850) e de Harcourt e William Esson (1865) que foram importantes para o entendimento inicial da velocidade de uma reação química.

- Ludwig Ferdinand Wilhelmy (1812-1864): A lei pela qual a reação da cana de açúcar com o ácido ocorre (1850) (tradução nossa)

No século dezenove, muitos estudos experimentais foram realizados, nos quais observou-se que alguns fatores, como a concentração dos reagentes, podiam influenciar a velocidade de uma reação, mas foi somente em 1850, quando o físicoquímico alemão Ludwig Ferdinand Wilhelmy (1812-1864) estudou a velocidade da inversão da sacarose, é que a cinética química foi reconhecida como um campo de estudo da química (Laidler; 1993). A reação estudada por ele foi:

$$
\begin{gathered}
\mathrm{C}_{12} \mathrm{H}_{22} \mathrm{O}_{11}+\mathrm{H}_{2} \mathrm{O} \rightarrow \mathrm{C}_{6} \mathrm{H}_{12} \mathrm{O}_{6}+\mathrm{C}_{6} \mathrm{H}_{12} \mathrm{O}_{6} \\
\text { Sacarose(+) } \quad \text { Glucose (+) Frutose(-) }
\end{gathered}
$$

Nessa reação, a sacarose em presença de um ácido, sofre hidrólise formando frutose e glicose. $O$ curso da reação pode ser seguido facilmente, e com grande exatidão, com o uso de um polarímetro, pois a sacarose desvia para a direita o plano de polarização da luz, enquanto que a frutose é levogira, isto é, desvia o plano da luz polarizada para a esquerda.

Este método de seguir o curso de uma reação química mediante uma medida óptica muito sensível se fundamenta na hipótese de que o giro do plano de polarização é proporcional à concentração do açúcar em solução.

Esse fato já era de conhecimento de Wilhelmy (1850), portanto, antes de realizar seus experimentos ele propôs uma equação matemática que relacionava a concentração do açúcar produzido com a rotação do plano de luz.

Após desenvolver esse tratamento matemático, ele elaborou um estudo experimental para estudar influência de alguns fatores nessa reação química, como 
a influência do tempo. A sua hipótese inicial era que: "A quantidade invertida por unidade de tempo é proporcional à quantidade de açúcar que continua sem ser invertido na solução" (Wilhelmy, 1850) (tradução nossa).

É importante ressaltar que Wilhelmy estava suficientemente interessado em realizar não só os experimentos necessários para confirmar ou não a sua hipótese, mas também estava interessado na especial tarefa de formular conceitos (Ostwald,1909). Em seu estudo ele esperava estabelecer uma relação que descrevesse o comportamento da reação de um ácido com um determinado açúcar em diferentes concentrações desses dois reagentes.

O estudo experimental de Wilhelmy (1850) está dividido em duas etapas: na primeira ele tenta estudar a influência do tempo na reação de hidrolise da sacarose, na segunda etapa ele estuda a Influência da quantidade de açúcar nessa reação. A seguir será apresentada a descrição de cada etapa.

\section{A influência do tempo:}

Nesse experimento (fig. 2.1), ele acompanhou a reação durante um dia inteiro. Enquanto a reação ocorria no recipiente de amostra do polarímetro, ele foi anotando os valores de rotação da luz e a partir da equaçãoa que relacionava a concentração do açúcar inicial $\left(Z_{0}\right)$ com a rotação $(D)$ :

$$
Z=Z_{0}-\left(Z_{0}-D\right) /(1+\mu)
$$

onde $\mu$ é o coeficiente de inversão calculado para o açúcar. Assim, ele ia calculando o valor da quantidade de açúcar convertido $(Z)$.

A influência do tempo ( $T$ ) nesta reação era estudada a partir da equação que ele tinha elaborado anteriormente:

$$
-d Z / d T=M Z S
$$

onde $M$, denominado coeficiente de inversão, é o valor médio da quantidade infinitamente pequena de unidades de açúcar que são alterados durante o tempo pela ação da quantidade de ácido (S) presente. 
Nesse estudo Wilhelmy chegou à conclusão de que a quantidade de açúcar convertido, em um determinado período de tempo, é proporcional à quantidade de açúcar que não era convertido, confirmando assim a sua hipótese inicial.

Ele também pôde observar, enquanto acompanhava o curso da reação durante um dia inteiro, que a temperatura poderia ter influência na quantidade de produto formado, mas ele reconheceu que esse fato, por sua aparente importância, merecia um estudo independente, portanto, essa influência não foi estudada naquele momento.

\begin{tabular}{|c|c|c|c|}
\hline \multicolumn{4}{|c|}{ Table III } \\
\hline $\mathbf{T}$ & Rotation & $\begin{array}{c}{\left[\log \mathrm{Z}_{0}-\log \right.} \\
\text { Z) MS }[3]\end{array}$ & \multirow[t]{2}{*}{ t } \\
\hline & \multicolumn{2}{|c|}{$46^{\circ}, 75$ before mixing } & \\
\hline \$ h. & $\begin{array}{l}\text { Mixing of acid } \\
\text { with sugar solution }\end{array}$ & & \\
\hline $8 \mathrm{~h} .15^{\prime}$ & $+43^{\circ}, 75$ & & $15^{\circ 5}$ \\
\hline " 30 & +41 & & \\
\hline " 45 & $+38,25$ & & \\
\hline $9 \mathrm{~h}$. & $+35,75$ & 0.0801671 & \\
\hline 9 h. 15 & $+33,25$ & & \\
\hline 9 h. 30 & $+30,75$ & & \\
\hline $9 \mathrm{~h} .45$ & +28.25 & & \\
\hline $10 \mathrm{~h}$. & +26 & 0.1661271 & \\
\hline 10 h. 30 & +22 & & \\
\hline $11 \mathrm{~h}$. & $+18,25$ & 0.2504869 & \\
\hline $11 \mathrm{~h} .30$ & +15 & & \\
\hline $12 \mathrm{~h}$. & $+11,5$ & 0.3393678 & \\
\hline $12 \mathrm{~h} .30$ & +8.25 & & \\
\hline $1 \mathrm{~h} .30$ & +2.75 & 0.4882238 & $18^{\circ}$ \\
\hline 2h. 30 & $-1,75$ & 0.5859208 & $16^{\circ}$ \\
\hline 3 h. 30 & -4.5 & 0.6628879 & \\
\hline 4 h. 30 & -7 & 0.7470561 & $15^{\circ}$ \\
\hline 5 h. 30 & $-8,75$ & $0 . \$ 173016$ & \\
\hline $6 \mathrm{~h} .30$ & -10 & 0.8752936 & $14 \div 5$ \\
\hline
\end{tabular}

Figura 2.1 Extrato do "Poggendorf's Annalen der Physik und chemie, The law by the action of acids on cane sugar occurs", onde Wilhelmy estuda a influência do tempo na velocidade da hidrólise da sacarose.

Influência da quantidade de açúcar:

No experimento anterior Wilhelmy pode observar que o coeficiente de inversão $M$ era independente da quantidade de açúcar: " $O$ coeficiente $M$ é independente da quantidade de açúcar, isto aparece na série de observações que foram anotadas" (Wilhelmy, 1850). (tradução nossa). 
Ele então resolveu calcular $M$ (fig. 2.2) para cada intervalo de tempo da reação de inversão da sacarose.

\begin{tabular}{|c|c|}
\hline $\mathrm{M}=0.0204467 \cdot 1 / 5$ & $\left(\mathrm{t} 15^{\circ}, 5\right)$ \\
\hline \multicolumn{2}{|l|}{$\mathrm{M}=0.0197215^{\prime \prime}$} \\
\hline \multicolumn{2}{|l|}{$\mathrm{M}=0.0204460^{\prime \prime}$} \\
\hline \multicolumn{2}{|l|}{$\mathrm{M}=0.0195529^{\prime \prime}$} \\
\hline \multicolumn{2}{|l|}{$\mathrm{M}=0.0204748^{\prime \prime}$} \\
\hline \multicolumn{2}{|l|}{$\mathrm{M}=0.0214880^{\prime \prime}$} \\
\hline \multicolumn{2}{|l|}{$\mathrm{M}=0.0226069^{\prime \prime}$} \\
\hline \multicolumn{2}{|l|}{$\mathrm{M}=0.0213903^{\prime \prime}$} \\
\hline \multicolumn{2}{|l|}{$\mathrm{M}=0.0210030^{\prime \prime}$} \\
\hline \multicolumn{2}{|l|}{$\mathrm{M}=0.0202667^{\prime \prime}$} \\
\hline \multicolumn{2}{|l|}{$\mathrm{M}=0.0241737^{\prime \prime}$} \\
\hline \multicolumn{2}{|l|}{$\mathrm{M}=0.0240091^{\prime \prime}$} \\
\hline $\mathrm{M}=0.0252094 "$ & $\begin{array}{l}\text { t } 18^{\circ} \text { (maximum } \\
\text { temperature) }\end{array}$ \\
\hline \multicolumn{2}{|l|}{$\mathrm{M}=0.0244242 "$} \\
\hline \multicolumn{2}{|l|}{$\mathrm{M}=0.0192418^{\prime \prime}$} \\
\hline \multicolumn{2}{|l|}{$\mathrm{M}=0.0210170^{\prime \prime}$} \\
\hline \multicolumn{2}{|l|}{$\mathrm{M}=0.0175614^{\prime \prime}$} \\
\hline $\mathrm{M}=0.0142906^{\prime \prime}$ & $t 14^{\circ}, 5$ \\
\hline
\end{tabular}

Figura 2.2 Extrato do "Poggendorf's Annalen der Physik und chemie, The law by the action of acids on cane sugar occurs", onde Wilhelmy estuda a influência da quantidade de açúcar na velocidade da hidrólise da sacarose.

Wilhelmy pode confirmar então, através de seus cálculos, que $M$ era independente da quantidade de açúcar:

Podemos observar que a ligeira irregularidade no valor de $M$ corresponde à temperatura, assim $M$ permanece constante, enquanto a quantidade de açúcar no líquido caiu de 46,75 para 6,23. (Wilhelmy, 1850). (tradução nossa).

Para entender a independência do valor de $\mathrm{M}$ da quantidade de açúcar Wilhelmy resolveu então fazer um estudo especial. Nesse estudo ele realizou uma série de experimentos, simultaneamente, mantendo constante a temperatura e a quantidade de ácido (S) e de água (W), variando-se somente a quantidade inicial de açúcar. As condições de execução e os resultados são apresentados na figura 2.3. 


\begin{tabular}{|c|c|c|c|c|c|}
\hline \multicolumn{7}{|c|}{ Tabela IV } \\
\hline $\mathrm{Z}_{\mathbf{0}}$ & $\begin{array}{c}\text { Anhydrous } \\
\text { HNO }_{3} \\
\text { S }\end{array}$ & W & T & D & M \\
\hline $45^{\circ}$ & $0.281 \mathrm{~g}$. & $7.542 \mathrm{~g}$ & $13 \mathrm{~h}$. & $+4^{\circ}, 25$ & 0.1240 \\
\hline 36 & $"$ & $"$ & $"$ & +3 & 0.1267 \\
\hline 27 & $"$ & $"$ & $"$ & +2 & 0.1290 \\
\hline 18 & $"$ & $"$ & $"$ & $+1,25$ & 0.1301 \\
\hline 9 & $"$ & $"$ & $"$ & +3 & 0.1201 \\
\hline
\end{tabular}

Figura 2.3 Extrato do "Poggendorf's Annalen der Physik und chemie, The law by the action of acids on cane sugar occurs", onde Wilhelmy estuda a independência do valor de M da quantidade de açúcar.

Pode-se dizer que, a partir do estudo da reação de inversão da sacarose, Wilhelmy elaborou conceitos que são importantes para a cinética química: o conceito de velocidade de uma reação química (variação de concentração por unidade de tempo) e que o coeficiente de inversão $M$ (que denominados atualmente de constante de velocidade) não depende da concentração inicial dos reagentes, mas sim que sofre influência da temperatura.

Inicialmente o trabalho de Wilhelmy recebeu pouco crédito da comunidade científica (Ostwald,1909). Somente 30 anos mais tarde, resultados similares foram publicados por van't Hoff e Arrhenius causando um impacto muito maior na comunidade científica da época. Van't Hoff, em seu trabalho, reconheceu o importante trabalho realizado por Wilhelmy.

- Augustus George Harcourt (1834-1919) e William Esson (1838-1916).

Outro estudo importante para o entendimento da velocidade de uma reação química foi o realizado pelos cientistas Augustus George Harcourt (1834-1919) e William Esson (1838-1916).

Seguindo os procedimentos Wilhelmy, ou seja, estudando reações orgânicas onde as medições experimentais eram mais precisas por serem reações mais lentas, em 1865, Augustus George Harcourt (1834-1919), realizou alguns estudos experimentais importantes da cinética de reações químicas. 
Harcourt contou com a colaboração do colega escocês William Esson (18381916), da faculdade de Merton (Reino Unido) e professor de matemática. Ele escolheu trabalhar com seu colega, Esson, por ser reticente sobre sua própria habilidade matemática. Esson aceitou o desafio e essa se tornou sua principal área de pesquisa sendo que publicou com Harcourt importantes artigos entre 1867 e 1868.

Juntos eles desenvolveram equações empíricas que relacionavam a quantidade de produto formado com o tempo. As equações resultantes foram usadas para a análise de resultados experimentais que Harcourt obteve em seu laboratório.

Um dos sistemas investigado por Harcourt e Esson, na Universidade de Oxford no inicio de 1865, foi o experimento denominado "iodine-clock" (relógio de iodo), que envolve a oxidação do íon iodeto e redução de peróxido de hidrogênio em solução ácida (Shorter, 1980):

$$
\mathrm{H}_{2} \mathrm{O}_{2}+2 \mathrm{H}^{+}+2 \mathrm{I}^{-} \rightarrow \mathrm{I}_{2}+2 \mathrm{H}_{2} \mathrm{O}
$$

A reação ocorre na presença de amido e de uma pequena quantidade de tiossulfato. $O$ aparecimento de uma cor azul indica a presença do iodo $\left(I_{2}\right)$ no sistema ${ }^{1}$. O intervalo de tempo entre a mistura dos reagentes e o aparecimento da cor azul é relacionada inversamente à velocidade da reação $(a)$, sob determinadas condições. Através da adição sucessiva de quantidades de solução de tiossulfato, o progresso da reação (a) pode ser seguido.

Esson, tentando elaborar uma fórmula matemática, que pudesse relacionar aos resultados obtidos experimentalmente formulou a seguinte hipótese: “.... total de mudança que acontece em qualquer momento será proporcional à quantidade da substância que então permanece" (Shorter, 1980).(tradução nossa)

Harcourt determinou a ordem de reação relativa ao iodo pelo método que hoje chamamos de "velocidades iniciais." Ele mediu a velocidade inicial de reação (na

\footnotetext{
${ }^{1}$ A reação ocorre da seguinte maneira: $\mathrm{H}_{2} \mathrm{O}_{2}(\mathrm{aq})+2 \mathrm{H}^{+}{ }_{(\mathrm{aq})}+3 \mathrm{I}^{-}{ }_{(\mathrm{aq})} \rightarrow \mathrm{I}_{3}^{-}{ }_{(\mathrm{aq})}+2 \mathrm{H}_{2} \mathrm{O}_{(\mathrm{aq})}$ $\mathrm{I}_{3(\mathrm{aq})}^{-}+2 \mathrm{~S}_{2} \mathrm{O}_{3}{ }_{(\mathrm{aq})}^{-2} \rightarrow 3 \mathrm{I}_{(\mathrm{aq})}^{-}+\mathrm{S}_{4} \mathrm{O}_{6}{ }^{-2}(\mathrm{aq})$
}

A reação com tiosulfato, quando termina, $\mathrm{I}_{3}{ }^{-}$reage com amido dando a cor azul. 
verdade, a fração de $\mathrm{H}_{2} \mathrm{O}_{2}$ consumida em um tempo fixo) para uma variedade de concentrações de iodo. Pelo experimento denominado "iodine-clock" a reação pode ser demonstrada cineticamente como sendo de primeira ordem ${ }^{2}$ em relação ao peróxido de hidrogênio, ao iodeto e ao ácido.

\section{Considerações}

Estes estudos, nesse período de tempo (1850-1865), foram de grande importância na cinética química, pois neles a velocidade de uma reação começou a ser estudada de forma quantitativa com a introdução de equações exponenciais e diferenciais que possibilitavam a determinação da concentração dos reagentes ou de produtos de uma reação química, portanto, esta união da química com a matemática, possibilitou aos cientistas realizarem previsões mais precisas das velocidades das reações.

Em relação às técnicas experimentais, o uso do polarímetro foi importante, pois permitiu a obtenção de dados quantitativos que permitiram a elaboração de equações matemáticas para o estudo da cinética das reações químicas.

No entanto, podemos observar que esses cientistas não tinham a preocupação de explicar esses novos conceitos através de um modelo de constituição da matéria. Assim, pode-se dizer que neste período o enfoque dados aos estudos cinéticos era empírico-matemático.

\section{Texto 2: Os estudos sobre a influência da temperatura e da concentração na velocidade de uma Transformação Química no período de 1862 a 1888.}

Um entendimento maior de uma reação química ocorreu com os estudos da termodinâmica. Com a cinética química conseguimos descrever como a reação química ocorre, mas a termodinâmica mostra que praticamente nenhuma reação se completa, ou seja, o sistema químico, após certo tempo, entra em equilíbrio. $\mathrm{O}$ estudo de reações químicas, em estado de equilibro químico, proporcionou um maior entendimento da influência da temperatura na velocidade da reação.

\footnotetext{
${ }^{2}$ O termo "primeira ordem" como é utilizado atualmente somente surgiu com Ostwald em 1893. (Laidler, 1993)
} 
Um estudo que contribuiu para isso foi o de Claude Louis Berthollet (17481822) e Péan de Saint-Gilles (1832-1862). Em 1862 eles estudaram a reação entre um álcool (metanol) e um ácido (ácido Benzoico) tendo como produtos éster e água

$$
\mathrm{CH}_{3} \mathrm{OH}+\mathrm{C}_{6} \mathrm{H}_{5} \mathrm{COOH} \rightleftharpoons \mathrm{CH}_{3} \mathrm{OOCC}_{6} \mathrm{H}_{5}+\mathrm{H}_{2} \mathrm{O}
$$

na qual nunca ocorre a conversão total dos reagentes a produtos, mas se aproxima lentamente de um limite correspondendo ao equilíbrio. Eles propuseram a seguinte hipótese: "a quantidade de éster formado em cada momento é proporcional ao produto das substâncias reagentes e inversamente proporcional ao volume“. (Partington, 1989, p. 325).

Nesse estudo eles demonstraram que o aumento de temperatura do sistema aumentava a velocidade de reação, mas que a pressão tinha pequena influência na velocidade.

Nesse período de tempo, portanto, houve um direcionamento maior dos estudos para a compreensão do efeito da temperatura na velocidade de reações químicas que se encontravam em estado de equilíbrio químico.

Uma grande contribuição no estudo da cinética química no que diz respeito à dependência da temperatura na velocidade de reações químicas, em estado de equilíbrio químico, foi feita por Jacobus Henricus van't Hoff (1852-1911) em 1884 (Laidler e King,1983).

Em seus estudos sobre a cinética das reações, van't Hoff reconheceu a natureza dinâmica das reações químicas, sendo que ele introduziu o símbolo dupla seta usado atualmente nas equações químicas.

Mas a ideia de que quando um sistema químico está em equilíbrio, mudanças químicas continuam a ocorrer, com velocidades iguais em direções opostas não é originalmente de van't Hoff. Esta ideia, segundo Laidler e King (1983) foi originalmente sugerida pelo químico britânico Alexander William Williamson (18241904).

Em 1850, Williamson (1851-1854), estudando as reações de esterificação, foi o primeiro cientista a propor um modelo submicroscópico para explicar o estado "estático" de equilíbrio químico. Ele não considerou o equilíbrio como uma situação 
em que nada acontece, pelo contrário, ele assumiu que duas reações ocorriam simultaneamente, cada uma na direção oposta. Assim, "reagentes" bem como "produtos" estavam constantemente sendo formandos e se decompondo de forma que o montante de todas as substâncias envolvidas permanece constante. Este equilíbrio dinâmico era atingido assumindo-se um intercâmbio de átomos, iguais em número absolutos, em cada período de tempo (Quílez, 2004).

Segundo Quílez (2004), uma nova tentativa para explicar as mudanças moleculares que ocorrem em um estado de equilíbrio foi feita por Pfaundler. Em 1867, ele escreveu um artigo que tratava de uma reação química em termos da teoria cinética dos gases desenvolvida por Clausius e Maxwell.

Estudando a decomposição parcial de um gás, Pfaundler admitiu que a uma dada temperatura, quantidades iguais de moléculas se decompõem e se unem pela colisão. Esta explicação exige que todas as moléculas não estejam no mesmo estado de movimento a uma determinada temperatura, porque apenas uma pequena quantidade de colisões era eficaz para produzir reações químicas, tanto no sentido da decomposição como na formação. Argumentando dessa forma, ele discordou da ideia Williamson de que havia uma troca contínua de elementos de um composto molecular, elaborando assim as suas próprias ideias sobre a distribuição do movimento sobre as moléculas individuais para fornecer uma melhor explicação, que se transformou em uma teoria geral mais aplicável (Quílez, 2004).

Pfaundler, então, para explicar porque nem todas as colisões entre as moléculas reagentes levavam à formação de produtos, sugeriu que somente aquelas moléculas que tinham uma quantia maior de energia que a energia crítica eram capazes de sofrer reação (Laidler, 1993).

Todas essas ideias, desenvolvidas por Williamson e Pfaundler, influenciaram os estudos desenvolvidos por van't Hoff. Um ponto importante a ser considerado sobre essas discussões é que elas incluíam as ideias de átomos e moléculas, que estavam ausentes nos estudos iniciais da cinética química.

- O Estudo de van't Hoff 
Em seu livro, Études de Dynamique Chimique (1884), van't Hoff discute, entre outros temas, a influência da concentração e da temperatura na velocidade de uma reação química.

Seu livro é dividido em duas partes:

1‥ Parte: A velocidade da reação química no equilíbrio: termodinâmica, onde discute o efeito da temperatura na velocidade das reações químicas em estado de equilíbrio químico.

2ª . Parte: Cinética das reações onde, através de experimentos, tenta relacionar suas equações matemáticas anteriormente desenvolvidas na primeira parte do livro (as leis de velocidade das reações químicas), com os dados experimentais obtidos.

A seguir serão apresentadas as principais ideias de cada parte desse livro.

A velocidade da reação química no equilíbrio: termodinâmica: O efeito da temperatura na velocidade de uma reação química.

Em seu estudo, van't Hoff usando o conceito de energia livre apresentou uma equação para a dependência da temperatura considerando-se uma reação em equilíbrio, que pode ser expressa como:

$$
\frac{d \ln K c}{d T}=\frac{\Delta U^{\circ}}{\mathrm{RT}^{2}}
$$

onde $\Delta U^{0}$ é a variação de energia para esse sistema, $K c$ é a constante de equilíbrio em função da concentração das substâncias evolvidas na reação e $R$ é a constante geral dos gases.

A partir dessa equação van't Hoff estabeleceu a seguinte relação para o cálculo da constante, conhecida atualmente, como constante de velocidade de uma determinada reação química:

$$
k=A e^{-\frac{E}{R T}}
$$

O fator $\mathrm{A}$ foi muito tempo conhecido como o fator de frequência, e agora se conhece como fator pré-exponencial.

Essa equação permitia, portanto, relacionar a constante de velocidade, $k$, de uma determinada reação com a temperatura, ou seja, propondo a ideia de que a 
constante de velocidade de uma reação química depende muito da temperatura, não dependendo da concentração das substâncias reagentes, ideia essa proposta anteriormente por Wilhelmy em 1850.

Cinética das reações: O efeito da concentração na velocidade de uma reação química

Um estudo importante para a determinação da lei de velocidade de uma reação química foi o estudo da reação de decomposição do gás arsina $^{3}$ :

$$
2 \mathrm{AsH}_{3(\mathrm{~g})}=2 \mathrm{As}_{(\mathrm{g})}+3 \mathrm{H}_{2}(\mathrm{~g})
$$

Para realizar esse estudo van't Hoff utilizou um aparelho descrito a seguir:.

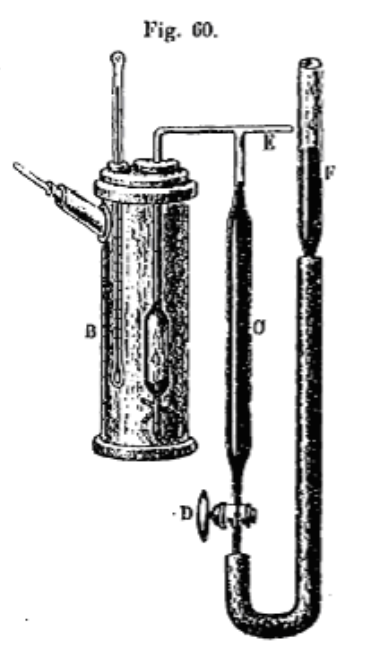

Figura 2.4 Esquema da aparelhagem que van't Hoff (1898) utilizou para estudar a marcha da reação de decomposição do gás arsina. (Études de Dynamique Chimique, pág.190,1898)

O aparelho (fig.2.4) consiste de um reservatório $A$ no qual após a expulsão do ar, o gás arsina é introduzido através de um tubo capilar $E$. O tubo é fechado, sem entrada de luz. O mercúrio está em $C$ e onde está colocado o reservatório $A$ existe um termômetro. Abre-se a válvula $D$ e o nível de mercúrio eleva-se até um determinado ponto. A diferença de nível do mercúrio entre $C$ e $F$ é a altura barométrica onde a pressão do gás $A$, é determinada. $A$ determinação da quantidade, decomposta ou não, se faz a partir da medição da pressão por volume à temperatura constante.

${ }^{3} \mathrm{~A}$ equação original que van't Hoff escreveu era: $A s \mathbf{I}_{x}=A s+3 \mathbf{s}$. (http://gallica.bnf.fr/ark:/12148/bpt6k91927k/f1.table; pág.189) 


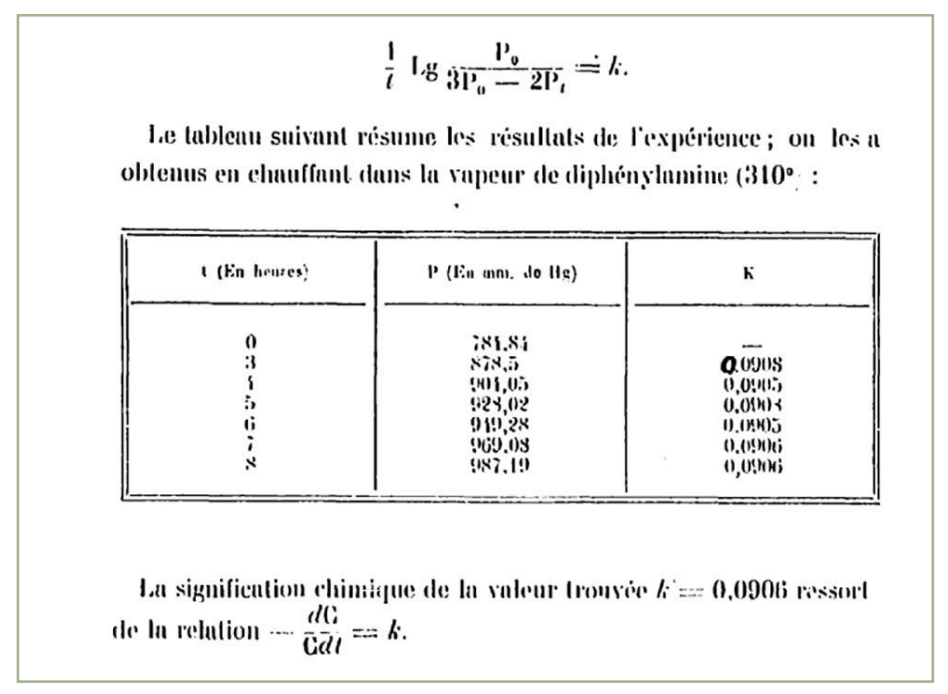

Figura 2.5 Dados experimentais obtidos por van't Hoff na decomposição do gás arsina a $310^{\circ} \mathrm{C}$ (Études de Dynamique Chimique, pág.190,1898).

Nesse estudo van't Hoff escreveu uma equação diferencial para esta reação:

$$
\frac{d c}{d t}=k C
$$

onde $C$ é a concentração do reagente no tempo $t$, e $k$ é a constante de velocidade.

Ele integrou essa equação, obtendo uma expressão para $c$ em função do $t$, e obteve disto o valor da constante $k$. Ele reconheceu assim que, para uma reação de primeira ordem a fração da substância que começa a ser consumida em um dado tempo é independente da quantidade inicial.

Essa expressão é, portanto, o que denominamos atualmente de lei de velocidade para a decomposição desse gás. Um ponto importante que deve ser salientado é que a lei de velocidade é uma característica da reação determinada experimentalmente.

No Études, van't Hoff introduziu também um método geral, ainda usado hoje, para análise de resultados cinéticos experimentais com o objetivo de determinar a ordem de uma reação química. Este é chamado de método diferencial, que envolve medições de velocidades, $v$, e variações da concentração $c$ do reagente. A relação entre os dois é então:

$$
v=k c^{n}
$$

O valor de n é a inclinação da curva do $\log v$ versus $\log c$ 


\section{Considerações}

Este período (1862 a 1888), foi importante para a cinética química principalmente, pelos estudos de van't Hoff, tanto em relação à influência da concentração como também influência da temperatura nas velocidades das reações químicas.

J. H. van't Hoff, ao pensar como uma reação química acontece, analisando o processo como um todo, conseguiu formular conceitos teóricos importantes, o que segundo Justi (1997), não era feito pelos químicos até o tempo dele. Podemos resumir as principais contribuições de van't Hoff a seguir:

- Ele propôs a existência de fatores que podem exercer influência no curso de uma reação química, por exemplo, o efeito da temperatura na velocidade de uma reação.

- Aplicou conceitos da termodinâmica para situações da físicoquímica;

- Estudo da cinética com ênfase sobre a realidade dos átomos e das moléculas. Ele relacionou estritamente a cinética com as propriedades das substâncias e à ocorrência de reações químicas.

Apesar desse grande aumento de entendimento da velocidade $\mathrm{e}$ principalmente do entendimento da influência da temperatura na velocidade de uma reação química, Laidler (1993) aponta que levando-se em consideração a concentração e a temperatura na determinação da lei de velocidade de uma reação química, nos estudos realizados nessa época, percebeu-se que o valor calculado era muito maior do que o valor determinado experimentalmente. Portanto, deveriam existir outros fatores que poderiam influenciar a velocidade de uma reação química. Este problema só foi resolvido posteriormente.

\section{Texto 3: O desenvolvimento da teoria das colisões e o conceito de energia de ativação (1889-1918)}

- O estudo de Arrhenius: O conceito de energia de Ativação

Em 1889, Svante Arrhenius (1859-1927) explicou o fato de que a maioria das reações químicas exigia mais energia térmica para acontecer, ao formular o conceito de energia de ativação, uma barreira de energia que devem ser superada antes que duas moléculas reajam. 
A equação de Arrhenius pôde então fornecer a base quantitativa da relação entre a energia de ativação e a velocidade na qual a reação se processa.

Em estudo de 1889, Arrhenius (Back e Laidler, 1967), usando o tratamento de van't Hoff, notou que a magnitude do efeito da temperatura nas velocidades dos processos químicos é geralmente muito grande para ser explicada em termos de como a temperatura afeta a energia molecular translacional, ou em termos de como a temperatura afeta a viscosidade do meio. Nas suas palavras:

O aumento da velocidade de reação difere de um modo muito importante do aumento com temperatura na maioria das quantidades físicas. Assim, a mudança destas quantidades é aproximadamente igual para um aumento em temperatura de $1^{\circ}$ (um grau), até mesmo para valores muito diferentes da temperatura (por exemplo, $0^{\circ}$ e $50^{\circ}$ ). Por outro lado, o aumento (em valor absoluto) por grau da velocidade de reação é talvez duas vezes maior a $6^{\circ}$ que a $0^{\circ}$, a $12^{\circ}$ quatro vezes maior que a $0^{\circ}$, a $30^{\circ}$ talvez trinta $\left(2^{5}\right)$ vezes maior que a $0^{\circ}$, etc. Este fato indica que o aumento da velocidade de reação com a temperatura não pode ser explicado em termos da mudança em propriedades físicas das substâncias reagentes. ${ }^{4}$ (tradução nossa)

Ele concluiu que um equilíbrio é estabelecido entre moléculas reativas normais e as ativas ${ }^{5}$, as quais são capazes de formar produtos sem a adição de energia mais adiante. $O$ equilíbrio entre moléculas normais e ativas poderá ser deslocado com a temperatura de acordo com a equação de van't Hoff, de forma que a velocidade poderá variar com a temperatura da mesma maneira. Ele não considerou a energia $E$ dependente da temperatura, adotando assim a equação de van't Hoff:

$$
k=A e^{\frac{-E}{R T}}
$$

Como resultado da interpretação de Arrhenius, esta equação passou a ser chamada de equação de Arrhenius, embora fosse essa elaborada inicialmente por van't Hoff. Com a sua modéstia característica, van't Hoff passou a impressão de que foi Arrhenius que tinha proposto primeiro a equação. (Laidler, 1993).

\footnotetext{
${ }^{4}$ Extrato do texto "On the reaction velocity of the inversion of cane sugar by acids" de Svante Arrhenius (1889), traduzido por Back, M e Laidler, J. K em 1967.

5 Para Arrhenius a diferença entre moléculas normais e ativas está na quantidade de energia, assim, uma molécula normal não tem energia suficiente para reagir, já a molécula ativa não necessita de mais energia, pois, já possui energia suficiente para reagir.
} 
Pode-se interpretar a equação de Arrhenius em termos de barreira de energia da reação; se $E$ é a altura da barreira, a fração de moléculas tendo energia em excesso de $E$ é igual a exp (-E/RT). Hoje, a energia de ativação é usualmente dada pelo símbolo Ea, e esta é considerada uma quantidade experimental definida com base na equação de Arrhenius.

- O estudo de Lewis: Princípios da teoria das colisões.

William Cudmore McCullagh Lewis (1885-1956) foi um dos primeiros físicoquímico que considerou que a constante de velocidade em sistemas químicos poderia ser tratada por métodos da mecânica estatística e da teoria quântica. Em 1918, Lewis formulou os principais princípios da teoria da colisão.

Em seu artigo "Estudos de Catálise" de 1918, Lewis aponta que, inicialmente outros estudos nesta área obtinham expressões com a ajuda da hipótese da radiação ${ }^{6}$ para a constante de velocidade e a constante de equilíbrio em função da temperatura. Contudo, nas expressões assim obtidas era necessário ter certo "fator de proporcionalidade" que tinha de ser determinado com a comparação direta com a experiência. Lewis propõe uma tentativa de lidar com este problema de uma maneira mais completa, calculando as constantes de velocidade e de equilíbrio em termos de quantidades, as quais possuem um significado físico definido e que pode ser determinada teoricamente, sem referências à velocidade real da própria reação química.

A primeira ideia sobre a qual Lewis fundamenta sua teoria é a de que as moléculas existem e que admitindo-se a sua existência pode-se explicar o comportamento dos gases em relação ao volume, pressão e temperatura:

A base da teoria cinética molecular ou da matéria, isto é, a existência real das moléculas foi considerada durante muito tempo com certa dose de desconfiança, mesmo por aqueles que estavam preparados o suficiente para admitir e apreciar a utilidade da hipótese cinética..... Evidentemente, o fato de que a teoria cinética foi capaz de dar uma explicação muito simples e razoável ao comportamento dos gases

\footnotetext{
6 De acordo com a hipótese da radiação, a transferência de energia ocorre por absorção da radiação infravermelha e não por choque entre as moléculas, ou seja, a reação química ocorre pela absorção da radiação infravermelha vinda das paredes do recipiente da reação (Laidler, 1993).
} 
em relação ao volume, pressão e temperatura era de forte evidência indireta de sua validade, embora isto fosse parcialmente compensado pelo fato de que o comportamento dos gases quando muito comprimidos, e mais ainda o comportamento dos líquidos e sólidos, não poderiam ser explicadas sem a introdução de alguns pressupostos, tais como a existência de forças de atração entre as moléculas. A justificativa final da teoria cinética em relação à demonstração experimental que as moléculas existem de fato só foi concluída na última década, independentemente, pelo notável físico francês Jean Perrin, por Millikan na América e Svedberg e na Suécia. (Lewis, 1914). (Tradução nossa)

Outro ponto considerado por Lewis, é que uma reação química ocorre quando determinadas moléculas possuem uma determinada quantidade de energia. Essas moléculas, que participam da reação química, são denominadas por ele de moléculas ativas:

O conceito de molécula ativa foi primeiramente postulado por Arrhenius, mas foi apenas nos anos recentes que na diferenciação entre as moléculas ativas e passivas tem sido atingido algum grau de precisão através da introdução do conceito de energia crítica e incremento crítico. (Lewis, p.472, 1918) (tradução nossa)

Para explicar a ativação das moléculas, Lewis utiliza a hipótese da radiação. Esta ideia foi inicialmente proposta em 1906 por Max Trautz (1880-1960) de uma forma um tanto obscura, e mais tarde foi desenvolvida com muito mais clareza, com provas de apoio adicional, por Lewis e por Perrin (Laidler e King, 1983). Uma importante razão para a popularidade da hipótese de radiação, por algum tempo, foi que as reações gasosas unimoleculares pareciam ser incapazes de serem explicadas, nos termos de colisões moleculares. A hipótese da radiação parecia oferecer a única explicação e para alguns investigadores era assumido que se aplicava à reação de todos os tipos.

Por volta de 1921 a hipótese foi amplamente desacreditada, principalmente através dos esforços do físico-químico americano Irving Langmuir (1881-1957) e do físico britânico Frederick Alexander Lindemann (1886-1957).

Segundo Laidler e King (1983), mesmo depois que a hipótese da radiação foi abandonada, a teoria de Trautz e Lewis manteve-se útil uma vez que, apesar de terem indicado que a teoria da radiação é responsável pela ativação das moléculas, eles consideraram que a velocidade da reação é determinada pela frequência das colisões moleculares. 
Para Lewis (1918) a velocidade da reação dependia do número de colisões por segundo que aconteciam entre as moléculas ativas das substâncias participantes da reação:

Moléculas ativas, em processos unimoleculares, não têm nenhuma existência real. Porém, quando nós lidarmos com reações multimoleculares, é concebível admitir que moléculas ativas existam, a velocidade da reação observada, depende do número de colisões por segundo que acontece entre moléculas ativas das substâncias participantes. (Lewis, p. 471; 1918) (tradução nossa).

Portanto, para Lewis (1918), as moléculas ativas diferem das outras moléculas restantes, no que diz respeito à sua energia interna, a qual é consideravelmente muito maior de que a energia média das moléculas de uma substância possui a uma determinada temperatura.

A partir de seu estudo, Lewis chegou à seguinte consideração:

Para um gás contendo moléculas de $\mathrm{A}$ e $\mathrm{B}$ consideradas como esferas rígidas que se chocam entre si, frequentemente, e em um recipiente fechado à determinadas condições, o número de colisões entre A e B é dado pela seguinte equação:

$$
Z_{A B}=N_{A} N_{B} d_{A B}^{2}\left(8 \Pi k_{B} T\left(m_{A}+m_{B} / m_{A} \cdot m_{B}\right)^{1 / 2}\right.
$$

Onde $N_{A}$ e $N_{B}$ são os números de moléculas por unidade de volume; $d_{A B}$ é a soma de seus raios (a distância entre seus centros quando colidem, ou seja, seu diâmetro); $m_{A}$ e $m_{B}$ são as massas das moléculas; $k_{B}$ é a constante de Boltzmann e $T$ a temperatura absoluta. A constante de velocidade $(k)$ dessa reação pode ser escrita como:

$$
k=L d_{A B}{ }^{2}\left(8 \Pi k_{B} T\left(m_{A}+m_{B} / m_{A} \cdot m_{B}\right)^{1 / 2} e^{-E / R T}\right.
$$

onde L, é a constante de Avogadro

O fator pré-exponencial nesta expressão é chamado de fator de frequência de colisão dado pelo símbolo $Z$. Portanto, a constante de velocidade pode ser expressa como:

$$
k=Z e^{-\frac{E}{R T}}
$$

Lewis (1918) utilizava o termo colisão efetiva, que significava: 
Por colisão efetiva o termo significa, naturalmente, o número de colisões entre as moléculas ativas. Esta relação é vista como sendo de extremamente pequena quantificação. Esta quantidade pode ser chamada convenientemente de "eficiência química" da reação, uma vez que indica o número de colisões quimicamente efetivas no mesmo tempo. (p.475) (tradução nossa)

Fazendo uso do conceito de moléculas ativas Lewis pôde calcular a constante de velocidade para a reação de decomposição do lodeto de hidrogênio, onde houve uma satisfatória concordância entre os valores observados e calculados.

Contudo, segundo Laidler (1993), foi percebido depois que havia muitas reações, particularmente algumas envolvendo reagentes moleculares de grande complexidade, para as quais eram grandes as discrepâncias entre os valores calculados e observados.

Essas discrepâncias mostraram que a teoria das colisões de esferas sólidas não era adequada para explicar as reações químicas. Esta teoria podia ser satisfatória para o tratamento da viscosidade e difusão dos gases, mas para uma teoria de reatividade química era requerida, então uma definição de colisão muito mais precisa. Se duas moléculas estão reagindo, elas não têm que meramente colidir com energia mútua suficiente, elas devem vir juntas com uma mútua orientação que é necessária para quebrar e formar ligações. Pela simples teoria cinética, sempre que a colisão for suficientemente energética ocorre uma colisão efetiva mas, na realidade, as moléculas podem não se aproximar uma da outra do modo adequado para que a reação ocorra. Mesmo elas possuindo energia suficiente para reagir (Laidler, 1993).

Uma maneira de remediar esta situação foi a introdução entre 1918-1930 por Hinshelwood e outros, do fator estérico $P$ que supostamente representa a fração do número total de colisões efetivas do ponto de vista da orientação (Laidler, 1987). A constante de velocidade pode ser então escrita como:

$$
k=P Z e^{-\frac{E}{R T}}
$$

\section{Considerações}

Pode-se observar nesse período de tempo, (1889-1918), que Lewis propôs uma explicação para a ocorrência de uma reação química em termos moleculares, 
utilizando para isso a construção de um modelo teórico: a sua teoria da colisão. Uma explicação dessa natureza não foi realizada pelos cientistas do período anterior, mesmo que estes já pensassem em velocidade de uma reação química em termos de moléculas e átomos.

A ideia de barreira de energia, proposta por Arrhenius, possibilitou 0 entendimento mais amplo de uma reação química e principalmente facilitou, mais adiante, o entendimento da ação dos catalisadores nas reações.

Até meados de 1930 importantes trabalhos experimentais em cinética foram realizados com base na interpretação da teoria da colisão, resultando em conclusões de considerável significância, mas estas interpretações, segundo Laidler (1993), foram sendo modificadas através de teorias mais sofisticadas, como a Teoria do estado de Transição.

\section{Texto 4: O desenvolvimento da teoria do estado de transição (1918-1935)}

Em relação ao desenvolvimento da teoria do estado de transição podemos reconhecer três linhas de desenvolvimento:

(1) primeira linha: tratamento termodinâmico,

(2) segunda linha: tratamento da teoria cinética, baseado na ideia de que as moléculas se comportam como esferas sólidas e

(3) terceira linha: tratamento baseado na mecânica estatística.

Estes tratamentos foram combinados com sucesso no desenvolvimento da teoria do estado de transição.

Um desenvolvimento de grande importância para essa teoria foi feito por Henry Eyring (1901-1981) e por Michael Polanyi (1891-1976). Em 1931, Eyring e Polanyi calcularam a energia potencial da reação $\mathrm{H}+\mathrm{H}_{2}$, a partir da equação de London, e desenvolveram assim uma metodologia que ainda hoje é empregada na determinação da energia potencial para reações triatômicas: a construção da superfície de energia potencial (superfície que representa a energia potencial entre os três átomos em função das distâncias entre os núcleos). 
Com o uso dessas superfícies (fig.2.6), tornou-se possível, pela primeira vez, estimar a energia de ativação, embora aproximada, e também responder a muitas questões com respeito ao mecanismo de uma reação.

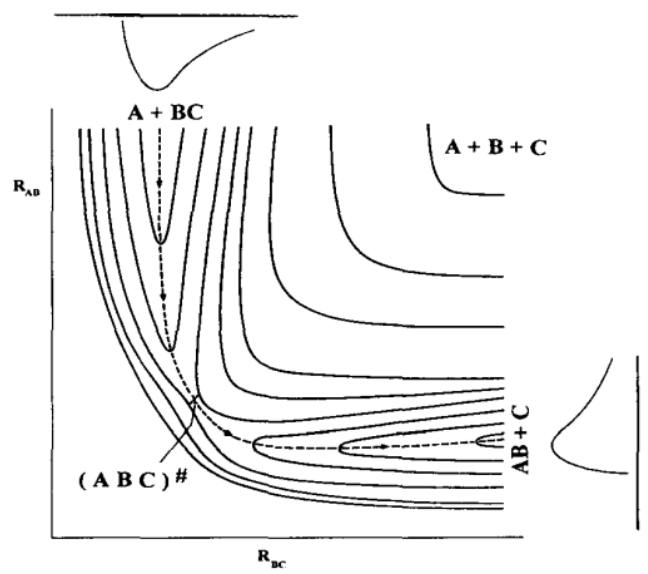

Figura 2. Superficie de potencial de uma reasâno colinear típica, $A+B C \rightarrow A B+C$. A linha tracejada representa o caminho de menor energia ligando reagentes a produtos.

Figura 2.6 Superfície de energia potencial de uma reação (Schor, p. 484,1994).

Mas para que serve a energia de ativação? A resposta a essa pergunta foi dada por Fritz London (1900-1954), que mostrou que a energia de ativação é usada na quebra de uma ligação química e compensada na formação da nova ligação.

Em 1932, uma importante contribuição foi feita por H. Pelzer e Eugene Paul Wingner (Laidler,1993). Nesse trabalho eles consideraram a passagem de um sistema sobre a superfície de energia potencial (fig. 2.6), e este foi importante, por ser o primeiro a ter atenção no foco no "ponto de sela" ${ }^{7}$ de uma superfície de energia potencial. Eles perceberam que o movimento do sistema pelo ponto de sela controla a velocidade de reação.

O artigo de Peltzer e Winger contribuiu significativamente para a formulação em 1935 do que veio a ser chamada de teoria do Estado de Transição. Esta teoria, que provê uma valiosa estrutura para o entendimento de todos os tipos de processos químicos e físicos foi desenvolvida independentemente por Henry Eyring e por Michael Polanyi e Meredith Gwynne Evans (1904-1952).

\footnotetext{
${ }^{7}$ Ponto de cela corresponde $\left((\mathrm{ABC})^{\#}\right.$ da figura 2.6) ao ponto de maior energia do caminho de reação pela superfície de energia potencial e define a barreira para a reação. A configuração do ponto de cela corresponde à configuração de equilíbrio do estado de transição (Schor, p. 484. 1994);
} 
Em seu artigo de 1935, Eyring descreve o desenvolvimento da Teoria do Estado de transição, identificando a energia de ativação $E_{0}$ da equação de Arrhenius ${ }^{8}$ com a energia correspondente à configuração de equilíbrio do estado de transição, que é um ponto sem retorno na superfície de potencial. Quando o sistema atinge essa configuração, ele necessariamente prosseguirá formando os produtos. A decomposição do estado de transição em produtos é muito rápida, e a constante de velocidade da reação, corresponde à constante de velocidade da etapa de formação do estado de transição.

A essência desta teoria é que espécies representadas por pontos próximos ao ponto de sela da superfície de energia potencial, isto é, os complexos ativados, são considerados como estando em um estado de quase-equilíbrio com os reagentes, de forma que suas concentrações podem ser calculadas.

O estado de transição, segundo Evans e Polanyi (1935), pode ser representado pela equação:

$$
\mathrm{A}+\mathrm{B}+\mathrm{C} \ldots \rightarrow(\mathrm{ABC} \ldots) \rightarrow \alpha+\beta+\gamma \ldots
$$

Estado inicial Estado de transição Estado final

onde o termo (ABC...) representa a formação do complexo ativado:

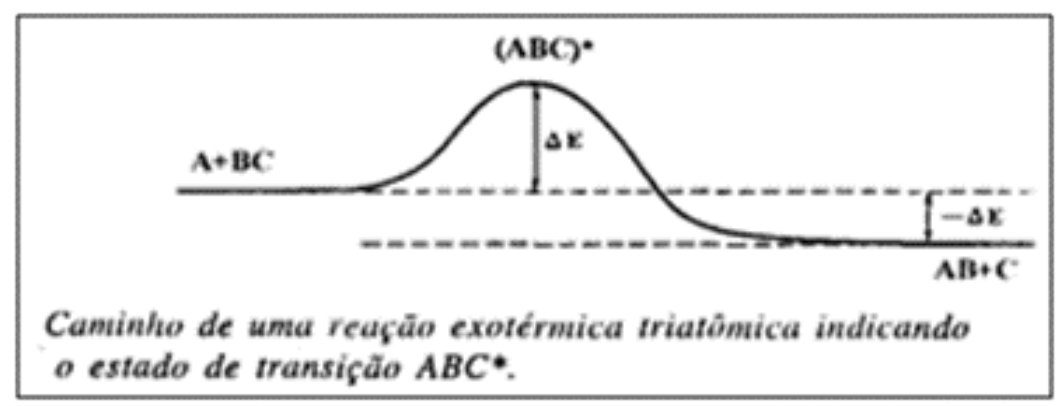

Figura 2.7 Representação de Evans e Polanyi (1935) para indicar o estado de transição. (Schor, p. 484, 1994).

A velocidade da reação é então a concentração desses complexos multiplicada pela frequência com que eles são convertidos em produtos:

\footnotetext{
${ }^{8}$ Equação de Arrhenius: $k=A \times e^{\frac{-E_{0}}{R T}}$
} 
Velocidade $=k$ (concentração do complexo ativado) $x$ (frequência de decomposição do complexo ativado)

De acordo com esta teoria a frequência é $k_{B} T / h$, onde $k_{B}$ é a constante de Boltzmann, $h$ a constante de Planck e T a temperatura absoluta.

\section{Considerações}

A teoria do Estado de Transição foi uma tentativa de identificar os aspectos principais que governam o valor de uma constante de velocidade (equação de Arrhenius) em termos de um modelo de eventos que ocorrem durante a reação.

Com a teoria do Estado de Transição passou-se a explicar a velocidade de uma reação química em termos de quebra e formação de ligações químicas e não mais apenas, como na teoria das colisões, em termos de choques entre esferas sólidas.

Outro ponto importante é a interpretação da Energia de ativação que antes estava relacionada à barreira de energia de uma reação química, e que nesse período de tempo está relacionada a energia envolvida na quebra e formação de ligações químicas.

A teoria do Estado de Transição trouxe, portanto, um grande entendimento da ocorrência de uma reação química. Segundo Laidler (1993, p.249):

Embora seja ainda difícil fazer cálculos confiáveis sobre velocidade com base na teoria do estado de transição, ou mesmo de qualquer teoria, a teoria do estado de transição tem-se revelado de grande valia no fornecimento de uma ferramenta de trabalho para aqueles que não estão muito preocupados em fazer cálculos precisos e sim em ganhar alguns insights sobre como os processos químicos e físicos ocorrem na química. (tradução nossa). 


\section{Capítulo 3. Caminhos metodológicos}

Esta pesquisa envolveu a intervenção da autora deste trabalho como professora e investigadora em um curso de formação continuada dirigido a professores de química do ensino médio.

Nesse curso procurou-se apresentar aos professores uma abordagem diferenciada do tema cinética química, tendo-se como orientação o desenvolvimento histórico desse tema (reconstrução histórica), permitindo assim uma melhor compreensão do contexto no qual esses conceitos foram desenvolvidos.

O curso teve início em agosto de 2010 e seu término em outubro de 2010. Nesse período foram realizados oito encontros, com 4 horas de duração cada.

A coleta de dados foi realizada mediante a gravação em áudio e vídeo das aulas, assim como através de instrumentos de coleta de dados (por exemplo, questionários, exercícios e demais atividades) direcionados aos professores.

Após o curso, iniciou-se a etapa de acompanhamento da aplicação, em sala de aula, dos planos de ensino elaborados pelos professores durante o curso de formação, nas suas turmas do ensino médio.

A seguir será feita uma descrição mais detalhada de cada etapa da pesquisa.

\subsection{Primeira Etapa: Curso de formação continuada para professores de química.}

O curso foi organizado levando-se em consideração alguns dos objetivos apontados por Schnetzler (2002), que são importantes na elaboração de um curso de formação continuada. São eles:

- Socialização de natureza voluntária.

No curso de formação continuada, tentou-se na sua elaboração e aplicação, levar em consideração essas importantes condições apontadas pela autora. $O$ convite foi aberto a todos os professores de química como também não houve seleção por parte da pesquisadora. 
- Apoio institucional.

A equipe do grupo Gepeq, do Instituto de Química da USP, proporcionou toda a infraestrutura, como a participação dos membros do grupo durante todo o período do curso de formação, como também o local e equipamentos.

- Problemas da prática docente devem ser apontados pelos professores.

A escolha do tema cinética química deve-se ao fato de que muitos professores de química, do ensino médio, possuem grande dificuldade em abordar esse tema em suas aulas.

- Importância da coletividade.

Acredita-se que o convívio, a troca de experiência entre pares, o contato com o ambiente da universidade, são importantes para atingir os objetivos propostos nesse trabalho.

Portanto, pretendeu-se nesse curso de formação continuada atingir as seguintes metas:

Para a pesquisa:

Acompanhar o processo de elaboração e modificação dos planos de ensino dirigidos ao ensino de cinética química, levando-se em consideração os aspectos relativos ao entendimento dos conceitos da cinética química, do papel da História da Química no ensino e a mudança dos professores em relação a sua imagem sobre a natureza da ciência.

Para a formação continuada dos professores:

Apresentar e discutir com os professores uma abordagem diferenciada do tema cinética química, tendo-se como orientação o desenvolvimento histórico desse tema, permitindo assim uma melhor compreensão do contexto no qual esses conceitos foram desenvolvidos.

Apresentar e discutir aspectos relativos ao de ensino cinética química (dificuldades dos alunos sobre o tema, estratégias de ensino, entre outros).

A carga horária foi de 40 horas, sendo 32 horas presenciais e 8 horas destinadas a estudos. O curso foi realizado no Instituto de Química da USP. Contou 
com a colaboração de colegas na realização das gravações e das atividades experimentais.

No quadro 3.1 podem ser observadas as informações relativas a cada encontro, como, por exemplo, o tema, os conteúdos abordados, as atividades realizadas pelos professores e os instrumentos de pesquisa aplicados durante 0 curso de formação continuada.

- Produção final - Plano de ensino:

Como atividade final do curso, foi solicitado aos professores que elaborassem um plano de ensino sobre o tema: cinética química. Esse plano foi elaborado e reelaborado durante a participação dos professores no curso de formação. No final do curso foi solicitado ao professores que aplicassem o plano em suas aulas, sendo que no momento da aplicação esses planos passaram por uma nova reelaboração.

- Público alvo:

Professores de Química do ensino médio das redes pública e particular e alunos de licenciatura em Química.

A formação da turma foi iniciada com um convite aos professores (Apêndice 1) para participar de um curso de formação continuada, oferecido pela pesquisadora, no segundo semestre de 2010. Trinta professores iniciaram o curso de formação, sendo que vinte seguiram até o final. Houve também, a participação de estudantes da licenciatura.

É importante observar que muitos desses professores já haviam participado de outras atividades de formação continuada no IQUSP, oferecidos pelo Gepeq ${ }^{9}$ em parceria com a Secretaria da Educação ${ }^{10}$.

${ }^{9}$ Grupo de pesquisa em educação química-GEPEQ-IQUSP.

${ }^{10}$ Parceria feita com a CENP (coordenadoria de estudos e normas pedagógicas) da Secretaria de Educação do Estado de São Paulo. 


\begin{tabular}{|c|c|c|c|}
\hline PERÍODO & TEMAS & CONTEÚDOS & ATIVIDADES E INSTRUMENTOS DE PESQUISA \\
\hline $\begin{array}{l}\text { Primeiro } \\
\text { encontro }\end{array}$ & $\begin{array}{l}\text { Apresentação do curso de } \\
\text { formação continuada. }\end{array}$ & & $\begin{array}{l}\text { Pedido de autorização para o uso de imagens, gravações dos professores que } \\
\text { foram feitas durante o curso (Apêndice I) } \\
\text { Instrumento } 1 \text { (Apêndice II) } \\
\text { Folha de atividade } 1 \text { (Apêndice III): Leitura para o terceiro encontro }\end{array}$ \\
\hline $\begin{array}{l}\text { Segundo } \\
\text { Encontro }\end{array}$ & $\begin{array}{l}\text { O papel da História da Química no } \\
\text { ensino de Química./O contexto do } \\
\text { início dos estudos na cinética } \\
\text { química. }\end{array}$ & $\begin{array}{l}\text { Influência da concentração dos } \\
\text { reagentes na velocidade da reação. } \\
\text { Documentos oficiais referentes ao } \\
\text { papel da HQ no ensino de química. }\end{array}$ & $\begin{array}{l}\text { Experimento } 1 \text { (Apêndice IV): Influência da concentração dos reagentes na } \\
\text { velocidade da reação } \\
\text { Experimento } 2 \text { (Apêndice V): Polarímetro } \\
\text { Folha de Atividade 2(Apêndice VI): Análise do papel da História da Ciência no } \\
\text { ensino de Química } \\
\text { Instrumento } 2 \text { (Apêndice VII) - Identificação das imagens sobre a ciência. }\end{array}$ \\
\hline $\begin{array}{l}\text { Terceiro } \\
\text { encontro }\end{array}$ & $\begin{array}{l}\text { Apresentação dos estudos iniciais } \\
\text { referentes à determinação da } \\
\text { velocidade de uma reação química. }\end{array}$ & $\begin{array}{l}\text { Influência da concentração na } \\
\text { velocidade de uma reação química. } \\
\text { Mapas conceituais. }\end{array}$ & $\begin{array}{l}\text { Discussão do texto de Chagas (2003). Folha de atividade1 (Apêndice III) } \\
\text { Folha de atividade } 3 \text { (Apêndice VIII): Leitura e análise de artigo Dourado e } \\
\text { Sequeira } \\
\text { Folha de atividade } 4 \text { (Apêndice IX):elaboração de mapas conceituais. }\end{array}$ \\
\hline $\begin{array}{l}\text { Quarto } \\
\text { encontro }\end{array}$ & $\begin{array}{l}\text { Apresentação dos estudos } \\
\text { referentes ao efeito da temperatura } \\
\text { na velocidade das reações } \\
\text { químicas. }\end{array}$ & $\begin{array}{l}\text { Ideia de Maxwell da distribuição de } \\
\text { velocidade; } \\
\text { Distribuição de energia (Boltzmann); } \\
\text { Ideias sobre equilíbrio químico. } \\
\text { Imagens sobre a natureza da ciência } \\
\text { (E/l e R). }\end{array}$ & $\begin{array}{l}\text { Folha de atividade 5: Discussão do texto } 100 \text { anos de Nobel - Jacobus Henricus } \\
\text { van't Hoff (Apêndice X). } \\
\text { Folha de atividade } 6 \text { (Apêndice XI): Le mémoire de BERTHELOT et PEAN DE } \\
\text { SAINT-GILLES. } \\
\text { Experimento } 3 \text { (Apêndice XII): Influência da temperatura e da superfície de } \\
\text { contato na velocidade de reação, contextualizando os estudos históricos. } \\
\text { Folha de atividade } 7 \text { (Apêndice XIII): Roteiro para a elaboração do plano de } \\
\text { ensino sobre cinética química. }\end{array}$ \\
\hline $\begin{array}{l}\text { Quinto } \\
\text { encontro }\end{array}$ & $\begin{array}{l}\text { - Imagens sobre a natureza da } \\
\text { ciência. } \\
\text { - Apresentação do desenvolvimento } \\
\text { da teoria das Colisões/ Arrhenius. }\end{array}$ & $\begin{array}{l}\text { Perspectivas empirista/indutivista e a } \\
\text { Racionalista contemporânea (Lakatos). } \\
\text { As primeiras teorias de colisões entre } \\
\text { moléculas. Equação de Arrhenius. }\end{array}$ & $\begin{array}{l}\text { Discussão: Filosofia da ciência: (instrumentos } 2 \text { e } 3 \text {. Apêndices VII e XIV, } \\
\text { respectivamente) .Exercício } 1 \text { (Apêndice XV): Análise e discussão de exercício } \\
\text { com o uso de gráfico para interpretar a velocidade de uma reação química. }\end{array}$ \\
\hline $\begin{array}{l}\text { Sexto } \\
\text { encontro: }\end{array}$ & $\begin{array}{l}\text { Apresentação: Período de 1918- } \\
\text { 1935: A teoria do Estado de } \\
\text { Transição. }\end{array}$ & $\begin{array}{l}\text { Teoria do Estado de Transição } \\
\text { Estratégia de ensino: uso de } \\
\text { simulações. }\end{array}$ & $\begin{array}{l}\text { Laboratório de informática: Simulações no ensino de cinética química. Fontes para } \\
\text { pesquisa em história da química (Apêndice XVI). }\end{array}$ \\
\hline $\begin{array}{l}\text { Sétimo } \\
\text { encontro: }\end{array}$ & $\begin{array}{l}\text { Programas de Investigação } \\
\text { Científica (Lakatos)/Planos de } \\
\text { ensino. }\end{array}$ & $\begin{array}{l}\text { Filosofia da ciência: as ideias de } \\
\text { Lakatos }(1998,1999)\end{array}$ & $\begin{array}{l}\text { Folha de atividade } 8 \text { (Apêndice XVII): Análise do plano de ensino. } \\
\text { Apresentação: Programas de Pesquisa de Imre Lakatos } \\
\text { Folha de atividade } 9 \text { (Apêndice XVIII): Identificação dos Programas de Pesquisa } \\
\text { no desenvolvimento da cinética química. }\end{array}$ \\
\hline $\begin{array}{l}\text { Oitavo } \\
\text { encontro: }\end{array}$ & $\begin{array}{l}\text { Discussão dos planos de ensino } \\
\text { reelaborados. }\end{array}$ & $\begin{array}{l}\text { Cinética química - Linha do tempo } \\
\text { (1850 a 1935) }\end{array}$ & $\begin{array}{l}\text { Folha de atividade } 9 \text { (Apêndice XVIII): Discussão da atividade de identificação } \\
\text { dos Programas de Investigação Científica. Avaliação final do curso (Apêndice } \\
\text { XIX). } \\
\text { Definição dos encontros para a aplicação do plano pelo professor. }\end{array}$ \\
\hline
\end{tabular}

Quadro 3.1 Temas, conteúdos e atividades de cada um dos encontros do curso de formação continuada. 
- Caracterização da turma:

Os professores são identificados nesta pesquisa por $\mathrm{P}$ (professor) seguidos por um número a eles atribuídos (P1, P2, P3). O perfil profissional e a experiência profissional de cada professor são apresentados no quadro a seguir.

\begin{tabular}{|c|c|c|c|c|}
\hline Professor & Formação & $\begin{array}{l}\text { Tempo } \\
\text { que } \\
\text { leciona }\end{array}$ & $\begin{array}{l}\text { Rede de } \\
\text { Ensino }\end{array}$ & Observações \\
\hline P1 & $\begin{array}{l}\text { Bacharel e licenciado em } \\
\text { química }\end{array}$ & 3 anos & - & $\begin{array}{l}\text { Atualmente não } \\
\text { leciona }\end{array}$ \\
\hline P2 & $\begin{array}{l}\text { Bacharel e licenciado em } \\
\text { química }\end{array}$ & 8 anos & Particular & \\
\hline P3 & $\begin{array}{l}\text { Bacharel e licenciado em } \\
\text { química }\end{array}$ & 4 anos & $\begin{array}{l}\text { Pública e } \\
\text { particular }\end{array}$ & \\
\hline P4 & $\begin{array}{l}\text { Engenheiro e licenciado em } \\
\text { química }\end{array}$ & 5 anos & $\begin{array}{l}\text { ETEC e } \\
\text { particular }\end{array}$ & \\
\hline P5 & $\begin{array}{l}\text { Estudante de licenciatura em } \\
\text { química }^{2}\end{array}$ & - & - & \\
\hline P6 & Licenciado em química & 13 anos & Estadual & $\begin{array}{l}\text { Atualmente } \\
\text { afastado para } \mathrm{DE}^{1}\end{array}$ \\
\hline P7 & $\begin{array}{l}\text { Bacharel e licenciado em } \\
\text { química com atribuições } \\
\text { tecnológicas }\end{array}$ & 8 anos & Estadual & \\
\hline P8 & $\begin{array}{l}\text { Bacharel e licenciado em } \\
\text { química }\end{array}$ & 14 anos & $\begin{array}{l}\text { ETEC e } \\
\text { Estadual }\end{array}$ & \\
\hline P9 & Licenciado em química & 14 anos & $\begin{array}{l}\text { Estadual e } \\
\text { SESI }{ }^{11}\end{array}$ & \\
\hline P10 & $\begin{array}{l}\text { Tecnologia em saúde- } \\
\text { Licenciado em ciências } \\
\text { ênfase em química }\end{array}$ & 17 anos & Estadual & $\begin{array}{l}\text { Atualmente } \\
\text { afastado para DE }\end{array}$ \\
\hline P11 & $\begin{array}{l}\text { Bacharel e licenciado em } \\
\text { química }\end{array}$ & 19 aos & $\begin{array}{l}\text { Estadual e } \\
\text { particular }\end{array}$ & \\
\hline P12 & $\begin{array}{l}\text { Ciências com licenciatura } \\
\text { plena em Química }\end{array}$ & 16 anos & $\begin{array}{l}\text { Estadual e } \\
\text { Municipal } \\
\end{array}$ & \\
\hline $\mathrm{P} 13$ & $\begin{array}{l}\text { Bacharel e licenciado em } \\
\text { química }\end{array}$ & 25 anos & Estadual & \\
\hline
\end{tabular}

\footnotetext{
${ }^{11}$ SESI: serviço social da indústria.
} 


\begin{tabular}{|c|l|c|c|c|}
\hline P14 & Licenciado em química & 10 anos & Estadual & \\
\hline P15 & $\begin{array}{l}\text { Bacharel e licenciado em } \\
\text { química }\end{array}$ & 29 anos & Estadual & \\
\hline P16 & $\begin{array}{l}\text { Bacharel e licenciado em } \\
\text { química }\end{array}$ & $\begin{array}{c}\text { Não } \\
\text { leciona }\end{array}$ & - & Trabalha na DE ${ }^{12}$ \\
\hline P17 & $\begin{array}{l}\text { Bacharel e licenciado em } \\
\text { química }\end{array}$ & 1 ano & Estadual $^{\text {Auciona }}$ & $\begin{array}{l}\text { Atualmente não } \\
\text { leciona }\end{array}$ \\
\hline P18 & $\begin{array}{l}\text { Bacharel e licenciado em } \\
\text { química }\end{array}$ & 10 anos & $\begin{array}{c}\text { ETEC } \\
\text { Estadual }\end{array}$ & \\
\hline P19 & $\begin{array}{l}\text { Bacharel e licenciado em } \\
\text { química e física }\end{array}$ & 16 anos & Estadual & \\
\hline P20 & $\begin{array}{l}\text { Estudante de licenciatura em } \\
\text { química }\end{array}$ & - & - & \\
\hline
\end{tabular}

Quadro 3.2 Perfil e experiência profissional de cada professor. Nota: 1- Professores Coordenadores das Oficinas Pedagógicas das diretorias de Ensino da Rede Pública de São Paulo. 2- Estudantes do primeiro ano da licenciatura em química.

O perfil dos professores participantes mostra que estes apresentam uma formação acadêmica qualificada (quadro 3.2). Desses, 12 são bacharéis e licenciados em química, 3 são licenciados em química, 1 engenheiro químico com licenciatura em química, 2 em ciência com ênfase em química e 2 são alunos do curso de licenciatura em química. Nesse grupo de professores 16 são do sexo feminino e 4 do masculino.

Quanto à situação funcional destes professores, 16 são efetivos da rede pública de ensino do Estado de São Paulo, sendo que 12 deles atuam apenas em escola estadual. Os demais atuam, além da escola estadual, em outras redes de ensino. Quanto à experiência profissional, constatamos que 9 deles estão no magistério há mais de 11 anos. A idade do grupo varia de 19 a 60 anos.

- Conteúdos abordados no curso:

Conteúdos relativos à química:

\footnotetext{
${ }^{12} \mathrm{DE}$ : diretoria de ensino.

${ }^{13}$ ETEC: escola técnica estadual.
} 
- Estrutura da matéria: modelo atômico de Dalton.

- Velocidade de uma reação química, Lei da velocidade.

- Fatores que influenciam a velocidade de uma reação química: concentração, temperatura e superfície de contato.

- Modelos explicativos para a velocidade: teorias da colisão e do estado de transição.

Aspectos relativos à História e filosofia da Ciência:

- História e filosofia da ciência e o ensino de química.

- Fontes e materiais sobre a História da Química.

- Estratégias de ensino com o enfoque na história da ciência.

Aspectos relativos ao processo de ensino:

- Dificuldades encontradas no ensino de cinética química.

- Organização dos conteúdos relativos ao tema.

- Fundamentos epistemológicos do Ensino de Química: diferentes naturezas do saber científico e implicações no ensino de Química.

- Estratégias de ensino e aprendizagem geralmente utilizadas no ensino de cinética química: experimentação, simulações entre outras.

- Leituras sugeridas para os professores durante o curso:

1. CHAGAS, Aécio Pereira. Os noventa anos de Les Atomes. Química Nova na Escola. № 17, maio 2003.

2. CHAGAS, Aécio Pereira. 100 anos de Nobel - Jacobus Henricus van't Hoff. Química Nova na Escola. № 14, novembro. 2001.

3. DOURADO, Luís; SEQUEIRA, Manuel. Uma análise da relação entre os conceitos de método científico e de investigação. Instituto de Educação e Psicologia, Universidade do Minho, Braga, Portugal, 2002. Disponível em: http://webpages.ull.es/users/apice/pdf/351-076.pdf 
4. MOREIRA, M. A.; Mapas conceituais e aprendizagem significativa. Texto base de um minicurso realizado no XV SNEF, março 2003, Curitiba. Disponível em: http://omnis.if.ufrj.br/ marta/aprendizagememfisica/mapasconceituais.pdf

5. PORTO, Paulo Alves. História e Filosofia da Ciência no Ensino de Química: Em busca dos objetivos educacionais da atualidade. Ensino de química em foco. Editora Unijuí, p.160-180, 2010.

6. ROCHA-FILHO, Romeu C.; Femtoquímica: reações químicas em tempo real. Química Nova na Escola.10, Nov., 1999.

7. SABADINI, Edvaldo; BIANCHI, José Carlos de Azambuja. Ensino do conceito de equilíbrio químico: Uma breve reflexão. Química Nova na Escola, 25, Maio, 2007.

8. SÃO PAULO (Estado). Secretaria da Educação. Coordenadoria de Estudos e Normas Pedagógicas. Proposta curricular para o ensino de Química.. São Paulo: SEE/CENP, p. 36, 1986.

9. SEQUEIRA, M.; LEITE,L. A História da Ciência no Ensino-Aprendizagem de ciências. Revista Portuguesa de Educação, 1, (2), 29-49,1988.

10. SILVEIRA, Fernando Lang. A metodologia dos programas de pesquisa: a epistemologia de Imre Lakatos. UFRGS. Disponível em : http ://www.if.ufrgs.br/ lang/Textos/LAKATOS.pdf

\subsubsection{Descrição dos encontros}

A seguir apresenta-se uma descrição de cada encontro do curso procurando-se mostrar a sequência e objetivos de cada atividade proposta.

\section{Primeiro encontro}

Nesse primeiro encontro foi apresentada a estrutura do curso, como também aplicados instrumentos com o objetivo de verificar como os professores abordam esse tema em suas aulas, também foi pedida a autorização para o uso 
das imagens e gravações que serão realizadas durante todo o curso de formação continuada (Apêndice I).

Descrição das atividades:

1. Aplicação dos instrumentos de coleta de dados (instrumento I, adaptado de Justi,1997).

A intenção do instrumento 1 (Apêndice II) foi 0 de identificar quais conteúdos o professor geralmente aborda em suas aulas e suas dificuldades, como também, as estratégias que utiliza no ensino de cinética química.

2. Atividade para o próximo encontro:

- Leitura para o terceiro encontro: Os noventa anos de Les Atomes( (texto 1 da lista de leitura sugerida, pág. 87). Folha de atividade 1 (Apêndice III).

\section{Segundo encontro: Os estudos iniciais da cinética química}

Nesse encontro, inicialmente, foi discutido o contexto dos primeiros estudos empíricos realizados na cinética quimica, apresentando-se aos professores alguns dos experimentos que foram realizados nessa época (final do século XVIII até a metade do século XIX).

A segunda parte do encontro teve como foco conhecer as ideias dos professores sobre o papel da História da Ciência $(\mathrm{HC})$ no ensino de química. Também, foi discutido o papel da HC no ensino de quimica, segundo alguns documentos oficiais. Ainda, foi aplicado um instrumento (A para a Identificação das imagens sobre a ciência dos professores.

Descrição das atividades:

1. Experimentos:

Uma das estratégias utilizadas para fazer uma abordagem histórica de um determinado conteúdo é a exploração de experimentos pensados pelos cientistas (Domingues e Duarte, 2008). Assim, os trabalhos escolhidos procuraram refletir os estudos experimentais que foram realizados para se entender o efeito da 
concentração na velocidade de uma reação química, no final do século XVIII até a metade do século XIX.

- Experimento1 (Apêndice IV): Estudo da influência da concentração em uma reação química. Discussão do conhecimento que se tinha anteriormente ao ano de 1850 sobre a velocidade de uma reação química.

- Experimento 2 (Apêndice $V$ ): efeito de uma substância quiral na rotação da luz polarizada. No caso desse estudo, escolheu-se um experimento em que se utiliza um polarímetro, porque, esse foi um importante instrumento usado pelos cientistas nos estudos iniciais da cinética química. Também foi possível apresentar aos professores uma fonte secundária da História da Química, dirigida ao ensino de química, nesse caso, a revista Química Nova na Escola.

3. Análise do papel da História da Ciência no ensino de Química (Folha de Atividade 2- Apêndice VI). Nessa atividade procurou-se:

- Discutir as justificativas para a utilização da História da Ciência no ensino de Química apresentadas em documentos oficias (texto 8 da lista de leitura sugerida, pag. 87). Esse documento foi escolhido porque reflete uma posição atual de como abordar a História da Química no ensino. As principais ideias defendidas nele são:

$\checkmark$ A História da Ciência é introduzida no sentido de rebater a tendência de se vincular a química como uma ciência determinada, pronta, lógica e sem falhas.

$\checkmark$ A História da ciência mostra que numa mesma época, podem coexistir explicações diferentes para os mesmos fatos, gerando conflitos que poderão ser superados pelo surgimento de explicações que sintetizam os pensamentos anteriores, os esquecem, ou os desprezam.

$\checkmark$ A História da Ciência deve aparecer em varias etapas do programa, não com tópicos estanques, porém misturada, confundida de modo a fluir com o próprio conhecimento químico; num momento, mostrando as várias explicações para o mesmo fato, numa mesma época, para que o aluno possa compreender a elaboração do conhecimento químico e para facilitar 
a compreensão de determinados conceitos químicos; noutro, apresentando conceitos e teoria em diferentes épocas, de modo que o aluno perceba as explicações sendo abandonadas, alteradas, ou mesmo retomadas evidenciando-se assim, o dinamismo do processo de elaboração da ciência.

- Levantar entre os professores, quais seriam as maiores dificuldades encontradas por eles, para inserir a História da Química em suas aulas.

- Analisar trechos de textos, retirados de livros didáticos de química (ensino médio), procurando identificar o papel da história na abordagem do autor, como também verificar se essas ideias estão de acordo com as defendidas pelo documento da CENP ${ }^{14}$ (São Paulo, 1986).

2. Aplicação do Instrumento 2 (Apêndice VII): Imagem sobre a ciência: adaptado de Porlán et al (2005). A intenção aqui era a de conhecer quais seriam as imagens que esses professores tinham sobre a ciência.

O instrumento foi elaborado a partir do inventário de crenças pedagógicas - INPECIP proposto por Porlán et al (2005). O questionário INPECIP foi construído pelos autores para conhecer as concepções didáticas e epistemológicas de professores das ciências experimentais da Espanha. Consta de 56 itens, distribuídos em quatro categorias: modelo didático pessoal, imagem da ciência, teoria da aprendizagem e metodologia de ensino de ciências. Utilizouse como referência para a construção do instrumento 3 somente os itens da categoria da imagem da ciência desse questionário (Porlán et al, 2005).

3. Atividades para o próximo encontro:

- Leitura do texto de Dourado e Sequeira (2002) (texto 3, leitura sugerida, vide página 87 ). Folha de atividade 3 (Apêndice VIII): O objetivo dessa atividade era

${ }^{14}$ CENP: Coordenadoria de Estudos e Normas Pedagógicas do Estado de São Paulo. 
propiciar aos professores uma discussão sobre as ideias relacionadas ao método científico e a investigação científica visando conhecer as visões dos professores a esse respeito. Os professores foram convidados a selecionar as ideias que consideravam importantes para apresentar para a classe, assim como as dúvidas surgidas na leitura, e elaborar três questões para serem discutidas no grupo.

\section{Terceiro encontro: 0 reconhecimento da cinética química como campo da química (1850 a 1867)}

Na primeira parte do encontro foi introduzido o primeiro período da história da cinética química (texto 1 da reconstrução histórica). Iniciou-se essa discussão a partir do texto lido anteriormente pelos professores (Folha de atividade 2Apêndice II) para que fosse possível tentar criar o contexto no qual ocorreram os primeiros estudos da cinética química. Na segunda parte do encontro foi discutido o artigo de Dourado e Sequeira (2002), Uma análise da relação entre os conceitos de método científico e de investigação (folha de atividade 3, Apêndice VIII), e realizada uma atividade de construção de mapas conceituais para poder verificar o entendimento dos professores sobre o texto.

Descrição das Atividades:

1. Discussão do texto de Chagas (2003). Folha de atividade1 (Apêndice III): Nesse texto o autor discute o lançamento do livro Les Atomes, de Jean Perrin. Este livro é um marco na história das Ciências, pois reuniu evidências experimentais sobre a existência dos átomos e moléculas.

Antes de se iniciar a discussão do texto, foram propostas para o grupo de professores, as seguintes questões: Quais modelos, sobre a estrutura da matéria, já eram conhecidos nesse período de tempo? Por que o modelo atômico de Dalton não foi utilizado pelos cientistas, nos primeiros estudos cinéticos?

Com essa atividade procurou-se:

- Apresentar aos professores uma fonte para a pesquisa de artigos sobre a História da Química, que eles podem usar em suas aulas ; 
- Construir o contexto histórico: Na época dos estudos iniciais da cinética química, muitos cientistas não aceitavam a existência das partículas atômica, quais poderiam ser então os motivos para essa rejeição.

2. Apresentação do primeiro periodo do desenvolvimento Histórico da Cinética Química: Os estudos iniciais - uma breve tentativa de sinalizar o contexto (1850-1862) :

Apresentação do contexto histórico do período de 1850 a 1867, com a identificação das principais ideias que eram conhecidas nessa época e que poderiam ter alguma influência nos estudos cinéticos que estavam em desenvolvimento.

A construção desse contexto envolveu as seguintes estratégias:

- Construção de uma linha do tempo, indicando os estudos e os cientistas envolvidos.

- Apresentação dessas ideias pela pesquisadora, elaborada a partir do texto 1 da reconstrução história

- Construção de um gráfico da variação da concentração pelo tempo, com os dados experimentais de Harcourt e Esson ${ }^{15}$ : para se determinar o valor da constante de velocidade para essa reação química (usando-se a planilha do programa Excel). A intenção desse exercício é que os professores entendam como foi determinado experimentalmente, pelos cientistas, o valor da constante de velocidade de uma reação química e qual é o seu significado.

3. Discussão de texto de Dourado e Sequeira (texto 3 da lista de leitura sugerida, p.87) sobre o método científico e a investigação científica (atividade 3 , Apêndice VIII). A intenção desta atividade era a de promover uma discussão

15 Dados experimentais extraídos do texto de Harcour disponível em: http://web.lemoyne.edu/ giunta/classicalcs/harcourt.html (acesso 02/05/2012) 
sobre 0 texto a partir das questões elaboradas anteriormente pelos professores.

Como os cientistas constroem suas teorias e leis? De acordo com a nova filosofia da ciência, não existe um método científico único que possa indicar quais são os passos que os cientistas devem dar em direção à construção de teorias e leis científicas. Vários filósofos abordam o desenvolvimento da ciência de diferentes perspectivas, propondo diferentes caminhos para a construção do conhecimento cientifico (Mellado e Carracedo, 1993). Isso é discutido no texto, através da comparação, pelos autores, entre o método científico e a investigação científica na ciência.

4. Elaboração de um mapa conceitual sobre o conteúdo discutido no encontro. (Folha de atividade 4, Apêndice IX):

Com essa atividade tentou-se identificar as ideias sobre ciência que o professor considera importante que seu aluno construa durante as suas aulas de química e quais são as implicações dessas ideias no ensino. (Texto de apoio: texto 4, leitura sugerida, p. 87) .

5. Atividades para o próximo encontro:

Leitura e Análise do texto de Aécio Pereira Chagas. 100 anos de Nobel Jacobus Henricus van't Hoff. Folha de atividade 5 (Apêndice X) (texto 2, leitura sugerida, p. 87) .

\section{Quarto encontro: 0 uso do conceito de energia para explicar a velocidade de uma reação (1872 a 1888)}

Foram propostas atividades com o objetivo de investigar a compreensão dos professores sobre o tratamento de dados relativos a variação da temperatura e da concentração no entendimento da velocidade de uma reação química, como 
também sobre o conceito de equilíbrio químico. Foi apresentado o segundo período do desenvolvimento da cinética química (texto 2 da reconstrução histórica), tendo como objetivo apresentar os primeiros estudos sobre a influência da temperatura em uma reação química.

$\mathrm{Na}$ segunda parte do encontro foram discutidas ideias sobre a experimentação, enfatizando como os diferentes enfoques dados às atividades no ensino, podem influenciar a construção da imagem de ciência dos alunos.

\section{Descrição das atividades:}

1. Discussão da análise feita pelos professores do texto de Aécio Pereira Chagas (texto 2 da lista de leitura sugerida, p.87). Folha de atividade 5 (Apêndice X). Esse texto foi escolhido porque descreve a vida e o trabalho de um importante cientista que pesquisou sobre a cinética química, outro motivo foi o de apresentar ao professor um texto, com o enfoque na historia da ciência, que pode ser utilizado, de diferentes maneiras, em sala de aula.

2. Realização de um exercício elaborado a partir de um texto original: Le mémoire de BERTHELOT et PEAN DE SAINT-GILLES sur les réactions d'estérification et d'hydrolyse (1861). Folha de atividade 6 (Apêndice XI). Exercício extraído dos experimentos realizados por Berthelot e Péan de Saint-Gilles (1861), sobre as reações de esterificação e hidrólise. Nele os professores tinham que, a partir dos dados fornecidos, traçar a curva que representava a percentagem de ácido esterificado com o tempo e explicar como a velocidade dessa reação iria variar através do tempo.

Com esse exercício pretendeu-se que os professores:

- Entendessem a relação da temperatura com a rapidez de uma transformação química a partir dos dados experimentais que os cientistas obtiveram em sua pesquisa. 
- Fossem capazes de traduzir os resultados de uma curva a partir de uma série de medidas.

- Conhecessem um exemplo de exercício que utiliza um fragmento do artigo original de um cientista, em sua elaboração.

3. Apresentação do segundo período do desenvolvimento Histórico da Cinética Química : os estudos sobre a influência da temperatura e da concentração na velocidade de uma Transformação Química no período de 1862 a 1888.

A construção desse contexto envolveu as seguintes estratégias:

- Construção da linha do tempo, indicando os estudos e os cientistas envolvidos.

- Discussão de fragmentos de trabalhos originais dos cientistas. O objetivo de usar partes dos artigos originais dos cientistas, era o de discutir os experimentos realizados, por exemplo, por van't Hoff, Berthelot e Péan de Saint-Gilles, como também de outros cientistas desse período histórico da cinética química, que estavam relacionados aos estudos sobre o efeito da temperatura na velocidade das reações químicas.

Segundo Duarte e Domingues (2008), o documento histórico, ou um fragmento deste, além de trazer à tona um assunto especifico, que se deseja discutir com os alunos, fornece também uma série de dados que contribuem para a compreensão de uma ampla conjuntura, na qual o estágio das ciências e sobretudo a sua prática, podem ser relacionados a certas tendências culturais, ou pressões das mais variadas naturezas

- Apresentação pela pesquisadora do desenvolvimento histórico da cinética química referente ao texto: A influência da temperatura na rapidez de uma transformação química (texto 3 da reconstrução histórica).

4. Realização da atividade experimental 3 (Apêndice XII): efeito da temperatura e da superfície de contato na velocidade de uma transformação química. Com esse experimento espera-se apresentar aos professores uma abordagem experimental 
para o estudo do efeito da temperatura e superfície de contato na velocidade de uma reação química e proporcionar a oportunidade de elaboração de uma situação problema para esse experimento.

O objetivo foi o de discutir com os professores um experimento que aborda a influência dos fatores, no caso a temperatura, na velocidade de uma reação química, como também a ideia de energia, conceitos que foram desenvolvidos no período histórico apresentado anteriormente.

5. Atividade para o próximo encontro:

- Roteiro para a elaboração do plano de ensino sobre cinética química Folha de atividade 7 (Apêndice XIII).

Os planos de ensino, inicialmente elaborados pelos professores, a partir de discussões feitas nos encontros, foram modificados durante o curso. Após a leitura e análise de cada versão do plano, foi dado um retorno ao professor com observações e questionamentos, para que pudessem reelaborar, ou não, seu planos de ensino.

$\mathrm{Na}$ elaboração do plano de ensino, foi sugerido aos professores que levassem em consideração alguns aspectos relativos a conteúdos específicos, estratégias e atividades de avaliação. São eles:

- Conteúdos relativos ao tema cinética química

- Conteúdo da História da cinética química.

- Conteúdos relativos à construção de uma visão de ciência.

- Estratégias de ensino (experimentação investigativa, textos, filmes, simulações, outros)

- Atividade de avaliação (questionário, mapa conceitual, pesquisa, elaboração ou interpretação de um texto, entre outros). . 


\section{Quinto encontro: As primeiras teorias de colisões entre molécula (1889- 1918)}

$\mathrm{Na}$ primeira parte desse encontro foi retomada a discussão sobre as imagens da natureza da ciência.

Na segunda parte do encontro foram discutidos os resultados obtidos pelos professores no experimento sobre a influência da temperatura e da superfície de contato na velocidade de uma reação química. Também, foi apresentado o desenvolvimento do primeiro modelo teórico utilizado para explicar, em termos microscópicos, a velocidade de uma reação química, a Teoria das Colisões.

Descrição das atividades:

1. Discussão- imagens sobre a ciência.

Aplicação de um instrumento com o objetivo de conhecer os entendimentos dos professores sobre as perspectivas Empirista/ Indutivista (E/I) e Racionalista $(R)$ da ciência. As respostas foram discutidas com toda a turma.

Após essa avaliação e discussão, os professores foram convidados a rever as ideias que manifestaram anteriormente (terceiro encontro, instrumento 2, Apêndice VII) e a elaborar um pequeno texto que resumisse suas ideias sobre 0 que é ciência, como ela se desenvolve e como o conhecimento científico é construído.

2. Apresentação do terceiro período do desenvolvimento histórico da cinética química: O desenvolvimento da teoria das colisões e o conceito de energia de ativação (1889-1918).

A construção desse contexto envolveu as seguintes estratégias:

- Construção da linha do tempo, indicando os estudos e os cientistas envolvidos. 
- Apresentação, pela pesquisadora, dos estudos de Arrhenius sobre o efeito da temperatura na velocidade das reações e do desenvolvimeto da Teoria das Colisões.

3. Discussão da atividade de elaboração do plano de ensino. Folha de atividade 8 (Apêndice XII): Nessa atividade os professores tiveram de apresentar os conteúdos especificos, as competências e habilidades que eles esperam que os alunos construam e desenvolvam no ensino da cinética química, tomando como base seus plano de ensino.

4. Interpretação de gráficos. Exercício 1 (Apêndice XV) : A intenção dessa atividade é avaliar a compreensão dos professores sobre o uso de gráficos no entendimento da velocidade de uma transformação química.

Durante o curso de formação continuada, foram realizadas atividades onde os professores teriam que interpretar gráficos e tabelas para entenderem como a velocidade de determinadas reações químicas iriam variar através do tempo.

Essas atividades foram escolhidas, pois percebeu-se, durante o curso, que alguns desses professores apresentavam uma grande dificuldade em interpretar tabelas e gráficos, e como esses estão presentes na história da cinética química, optou-se por abordar mais detalhadamente esse conteúdo.

Isso foi feito porque no ensino de cinética química, no ensino médio, o desenvolvimento de habilidades relacionadas à leitura de tabelas e elaboração de gráficos é essencial para que o aluno possa interpretar os diferentes dados cinéticos que são obtidos experimentalmente, para poder entender, por exemplo, o efeito da concentração na velocidade de uma reação química.

Segundo Cakmakci et al (2005), a velocidade de uma reação química e os fatores que a afetam podem ser explicados por uma abordagem qualitativa (modelos de partícula), como também através de uma abordagem quantitativa (modelos matemáticos). Contudo, muitos professores evitam trabalhar com gráficos e tabelas em suas aulas. 
Consciente dessa dificuldade procurou-se nesse trabalho, investigar a compreensão dos professores sobre o uso de gráficos no entendimento da velocidade de uma reação química.

Para a análise das respostas desse exercício assim como o gráfico elaborado pelos professores na atividade 6 (Apêndice $\mathrm{XI}$ ), foram usadas as categorias elaboradas por Cakmakci et al (2005), onde eles identificaram seis modelos, que são:

- Modelo científico (MC): Nesse modelo a reação se inicia com velocidade alta e diminui através do tempo.

- Modelo de aumento (MA): De acordo com esse modelo a reação se inicia lentamente e ocorre com mais rapidez posteriormente.

- Modelo de aumento-constante (MAC): Nesse modelo a reação se inicia com velocidade igual a zero e vai aumentando até atingir um valor onde este permanece constante até o final da reação.

- Modelo constante (MCE): Nesse modelo a reação se inicia com um determinado valor que é mantido constante até o final da reação.

- Modelo de aumento-constante-decréscimo (MACD): Nesse modelo a reação se inicia com velocidade igual a zero e vai aumentando até atingir um valor máximo; a partir desse valor sofre um decréscimo gradual até atingir zero quando o reagente limitante é consumido.

- Modelo de decréscimo (MD): Nesse modelo a reação se inicia com um valor mas este vai diminuindo muito lentamente, levando mais tempo para ocorrer.

5. Atividade para o encontro seguinte: foi solicitado aos professores que trouxessem para esse encontro, uma primeira versão de seus planos de ensino.

\section{Sexto encontro: A teoria do Estado de Transição (1918 - 1935)}

O objetivo desse encontro foi apresentar e discutir o quarto período do desenvolvimento da cinética química, para que os professores percebessem a 
mudança de modelo teórico usado para explicar, em termos microscópicos, a velocidade de uma reação química. Outro objetivo era o de conhecer outra estratégia usada no ensino de cinética química, as simulações computadorizadas.

Descrição das atividades:

1. Apresentação do quarto período do desenvolvimento histórico da cinética química: O desenvolvimento da teoria do estado de transição (1918-1935).

A construção desse contexto envolveu as seguintes estratégias:

- Construção da linha do tempo, indicando os estudos e os cientistas envolvidos. - Apresentação, pela pesquisadora, de como a teoria do Estado de Transição foi desenvolvida, qual problema estava sendo investigado e quais cientistas estavam envolvidos nesse processo.

- Após a apresentação, foram feitos comentários a respeito do texto indicado para leitura: Romeu C. Rocha-Filho. Femtoquímica: reações químicas em tempo real. (texto 6 da lista de leitura sugerida, pag. 87). O objetivo aqui era 0 de apresentar aos professores alguns dos estudos atuais da cinética química. Esse artigo se refere ao trabalho do químico egípcio-estadunidense Ahmed H. Zewail que recebeu o premio Nobel de 1999, por seus estudos de estados de transição de reações químicas por meio da espectroscopia em femtosegundos.

2. Uso de simulações no ensino de cinética química.

Essa atividade ocorreu na sala de multimídia onde os professores, em duplas, realizaram a análise de algumas simulações, selecionadas anteriormente pela pesquisadora. Essa análise consistia em discutir o uso desse recurso no ensino de cinética química e também identificar as vantagens e desvantagens de se utilizar esse recurso. Segundo Melo e Melo (p.61, 2005):

Os softwares de simulação têm surgido como uma nova opção no ensino da química, visando substituir as representações pictóricas, esquemáticas e os modelos estáticos anteriormente utilizados por ferramentas que proporcionam visualização de representações de modelos dinâmicos, proporcionando condições aos alunos de desenvolverem a compreensão conceitual dos estudos, sem 
que haja apenas o uso mecânico dos conceitos que envolvem os fenômenos estudados.

Segundo os autores, os softwares apesar de não serem projetados para que 0 aluno os modifiquem, proporciona um tipo de interação com o programa que permite ao aluno visualizar eventos que acontecem em nível microscópico para construir posteriormente um modelo mental do fenômeno macroscópico, fazendo assim suas próprias inferências e previsões.

Portanto, o uso de simulações no ensino de cinética química, desde que essa atividade seja feita de uma maneira orientada, pode ser uma opção para os professores abordar conceitos que requerem uma maior abstração por parte dos alunos.

3. Apresentação de fontes para pesquisa, na internet, sobre a História da Química (Apêndice XVI): Essa atividade ocorreu na sala de multimídia e teve como objetivo criar a oportunidade para que o professor conheça e acesse algumas fontes primárias e secundárias de pesquisa na área da história da ciência, para que no futuro, tenha material disponível para a elaboração de seu plano de ensino.

\section{Sétimo encontro: Os Programas de Investigação Científica (Lakatos)}

O objetivo desse encontro foi o de discutir, com os professores, os conteúdos relativos à cinética química como também da História e Filosofia da Ciência, escolhidos por eles, em seus planos de ensino. Outro objetivo foi o de apresentar, aos professores, a base teórica da metodologia dos programas de investigação científica do filósofo da ciência Imre Lakatos $(1998,1999)$.

Descrição das atividades:

1. Análise do plano de ensino (folha de atividade 8, Apêndice XVII): Nessa atividade os professores apontaram as competências e habilidades que pretendiam que seu aluno desenvolvesse em relação aos conteúdos da cinética química, história da ciência e imagem da ciência. Após a realização da atividade, 
os professores apresentaram individualmente o resultado para todo o grupo. Com esse exercício espera-se que o professor verifique se estes conteúdos estão presentes em seu plano de ensino, como também analise as estratégias de ensino que escolheu-se para abordá-los, por exemplo, se eles estão associando a História da Química a essas estratégias.

2. Apresentação dos programas de Investigação cientifica de Imre Lakatos: exposição das ideias centrais de Lakatos, para dar apoio aos professores para a realização da atividade 9 (Apêndice XVIII).

\section{Oitavo encontro}

Nesse encontro foi discutida com os professores a elaboração dos Programas de Investigação Científica da cinética química, justificando assim a apresentação, no curso, da história da cinética química em quatro períodos de tempo. Em um segundo momento, também se discutiu com eles, o processo de elaboração de seus planos de ensino, tendo em vista a incorporação de aspectos históricos no desenvolvimento do conteúdo.

Descrição das atividades:

1. Discussão da Atividade 9 (Apêndice XVIII): essa atividade teve como objetivo facilitar a compreensão do desenvolvimento da cinética química na perspectiva da reconstrução do conhecimento científico segundo Lakatos $(1998,1999)$. Após o término da atividade, voltou-se novamente à linha de tempo, construída durante o curso, para que os professores pudessem identificar nela os quatro programas.

2. Apresentação dos planos reelaborados e discussão do processo. O objetivo dessa atividade foi o de discutir com o grupo, o processo de elaboração do plano de ensino, quais conceitos foram escolhidos, como foi abordada a História da Química, quais foram as maiores dificuldades, entre outros aspectos.

3. Avaliação final do curso (Apêndice $X I X)$ : instrumento formado por questões abertas. Esse questionário teve como intenção: identificar os pontos positivos e negativos do curso, verificar se algumas das dificuldades, 
indicadas inicialmente pelos professores, tanto em relação ao entendimento do papel da História da Química no ensino como também em relação aos conteúdos do tema cinética química, foram superadas, ou não, e saber quais foram as reflexões que estes professores fizeram em relação ao seu ensino.

Isso é importante para se identificar as possíveis contribuições que um curso de formação continuada pode proporcionar aos professores do ensino médio.

4. Definição das datas para a aplicação do plano (solicitação que foi enviada previamente por email): convite aberto a todos os participantes do curso, para o acompanhamento da aplicação do plano de ensino em suas respectivas salas de aula.

\subsection{Segunda Etapa: Acompanhamento da aplicação dos planos de ensino pelos professores}

Do total de 20 participantes do curso, oito concordaram em participar dessa etapa da pesquisa. $O$ convite foi feito para todos os professores e a aceitação deles foi voluntária.

Esse pequeno número, em relação ao total de professores que participaram integralmente do curso foi devido, em primeiro lugar, ao fato de que muitos deles não estavam lecionando no momento do convite (5 atuam nas diretorias de ensino e 2 são alunos da licenciatura), o segundo fator identificado nas justificativas foi o fato que, alguns desses professores lecionarem em escolas particulares que não permitem o acompanhamento de uma pessoa externa, no caso a pesquisadora, em sala de aula.

Contudo, pode-se ainda apontar outros fatores relacionados à insegurança do professor em relação à abordagem da cinética química nessa perspectiva histórica, ou mesmo até a falta de interesse de alguns professores, conforme observamos no andamento do curso. 
Após o término do curso, dois professores, desse grupo de oito, se prontificaram a ser acompanhados pela pesquisadora em sala de aula, pois estavam dispostos a aplicar seus planos. Os demais professores do grupo justificaram sua desistência ao acompanhamento devido a problemas, como por exemplo, na carga horária, pois não podiam dispor do número de aulas que seu plano exigia, atraso no conteúdo o que acarretaria não abordar cinética naquele ano letivo, bem como mudança de escola e de função, entre outros.

Os dois professores, P11 e P15, aplicaram seus planos na escola particular e na rede publica respectivamente. Durante a aplicação do plano de ensino, após cada aula, os professores eram convidados a fazer uma reflexão sobre alguns aspectos, como por exemplo, se seu objetivo foi alcançado, qual foi a reação e entendimento dos seus alunos, o que deu certo o que precisa ser modificado.

\subsection{Instrumentos de análise dos dados da pesquisa}

A análise relativa à transição progressiva foi baseada nas ideias de Níaz (2000, 2008, 2009). Segundo o autor, as mudanças dos modelos explicativos podem ser comparadas às sequências de transições progressivas, semelhante ao que a história da ciência se refere como mudança de teorias pelo aumento do poder explicativo/heurístico dos modelos.

Segundo Lakatos (1998), ocorre transição progressiva, ou seja, mudança de modelo, quando um novo explica determinada ideia de forma mais abrangente.

Nesta pesquisa, baseando-se na perspectiva de Lakatos (1998, 1999), foram construídos modelos, a partir das ideias dos professores, procurando-se verificar se esses modelos formam sequências de transição progressiva (Níaz, 2009).

A ideia aqui é a de verificar a influência da abordagem histórica do tema cinética química na transição progressiva dos modelos de ensino dos professores que participaram do curso de formação continuada, ou seja, se houve modificação 
nas explicações teóricas usadas nos modelos desses professores (por exemplo, mudança de uma explicação macroscópica para uma submicroscópica para o mesmo fenômeno) e também verificar em quais aspectos desse modelo essas modificações ocorreram mais significativamente.

Esses aspectos, que fazem parte do modelo de ensino de cinética química dos professores estão descritos a seguir.

\section{A construção dos modelos de ensino}

Foram considerados três aspectos na análise dos modelos de ensino. $O$ primeiro está relacionado ao entendimento dos modelos teóricos referentes ao tema cinética química durante os três momentos da pesquisa: inicio, durante e após o curso de formação continuada. $O$ segundo aspecto se refere a como o professor entende o papel da história da química, também nesses três momentos e o terceiro aspecto está relacionado à imagem manifestada sobre a natureza da ciência.

Os modelos de ensino de cinética química foram elaborados a partir de diversos instrumentos de coletas de dados, aplicados durante o curso de formação continuada, incluindo também os discursos gravados, em áudio e vídeo, desses mesmos professores. A elaboração desses modelos está também relacionada à reconstrução histórica do desenvolvimento da cinética química em um determinado período de tempo (1850 a 1935).

Para a análise das respostas dadas pelos professores nos instrumentos de coletas de dados, escolheu-se, nessa pesquisa, a técnica da análise temática ou categorial que de acordo com Bardin (1977), se baseia em operações que desmembram um determinado texto em unidades, ou seja, tentou-se descobrir os diferentes núcleos de sentido que constituem o texto, e posteriormente, realizar o seu reagrupamento em modelos.

Assim, em relação ao primeiro aspecto a ser analisado, o entendimento referente ao tema cinética química, buscou-se no texto do professor identificar o núcleo que daria sentido a cada modelo teórico. Por exemplo, procurou-se 
identificar nos textos produzidos pelos professores termos e explicações que faziam referencia ao copo teórico da teoria das colisões (núcleo), como por exemplo, choque efetivo entre moléculas, orientação espacial adequada, moléculas com energia suficiente (energia de ativação) para reagirem, entre outros conceitos que foram desenvolvidos nesse período (texto 3 da reconstrução histórica) e em seguida esses termos foram reagrupados constituindo assim o modelo de ensino submicroscópico 1 (MES1).

> 1‥ Aspecto: Modelos teóricos relacionados ao tema cinética química

A partir da análise de conteúdo, construíram-se quatro modelos de ensino de cinética química. O primeiro modelo de ensino, o Macroscópico (MEM) referese ao primeiro período dos estudos da cinética química (1850-1865), onde os estudos eram somente de caráter empírico e matemático. O modelo de ensino pseudomicroscópico (MEP), envolve uma explicação teórica mais ampla envolvendo o conceito de energia, para explicar a velocidade. $O$ terceiro modelo de ensino (MES1), inclui o desenvolvimento da teoria das colisões e finalmente uma explicação mais atualizada, que inclui a Teoria do estado de Transição (faz parte do quarto modelo de ensino de cinética química (MES2)). Os modelos são:

- Modelo de ensino macroscópico (MEM):

Nesse modelo, o ensino do professor está baseado apenas nas características macroscópicas de uma reação química, com o enfoque somente nos fatores que podem influenciar essa reação. Em suas explicações e estratégias empregadas, não há o uso de qualquer modelo teórico para explicar, em termos microscópicos, a influência desses fatores na velocidade de uma reação química.

- Modelo de ensino pseudomicroscópico (MEP):

Nesse modelo, o ensino do professor ainda está baseado apenas nas características macroscópicas de uma reação química, com o enfoque somente nos fatores que podem influenciar a velocidade dessa reação. Contudo, em suas explicações e estratégias, embora não haja o uso de qualquer modelo teórico, já 
começam a aparecer o uso de termos relacionados às características microscópicas da matéria, como, por exemplo, movimento de moléculas.

- Modelo de ensino submicroscópico 1 (MES1):

Nesse modelo, no ensino do professor já aparecem afirmações relacionadas a modelos teóricos para explicar a velocidade das reações e os fatores que as influenciam em termos microscópicos. A teoria usada em suas explicações e estratégias de ensino é a teoria das colisões (com o enfoque nos choques entre partículas e orientação espacial adequada). Também, nesse modelo, aparece o conceito relacionado à energia de ativação.

- Modelo de ensino submicroscópico 2 (MES2):

Nesse modelo de ensino, já aparecem explicações relacionadas a um modelo teórico, mais elaborado, para explicar a velocidade das reações e os fatores que as influenciam em termos microscópicos. A teoria usada em suas explicações e estratégias de ensino é a teoria do Estado de Transição (com o enfoque na quebra e formações de ligações químicas e na ideia do complexo ativado).

> 2. Aspecto: Papel da História da Química no ensino

Para caracterizar o entendimento dos professores sobre o papel da Historia da Química no ensino de cinética química foram elaboradas, a partir das respostas dos professores ao questionário inicial (instrumento 1, Apêndice II), as seguintes categorias:

C1: Interesse pela química. A história da química pode ajudar a despertar o interesse do aluno pela química.

C2: O caráter dinâmico da ciência. A história da química pode ajudar o aluno a perceber que o conhecimento científico pode ser provisório, que as teorias e leis podem ser abandonadas e substituídas por outras.

C3: A origem do conhecimento científico. A história da química pode facilitar o entendimento de onde vieram as ideias e conhecimentos que possuímos atualmente. 
C4: A construção do conhecimento científico. Nessa categoria a História da Química pode ajudar os alunos a entender como um determinado conceito foi construído como também ajuda-los a entender como os cientistas trabalham.

Irá ser observado se, as ideias sobre a História da Química que esses professores possuíam no início do curso sofreram modificações após estes professores passarem pelo curso, com o enfoque na história do desenvolvimento da cinética química, ou seja, se houve a ampliação do entendimento do papel da História da Química no ensino de cinética química.

> 3 . Aspecto: Imagem sobre a natureza da ciência

Para Praia e Chachapuz (1994), a imagem de ciência que os alunos possuem depende, algumas vezes, do que thes é proporcionado pelos seus professores de ciência, assim eles acham compreensível o crescente interesse da investigação educacional pelo ensino de ciência dum ponto de vista epistemológico. Segundo os autores, há atualmente evidências claras de que as concepções dos professores acerca da natureza da ciência, do conhecimento científico e do que é o método, influencia a forma de abordar um determinado conteúdo e, portanto a imagem da ciência transmitida ao aluno.

Para essa análise foram usadas três categorias (Quadro 2.2.1) que estão relacionadas a duas perspectivas filosóficas, a perspectiva Empirista/Indutivista (E/I) e a perspectiva Racionalista $®$ elaboradas por Martorano (2007), baseadas nas ideias de Lakatos.

Essas duas perspectivas foram escolhidas porque representam duas linhas bem distintas entre as perspectivas filosóficas ligadas ao entendimento da ciência. Níaz (2009) aponta que a diferença mais importante, entre as metodologias positivista/empirista e a racionalista (por exemplo, a perspectiva de Lakatos), é a ideia de que a ciência não se desenvolve em linha reta, e sim através de muitos pontos de vistas conflituosos. É somente através destes conflitos que é gerada concorrência entre programas rivais, e a ciência aumenta o poder explicativo de suas teorias. 
Foram consideradas três dimensões:

1-Concepção de ciência: Nesta categoria pretende-se verificar como o professor entende a ciência. Na perspectiva racionalista, o conhecimento científico é visto como uma construção humana e formado por um conjunto de hipóteses que são modificáveis e que tendem a fazer uma descrição da realidade. Na perspectiva empirista/indutivista o conhecimento é visto como um conjunto de enunciados universais.

Como critério de análise desta categoria, procurou-se verificar se o professor manifesta uma imagem da ciência como sendo uma verdade definitiva ou como um conjunto de modelos teóricos que são utilizados até que novos modelos, com maior poder explicativo, sejam elaborados.

2- O desenvolvimento da ciência: Esta categoria está ligada à maneira pela qual o professor vê o desenvolvimento dos conceitos químicos. Por exemplo, na perspectiva racionalista o conhecimento científico vai aumentando seu poder explicativo, ou seja, vão surgindo modelos com explicações mais amplas, de acordo com o tempo, para um determinado fenômeno em estudo.

Para a perspectiva empirista/indutivista somente a teoria mais atual é a verdadeira, as explicações anteriores são consideradas como erros que devem ser esquecidos. Como critério de análise desta categoria, procurou-se verificar se o professor indica o desenvolvimento da ciência.

3- A construção do conhecimento científico: Esta categoria está relacionada ao processo de construção do conhecimento científico.

Segundo Lakatos (1998), para um indutivista: “...somente estas proposições podem ser aceitas no corpo das ciências as quais, ou descrevem fatos sólidos ou são generalizações indutivas infalíveis a partir destes".

Segundo Praia e Chachapuz (1994), as correntes contemporâneas da epistemologia (por exemplo, Bachelard, Popper, Kuhn, etc.), que alguns autores denominam "nova" filosofia da ciência, defendem uma concepção, segundo o qual, o conhecimento é construído com base em teorias que orientam a 
observação, em outras palavras, uma observação depende da teoria. Para estes filósofos da ciência, o método científico não é entendido como uma sucessão linear de etapas, mas antes um processo conducente à elaboração de ideias sucessivamente mais complexas.

Como critério de análise desta categoria, procurar-se-á verificar como professor aborda a construção do conhecimento científico.

\begin{tabular}{|c|c|c|}
\hline Categorias & Empirista/Indutivista & Racionalista (Lakatos) \\
\hline $\begin{array}{l}\text { 1- Concepção de } \\
\text { ciência }\end{array}$ & $\begin{array}{l}\text { Conjunto de enunciados } \\
\text { universais. }\end{array}$ & $\begin{array}{l}\text { Conjunto de hipóteses, } \\
\text { modificáveis, organizadas e que } \\
\text { tendem a fazer uma descrição da } \\
\text { realidade. } \\
\text { Construção Humana. }\end{array}$ \\
\hline $\begin{array}{l}\text { 2- } 0 \\
\text { Desenvolvimento } \\
\text { da Ciência }\end{array}$ & $\begin{array}{l}\text { O desenvolvimento da ciência } \\
\text { é apresentado de uma forma } \\
\text { continua e acumulativa. }\end{array}$ & $\begin{array}{l}\text { O progresso da ciência é } \\
\text { caracterizado como uma } \\
\text { "problemática progressiva" de } \\
\text { uma tentativa teórica para outra. }\end{array}$ \\
\hline $\begin{array}{l}\text { 3- A construção } \\
\text { do conhecimento } \\
\text { científico }\end{array}$ & $\begin{array}{l}\text { A partir de dados } \\
\text { experimentais, elaboram-se } \\
\text { hipóteses e estas se tornam } \\
\text { teorias que depois se tornam } \\
\text { leis dependendo da } \\
\text { quantidade de "provas por trás } \\
\text { da ideia". } \\
\text { A observação é tida como a } \\
\text { etapa mais importante do } \\
\text { método científico. } \\
\text { O papel da experimentação é } \\
\text { a comprovação do } \\
\text { conhecimento. } \\
\text { O papel dos cientistas é o de } \\
\text { induzir e estabelecer } \\
\text { comprovações empíricas de } \\
\text { leis e princípios. }\end{array}$ & $\begin{array}{l}\text { O conhecimento é construído } \\
\text { com base em teorias que } \\
\text { orientam a observação, em } \\
\text { outras palavras, uma observação } \\
\text { depende da teoria. } \\
\text { O método científico não é } \\
\text { entendido como uma sucessão } \\
\text { linear de etapas, mas antes um } \\
\text { processo conducente à } \\
\text { elaboração de ideias } \\
\text { sucessivamente mais complexas. } \\
\text { O papel dos cientistas é o } \\
\text { estabelecer hipóteses e elaborar } \\
\text { explicações racionais (dedutivas). }\end{array}$ \\
\hline
\end{tabular}

Quadro 3.3. Categorias para a identificação da perspectiva filosófica dos professores (Martorano, 2007). $\cdot$

\subsubsection{A Análise}


A análise dos dados dos professores, considerando-se os três aspectos descritos anteriormente, foi feita em três momentos, no início, durante e após o curso de formação continuada:

- Fase inicial: Esta análise é caracterizada pelas ideias emitidas pelos professores no início do curso de formação continuada. No inicio do curso (primeiro encontro) foram aplicados três instrumentos para que fosse identificado o que esses professores achavam importante ensinar sobre o tema, o que eles ensinavam em suas aulas, quais eram as suas maiores dificuldade e quais eram as estratégias que eles empregavam no ensino de cinética química (experimentação e História da Química). Outro ponto identificado nesses instrumentos era qual visão, sobre a natureza da ciência, esses professores possuíam no início do curso.

- Fase intermediária: Esta análise é caracterizada pelas ideias emitidas pelos professores durante o curso de formação continuada. Durante o curso, os professores realizaram atividades como, exercícios de elaboração e interpretação de gráficos e tabelas, leitura e interpretação de textos e experimentos, relacionados ao desenvolvimento histórico da cinética química, que poderiam ser aplicados em suas aulas. Além de fornecer exemplos de estratégias para poder trabalhar com a História da Ciência no ensino, outro objetivo dessas atividades era o de poder verificar qual o entendimento desses professores sobre o tema cinética química. Também foram realizadas atividades onde os professores puderam discutir e refletir sobre suas imagens a respeito da natureza da ciência, como também sobre o papel da história da ciência no ensino.

- Fase final: Esta análise é caracterizada pelas ideias emitidas pelos professores no final do curso de formação. As atividades analisadas nessa etapa foram a avaliação no final de curso, as habilidades e competências que estes professores esperavam desenvolver em seus alunos e seus planos de ensino. 


\section{Capítulo 4. A transição progressiva dos modelos de ensino de cinética química}

Neste capitulo será apresentada a construção dos modelos de ensino de um grupo de professores. A análise foi feita com o objetivo de se verificar se o curso de formação continuada facilitou a transição progressiva dos modelos de ensino desses professores. Esta análise foi realizada em duas etapas. A primeira etapa corresponde a análise realizada a partir dos dados coletados dos professores do período do curso de formação continuada, e a segunda etapa corresponde a análise dos dados dos professores que aplicaram o seu plano de ensino.

\subsection{Transição progressiva dos modelos de ensino durante o curso de formação continuada}

P1

\section{Fase inicial}

Para a professora é importante aprender cinética química, pois:

Acredito que, para a formação de um cidadão pensante na sociedade, um cidadão que participe, critique e construa a nossa sociedade, é necessário que ele aprenda conceitos que o façam entender a química como parte de seu cotidiano, de modo que, ao se deparar com determinadas situações em sua vida, ele possa relacionar o conhecimento que tem sobre cinética química com sua realidade. (Instrumento 1,Questão 3, Apêndice II)

Quanto ao conteúdo que leciona ela indica que: "Sinceramente, somente a Influência da temperatura, concentração, pressão, superfície de contato e catalisadores nas velocidades da reação". (Instrumento 1, Apêndice II)

Em relação ao que ensina o aspecto mais importante para ela é:

Hoje, sei que acabaria por ensinar cinética química com o foco em velocidade de reação, mas acho importante o ensino de cinética como um todo (história dos primeiros conceitos, teorias atuais, experimentos e aplicações 
práticas), isto porque acho que o aluno deve ter uma visão do todo, e não de uma ciência em "partes"..(Instrumento 1, Apêndice II)

No ensino de cinética química, a sua maior dificuldade está em ensinar a teoria das colisões, por considerá-la abstrata para os alunos.

Em suas aulas, a estratégia que normalmente usa é um experimento para demonstrar o efeito da superfície de contato e da temperatura na velocidade de uma reação química. $O$ experimento que usa é o da dissolução de um comprimido efervescente em diferentes condições..

Quando questionada por que este experimento pode ajudar no ensino de cinética química ela aponta que: "Ajuda o aluno a entender o conceito de forma prática, podendo aplicar este conceito no seu cotidiano." (Instrumento 1, Apêndice II)

Em relação à História da Química (Instrumento 1, questão 9, Apêndice II), embora ela considere importante a sua inclusão no ensino, "Para entender de onde vieram os conceitos e teorias que aprendemos hoje e para perceber que a ciência está sempre em movimento de criação e novas descobertas, não sendo estática, pronta, finalizada.", ela afirma não usar em suas aulas.

As suas ideias iniciais sobre a natureza da ciência (instrumento 2, Apêndice VII), em relação ao desenvolvimento do conhecimento científico são:

- O conhecimento científico é gerado graças à capacidade que os seres humanos possuem para propor problemas e imaginar possíveis soluções aos mesmos. (R)

Contudo, em relação à construção do conhecimento científico ela escolhe a afirmação referente à perspectiva filosófica empirista/ indutivista:

- Ao realizar uma observação o cientista não deve sofrer a influência de teorias prévias sobre o problema investigado. (E/l)

Pela análise das respostas da professora, observa-se que suas ideias estão baseadas, principalmente, nos aspectos macroscópicos da cinética química (MEM). Nessa fase, suas ideias sobre a natureza da ciência embora já tenham alguma relação com a perspectiva racionalista, possuem ainda características da 
perspectiva filosófica empirista/indutivista (E/I). Sua ideia sobre o papel da HQ no ensino está relacionada ao se poder conhecer a origem dos conhecimentos científicos (categoria C3), como também o caráter dinâmico da ciência (categoria $\mathrm{C2).}$

\section{Fase intermediária}

Durante o curso de formação continuada, em 2010, foram realizadas duas atividades em que os alunos do curso teriam de interpretar gráficos e tabelas para entenderem como a velocidade de determinadas reações químicas variaram com o tempo.

$\mathrm{Na}$ atividade 6 (Apêndice $\mathrm{XI}$ ), extraída dos experimentos realizados por Berthelot e Péan de Saint-Gilles (1861), sobre reações de esterificação e hidrólise, os professores tinham de, a partir dos dados fornecidos, traçar a curva que representava a percentagem de ácido esterificado com o tempo e explicar como a velocidade dessa reação variava com o tempo.

A professora mostrou ter o entendimento de como varia a velocidade de uma reação com o tempo: "A velocidade da reação decresce com o tempo" (modelo de científico - MC; Cakmakci et al, 2005), e também, de como se dá a influência da temperatura na velocidade da reação. Contudo, em suas explicações não aparece ainda um modelo explicativo. As explicações são do tipo: o aumento da temperatura acarreta o aumento da velocidade: "O aumento da temperatura da reação leva ao aumento na velocidade de formação do éster."

$\mathrm{Na}$ atividade experimental (experimento 3, Apêndice XII), sobre o efeito da temperatura na velocidade de uma reação, realizada no mesmo encontro, suas explicações já incluem termos microscópicos para explicar esse efeito, e nesse caso podemos relacionar a ideia da professora à teoria das colisões: "A reação é mais lenta devido a menor agitação das partículas no sistema e consequentemente o menor choque efetivo entre elas"(MES1) 
Essa atividade experimental foi realizada após a apresentação dos estudos referentes ao efeito da temperatura na velocidade das reações químicas (período: 1862 a 1888).

No quinto encontro (exercício 1, Apêndice $X V$ ), foi solicitado aos professores que desenhassem um gráfico que mostrasse a variação da velocidade de uma reação com o tempo. O professor também tinha de justificar porque considerava que o seu gráfico estava correto. O propósito desse segundo exercício era o de conhecer a extensão do conhecimento do professor, sobre a relação entre a concentração dos reagentes e a velocidade de uma reação química.

Nessa atividade a professora desenhou o seguinte gráfico:

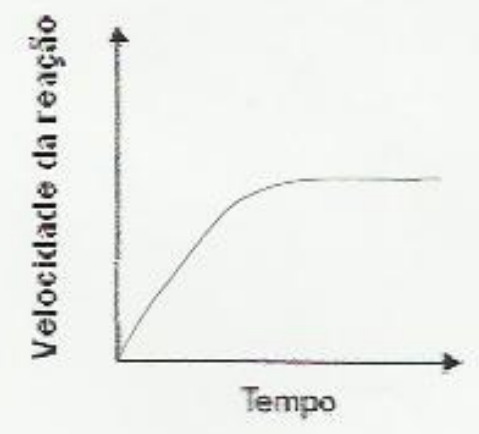

Figura 4.1 A variação da velocidade de uma reação em função do tempo segundo P1.

Percebe-se que o modelo de seu gráfico refere-se ao modelo de aumento constante - MAC (Cakmakci et al,2005). Ela não justificou o seu desenho.

Embora no exercício sobre gráficos realizado anteriormente (atividade 6, Apêndice $\mathrm{XI}$ ), a professora tenha interpretado o gráfico da velocidade de forma correta, nesse exercício, onde se pediu que ela desenhasse o gráfico, ela não usou o modelo cientifico, portanto, percebe-se sua dificuldade em estabelecer a relação entre consumo de reagentes e a velocidade de uma reação química.

Essa atividade foi realizada após a apresentação do desenvolvimento da teoria das colisões e o conceito de energia de ativação (período: 1889-1918) 
Em relação à História da Química (HQ), no primeiro encontro foi dado como tarefa a leitura de um artigo de sobre as ideias atomísticas do sec. XIX (atividade 1, Apêndice III), onde os professores deveriam indicar como usariam e as vantagens e desvantagens de se utilizar essa estratégia no ensino. A professora usaria o artigo para: "Discussão sobre conceitos/teorias químicas utilizadas em tempos passados e como chegamos as teorias vigentes na atualidade".

Portanto, o papel da $\mathrm{HQ}$ no ensino seria o de facilitar o entendimento de onde vieram as ideias e conhecimentos que possuímos atualmente (categoria C3).

Para a professora a vantagem em se usar artigos da História da Química no ensino seria a de: "O aluno conhecer a ciência como estando em constante transformação; Conhecer como surgiram as teorias atuais."

Para essa professora, não há nenhuma desvantagem no uso dessa estratégia: "Não consigo ver desvantagens".

No segundo encontro, os professores realizaram a atividade 2 (Apêndice $\mathrm{VI}$ ). Após a leitura do texto da atividade os professores deveriam responder se concordavam ou não com as ideias apresentadas no texto em defesa do uso da $\mathrm{HQ}$ no ensino de ciências, justificando a sua escolha. A professora concordou com a ideia defendida, porém, não justificou porque concordava com ela.

Para ela a dificuldade em abordar a HQ está em mudar no aluno a visão que este já possui sobre a natureza da ciência: "Creio que a maior dificuldade seria mostrar aos alunos que já tem a ideia prévia da ciência como estática esta nova visão de ciência como um processo em constante transformação."

Percebe-se que para a professora o papel da $\mathrm{HQ}$ no ensino é o de mostrar o caráter dinâmico da ciência (categoria C2).

Durante o curso foi realizada pelos professores uma atividade (terceiro encontro, atividade 4, Apêndice IX) relativa à imagem da natureza da ciência, que foi a construção de um mapa conceitual. Com essa atividade se tentou identificar 
as ideias sobre ciência que o professor considera importante que seu aluno construa durante as suas aulas de química, e quais são as implicações dessas ideias no ensino.

$\mathrm{Na}$ figura 4.2 está representado o mapa conceitual sobre a imagem da ciência elaborado pela professora P1:

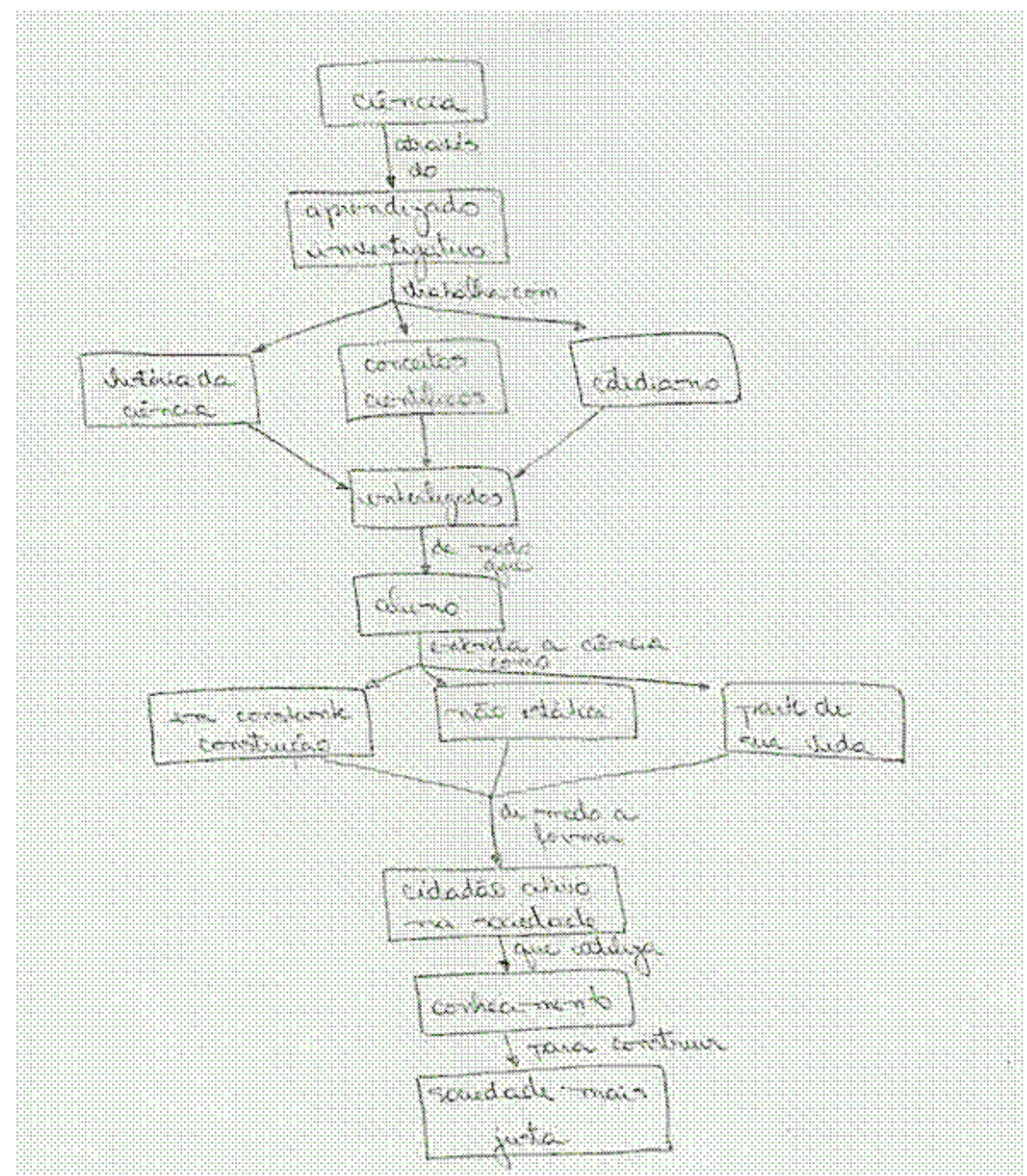

Figura 4.2 Mapa conceitual sobre a imagem da ciência elaborado pela professora P1.

Pela análise do mapa, verifica-se que a imagem sobre a natureza da ciência que a professora espera que seus alunos construam, está relacionadas à perspectiva filosófica racionalista: "Entender a ciência como em constante construção, não estática, parte de sua vida", 
Em outra atividade (instrumento 3, Apêndice XIV), realizada no quinto encontro, pretendia-se proporcionar aos professores a reflexão sobre a imagem de ciência que eles possuíam anteriormente e se ela se modificou após as discussões e leituras feitas nos encontros anteriores. Nessa atividade foi solicitado aos professores que escrevessem um pequeno texto, sobre suas ideias da natureza da ciência, naquele momento. A professora escreveu:

\begin{abstract}
A ciência é um conjunto de ideias/teorias que buscam explicar fenômenos em geral, podendo desenvolver-se de diversas formas: - a partir de teorias já existentes, são desenvolvidas novas teorias científicas, -a partir de experimentação, desenvolvem-se novas teorias; -novas teorias surgem, podendo ou não se comprovadas experimentalmente, etc. O conhecimento científico é construído a partir destas teorias e experimentações. Algumas vezes, novas teorias substituem teorias anteriores, outras vezes, novas teorias são aprimoramentos de teorias anteriores.
\end{abstract}

No texto da professora pode-se verificar que a imagem manifestada está relacionada à perspectiva filosófica racionalista, pois, para ela na ciência não existe um único método científico, a ser seguido para construir o conhecimento científico.

Pela análise das respostas da professora, percebemos que durante o curso o seu modelo foi se modificando, passando do MEM para o MES1, quando ela passou a incluir nas suas explicações termos relacionados à teoria das colisões, como o termo colisões efetivas. Este modelo é marcado principalmente pela perspectiva filosófica perspectiva racionalista $(\mathrm{R})$. Como na fase inicial sua ideia sobre o papel da $\mathrm{HQ}$ no ensino continua sendo aqueles relacionados as categorias $\mathrm{C} 2$ e $\mathrm{C} 3$.

\title{
Fase final
}

No final do curso foi aplicada uma avaliação (Apêndice XIX), na qual os professores tinham de indicar se suas dificuldades em relação ao ensino de cinética química e em relação a História da Química, tinham sido superadas, com as atividades do curso: A professora P1 manifestou-se da seguinte maneira: 
- Em relação à cinética química, as dificuldades foram superadas "Pelas discussões sobre esses temas no curso"

- História da Química: “com o curso foram divulgadas várias fontes de informação à respeito da história da ciência, o que pode ajudar, (e muito) a superar as dificuldades citadas. Porém, materiais adicionais são difíceis de conseguir, o que ainda pode dificultar um aprofundamento do professor no tema história da ciência".

- Sobre os aspectos relacionados a sua prática ela respondeu que:

Acho que os principais aspectos foram: qual a visão de ciência eu quero que meus alunos tenham e qual a melhor maneira de tratar a $\mathrm{HQ}$ nas aulas do dia-a-dia. Isso porque, com o curso, esta abordagem foi bastante discutida, o que me levou a avaliar a importância desses tópicos no ensino de química.

\section{$\underline{\text { Plano de ensino }}$}

Em relação ao plano de ensino (folha de atividade 8, Apêndice XVII) elaborado por essa professora, podem-se observar no Quadro 4.1 as habilidades e competências em relação aos conceitos de cinética química, a História da química e a visão sobre a natureza da ciência que a professora pretende que seus alunos desenvolvam:

\begin{tabular}{llc} 
Temas & Habilidade e competências & Análise \\
\hline $\begin{array}{ll}\text { Conceitos da } \\
\text { cinética química }\end{array}$ & $\begin{array}{l}\text { Que o aluno consiga entender a influencia de } \\
\text { fatores como temperatura, concentração e } \\
\text { superfície de contato na velocidade de uma } \\
\text { reação química. }\end{array}$ & MEM \\
Visão sobre a & $\begin{array}{l}\text { Desenvolver no aluno a percepção de que a } \\
\text { ciência não é estática e está sempre em }\end{array}$ & R \\
natureza da & $\begin{array}{l}\text { construção. } \\
\text { ciência }\end{array}$ & C4 \\
História da & $\begin{array}{l}\text { A partir da história da ciência, que o aluno } \\
\text { perceba a evolução dos conceitos científicos } \\
\text { a partir do trabalho de diversos } \\
\text { pesquisadores, e não só as ideias que algum } \\
\text { "gênio" tenha desenvolvido sozinho e sem } \\
\text { embasamento anterior. }\end{array}$ & \\
\hline
\end{tabular}

Quadro 4.1 Habilidades e competências indicadas no plano de ensino da professora P1.

Outros tópicos do plano dessa professora: 
No plano de ensino dessa professora, em relação aos conceitos químicos que ela deseja abordar com seus alunos, percebe-se que seu foco está nos fatores que afetam a velocidade de uma reação química sem, contudo, abordar um modelo teórico para explicá-los: "Os conteúdos conceituais trabalhados tratarão da Cinética Química e especificamente, dos fatores que influenciam a velocidade de reações químicas".

As estratégias escolhidas pela professora foram:

Para este plano de ensino, as estratégias de ensino aplicadas serão: questionário para avaliação de ideias prévias, experimentação investigativa, texto para orientação e discussão e um questionário para avaliação de aprendizado.

A justificativa da escolha dessas estratégias foi:

As aulas contidas neste plano de ensino buscam uma orientação investigativa, mais voltada para o construtivismo, podendo ser aplicadas tanto em escolas que tenham como orientação didática esta forma de ensino bem como em escolas tradicionais como uma forma diferenciada de avaliar o ensino (deste modo, o professor pode avaliar o aprendizado tradicional $\mathrm{x} 0$ aprendizado investigativo).

Sequência:

1. Questionário levantamento das ideias prévias sobre cinética química

2. Experimento sobre cinética química - fatores que alteram a velocidade das reações químicas

3. Discussão do experimento.

4. Texto para discussão: Conservação de alimentos. O texto será entregue aos alunos para leitura e interpretação em casa para discussão na próxima aula (adaptado de Cadernos de Educação Escolar Indígena - Universidade do Estado de Mato Grosso). Embora seja um texto simples, o objetivo é relacionar o que já foi trabalhado com os alunos nas aulas anteriores com um pouco de seu cotidiano.

5. Texto sobre história da ciência para discussão: Aula 4 - Atividade 1: 0 texto "Paradigmas, crises e revoluções: a história da química na perspectiva Kuhniana" será entregue aos alunos para leitura e discussão em sala de aula. Iniciando-se a discussão do texto, serão apresentados aos alunos alguns fatos históricos a respeito da cinética 
química, baseados nos textos: 100 anos de Nobel - Jacobus Henricus van't Hoff e Desenvolvimento Histórico da Cinética Química.

6. Avaliação dos conhecimentos adquiridos.

Em seu plano, a professora propôs iniciar a aula realizando, por meio de um questionário, o levantamento das ideias prévias dos estudantes sobre o tema. O objetivo desse instrumento é, segundo a professora: "O questionário será aplicado aos alunos com o objetivo de avaliar as ideias prévias que possuem e, assim, direcionar as discussões a respeito dos fatores que alteram a velocidade de uma reação química".

As estratégias propostas para o ensino de conceitos de cinética química foram: uma atividade experimental (experimentos com alumínio) e a leitura e discussão de um texto sobre conservação de alimentos. $\mathrm{Na}$ atividade experimental, como também na leitura do texto ,são abordados somente os aspectos macroscópicos do estudo da velocidade e uma reação química..

Em relação à História da Química, a professora em seu plano faz uma abordagem desse tema na quarta aula, conforme se pode ler no seu plano:

O objetivo desta aula é apresentar a ciência como em constante transformação, sendo sempre desenvolvida por diversos indivíduos, desmistificando a ideia de ciência como pronta e acabada, sendo proveniente das ideias surgidas da mente de alguns poucos "gênios" que desenvolveram suas teorias partindo do nada. Neste contexto, a história da cinética química será apresentada para que o aluno conheça um pouco de como foi o desenvolvimento histórico das teorias e fatos que estão em estudo nestas aulas e em futuras aulas sobre cinética química. (4르. Aula, plano de ensino, P1).

Pela análise das respostas da professora, percebemos que no final do curso o seu modelo sobre cinética química retrocedeu do MES1 para o MEM. Em relação à História da Química, percebe-se a ampliação de seu papel e significado no ensino para essa professora, pois ela passou da categoria C2 para a C4. Este modelo é marcado principalmente pela perspectiva filosófica perspectiva racionalista $(\mathrm{R})$, como pode-se verificar no texto acima da professora. 
No quadro a seguir podem ser observados, nos três momentos do curso de formação continuada, os modelos de ensino dessa professora:

\begin{tabular}{|c|c|c|c|c|}
\hline ETAPA & INSTRUMENTOS & $\begin{array}{l}\text { CINÉTICA } \\
\text { QUÍMICA }\end{array}$ & $\begin{array}{l}\text { HISTÓRIA DA } \\
\text { QUÍMICA }\end{array}$ & $\begin{array}{c}\text { IMAGEM DA } \\
\text { CIÊNCIA }\end{array}$ \\
\hline \multirow{2}{*}{ INICIO } & INSTRUMENTO 1 & MEM & $\mathrm{C} 2, \mathrm{C} 3$ & \\
\hline & INSTRUMENTO 2 & & & $E / I, R$ \\
\hline \multirow{7}{*}{ DURANTE } & ATIVIDADE 1 & & $\mathrm{C3}$ & \\
\hline & ATIVIDADE 2 & & $\mathrm{C} 2$ & \\
\hline & ATIVIDADE 4 & & & $\mathrm{R}$ \\
\hline & ATIVIDADE 6 & MEM & & \\
\hline & INSTRUMENTO 3 & & & $\mathrm{R}$ \\
\hline & EXPERIMENTO 3 & MES1 & & \\
\hline & EXERCICIO 1 & MES1 & & \\
\hline \multirow{2}{*}{ FINAL } & ATIVIDADE 8 & MEM & C4 & $\mathrm{R}$ \\
\hline & PLANO DE ENSINO & MEM & $\mathrm{C} 3, \mathrm{C} 4$ & $\mathrm{R}$ \\
\hline
\end{tabular}

Quadro 4.2 Modelos de ensino de cinética química do professor P1, em relação aos três aspectos analisados (cinética química, Historia da Química e imagem da ciência) nas diferentes etapas do curso de formação.

A partir do quadro acima elaborou-se um gráfico (fig. 4.3) com o objetivo de se representar a transição progressiva da professora $\mathrm{P} 1$ em relação aos seus modelos de ensino e assim ter uma ideia sobre qual aspecto do seu modelo o curso de formação continuada favoreceu essa transição.

Cada linha desse gráfico representa um dos três aspectos que foram analisados nesse trabalho. Portanto, a linha verde, IC, representa a transição da professora em relação à imagem da ciência, a linha azul a transição em relação a cinética química e finalmente a linha vermelha que representa a transição em relação ao entendimento do papel História da Química.

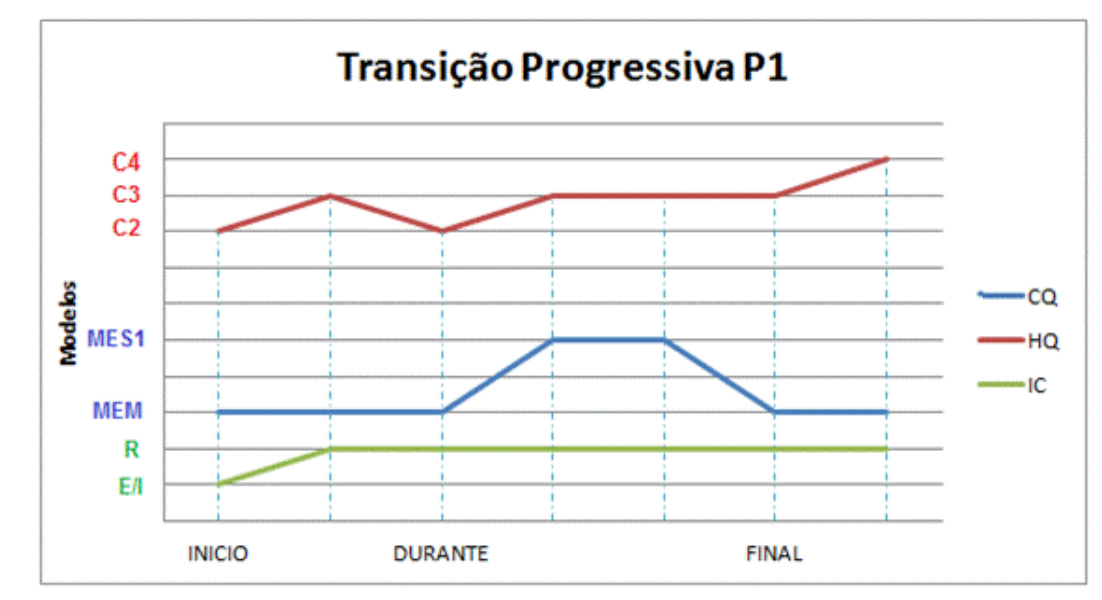


Figura 4.3 Transição progressiva da professora P1 nas três fases da pesquisa, em relação aos seguintes aspectos de seu modelo de ensino: $C Q$ : cinética química, $H Q$ : História da Química e IC: imagem da ciência. Nota: Em relação a imagem da ciência indicada no inicio do curso, na construção do gráfico, quando o professor indica afirmações das duas perspectivas seguiu-se a seguinte forma de indicação: número de afirmações iguais das duas perspectivas, indica-se a perspectiva E/l, número diferente de afirmações, indica-se a perspectiva filosófica com maior número de afirmações.

Percebe-se que passou a ser uma preocupação da professora a imagem sobre a natureza da ciência de seus alunos. Pode-se verificar isso nas suas reflexões sobre a sua prática:

Acho que os principais aspectos foram: qual a visão de ciência eu quero que meus alunos tenham e qual a melhor maneira de tratar a $\mathrm{HQ}$ nas aulas do dia-a-dia. Isso porque, com o curso, esta abordagem foi bastante discutida, o que me levou a avaliar a importância desses tópicos no ensino de química (P1, avaliação final, Apêndice IX) (grifo nosso).

E esta preocupação está refletida em seu plano de ensino, nas habilidades e competências que ela espera que seus alunos desenvolvam e na sua estratégia de ensino

Em relação ao papel da Historia da Química (HQ) no ensino de cinética química, percebe-se que o entendimento da professora foi ampliado ao final do curso, portanto, para ela o estudo da HQ não permite apenas que o aluno saiba de onde se originou um determinado conceito, mas permite também que ele entenda como esse conceito científico foi construído.

Neste contexto, a história da cinética química será apresentada para que o aluno conheça um pouco de como foi o desenvolvimento histórico das teorias e fatos que estão em estudo nestas aulas e em futuras aulas sobre cinética química (plano de ensino, P1).

Em relação ao entendimento dos modelos teóricos relacionados ao tema cinética química, percebe-se que embora a professora durante o curso de formação tenha em suas explicações incluído um modelo teórico para explicar a velocidade de uma reação química, ela não incluiu em seu plano de ensino esse 
modelo, focalizando seu ensino somente nos aspectos macroscópicos da velocidade de uma reação química.

De acordo com pesquisadores (Justi e Ruas. 1997; Perez, 2006; Cakmakci et al,2005), essa dificuldade dos professores, de não trabalharem com um modelo submicroscópico no ensino de cinética química, pode estar relacionada ao pouco entendimento que esses possuem sobre esse conteúdo. Muitos professores que participaram do curso afirmaram não ter uma boa formação em relação à cinética química, devido a falhas nos seus cursos de graduação.

P2

Fase inicial

Para a professora P2 o ensino de cinética química é importante, pois permite:

Trabalhar respeito mútuo e o uso construtivo do conhecimento, porque a cinética envolve sobrevivência real. Aborda-se desde a necessidade da humanidade em mudar suas práticas agrícolas/industriais, para formas mais sustentáveis, se quiser sobreviver e aprender a aceitar e respeitar seu próprios limites como seres vivos. (Instrumento 1,questão 3, Apêndice II)

Quanto ao conteúdo, o aspecto mais importante para ela é:

Falar inicialmente sobre exemplos como perfumes, alergias, radiação. Focar o meio ambiente, buscando mostrar uma visão ora restrita ora ampla. Citar exemplos macroscópicos e microscópicos. Justificando que esses estudos são importantes para a sobrevivência humana.

Para esta professora a maior dificuldade esta em ensinar: "fazer o aluno comparar custo e beneficio frações, relações matemáticas, por serem muito abstratos". (Instrumento 1, Apêndice II)

Quanto às estratégias usadas pela professora em suas aulas, como aplicação desse conhecimento, ela cita a importância da cinética especialmente para a medicina, agricultura, pecuária, na preparação de alimentos/conservação, 
não usa atividade experimental em suas aulas sobre cinética química, mas sim, filmes e textos.

Em relação à História da Química (Instrumento 1, questão 9, Apêndice II), embora considere importante a sua inclusão no ensino, não a aborda em suas aulas. A professora não justificou a sua resposta.

Em relação a sua imagem sobre a natureza da ciência (instrumento 2, Apêndice VII), a professora escolheu as seguintes afirmações:

- O conhecimento científico se gera graças à capacidade que os seres humanos possuem para propor problemas e imaginar possíveis soluções aos mesmos. (R)

- Através do experimento, o investigador comprova se sua hipótese de trabalho é verdadeira ou falsa. (E/l)

- O método científico é um conjunto de etapas de atividades práticas e mentais que sem duvida alguma levará a um conhecimento verdadeiro. (E/I)

- As hipóteses dirigem o processo de investigação científica. (R)

Embora a professora veja a ciência como uma construção humana (Perspectiva $\mathrm{R}$ ), verifica-se em sua escolha a importância do método cientifico e da experimentação na construção do conhecimento científico (perspectiva E/I)

Pela análise das respostas da professora, observa-se que o modelo de ensino inicial está baseado, principalmente, nos aspectos macroscópicos da cinética química (MEM). Este modelo inicial de ensino é marcado tanto pela perspectiva filosófica empirista/indutivista (E/l) como a perspectiva racionalista (R).

\section{Fase intermediária}

Quanto à atividade 6 (quarto encontro, Apêndice $\mathrm{XI}$ ), a professora não mostrou ter o entendimento de como varia a velocidade de uma reação com 0 tempo, justificando que: "A velocidade da reação aumenta" conforme a reação vai transcorrendo (modelo de aumento - MA; Cakmakci et al, 2005). A sua explicação de como se dá a influência da temperatura na velocidade da reação é: "O aumento da temperatura acelera o tempo para a obtenção do éster", portanto, percebe-se que em suas explicações não aparece um modelo explicativo. 
$\mathrm{Na}$ atividade experimental 3, sobre o efeito da temperatura na velocidade de uma reação (quarto encontro, Apêndice XII ), suas explicações já incluem termos relacionados a partículas: "Aumenta o choque entre as moléculas." Contudo, ela não respondeu à questão que pedia que se utilizasse um modelo de partículas para explicar por que a transformação é mais lenta quando realizada em água gelada.

No próximo exercício sobre gráficos (exercício 1, quinto encontro, Apêndice $\mathrm{XV}$ ) a professora desenhou o seguinte gráfico:

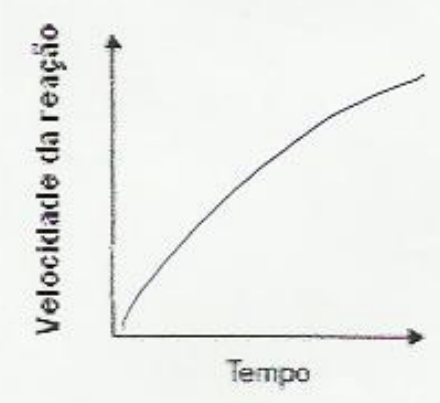

Figura 4.4 A variação da velocidade de uma reação em função do tempo segundo P2.

Percebe-se que o modelo de seu gráfico refere-se ao modelo de aumento MA (Cakmakci et al, 2005). Isto é, para ela no inicio da reação a velocidade é igual a zero, e com o passar do tempo, vai aumentando.

Sua justificativa para o seu desenho é: " $A$ concentração diminui com $o$ tempo. A reage com $B$ e transforma-se em $C$ ". Embora em sua explicação indique que a concentração de $A$ diminui, ela não relaciona essa informação com a construção do seu gráfico, ou seja, não relaciona a diminuição da concentração do reagente por unidade de tempo. Percebe-se também que ela não usa nenhum termo relacionado a partículas, ou um modelo teórico para explicar seu gráfico.

Em relação ao uso de artigos sobre a História da Química (atividade 1, primeiro encontro, Apêndice III), a professora indicou como usaria essa estratégia no ensino: "Colocando um exemplo atual e em seguida voltando ao passado para 
mostrar como foi o inicio". Percebe-se que para a professora o papel da HQ no ensino é o de mostrar o a origem do conhecimento científico (categoria C3).

No segundo encontro, os professores na atividade 2 (Apêndice $\mathrm{VI}$ ). A professora concordou com a ideia sobre a inclusão da HC no ensino de ciências defendida no documento justificando:

\begin{abstract}
São plausíveis. Desde que focadas no fato de que a química não é uma arma destrutiva, mas sim, um instrumento, uma ferramenta real, útil, usada cotidianamente e que se utilizada de forma construtiva, sustentável só tem a trazer melhoria da qualidade de vida das pessoas. Formação de elos com os contextos que lhes são significativos.
\end{abstract}

Para ela a dificuldade em abordar a está em: "Levar o aluno a fazer a ponte entre o antigo e o novo. São muito pouco reflexivos (os alunos). São hoje mais induzidos a serem críticos do que reflexivos".

Em relação ao mapa conceitual (atividade 4, terceiro encontro, Apêndice IX) a professora não construiu um esquema mas sim escreveu uma relação de ideias sobre a natureza da ciência que ela espera que seus alunos construam. Elas são:

- Que eles tenham consciência de que o consumo responsável, sustentável é vital para a sobrevivência;

- Que compreendam que os erros do passado não sejam mais cometidos por acomodação;

- Ter a visão que a única coisa constante no universo é a mudança. Todos, tudo muda o tempo todo no mundo.

Pela análise de suas afirmações acima, observa-se que a imagem sobre a natureza da ciência que a professora espera que seus alunos construam, podem estar relacionadas à perspectiva filosófica racionalista: "Ter a visão que a única coisa constante no universo é a mudança. Todos, tudo muda o tempo todo no mundo" (categoria 1, Quadro 3.3).

Sua imagem sobre a natureza da ciência, após a discussão (instrumento 3, Apêndice XIV) no quinto encontro, é:

Os métodos usados, sejam indutivistas/Racionalistas também são influenciados pelos interesses não só dos cientistas, mas também de quem financia ou necessita 
dessa pesquisa. As pessoas usam tanto a acumulação de teorias prévias, assim, como podem partir de uma observação de um fato novo, observado, e/ou um fato reobservado com um novo olhar.

Pode-se verificar no texto da professora a presença da ideia de que não existe um único método científico a ser seguido e que a ciência não é neutra perspectiva filosófica racionalista.

Nas respostas da professora, observa-se que seu modelo de ensino já começa a apresentar alguns aspectos microscópicos da cinética química, contudo a professora não usa um modelo teórico para explicar os conceitos relacionados a cinética química como, por exemplo, a ideia probabilidade de choque efetivo, que está presente na Teoria das Colisões, portanto, podemos caracterizar esse modelo de ensino como MEP: modelo de ensino pseudomicroscópico. Este modelo de ensino é caracterizado por uma perspectiva filosófica predominantemente racionalista $(R)$. Em relação ao papel da $H Q$ no ensino suas ideias são coerente com a categoria $\mathrm{C} 3$, mostrar ao aluno a origem do conhecimento científico.

\section{Fase final}

$\mathrm{Na}$ avaliação final (oitavo encontro, Apêndice XIX) a professora apontou em relação à cinética química: "que o curso permitiu visualizar a minha própria dificuldade e a dificuldade dos alunos".

Com relação a História da Química:

A falta de fontes ainda continua em parte, mas já obtive caminhos para continuar a buscar fontes e consultas. Quanto a materiais, estratégias o contato com os colegas abriu caminhos para o conhecimento e o uso de novas formas de agir. Obtive em parte no curso, assim como nos materiais divulgados pelas mestras que ministraram o curso.

Sobre quais aspectos relacionados à sua prática a professora refletiu através do curso, ela respondeu que refletiu:

Sob vários aspectos, como o tempo que leva para aplicar e de que forma, qual a linguagem, qual estratégia usar, buscando focar as dificuldades do dia-a-dia dos alunos, 
levando em conta que a cinética química é uma ferramenta útil sobre vários aspectos da vida diária.

\section{Plano de ensino}

Em relação ao plano de ensino (folha de atividade 8, Apêndice XVII) dessa professora, podem-se observar no quadro abaixo as habilidades $\mathrm{e}$ competências em relação aos conceitos de cinética química, a História da Química, e a visão sobre a natureza da ciência que a professora pretende que seus alunos desenvolvam:

\begin{tabular}{llc} 
Temas & Habilidade e competências & Análise \\
\hline $\begin{array}{l}\text { Conceitos da } \\
\text { cinética química }\end{array}$ & $\begin{array}{l}\text { Responsabilidade/sustentabilidade no uso de } \\
\text { materiais. Compreender reações. Rapidez da } \\
\text { velocidade de reação. Avaliar a influencia da } \\
\text { concentração dos reagentes. }\end{array}$ & MEM \\
$\begin{array}{l}\text { Visão sobre a } \\
\text { natureza da } \\
\text { ciência }\end{array}$ & $\begin{array}{l}\text { A ciência explica muitas coisas; A ciência é } \\
\text { instrumento útil quando usada de forma construtiva e } \\
\text { sustentável; Ética no uso da ciência. Interesses } \\
\text { econômicos versus sobrevivência. }\end{array}$ & C3 \\
$\begin{array}{l}\text { História da } \\
\text { Química }\end{array}$ & $\begin{array}{l}\text { Que a história também se faz todo dia; Se usa os } \\
\text { conhecimentos do passado para evitar repetirem-se } \\
\text { os erros do passado no presente. }\end{array}$ & E/l \\
\hline
\end{tabular}

Quadro 4.3 Habilidades e competências indicadas no plano de ensino da professora P2.

Em relação aos outros tópicos do plano dessa professora:

No seu plano de ensino a estratégia que a professora usa para trabalhar com a História da Química é a leitura e discussão de textos sobre o desenvolvimento de medicamentos:

Dois textos escritos com exercícios e com interpretação de texto. Que serão feitos na segunda, e quarta aulas, respectivamente. Texto "A semente mais antiga" Referências: $s$ it true that wheat from ancient Egyptian tombs can still grow? Texto 2 Introdução a medicina antienvelhecimento. Autor: Dr. Fernando de Almeidaendocrinologista.

Percebe-se que para a professora o papel da $H Q$, no seu plano de ensino é o de mostrar a origem do conhecimento científico (categoria C3). 
- Estratégias:

As outras estratégias usadas durante suas aulas são segundo a professora:

Aulas expositivas, com uso de textos, xérox de textos, e com efetuação de exercícios de cinética química. Uso de exemplos cotidianos. Abordagem contextualizada. Uso de exercícios, de cinética química. Uma aula com uma experiência de laboratório, e correção de exercícios, ao final da aula.

\section{- Conceitos:}

Velocidade média (cálculo), fatores que influem na velocidade de uma reação química, catalisador.

- Sequência das aulas:

Divido meu plano de aula em plano A e plano B: A parte A, vai para 4 aulas, duas de teoria e uma de laboratório e exercícios, uma quarta aula, para entrega de atividades, e debate, dividido entre pares e ímpares, na sala. A parte B, vai para 4 aulas de estudos de ensino de técnicas de estudos. Porque os alunos não sabem estudar. Onde uso exercícios, textos, um filme em DVD.

Em relação à imagem da ciência da professora P2, observa-se no seu plano que esse aspecto não é explicitamente abordado, mas pode-se observá-lo na maneira em que ela elaborou a sua sequência do ensino. No seu plano o papel do experimento é o de comprovar a teoria que já foi vista pelos alunos em aulas anteriores, e a habilidade valorizada no experimento é a de observação: "Objetivo do experimento: Observar a influencia da temperatura na velocidade das transformações ou reações" (plano de ensino, P2).

Percebe-se, portanto, no plano de ensino dessa professora, a influência da perspectiva filosófica empirista/indutivista (E/I).

Pela análise das respostas da professora, percebemos que no final do curso o seu modelo continuou coerente com o modelo de ensino macroscópico (MEM), percebe-se que houve apenas mudança nas estratégias empregadas.

Em relação à inclusão da Historia da Química em seu plano, observa-se que a professora fez uso de dois textos que estavam relacionados diretamente 
com o seu tema (medicamentos). O objetivo desses textos era o de fornecer aos alunos informações sobre a origem e o uso desses medicamentos (Categoria C3). Contudo, a História da Química, não é abordada como o eixo condutor de seu ensino (Gil Pérez, 1993).

No quadro a seguir podem ser observados, nos três momentos do curso de formação, os modelos de ensino dessa professora:

\begin{tabular}{|c|c|c|c|c|}
\hline ETAPA & INSTRUMENTOS & $\begin{array}{l}\text { CINÉTICA } \\
\text { QUÍMICA }\end{array}$ & $\begin{array}{l}\text { HISTÓRIA DA } \\
\text { QUÍMICA }\end{array}$ & $\begin{array}{l}\text { IMAGEM DA } \\
\text { CIÊNCIA }\end{array}$ \\
\hline \multirow{2}{*}{ INÍCIO } & INSTRUMENTO 1 & MEM & & \\
\hline & INSTRUMENTO 2 & & & $E / I, R$ \\
\hline \multirow{7}{*}{ DURANTE } & ATIVIDADE 1 & & $\mathrm{C3}$ & \\
\hline & ATIVIDADE 2 & & $\mathrm{C} 3$ & \\
\hline & ATIVIDADE 4 & & & $R$ \\
\hline & ATIVIDADE 6 & MEM & & \\
\hline & INSTRUMENTO 3 & & & $\mathrm{R}$ \\
\hline & EXPERIMENTO 3 & MEP & & \\
\hline & EXERCICIO 1 & MEM & & \\
\hline \multirow{2}{*}{ FINAL } & ATIVIDADE 8 & MEM & $\mathrm{C3}$ & $\mathrm{R}$ \\
\hline & PLANO DE ENSINO & MEM & $\mathrm{C3}$ & $E / I$ \\
\hline
\end{tabular}

Quadro 4.4. Modelos de ensino de cinética química do professor $\mathrm{P} 2$, em relação aos três aspectos analisados (cinética química, Historia da Química e imagem da ciência) nas diferentes etapas do curso de formação.

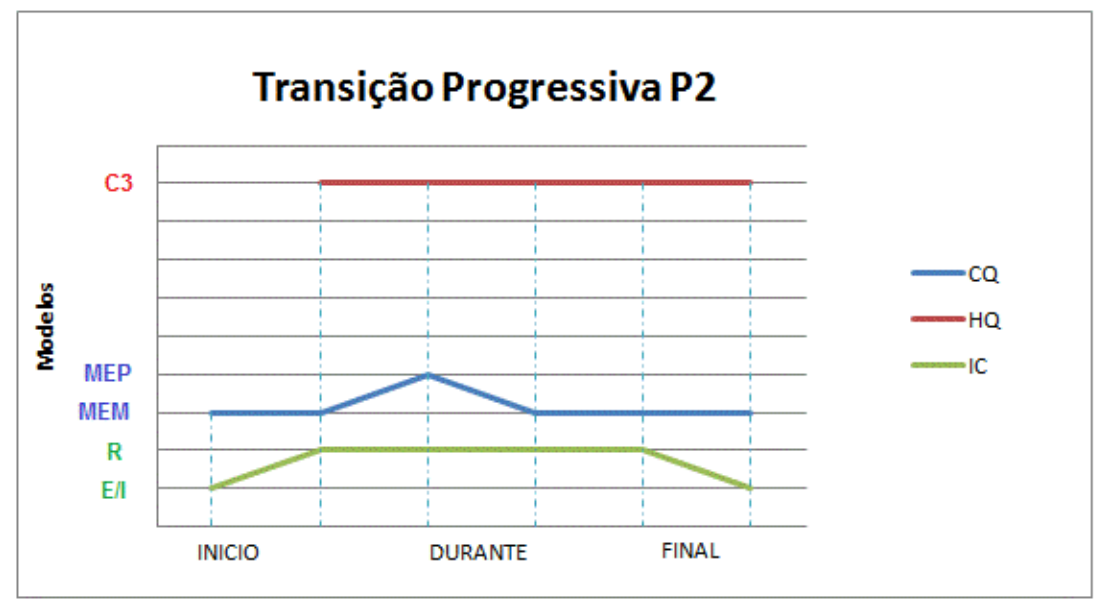

Figura 4.5 Transição progressiva da professora P2 nas três fases da pesquisa, em relação aos seguintes aspectos de seu modelo de ensino: $C Q$ : cinética química, $\mathrm{HQ}$ : História da Química e IC: imagem da ciência. 
Na figura acima observa-se que o curso de formação continuada facilitou a transição progressiva, na fase intermediária, principalmente no aspectos relacionados à imagem da ciência, embora na fase final pode ser observado uma retrocesso.

Em nenhum momento do curso, a professora usou em suas explicações um modelo teórico para explicar os fatores que interferem na velocidade de uma reação química. A única atividade em que apareceram termos relacionados a partículas foi a atividade experimental 3 (quarto encontro, Apêndice XII ): "Aumenta o choque entre as moléculas" (MEP). Verifica-se portanto, a dificuldade da professora em trabalhar com um modelo teórico. Nota-se que, embora a professora trabalhe com a representação matemática da velocidade média em seu ensino, segundo Peréz (2006), ela pode não ter o entendimento do avanço da reação em termo da variação da concentração de reagentes e produtos por unidade de tempo, e isso, segundo o autor, dificulta o professor transitar entre os níveis macroscópico e submicroscópico e simbólico da química.

Comparando-se o seu modelo de ensino inicial com o seu modelo final, em relação à cinética química, o único aspecto que sofreu mudança foi a estratégia empregada, nesse caso a inclusão de uma atividade experimental.

P3

\section{Fase inicial}

Para a professora P3 o ensino de cinética química é importante, pois: "Os alunos percebem como as transformações químicas acontecem, porque elas acontecem e o que é preciso para que elas ocorram" (Instrumento 1,questão 3, Apêndice II).

Quanto ao conteúdo que "O básico, velocidade, catalisadores, pois, é um conteúdo um pouco complp5ado, principalmente se eles não tiverem bons conhecimentos em química" (Instrumento 1, Apêndice II).ensina normalmente em suas aulas: 
Em relação ao conteúdo que é importante ensinar, ela acha importante falar inicialmente sobre: "as reações, equilíbrio químico, velocidade da reação, como a concentração interfere, justificando: São conteúdos que podem ser ligados com o cotidiano do aluno" (Instrumento 1, Apêndice II).

Para esta professora um dos conteúdos que ela indica que tem maior dificuldade em ensinar é o estudo do equilíbrio químico, porque, segundo ela: " $E$. muito difícil fazer o aluno imaginar como a reação pode ocorrer nos dois sentidos" (Instrumento 1, Apêndice II).

Em suas aulas, a estratégia normalmente usada é a experimentação (Concentração, superfície de contato, temperatura: Comprimido Efervescente; Catalisador: água oxigenada com fígado de boi). Quando questionada por que estes experimentos podem ajudar no ensino de cinética química ela aponta que: "Os alunos observam na prática como acontece e compreendem com maior facilidade o conteúdo". (Instrumento 1, Apêndice II).

Em relação à História da Química (Instrumento 1, questão 9, Apêndice II), embora ela considere importante a sua inclusão no ensino, "Acredito que até pode ajudar, pois fatos históricos podem marcar o conteúdo. Mas como as aulas de química são poucas, o tempo é escasso, a História da Química acaba não sendo abordada com tanta ênfase", ela afirma não usar em suas aulas.

Em relação a sua imagem sobre a natureza da ciência (instrumento 2, Apêndice VII), a professora escolheu as seguintes afirmações:

- Toda investigação científica começa pela observação rigorosa do fenômeno que se estuda.(E/I)

- O conhecimento científico se gera graças à capacidade que os seres humanos possuem para propor problemas e imaginar possíveis soluções aos mesmos.(R)

- Através do experimento, o investigador comprova se sua hipótese de trabalho é verdadeira ou falsa.(E/l)

- O método científico é um conjunto de etapas de atividades práticas e mentais que sem duvida alguma levará a um conhecimento verdadeiro.(E/I)

- As hipóteses dirigem o processo de investigação científica. (R) 
Pela análise das respostas da professora, observa-se que a fase inicial está baseada, nos aspectos macroscópicos da cinética química (MEM), pois o foco de seu ensino está somente na visualização do efeito de certos fatores (concentração, temperatura, sup. de contato e catalisadores) na velocidade de uma reação química. Ela não indica nenhum modelo explicativo.

Este modelo inicial de ensino é marcado tanto pela perspectiva filosófica empirista/indutivista (E/I) como a perspectiva racionalista $(R)$. Contudo, em relação ao papel da observação e do experimento pode-se perceber que a professora possui uma visão predominantemente empirista/indutivista, como podemos observar na justificativa dada por ela anteriormente para a importância da atividade experimental no ensino de cinética química: "Os alunos observam na prática como acontece e compreendem com maior facilidade o conteúdo". (P3, instrumento 1, Apêndice II). Pode-se inferir que o papel da $\mathrm{HQ}$ para esta professora, nesse momento do curso seria o de apenas atrair a atenção do aluno para um determinado conteúdo (categoria C1).

\section{Fase intermediária}

Quanto à atividade 6 (quarto encontro, Apêndice $\mathrm{XI}$ ), a professora mostrou não ter o entendimento de como varia a velocidade de uma reação com o tempo: "A velocidade da reação aumenta" (modelo de aumento - MA; Cakmakci et al, 2005). Sua explicação sobre a influência da temperatura na velocidade da reação é: "Quanto mais horas sujeito à alta temperatura, maior o rendimento". Percebese que, em suas explicações, não aparece um modelo explicativo.

$\mathrm{Na}$ atividade experimental 3, sobre o efeito da temperatura na velocidade de uma reação (quarto encontro, Apêndice XII ), sua explicação não inclui termos relacionados a partículas: "Quanto maior a temperatura dos reagentes, maior a velocidade da reação". Contudo, quando se pedia que utilizasse um modelo de partículas para explicar por que a transformação é mais lenta quando realizada em água gelada ela escreve: "Na água fria as partículas possuem menor agitação entre as moléculas".(MEP) 
$\mathrm{Na}$ próxima atividade (exercício 1, quinto encontro, Apêndice XV), a professora não soube responder, deixando-a em branco.

Em relação ao uso de artigos sobre a História da Química (atividade 1, primeiro encontro, Apêndice IIII), a professora indicou como usaria: "Para que os alunos percebam que os pesquisadores erravam muito para conseguir achar a resposta e quando descobriam verdades eram mal vistos".

As vantagens em se utilizar essa estratégia no ensino: "A história da pesquisa e dos pesquisadores pode trazer mais conhecimentos aos alunos".

No segundo encontro, os professores leram um documento oficial sobre o papel da $H Q$ no ensino de ciências (atividade 2, Apêndice VI). A professora concordou com a ideia defendida no documento justificando:

Sim, os alunos de hoje acham que as respostas deveriam ser mais fáceis e devido a era digital, onde as respostas são muito rápidas, eles querem também respostas e conteúdos rápidos, a abordagem da história mostra que as respostas não vem prontamente e são resultados de muitos erros e acertos. (categoria C4)

Para ela a dificuldade em abordar está em: "A resistência a conteúdos que devem ser pensados e analisados um pouco, com respostas que não prontas rapidamente e o tempo das aulas de química que passa muito rapidamente sem que o professor consiga passar todo o conteúdo".

$\mathrm{Na}$ atividade 4 (terceiro encontro, Apêndice IX), a professora construiu o seguinte mapa conceitual: 


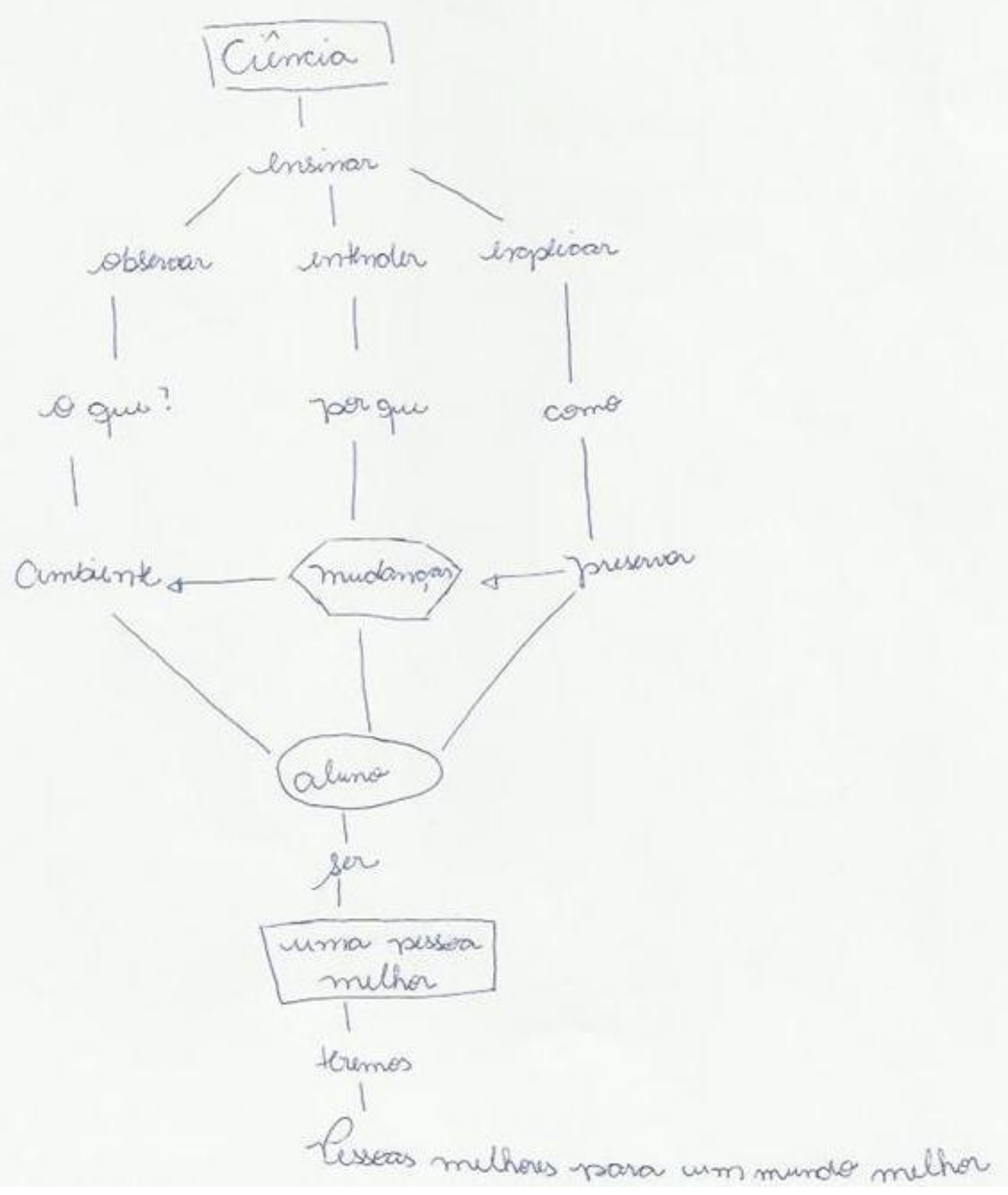

Figura 4.6 Mapa conceitual sobre a imagem da ciência elaborado pela professora P3.

Pela análise desse esquema, observa-se que a imagem sobre a natureza da ciência que a professora espera que seus alunos construam está relacionada, principalmente, a perspectiva filosófica empirista/indutivista, onde a ciência ensina o aluno a observar, entender e explicar o mundo em que ele vive. Nota-se nesse 
sequência a ideia do método científico, onde a partir da observação se elaboram as teorias.

Em outra atividade (instrumento 3, Apêndice XIV), após a discussão, foi solicitado que os professores escrevessem um pequeno texto, sobre a sua nova visão a respeito da natureza da ciência. A professora escreveu:

Ciência é o desenvolvimento do conhecimento, construindo a imagem correta ou não dos fenômenos. Pode-se desenvolver de duas maneiras, se tivermos uma ideia se como talvez possa acontecer, faremos ciência para comprovar, melhorar e perceber se a ideia anterior pode estar certa ou se está errada e pode ser melhorada. Fazer com que a ciência seja construída, percebendo que passo a passo, o conhecimento aumenta, mas com qualidade, mas que essa ideia pode ser alterada conforme os resultados obtidos.(grifo nosso)

No texto acima, pode se observar, que a sua imagem sobre a natureza da ciência está ligada fortemente à perspectiva empirista/indutivista, pois o conhecimento anterior é apontado por ela como sendo erros que devem ser corrigidos pelas novas teorias e o desenvolvimento da ciência, para essa professora, é visto de uma forma continua e acumulativa (categoria 2, Quadro 3.3).

Verifica-se então, que nessa fase o modelo de ensino da professora já começa a apresentar alguns aspectos microscópicos da cinética química, portanto, podemos caracterizá-lo como MEP: modelo de ensino pseudomicroscópico. Este modelo intermediário de ensino é caracterizado por uma perspectiva filosófica predominantemente empirista/indutivista (E/I). Pode-se notar, no texto da professora, que o papel da HQ nesse momento do curso seria o de conhecer a origem de um determinado conhecimento científico e como este foi sendo construído (categorias C3 e C4).

\section{Fase final}

$\mathrm{Na}$ avaliação final (oitavo encontro, Apêndice XIX) a professora apontou em relação à superação das dificuldades sobre o ensino de cinética química: 
"Com certeza foram superadas, principalmente os conceitos de teoria das colisões, além do material que nos ajudou a compreender melhor".

Quanto ao assunto da História da Química, ela diz: "Sim, textos e fontes de consulta da história da química e da ciência, e com esse conteúdo surgem ideias para estratégias de ensino."

Questionada sobre quais aspectos relacionados à sua prática a professora refletiu através do curso, ela respondeu: “Aumentar a parte da história e (o curso) ajudou-a fazer a ligação da história com o cotidiano do aluno e a fez refletir sobre a maneira de como ministrar as aulas de cinética".

\section{$\underline{\text { Plano de ensino }}$}

Em relação ao plano de ensino (folha de atividade 8, Apêndice XVII) dessa professora, podem-se observar no quadro a seguir as habilidades e competências em relação aos conceitos de cinética química, a História da química e a visão sobre a natureza da ciência, que a professora pretende que seus alunos desenvolvam:

Temas Habilidade e competências

Observar: fazer com que o aluno observe as reações e observe que há fatores que influenciam. Realizar: fazer com que o aluno realize e

Conceitos da cinética química

Visão sobre a natureza da ciência

História da Química observe o experimento e despertar o olhar mais crítico de como está acontecendo as reações e o que está influenciando, Compreender a cinética química de uma visão mais ampla e entender como acontece a reação e como os fatores podem interferir nas reações. Podendo explicar o que ele pode entender. Analise e interpretação de gráficos relacionados à cinética química e os fatores que influenciam. Fazer com que o aluno observe a ciência em seu cotidiano, relacionando o ensino de sala de aula com o seu dia a dia. Realizar comparações, levar o aluno a perceber a ligação entre o conhecimento histórico, o conteúdo de aula e o seu cotidiano, ele poderá perceber que a ciência não está fora de seu alcance.

Leitura e interpretação: texto com algum fator histórico ligado ao cotidiano e fazer com que o aluno observe e compreenda a Análise dificuldade da pesquisa e a dificuldade de mudar novos conceitos.

Quadro 4.5 Habilidades e competências indicadas no plano de ensino da professora P3.

Em relação aos outros tópicos do plano dessa professora:

- Conteúdo: 
Variáveis que podem modificar a rapidez de uma transformação química (concentração, temperatura, pressão, estado de agregação e presença do catalisador).

- Estratégias:

Levantamento das ideias prévias dos estudantes sobre o tema, experimentos, textos, laboratório de informática e mapa conceitual.

- Sequência das atividades:

1. Levantamento das ideias prévias dos estudantes sobre o tema: conhecer as ideias dos alunos sobre a influência de alguns fatores sobre a velocidade de uma reação química. Exemplos: "Por que as embalagens dos alimentos trazem o prazo de validade? Alimentos guardados na geladeira conservam-se por mais tempo?)Por que a lenha queima mais rapidamente quando abanamos o fogo?"

2. Experimento: Rapidez da transformação química envolvendo comprimido de vitamina $\mathrm{C}$ efervescente e água. Exemplos de questões direcionadas aos alunos: "Houve reação? Quais as observações que comprovam isso? O que aconteceu na reação? Podemos estabelecer se uma reação é mais rápida que a outra?"

3. Laboratório de informática: simulação, questões da atividade: O que acontece com as moléculas? Como elas estão nas diferentes temperaturas? Como elas estão nas diferentes concentrações?

4. Texto: Introdução da história da química.

Como o experimento é realizado com poucos recursos, podemos utilizar o exemplo dos grandes estudiosos da química para demonstrar seus estudos. Texto: Vida de cientista: Wilhelm Ostwald. Fonte: Reis, Martha - Química: Textos e Atividades Complementares. (plano de ensino, P3)

Nessa atividade não há um roteiro de como a professora pretende trabalhar com o texto em sala de aula. O papel da historia da química aqui serio de conhecer a origem de determinados conhecimentos científicos (categoria C3)

5. Mapa conceitual: feito pela própria professora para, segundo ela, contextualizar o conhecimento sobre cinética química: 


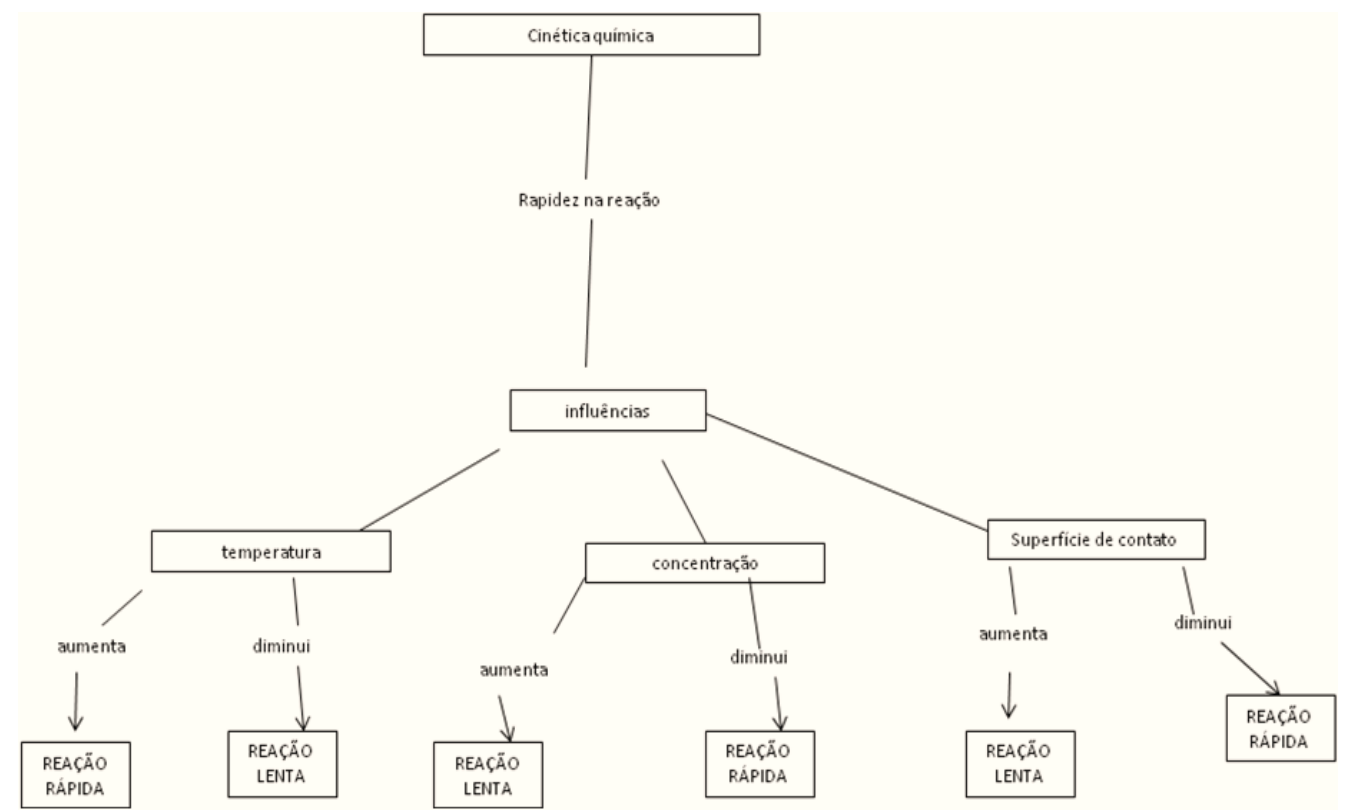

Figura 4.7 Mapa conceitual sobre o tema cinética química elaborado pela professora P3.

No esquema acima observa-se somente a relação entre os conceitos trabalhados por ela dentro do tema, e estes só estão relacionados aos aspectos macroscópicos de uma reação química.

Em relação à imagem da natureza da ciência, nessa fase final, percebe-se a preocupação da professora com que seus alunos vejam a ciência como uma construção humana que está presente no seu dia a dia (perspectiva racionalista):

Fazer com que o aluno observe a ciência em seu cotidiano, relacionando o ensino de sala de aula com o seu dia a dia. Realizar comparações, levar o aluno a perceber a ligação entre o conhecimento histórico, o conteúdo de aula e o seu cotidiano, ele poderá perceber que a ciência não está fora de seu alcance.

Contudo, observa-se ainda a grande importância que essa professora dá ao papel da observação na construção do conhecimento científico:

Observar: fazer com que o aluno observe as reações e observe que há fatores que influenciam. Realizar: fazer com que o aluno realize e observe o experimento e despertar o olhar mais crítico de como está acontecendo as reações e o que está influenciando.

Embora presente no seu plano, a História da Química não é abordada com a finalidade de possibilitar o desenvolvimento dos conceitos químicos (Gil Pérez, 
1993), mas sim como uma estratégia que pode substituir o uso de outra, como no caso de seu plano a experimentação.

O texto escolhido pela professora é um relato sobre a vida e a produção científica do cientista Wilhelm Ostwald, onde são discutidas algumas de suas ideias que geraram controvérsias no meio científico. Com a leitura e discussão desse texto, podem ser destacados alguns aspectos relacionados ao desenvolvimento do conhecimento científico e à influência da sociedade científica na aceitação de uma determinada teoria, entre outros.

Pela análise das respostas da professora, percebemos que no final do curso o seu modelo evoluiu do MEM para o MEP, quando ela incluiu em seu plano a atividade de simulação para trabalhar com o comportamento das moléculas quando se alteram determinados fatores (concentração e temperatura).

No quadro a seguir podem-se ser observados, nos três momentos do curso de formação, os modelos de ensino dessa professora:

\begin{tabular}{|c|c|c|c|c|}
\hline ETAPA & INSTRUMENTOS & CINÉTICA QUÍMICA & HISTÓRIA DA QUÍMICA & $\begin{array}{l}\text { IMAGEM DA } \\
\text { CIÊNCIA }\end{array}$ \\
\hline \multirow{2}{*}{ INICIO } & INSTRUMENTO 1 & MEM & C1 & \\
\hline & INSTRUMENTO2 & & & $E / I, R$ \\
\hline \multirow{7}{*}{ DURANTE } & ATIVIDADE 1 & & $\mathrm{C} 3, \mathrm{C} 4$ & \\
\hline & ATIVIDADE 2 & & C4 & \\
\hline & ATIVIDADE 4 & & & $E / I$ \\
\hline & ATIVIDADE 6 & MEM & & \\
\hline & INSTRUMENTO 3 & & & $E / I$ \\
\hline & EXPERIMENTO 3 & MEP & & \\
\hline & EXERCICIO 1 & - & & \\
\hline \multirow{2}{*}{ FINAL } & ATIVIDADE 8 & MEM & $\mathrm{C4}$ & $R$ \\
\hline & PLANO DE ENSINO & MEP & C3 & $E / I$ \\
\hline
\end{tabular}

Quadro 4.6 Modelos de ensino de cinética química do professor P3, em relação aos três aspectos analisados (cinética química, Historia da Química e imagem da ciência) nas diferentes etapas do curso de formação. 


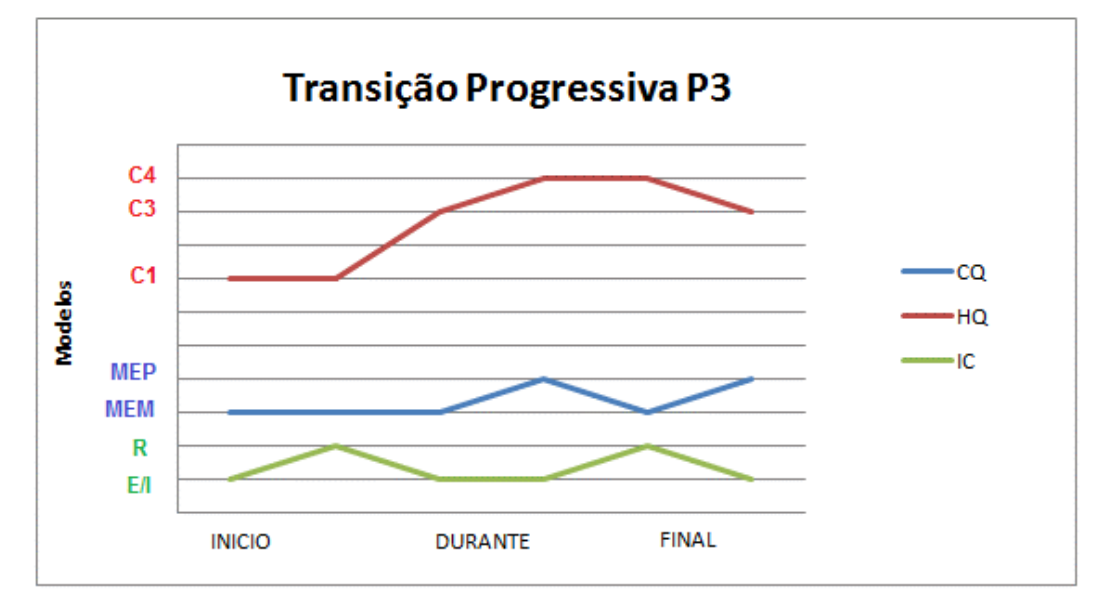

Figura 4.8 Transição progressiva da professora P3 nas três fases da pesquisa, em relação aos seguintes aspectos de seu modelo de ensino: $C Q$ : cinética química, $H Q$ : História da Química e IC: imagem da ciência.

Em relação a sua visão sobre a natureza da ciência (Fig. 4.8), percebe-se que a professora, embora durante o curso tenha expressado ideias relacionadas a perspectiva filosófica racionalista, ainda manteve pensamentos coerentes com a perspectiva filosófica empirista/indutivista principalmente aquelas relacionadas ao método científico.

Segundo Gil Pérez et al (p. 126, 2001): " as concepções dos estudantes incluindo as dos futuros docentes - não se afastam daquilo a que se pode chamar de uma imagem "folk", "naif" ou "popular" da ciência, associada a um suposto método científico, único, algorítmico, bem definido e quiçá, mesmo, infalível". Essa concepção, sobre o método científico, também foi encontrada em alguns professores desse grupo analisado, como por exemplo a professora P3.

\section{P4}

\section{Fase inicial}

Para a professora P4 o ensino de cinética química é importante: "Porque a velocidade é um fator importante em todos os aspectos da nossa vida, ainda mais trazendo os exemplos do próprio cotidiano". (Instrumento 1,questão 3, Apêndice II). 
Quanto ao conteúdo que é importante ensinar, ela destacou os fatores que alteram a rapidez de uma transformação química. Um dos conteúdos que ela indica que tem maior dificuldade em ensinar é: "Reações não elementares", porque, segundo ela: "O aluno acha difícil aceitar que o reagente $A$ é "mais poderoso" que o reagente B".

Quanto às estratégias usadas em suas aulas, como aplicação desse conhecimento, ela não as utiliza com frequência, mas indica que podem ser usados experimentos (Concentração: Solução de $\mathrm{CuSO}_{4}$ em diversas concentrações; Superfície de contato e temperatura: comprimido efervescente; Catalisador: Peróxido mais bife de fígado cru). O que ela normalmente faz em suas aulas é dar exemplos do cotidiano: "Introduzo o tema cinética com visualizações que o próprio aluno faz em seu cotidiano".

Quando questionada por que o experimento é importante no ensino de cinética química a resposta da professora é: "Para comprovar a teoria vista em sala de aula, "eu particularmente não uso experimentos para introduzir um assunto. Acho que os alunos ficam perdidos".

Com relação à História da Ciência, embora ela considere importante a sua inclusão no ensino, "Acredito que sim quando se tem um púbico focado no tema. Por exemplo, no curso técnico, onde eu trabalho, qualquer assunto relacionado à química produz interesse" (C1), ela afirma não usar em suas aulas.

Em relação a sua imagem sobre a natureza da ciência (instrumento 2, Apêndice VII), a professora escolheu as seguintes afirmações:

- A ciência tem evoluído historicamente mediante a acumulação sucessiva das teorias verdadeiras.(E/l)

- Toda investigação científica começa pela observação rigorosa do fenômeno que se estuda.(E/l)

- O conhecimento científico se gera graças à capacidade que os seres humanos possuem para propor problemas e imaginar possíveis soluções aos mesmos.(R)

- Através do experimento, o investigador comprova se sua hipótese de trabalho é verdadeira ou falsa.(E/l) 
- As hipóteses dirigem o processo de investigação científica.(R)

- Teorias científicas são derivadas, de um modo rigoroso, de fatos adquiridos pela observação e pela experimentação. (E/l)

Pela análise das respostas da professora, observa-se que o modelo do ensino inicial está baseado, principalmente, nos aspectos macroscópicos da cinética química (MEM). Este modelo inicial é marcado predominantemente pela perspectiva filosófica empirista/indutivista (E/I), pois sua justificativa para o uso da atividade experimental é coerente com à perspectiva filosófica empirista/indutivista: "Para comprovar a teoria vista em sala de aula...". Para ela o papel da $\mathrm{HQ}$ estaria relacionado a aumentar o interesse dos alunos sobre os conceitos ensinados (categoria C1).

\section{Fase intermediária}

Quanto à atividade 6 (quarto encontro, Apêndice XI), a professora não mostrou ter o entendimento de como se dá a variação da velocidade de uma reação com o tempo, justificando que: " $A$ Velocidade não varia. $A$ velocidade de formação do éster não é tão significativa em função do tempo porque ocorre o equilíbrio. Neste experimento a temperatura não varia”. (Modelo constante - MC; Cakmakci et al, 2005)

Na mesma atividade, a sua explicação de como se dá a influência da temperatura na velocidade da reação é: "Ambas as tabelas mostram que com o passar do tempo a quantidade de éster aumenta. Uma tabela expressa o tempo em dias, a outra em horas. Para a análise destas tabelas deve-se levar em conta, a temperatura. E no período de um ano (que a tabela contempla, temp. ambiente) ocorreram variações de temperatura”, mas percebe-se que ela não explica que com o aumento da temperatura diminui o tempo de produção da mesma quantidade de éster. Pode-se inferir que esta professora possui dificuldades em interpretar os dados da tabela. A sua explicação está baseada somente em aspectos macroscópicos de uma reação química.

$\mathrm{Na}$ atividade experimental 3, sobre o efeito da temperatura na velocidade de uma reação (quarto encontro, Apêndice XII ), suas explicações já incluem 
termos relacionados a partículas: "Aumenta a energia cinética das moléculas dos reagentes, fazendo com que elas se choquem mais eficientemente, e que a reação ocorra mais rapidamente" (MES1). Quando se pedia, o uso de um modelo de partículas para explicar por que a transformação é mais lenta quando realizada em água gelada, a professora escreveu:

$\mathrm{Na}$ água gelada a energia das partículas é menor, "não há muita mobilidade". Então a chance de estas moléculas serem "arrastadas" pelas moléculas de água é menor. Há menos choques e a velocidade (rapidez) da reação é menor.

No próximo exercício sobre gráficos (quinto encontro, Apêndice XV) a professora desenhou:

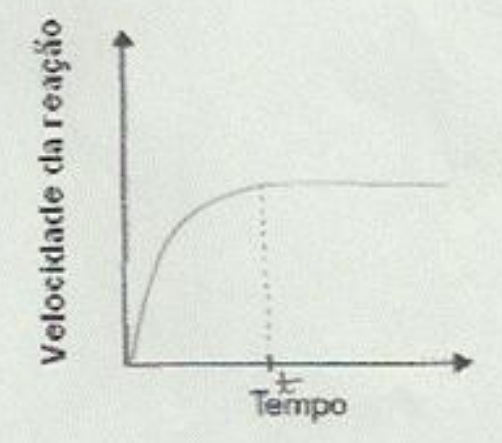

Figura 4.9 A variação da velocidade de uma reação em função do tempo segundo P4.

Percebe-se que seu gráfico refere-se ao modelo de aumento constante MAC (Cakmakci et al, 2005). Sua justificativa para esse modelo é:

No tempo zero o valor da velocidade é zero. Conforme os valores do tempo começam a variar os valores da velocidade aumentam, porque os reagentes A e B estão em grande quantidade e a chance de se chocarem são grandes. Está é uma reação que ocorre num só sentido, então as quantidades de reagentes diminuem e não são "repostas" . No tempo "t" todas as moléculas possíveis já se chocaram e neste caso a reação para de acontecer. Tem-se só produto no meio, caso A e B estejam em quantidades estequiométricas corretas.

$\mathrm{Na}$ justificativa da professora para a variação da velocidade da reação com o tempo, embora ela escreva que o aumento da velocidade se deve ao grande 
número de partículas que estão reagindo, ela afirma que no inicio da reação a velocidade é igual a zero. Segundo Cakmakci et al (2005), essa ideia pode estar relacionada à dificuldade da professora em pensar na reação química em termos de movimentos de partículas.

Em relação ao uso de artigos sobre a História da Química (atividade 1, primeiro encontro, Apêndice IIII), a professora indicou quais seriam as desvantagens em se utilizar essa estratégia no ensino: "Que a ciência é construída dia-a-dia não é pronta e acabada. É uma construção humana."

A desvantagem no uso dos artigos apontada pela professora é: "O aluno é muito imediatista, não quer ficar no vai-e-vem de erros e acertos".

No segundo encontro, os professores leram um documento oficial sobre 0 papel da HQ no ensino de ciências (atividade 2, Apêndice Vl). A professora concordou com a ideia defendida no documento, porem não justificou a sua resposta.

Para ela a dificuldade em abordar o assunto está no: "Tempo escasso, grande número de alunos numa sala e alunos desinteressados principalmente".

$\mathrm{Na}$ atividade 4 (terceiro encontro, Apêndice IX), a professora construiu o seguinte mapa conceitual: 


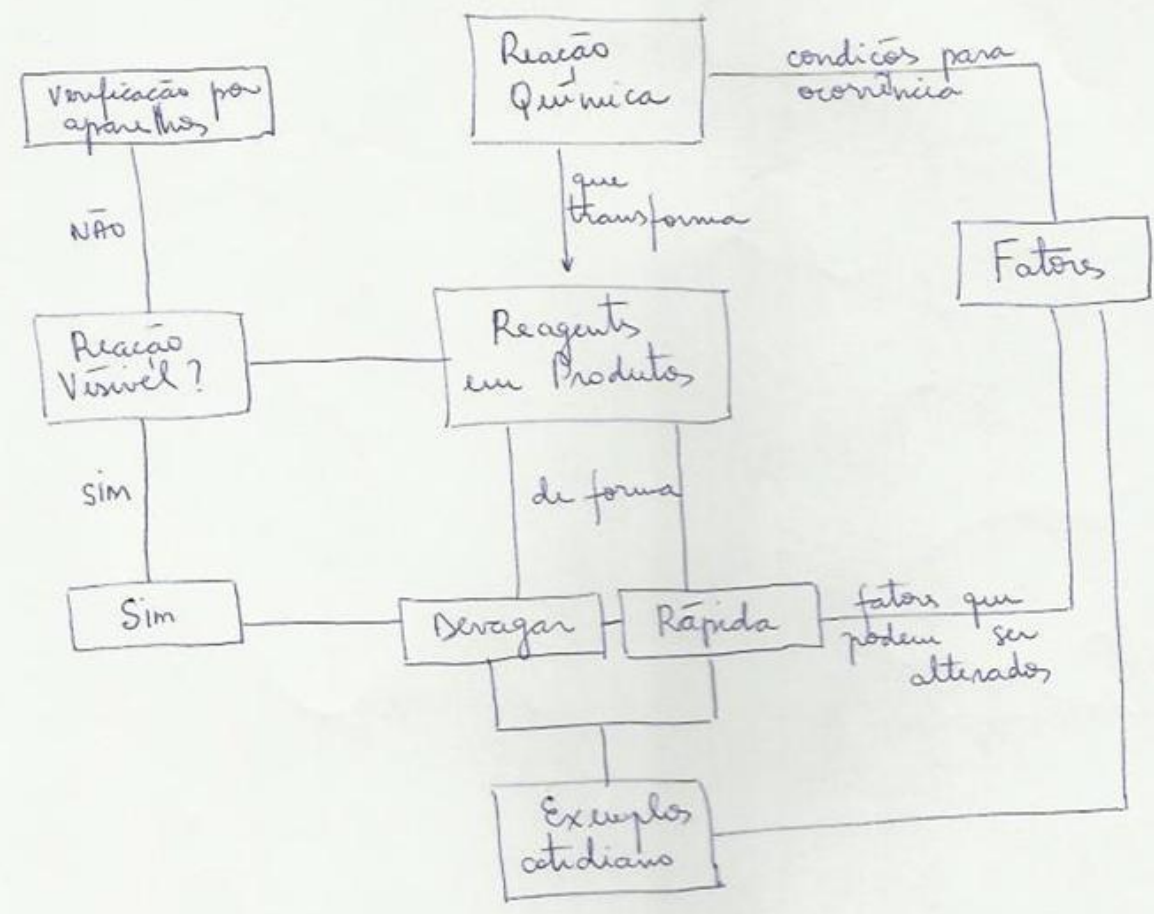

Figura 4.10 Mapa conceitual, sobre a imagem da ciência, elaborado pela professora P4.

Em seu mapa observa-se que a professora, não aponta as ideias sobre a natureza da ciência que ela espera que seus alunos construam, mas sim faz a relação entre os conceitos envolvidos no tema cinética química. Pode-se verificar a dificuldade da professora em discutir esse aspecto.

Sua imagem sobre a natureza da ciência, após a discussão (instrumento 3, Apêndice XIV) no quinto encontro, é:

Ciência é o conjunto de observações, teorias criadas a partir dessas observações e que se propõe a responder questões e resolver problemas. A ciência se desenvolve seguindo propósitos quer resolver problemas, ora de ordem econômica, ora para desbancar outras teorias. A ciência não é neutra é "política". Qualquer área da ciência é construída a partir da observação de fatos. Quando determinado experimento não comprova a teoria elaborada ou ele é abandonado (afinal não respondeu o que eu quero provar) ou ele nos faz rever a teoria. 
Observa-se no texto da professora, que suas ideias são coerentes principalmente, com a perspectiva filosófica empirista/indutivista (E/I), onde verifica-se a grande importância que ela dá a observação.

Pela análise de suas respostas, observa-se que o modelo de ensino intermediário já começa apresentar alguns aspectos microscópicos da cinética química, como a ideia de choque e de energia cinética das moléculas dos reagentes. Podemos, pois caracterizar esse modelo de ensino como MS1 (modelo de ensino submicroscópico 1). Esse modelo intermediário de ensino é caracterizado por uma perspectiva filosófica predominantemente Empirista/indutivista (E/I).

\section{Fase final}

$\mathrm{Na}$ avaliação final (oitavo encontro, Apêndice XIX) a professora apontou em relação à superação das dificuldades sobre o ensino de cinética química:

Temperatura e concentração são conceitos visíveis, sensíveis para os alunos. Colisão e geometria favorável é lógico, Complexo ativado que não entro muito nesse assunto, até porque não tenho profundidade no assunto. $O$ próprio conceito de catalisador é meio "mágico", sempre é dito que é uma substância adicionada ao meio e que acelera a reação, São fatores que muitos de nós não compreendem em profundidade para trabalhar em sala de aula.

Quanto à superação das dificuldades sobre o uso da História da Química:

O curso foi muito rico em termos de material didático, apesar de eu já ter bastante conteúdo que tiro das edições da química nova na escola. Vou ser sincera, sou resistente em algumas coisas, eu não me vejo discutindo "história da ciência", mas estou trabalhando mais aulas práticas no curso em geral.

Sobre quais aspectos relacionados à sua prática a professora refletiu através do curso, ela respondeu que refletiu sobre:

Introdução de assuntos ou através de textos contextualizados ou através de experimentos. Infelizmente os planos de ensino são formalidades, na prática de sala de aula é que determinamos o rumo a tomar. Esse curso me fez pensar em incluir mais aulas práticas, afinal o aluno é muito "concreto", tem que visualizar. E como temos grande 
parte dos alunos que não continuaram seus estudos no campo da química, ficará então esta lembrança das aulas.

\section{Plano de ensino}

Em relação ao plano de ensino (folha de atividade 8, Apêndice XVII) dessa professora, podem-se observar no quadro a seguir as habilidades e competências em relação aos conceitos de cinética química, História da Química e a visão sobre a natureza da ciência que a professora pretende que seus alunos desenvolvam:

\begin{tabular}{|c|c|c|}
\hline Tema & Habilidade e competências & Análise \\
\hline $\begin{array}{l}\text { Conceitos da } \\
\text { cinética } \\
\text { química }\end{array}$ & $\begin{array}{l}\text { Desenvolvimento de práticas. A partir da prática o aluno } \\
\text { criar a teoria. Conferir a "teoria criada" com o conteúdo } \\
\text { clássico dos livros. Cálculo de velocidade média. } \\
\text { Observação de que a reação para de acontecer porque } \\
\text { não há mais reaqentes. }\end{array}$ & MEM \\
\hline $\begin{array}{l}\text { Visão sobre a } \\
\text { natureza da } \\
\text { ciência }\end{array}$ & $\begin{array}{l}\text { Observação de um fato. Observação se este fato se } \\
\text { repete naturalmente. Reprodução deste fato (induzido). } \\
\text { Conclusão da observação. Criação de uma teoria para } \\
\text { explicar o fato. Conclusão: ciência é a observação e } \\
\text { formalização de um fato real. A ciência se propõe a } \\
\text { solucionar problemas, nunca é neutra. }\end{array}$ & $E / I$ \\
\hline $\begin{array}{l}\text { História da } \\
\text { Química }\end{array}$ & $\begin{array}{l}\text { Fazer o aluno compreender que a ciência é feita a partir } \\
\text { da observação de fatos, e pode ser considerada como } \\
\text { aceita se for reprodutível. O desenvolvimento da ciência } \\
\text { atende a determinados problemas vigentes ou tem uma } \\
\text { visão futurista. A ciência nunca é neutra. }\end{array}$ & $\mathrm{C} 2$ e $\mathrm{C} 4$ \\
\hline
\end{tabular}

Quadro 4.7 Habilidades e competências indicadas no plano de ensino da professora P4.

Em relação aos outros tópicos do plano dessa professora:

- Objetivos:

Fazer o aluno analisar a realidade a sua volta, identificando processos químicos que ocorrem visando a obtenção de materiais retirados da natureza; Levar o aluno a identificar em seu cotidiano bens de consumo que foram sintetizados pela indústria química.

- Conteúdo:

Reações de velocidades diferentes; fatores que influem na velocidade; cálculo da velocidade média das reações; colisões efetivas, energia de ativação, complexo ativado.

- Estratégias: 
Aula expositiva; experimentos (fatores que influem na velocidade, catálise); texto (exemplos de reações químicas no cotidiano); exercícios.

- Sequencia das atividades:

1.Introdução da aula com um pequeno texto sobre exemplos de reações de velocidades diferentes encontradas no cotidiano do aluno, seguido de questões. Com esse texto introdutório ao tema cinética eu induzo o aluno a observar os fatos e questionar se o ser humano pode interferir na velocidade dos processos químicos;

2. Aula: prática: cinco experimentos;

3.Formailização dos conceitos (variáveis) observados nas práticas, introdução de conceitos teóricos como colisões efetivas, energia de ativação, complexo ativado. Introdução ao cálculo da velocidade média das reações. Nos exercícios sobre velocidade média fazer o aluno perceber a diminuição da quantidade de reagentes com o passar do tempo. Construção de gráficos a partir de tabelas.

4.Atividade de avaliação.

Em relação à História da Química, embora fosse solicitado aos professores que a abordassem em seu plano a professora P4, não a incluiu, pois nas suas palavras: "Eu como professora vejo os alunos como pessoas muitos imediatistas, são muitos visuais, querem respostas rápidas. Particularmente não trato da história das ciências em minhas aulas".

Quanto a sua visão a respeito da a natureza da ciência, podemos avaliá-la através da sua justificativa, sobre a importância de aprender cinética química:

A ciência é a observação de um fato, a observação que este fato se repete naturalmente, a reprodução induzida deste fato e as conclusões que se pode tirar desta ação. A ciência nunca é neutra, sempre atende a um objetivo, não se faz ciência só por fazer. (P4, plano de ensino)

Pela análise das respostas da professora, percebemos que em seu plano de ensino seu modelo inicial que era MEM passou a ser MES2, contudo a sua imagem sobre a natureza da ciência permaneceu fortemente coerente com a perspectiva filosófica empirista/indutivista 
No quadro a seguir podem ser observados, nos três momentos do curso de formação, os modelos de ensino dessa professora:

\begin{tabular}{|c|l|c|c|c|}
\hline \multirow{2}{*}{ ETAPA } & INSTRUMENTOS & $\begin{array}{c}\text { CINÉTICA } \\
\text { QUÍMICA }\end{array}$ & $\begin{array}{c}\text { HISTÓRIA DA } \\
\text { QUÍMICA }\end{array}$ & IMAGEM DA CIÊNCIA \\
\hline \multirow{2}{*}{ INICIO } & INSTRUMENTO 1 & MEM & C1 & \\
\cline { 2 - 5 } & INSTRUMENTO 2 & & & E/I \\
\hline \multirow{5}{*}{ DURANTE } & ATIVIDADE 1 & & - & \\
\cline { 2 - 5 } & ATIVIDADE 2 & & & - \\
\cline { 2 - 5 } & ATIVIDADE 4 & & & E/I \\
\cline { 2 - 6 } & ATIVIDADE 6 & MEM & & \\
\cline { 2 - 6 } & INSTRUMENTO 3 & & & E/I \\
\cline { 2 - 6 } & EXPERIMENTO 3 & MES1 & & E/I \\
\cline { 2 - 6 } & EXERCICIO 1 & MES1 & & C2,C4 \\
\hline \multirow{2}{*}{ FINAL } & ATIVIDADE 8 & MEM & - & \\
\cline { 2 - 6 } & PLANO DE ENSINO & MES1, MES2 & - & \\
\hline
\end{tabular}

Quadro 4.8 Modelos de ensino de cinética química do professor P4, em relação aos três aspectos analisados (cinética química, Historia da Química e imagem da ciência) nas diferentes etapas do curso de formação.

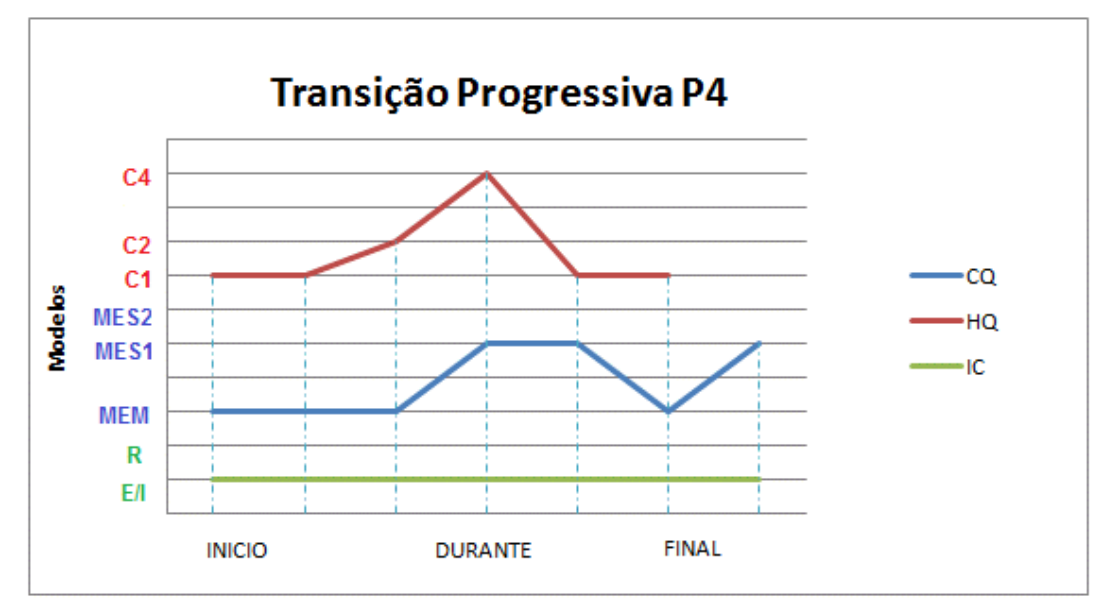

Figura 4.11 Transição progressiva da professora P4 nas três fases da pesquisa, em relação aos seguintes aspectos de seu modelo de ensino: $C Q$ : cinética química, $H Q$ : História da Química e IC: imagem da ciência.

Na figura acima, em relação à História da Ciência, verifica-se que, para a professora P4, ela é importante porque ajuda os alunos a entender como o conhecimento cientifico é construído, contudo, sua imagem da natureza da ciência está baseada na perspectiva filosófica empirista/indutivista: "Fazer o aluno 
compreender que a ciência é feita a partir da observação de fatos, e pode ser considerada como aceita se for reprodutível".

Sua imagem sobre a natureza da ciência, não sofreu alterações durante o curso de formação continuada, permanecendo até em seu plano de ensino, fortemente marcada pela perspectiva empirista/indutivista.

Em relação à cinética química, a professora passou a incluir em suas respostas e no seu plano de ensino, modelos teóricos para explicar os fatores que afetam a velocidade de uma reação química, o que não era usado por ela inicialmente. Outro ponto em que ocorreu mudança foi com relação às estratégias de ensino, no seu plano ela inclui textos e atividades experimentais:

Introdução de assuntos ou através de textos
contextualizados ou através de experimentos. Infelizmente
os planos de ensino são formalidades, na prática de sala de
aula é que determinamos o rumo a tomar. Esse curso me
fez pensar em incluir mais aulas práticas, afinal o aluno é
muito "concreto", tem que visualizar. E como temos grande
parte dos alunos que não continuarão seus estudos no
campo da química, ficará então esta lembrança das aulas.
(avaliação final, Apêndice XIX, P4)

Para a professora a função do experimento é coerente com a perspectiva filosófica empirista/indutivista: "Desenvolvimento de práticas. $A$ partir da prática $O$ aluno criar a teoria. Conferir a "teoria criada" com o conteúdo clássico dos livros". (P4,Quadro 3.3.)

Segundo Níaz (2009), ao abordamos como o conhecimento cientifico é construído estamos discutindo também sobre a filosofia da ciência, principalmente as metodologias de cada perspectiva filosófica. Assim, pela análise das atividades dessa professora percebe-se que a ideia da existência de um método científico único, rígido, é muito forte e para ela o papel da História da Química é o de mostrar essa construção.

\section{P5}

\section{Fase inicial}


Para o professor P5 o ensino de cinética química é importante porque: "No dia a dia, na construção de ideias, no manuseio de produtos que utilizam catalisadores, secantes, é importante ter uma ideia de cinética química" (Instrumento 1, questão 3, Apêndice II)

Embora ele não lecione (aluno da licenciatura), o conteúdo que ele acha importante ensinar é: "Acelerar uma reação química, fazer comparação como a indústria trabalha com isso". (MEM)

O professor indicou alguns experimentos para se trabalhar o conteúdo de cinética química. São eles: ação: decapagem de materiais metálicos; Pressão: comparar alimentos que são cozidos em panela de pressão ou panelas normais; Superfície de contato: ácido sulfúrico e magnésio em raspa ou sólido; Catalisador: fazer comparações de produtos como massa plástica e durepox.

Por que ajudam no ensino de cinética química?:"O aluno acaba entendendo que sempre está praticando química, fazendo comparações com o que ocorre normalmente no seu dia a dia".

Em relação à História da Ciência, ele considera importante a sua inclusão no ensino: "Pois você acaba fazendo comparações de como era feito antes no método experimental e com a evolução dos métodos para determinadas aplicações" (Instrumento 1, questão 9, Apêndice II).

Em relação a sua imagem sobre a natureza da ciência (instrumento 2, Apêndice VII), o professor escolheu as seguintes afirmações:

- A eficácia e a objetividade do trabalho científico consistem em seguir fielmente as fases ordenadas do método científico: observação, hipótese, experimentação e elaboração de teorias. (E/l)

- Toda investigação científica começa pela observação rigorosa do fenômeno que se estuda. (E/I)

- O conhecimento científico se gera graças à capacidade que os seres humanos possuem para propor problemas e imaginar possíveis soluções aos mesmos. (R)

- Através do experimento, o investigador comprova se sua hipótese de trabalho é verdadeira ou falsa. (E/l) 
- As hipóteses dirigem o processo de investigação científica. (R)

- Teorias científicas são derivadas, de um modo rigoroso, de fatos adquiridos pela observação e pela experimentação. (E/l)

Pela análise das respostas do professor, observa-se que nessa fase inicial seu modelo de ensino está baseado, principalmente, nos aspectos macroscópicos da cinética química (MEM). Este modelo inicial de ensino é marcado tanto pela perspectiva filosófica empirista/indutivista $(E / I)$ como a perspectiva racionalista (R). Em relação ao papel da $H Q$ no ensino, sua visão está relacionada a categoria C2: história da química pode ajudar o aluno a perceber que o conhecimento científico pode ser provisório.

\section{Fase intermediária}

Quanto à atividade 6 (quarto encontro, Apêndice XI), o professor não mostrou ter o entendimento de como se dá a variação da velocidade de uma reação com o tempo, justificando que: "A velocidade aumenta" (modelo de aumento - MA; Cakmakci et al, 2005) A sua explicação de como se dá a influência da temperatura na velocidade da reação é: "Comparando as duas tabelas, a reação ocorre em ambas, porém a que envolve a temperatura maior o rendimento é maior, pois a temperatura contribui para aumentar a velocidade da reação". Portanto, percebe-se que em suas explicações não aparece um modelo teórico.

$\mathrm{Na}$ atividade experimental 3, sobre o efeito da temperatura na velocidade de uma reação (quarto encontro, Apêndice XII ), suas explicações já incluem termos relacionados a partículas: "A temperatura aumenta a agitação das partículas no sistema”. Quando se pedia uma explicação com o uso de um modelo de partículas para explicar por que a transformação é mais lenta quando realizada em água gelada, o professor escreveu: “ $A$ transformação na água gelada ocorre mais lentamente, pois, as partículas estão mais presas, com grau de agitação menor". (MEP)

O professor não realizou o próximo exercício sobre gráficos (ex. 1, quinto encontro, Apêndice XV). 
Com relação ao uso de artigos sobre a História da Química (atividade 1, primeiro encontro, Apêndice IIII), o professor indicou como iria utilizar essa estratégia no ensino: "Como surgiu o conhecimento, como pode ser aplicado, qual o papel dele atualmente na evolução do homem; Relacionar a química buscando introduzir sobre a corrida do ouro, a busca da pedra filosofal; alguns fatos marcantes da história". (categorias C2 e C3 da HQ)

No segundo encontro, os professores leram um documento oficial sobre $o$ papel da $H Q$ no ensino de ciências (atividade 2, Apêndice $\mathrm{VI}$ ). O professor concordou com a ideia defendida no documento, justificando: "A proposta tenta passar como trabalhar o senso crítico do aluno, tentar buscar respostas para a ciência de hoje". (categoria C3 da HQ)

Ele aponta como uma dificuldade em abordar a historia da ciência no ensino: "A maior dificuldade, ao meu ver, seria deixar esses fatos históricos só na teoria. Deixar transparecer que hoje essa história um dia entrou em diversos conflitos científicos".

$\mathrm{Na}$ atividade 4 (terceiro encontro, Apêndice IX), o professor construiu o seguinte mapa conceitual: 


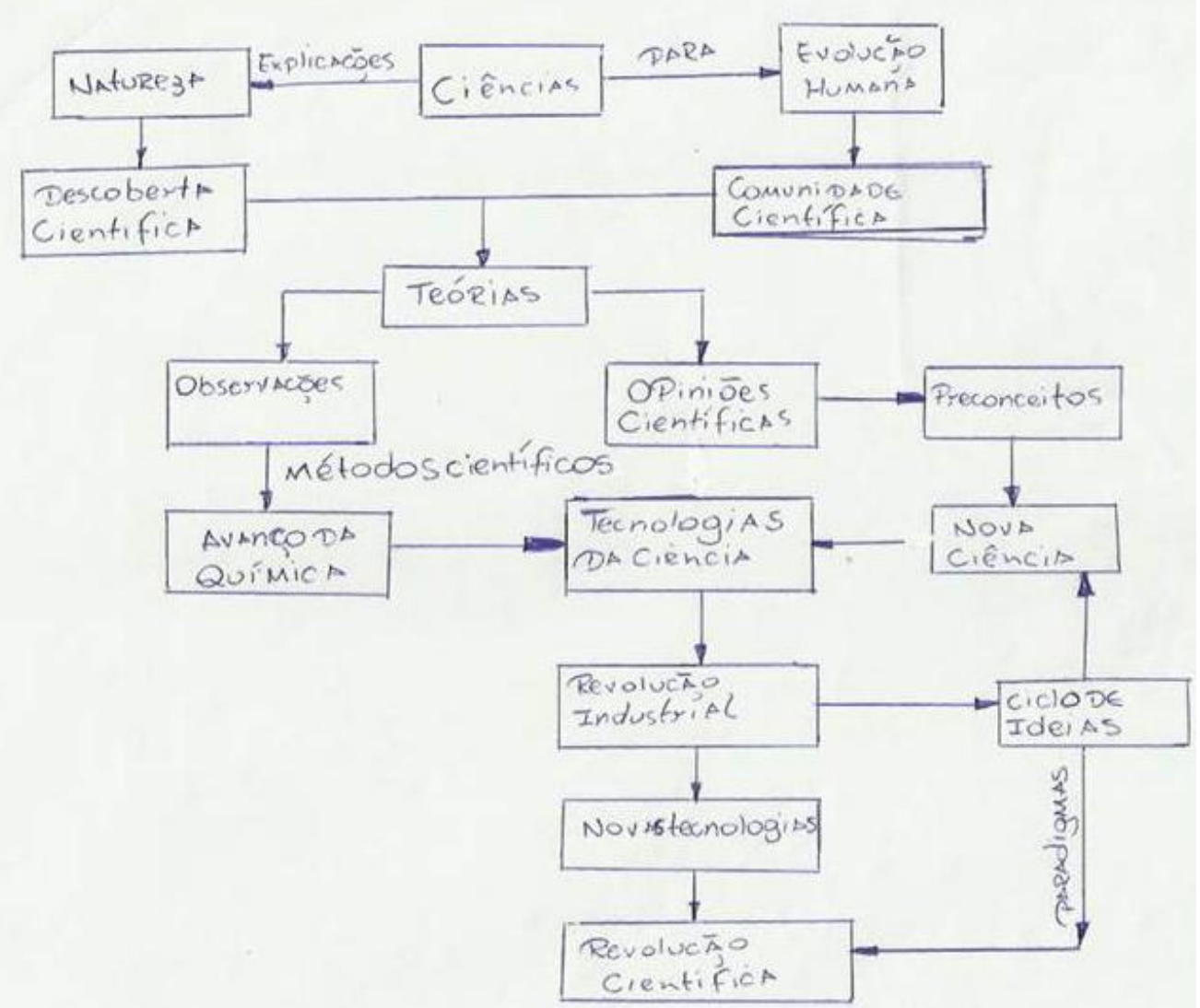

4.12 Mapa conceitual sobre a imagem da ciência elaborado pelo professor P5.

No esquema que representa o mapa conceitual que o professor P5 elaborou, observam-se ideias relacionadas a perspectiva filosófica racionalista, como, por exemplo, a ideia de revolução científica, da teoria orientando as observações e as influências no processo de escolha de teorias (opiniões científicas, preconceitos). O professor não respondeu o instrumento 3 (Apêndice VI), sobre a imagem da ciência aplicado no quinto encontro.

Verifica-se que no modelo do ensino desse professor, nessa fase intermediária, já aparecem termos relacionados a partículas em suas explicações, contudo, não ele não usa nenhum modelo teórico para explicar o comportamento dessas partículas: "A transformação na água gelada ocorre mais lentamente, pois, as partículas estão mais presas, com grau de agitação menor" (MEP). Este modelo é marcado pela perspectiva filosófica racionalista $(R)$. Suas ideias sobre o papel da HQ no ensino estão relacionadas as categorias C2 e C3. 


\section{Fase final}

$\mathrm{Na}$ avaliação final (oitavo encontro, Apêndice XIX) o professor apontou em relação à superação das dificuldades sobre o ensino de cinética química: "Acabei conhecendo uma nova maneira de trabalhar história da ciência com o conteúdo que vou aplicar".

Quanto à superação das dificuldades sobre o uso da História da Química: "As dificuldades ainda continuam, devido a esse material não ser acessível a todos. Como o curso foi específico ao estudo da cinética química o material foi muito proveitoso, excelente".

Sobre os aspectos relacionados à sua prática o professor respondeu que refletiu sobre: "Isso refletiu no conhecimento que obtive através do curso, e novos caminhos que posso seguir através desse aprendizado".

\section{Plano de ensino}

Em relação ao plano de ensino (folha de atividade 8, Apêncice XVII) desse professor, podem-se observar no quadro a seguir as habilidades e competências em relação aos conceitos de cinética química, História da Química e a visão sobre a natureza da ciência, que ele pretende que seus alunos desenvolvam:

\begin{tabular}{llc} 
Tema & Habilidade e competências & Análise \\
\hline $\begin{array}{l}\text { Conceitos da } \\
\text { cinética química }\end{array}$ & $\begin{array}{l}\text { Distinguir como a concentração e a temperatura influenciam } \\
\text { na velocidade de uma reação química. Habilidades de prática } \\
\text { laboratorial. Como ocorre a energia de ativação (importância } \\
\text { para uma reação química). Construir habilidades cognitivas. } \\
\text { Entendimento sobre superfície de contato e catalisadores. }\end{array}$ & MES1 \\
$\begin{array}{l}\text { Visão sobre a } \\
\text { natureza da } \\
\text { ciência }\end{array}$ & $\begin{array}{l}\text { Atividade contextual. Prática de leitura de texto científico. } \\
\text { Comparação entre passado, presente e futuro (como o ensino } \\
\text { de química está avançando). Importância do avanço da } \\
\text { ciência para o ser humano. }\end{array}$ & $\mathrm{R}$ \\
$\begin{array}{l}\text { História da } \\
\text { Química }\end{array}$ & $\begin{array}{l}\text { Entendimento contextual. Interpretação das atividades } \\
\text { propostas na sala. Senso crítico (praticar). }\end{array}$ & C3 \\
\hline
\end{tabular}

Quadro 4.9 Habilidades e competências indicadas no plano de ensino do professor P5.

Em relação aos outros tópicos do plano desse professor: 
- Objetivos:

Elaborar fundamentos sobre cinética química, desenvolver habilidades cognitivas, ser flexível para que o aluno possa desenvolver seu lado crítico.

- Conteúdos

$\mathrm{CQ}$ : Explicar para o aluno os fatores que alteram a velocidade de uma reação química, exemplos: •Temperatura;•Pressão;•Concentração;•Superfície de Contato;•Catalisador.

$H Q$ : usar um texto referente aos estudos de Jacobus $H$. van't Hoff, mostrar qual sua importância para o estudo da CQ.

- Estratégias:

Aula expositiva; questionário inicial; experimento, discussão do experimento; leitura do texto (van't Hoff); texto sobre teoria das colisões (Atkins); pesquisa (processos químicos que utilizam os fatores da CQ e sobre catalisadores; discussão do resultado da pesquisa (folder)).

- Sequência das aulas:

1‥ Aula: Passar uma breve explicação referente a cada tópico, explicando os fatores que alteram a velocidade de uma reação química. Aplicação de um questionário com cinco perguntas colocando em prática algumas questões que acontecem em nosso dia-a-dia;

2ª . aula: Retomada dos fatores que alteram a velocidade de uma reação química, fazendo um experimento em laboratório;

3a. Aula: Discussão do texto de van't Hoff: No final do experimento seria passado o texto de Jacobus Henricus Van't Hoff, e seria levantada uma questão para discussão em sala de aula e duas pesquisas:

1)Qual é a importância da cinética química para a indústria química de hoje, pesquisar processos químicos industriais que utilizam fatores da cinética química; 2)Pesquisa sobre catalisador, com entrega de folder.

Aplicação de um segundo texto referente a teoria das colisões e o conceito de energia de ativação. Nessa terceira aula serão passados os textos na lousa utilizando o livro de Peter Atkins: Questionado a vida moderna e o meio ambiente, Princípios da Química 3ำ edição. Observação: Nessa terceira aula o aluno vai obter conhecimento sobre teoria das 
colisões e conceito de energia de ativação, para o aluno ter uma visão microscópica das reações químicas.

4a. Aula: Atividade de Avaliação: O aluno terá nota participativa dos experimentos feitos em laboratório, do grupo de discussão e da pesquisa entregue sobre processos químicos e entrega do folder sobre catalisador.

Pela análise do plano de ensino desse professor percebe-se que seu modelo de ensino inclui um modelo teórico (MS1), quando ele aborda em seu plano a teoria das colisões (3a . Aula, plano de ensino, P5).

Em relação à História da Química, embora ele inclua o texto sobre van't Hoff no seu plano de ensino, percebe-se que o objetivo dessa atividade (leitura do texto), é somente o de informar sobre a vida do cientista e sobre a sua produção científica: “...Usar um texto referente aos estudos de Jacobus Henricus van't Hoff, artigo da Revista Química Nova na Escola, mostrar qual foi sua importância para estudo de cinética química" (plano de ensino,P5).

No plano desse professor, a História da Química não é abordada para desenvolver a aprendizagem dos conceitos químicos (Gil Pérez,1993), mas sim como fonte para se conhecer a origem de um conhecimento (categoria da História da Química C3).

Pode-se analisar a imagem sobre a natureza da ciência desse professor na sequência do seu plano de ensino, principalmente no que se refere ao papel da experimentação, que nesse caso é o de comprovar a teoria dada em sala de aula. Portanto, pode-se inferir que sua imagem é coerente com a perspectiva filosófica empirista/indutivista $(E / I)$.

No quadro a seguir, podem ser observados, nos três momentos do curso de formação, os modelos de ensino desse professor: 


\begin{tabular}{|c|c|c|c|c|}
\hline ETAPA & INSTRUMENTOS & $\begin{array}{l}\text { CINÉTICA } \\
\text { QUÍMICA }\end{array}$ & $\begin{array}{l}\text { HISTÓRIA DA } \\
\text { QUÍMICA }\end{array}$ & $\begin{array}{l}\text { IMAGEM DA } \\
\text { CIÊNCIA }\end{array}$ \\
\hline \multirow{2}{*}{ INICIO } & INSTRUMENTO 1 & MEM & $\mathrm{C} 2$ & \\
\hline & INSTRUMENTO 2 & & & $E / I, R$ \\
\hline \multirow{7}{*}{ DURANTE } & ATIVIDADE 1 & & $\mathrm{C} 2, \mathrm{C} 3$ & \\
\hline & ATIVIDADE 2 & & $\mathrm{C} 3$ & \\
\hline & ATIVIDADE 4 & & & $\mathrm{R}$ \\
\hline & ATIVIDADE 6 & MEM & & \\
\hline & INSTRUMENTO 3 & & & - \\
\hline & EXPERIMENTO 3 & MEP & & \\
\hline & EXERCICIO 1 & - & & \\
\hline \multirow{2}{*}{ FINAL } & ATIVIDADE 8 & MES1 & $\mathrm{C} 3$ & $\mathrm{R}$ \\
\hline & PLANO DE ENSINO & MES1 & $\mathrm{C} 3$ & $E / I$ \\
\hline
\end{tabular}

Quadro 4.10 Modelos de ensino de cinética química do professor P5, nas diferentes etapas do curso de formação.

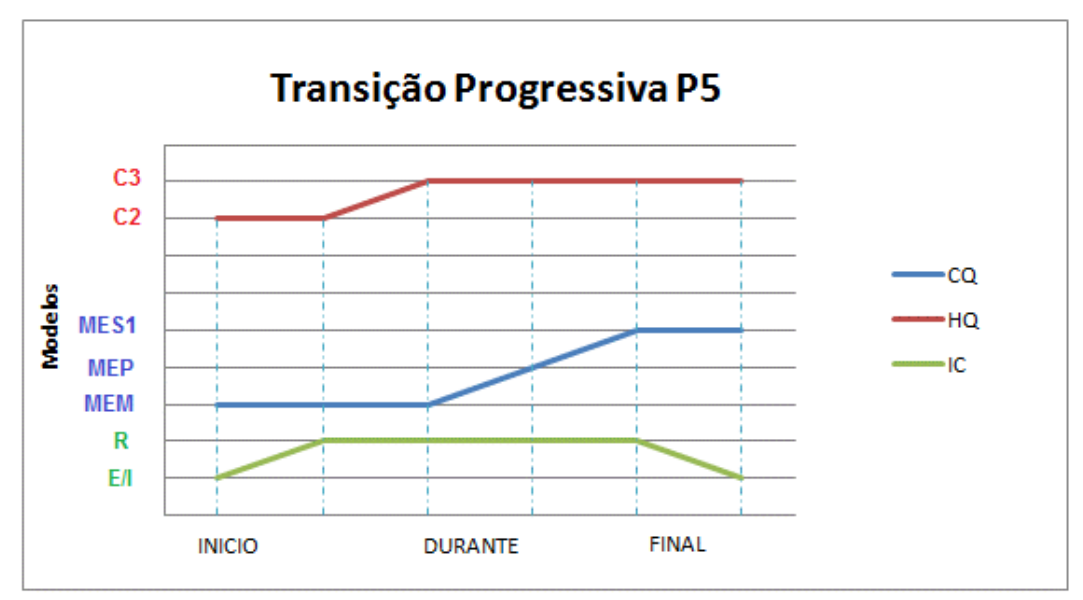

Figura 4.13 Transição progressiva do professor P5 nas três fases da pesquisa, em relação aos seguintes aspectos de seu modelo de ensino: $C Q$ : cinética química, $\mathrm{HQ}$ : História da Química e IC: imagem da ciência.

Na figura 4.13 observa-se que o curso de formação continuada facilitou a transição progressiva nos aspectos relacionados ao entendimento do papel da $\mathrm{HQ}$ no ensino e ao entendimento dos conceitos relativos à cinética química. Contudo, a sua imagem sobre a natureza da ciência que durante o curso passou a ser racionalista, no seu plano de ensino permaneceu coerente com a perspectiva empirista/indutivista. 
P6

Fase inicial

Para o professor o ensino de cinética química é importante: "Porque no próprio cotidiano do aluno ele se depara com situações que requerem esses conhecimentos" (Instrumento 1, questão 3, Apêndice II).

Quanto ao conteúdo que é importante ensinar, ele aponta: "Os fatores que influenciam a velocidade de uma transformação química são fundamentais”, pois, segundo ele: "São importantes porque contextualizam várias situações do cotidiano do aluno". E é esse conteúdo que ele normalmente aborda em suas aulas.(MEM).

Para este professor, um dos conteúdos que ele indica que tem maior dificuldade em ensinar é: "Quando envolve a questão da energia" porque o aluno, às vezes, não consegue entender a parte abstrata".

Quanto às estratégias usadas pelo professor em suas aulas, como aplicação desse conhecimento, ele cita alguns exemplos de produtos que podem ser obtidos na indústria de forma mais rápida ou mais lenta.

Quanto a experimentação para demonstrar os fatores que influenciam a velocidade de uma reação química, ele menciona: concentração: ácido Acético mais bicarbonato; Superfície de contato e temperatura: comprimido. Efervescente; Catalisador: catalase. Quando questionado por que o experimento é importante no ensino de cinética química sua resposta foi: "Porque o aluno consegue entender melhor quando visualiza algo".

Em relação à História da Ciência o professor considera que a sua inclusão no ensino:

É importante e pode ajudar muito, porque quando o aluno tem o conhecimento de onde surgiu determinado conceito teórico talvez desperte maior interesse e também é uma maneira dele entender que as teorias não são prontas e acabadas, mas elas vão sendo aprimoradas ao longo dos anos. (Instrumento 1, questão 9, Apêndice II). (categorias C2, C3 da Historia da Química) 
Quanto a sua visão sobre a natureza da ciência (instrumento 2, Apêndice VII), o professor escolheu as seguintes afirmações:

- Toda investigação científica começa pela observação rigorosa do fenômeno que se estuda.(E/I)

- O conhecimento científico se gera graças à capacidade que os seres humanos possuem para propor problemas e imaginar possíveis soluções aos mesmos. $(R)$

- Através do experimento, o investigador comprova se sua hipótese de trabalho é verdadeira ou falsa.(E/I)

- O método científico é um conjunto de etapas de atividades práticas e mentais que sem duvida alguma levará a um conhecimento verdadeiro.(E/I)

- Teorias científicas são derivadas, de um modo rigoroso, de fatos adquiridos pela observação e pela experimentação.(E/I)

- As teorias determinam quais experimentos são considerados legítimos e como eles devem ser conduzidos. Em outras palavras, não existem experimentos independentes de teorias. $(\mathrm{R})$

Pela análise das respostas do professor, observa-se que o nessa fase inicial seu modelo de ensino está baseado, principalmente, nos aspectos macroscópicos da cinética química (MEM). Este modelo pode ser caracterizado, principalmente pela perspectiva filosófica empirista/indutivista (E/I).

\section{Fase intermediária}

Quanto à atividade 6 (quarto encontro, Apêndice XI), o professor mostrou ter o entendimento de como se dá a variação da velocidade de uma reação com o tempo, justificando que: " $A$ velocidade diminui. $A$ variação de produto formado no começo da reação é maior do que no final" (modelo científico - MC; Cakmakci et al, 2005). A sua explicação de como se dá a influência da temperatura na velocidade da reação nesse mesmo exercício é: "A temperatura aumenta a velocidade da reação.", portanto, percebe-se que em suas respostas não aparece um modelo explicativo (MEM).

$\mathrm{Na}$ atividade experimental 3, sobre o efeito da temperatura na velocidade de uma reação (quarto encontro, Apêndice XII ), sua explicação não inclui termos relacionados a partículas: "Quanto maior a temperatura, mais rápida a 
dissolução". Quando, na mesma atividade se pedia uma explicação com o uso de um modelo de partículas para explicar por que a transformação é mais lenta quando realizada em água gelada, o professor escreveu: "Modelo de colisões, a temperatura influencia na agitação das moléculas, quanto maior agitação, maior o número de colisões, logo quanto menor a temperatura, menor o número de colisões" (MES1).

Portanto, o professor indica um modelo explicativo.

No próximo exercício sobre gráficos (quinto encontro, Apêndice $X V$ ) 0 professor desenhou o seguinte gráfico:

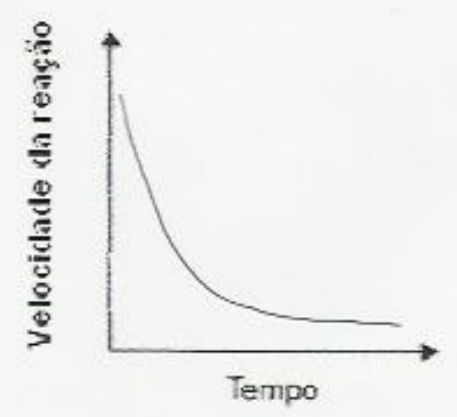

Figura 4.14 A variação da velocidade de uma reação em função do tempo segundo P6.

Percebe-se que o modelo de seu gráfico refere-se ao modelo científico MC (Cakmakci et al,2005). Sua justificativa para esse modelo é: "Diminuindo a concentração dos reagentes, diminui a probabilidade de colisões efetivas e assim diminui a velocidade da reação". (MES1)

Em relação ao uso de artigos sobre a História da Química (atividade 1, primeiro encontro, Apêndice III), o professor indicou como iria utilizar essa estratégia no ensino: "Ajudar os alunos além de entender a importância das teorias e conceitos em cada época, relacionem com as teorias atualmente aceitas".(C3, C4)

As vantagens dessa estratégia: A contextualização histórica dos conceitos atuais, se em trabalhados, estes podem ser compreendidos mais facilmente. 
No segundo encontro, os professores leram um documento oficial sobre o papel da HQ no ensino de ciências (atividade 2, Apêndice VI). O professor concordou com a ideia defendida no documento, Justificando: "Sim, pois permite o entendimento teórico como sendo passivo de mudanças com o decorrer do tempo".

Ele aponta como uma dificuldade em abordar a historia da ciência no ensino:

Os alunos muitas vezes trazem a ansiedade de saber logo aquilo que é aceito como verdadeiro para a época atual, quando se trata de ciência as vezes eles não querem saber sobre essas mudanças que ocorreram ao longo dos anos. O professor deve mostrar a importância de saber a historia da ciência ate mesmo para entender os conceitos estudados.

$\mathrm{Na}$ atividade 4 (terceiro encontro, Apêndice IX), o professor construiu o seguinte mapa conceitual:

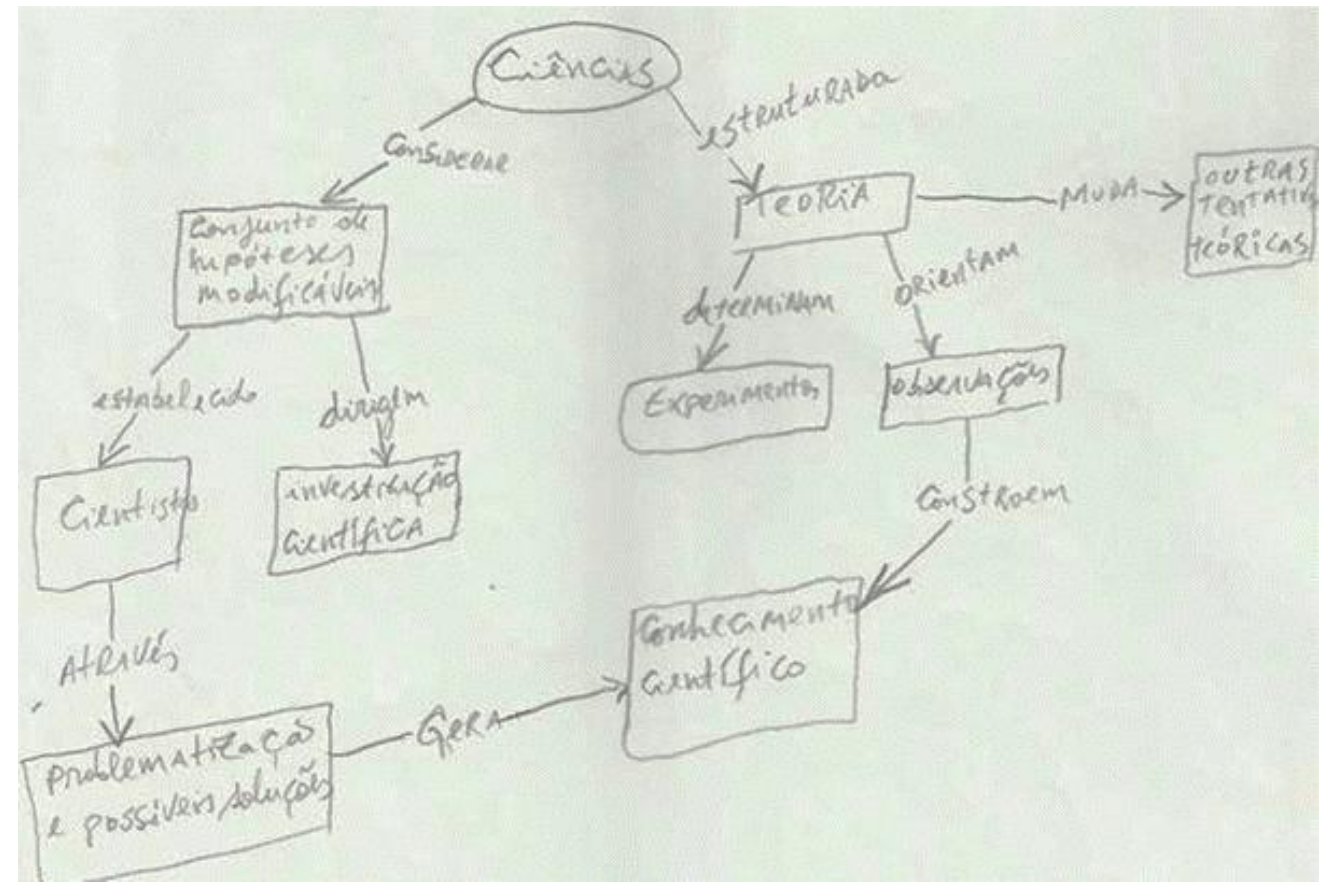

Figura 4.15 Mapa conceitual sobre a imagem da ciência elaborado pelo professor P6.

Pode-se observar em seu mapa conceitual, que suas ideias são coerentes com as ideias que pertencem à perspectiva filosófica racionalista: "ciência como 
um conjunto de hipóteses modificáveis", "construção do conhecimento cientifico a partir de teorias", "a teria determina os experimento", entre outras.

Sua imagem sobre a natureza da ciência, após a discussão (instrumento 3 , Apêndice XIV) no quinto encontro é: "A ciência é um conjunto de hipóteses que podem ser modificadas e organizadas e se desenvolve em observações que dependem das teorias". (perspectiva racionalista)

Pela análise das respostas do professor, percebe-se que seu modelo de ensino, nessa fase intermediária está baseado, principalmente, nos aspectos submicroscópicos da cinética química (MES1), onde já aparecem explicações com o uso da teoria das colisões. Este modelo é marcado principalmente pela perspectiva racionalista $(\mathrm{R})$.

\section{Fase final}

$\mathrm{Na}$ avaliação final (oitavo encontro, Apêndice XIX) o professor apontou em relação à superação das dificuldades sobre o ensino de cinética química: "Com relação aos modelos explicativos existentes as simulações foram muito importantes".

Com relação à superação das dificuldades sobre o uso da História da Química: "com certeza, principalmente a questão dos textos, fontes de consulta sobre a história da ciência, porque de muitos textos trabalhados no curso eu não tinha conhecimento".

Sobre quais aspectos relacionados à sua prática a professora refletiu através do curso, ele respondeu sobre: "A importância do conteúdo histórico da cinética química, o trabalho de alguns cientistas que tiveram grande importância e que eu não conhecia".

\section{Plano de ensino}

Quanto ao plano de ensino (folha de atividade 8, Apêncice XVII) desse professor, podem-se observar no quadro a seguir as habilidades e competências em relação aos conceitos de cinética química, a História da química e a visão sobre a natureza da ciência ele pretende que seus alunos desenvolvam: 
Conceitos da cinética

química

Visão sobre a natureza da ciência

História da química
Compreender que as transformações químicas (TQ) ocorrem

MEP com velocidades diferentes e as descobertas ao longo dos anos sobre o comportamento das moléculas dos reagentes e produtos em uma TQ. Entender os fatores que influenciam a rapidez dessas transformações químicas.

Entender que a ciência não é pronta e acabada, mas está sempre em mudança. Conhecimento científico é uma construção humana. velocidades das reações químicas e os fatores que influenciam a velocidade.

Quadro 4.11 Habilidades e competências indicadas no plano de ensino do professor P6.

Em relação aos outros tópicos do plano:

- Objetivos:

CQ: Levar o aluno a compreender os fatores que influenciam na rapidez das transformações químicas.

HFC: Compreendendo também as mudanças no conceito de $C Q$ ao longo dos anos e permitir ao aluno a construção de uma visa racionalista da ciência (em relação à experimentação)

- Conteúdos:

$\mathrm{CQ}$ : Fatores que alteram a velocidade de uma reação química (temperatura, concentração e superfície de contato); HFC: estudos iniciais na cinética química.

Estratégias: Questionamento inicial, experimentação investigativa; textos sobre o conteúdo histórico da cinética química (CQ); texto sobre a natureza da ciência (Chalmers); vídeo de experimento (relógio de iodo).

- Sequência das atividades no plano de ensino:

Primeira aula: expor aos alunos algumas questões para levantamento de ideias prévias sobre a descoberta da Cinética Química. Por exemplo: As transformações químicas sempre foram estudadas considerando a rapidez? Você tem ideia de quando iniciaram os estudos sobre a rapidez das transformações químicas? 
Segunda aula: fazer uma leitura compartilhada do texto: os estudos iniciais: o reconhecimento da cinética química como campo da química .

Terceira e quarta aula: Apresentar por meio da experimentação, alguns fatores que influenciam na rapidez das transformações químicas (temperatura, superfície de contato e concentração).

Quinta aula: Conteúdo referente à visão de Ciências: Propor aos alunos a leitura do texto: Observação e experimento orientam-se pela teoria (A.F.Chalmers - O que é Ciência afinal; p. 59,60). Depois da leitura, propor um debate com os alunos acerca da importância da teoria na realização de uma observação e de um experimento.

Pela análise do plano de ensino desse professor percebe-se que seu modelo e ensino não inclui um modelo teórico (MEM), pois ele indica que será estudado apenas o desenvolvimento histórico da cinética química correspondente ao primeiro período (1850-1862).

No plano dele, a abordagem dos conceitos relativos a cinética química é feita através do desenvolvimento histórico da mesma (Gil-Pérez,1993).

No quadro a seguir podem ser observados, nos três momentos do curso de formação, os modelos de ensino desse professor:

\begin{tabular}{|c|c|c|c|c|}
\hline ETAPA & INSTRUMENTOS & $\begin{array}{l}\text { CINÉTICA } \\
\text { QUÍMICA }\end{array}$ & $\begin{array}{l}\text { HISTÓRIA DA } \\
\text { QUÍMICA }\end{array}$ & $\begin{array}{l}\text { IMAGEM DA } \\
\text { CIÊNCIA }\end{array}$ \\
\hline \multirow{2}{*}{ INICIO } & INSTRUMENTO 1 & MEM & $\mathrm{C} 2, \mathrm{C} 3$ & \\
\hline & INSTRUMENTO2 & & & $E / I$ \\
\hline \multirow{7}{*}{ DURANTE } & ATIVIDADE 1 & & $\mathrm{C} 3, \mathrm{C} 4$ & \\
\hline & ATIVIDADE 2 & & $\mathrm{C} 2$ & \\
\hline & ATIVIDADE 4 & & & $\mathrm{R}$ \\
\hline & ATIVIDADE 6 & MEM & & \\
\hline & INSTRUMENTO 3 & & & $\mathrm{R}$ \\
\hline & EXPERIMENTO 3 & MES1 & & \\
\hline & EXERCICIO 1 & MES1 & & \\
\hline \multirow{2}{*}{ FINAL } & ATIVIDADE 8 & MEP & $\mathrm{C} 3$ & $\mathrm{R}$ \\
\hline & PLANO DE ENSINO & MEM & $\mathrm{C4}$ & $\mathrm{R}$ \\
\hline
\end{tabular}

Quadro 4.12 Modelos de ensino de cinética química do professor P6, nas diferentes etapas do curso de formação. 


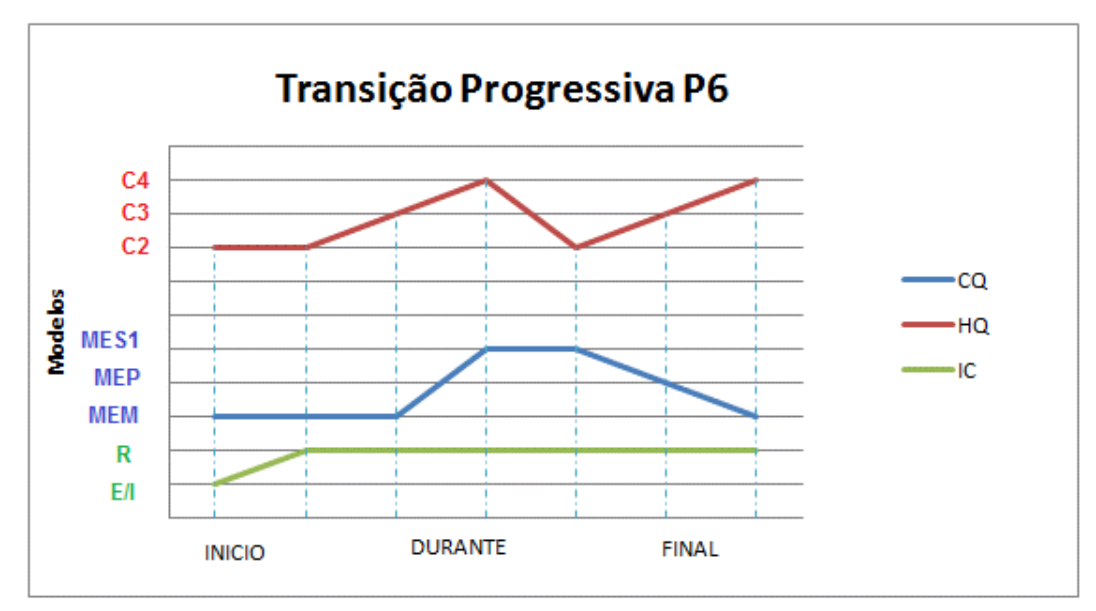

Figura 4.16 Transição progressiva do professor P6 nas três fases da pesquisa, em relação aos seguintes aspectos de seu modelo de ensino: $C Q$ : cinética química, $H Q$ : História da Química e IC: imagem da ciência.

Na figura 4.16 observa-se que o curso de formação continuada facilitou a transição progressiva nos aspectos relacionados ao entendimento do papel da $\mathrm{HQ}$ no ensino como também promoveu a transição em sua imagem sobre a natureza da ciência, que no inicio do curso era referente à perspectiva E/l, passando a ser racionalista $(R)$ na fase intermediária, mantendo-se assim até a fase final.

Em relação ao entendimento relacionado ao tema cinética química, percebe-se que o professor pode ter enfrentado alguma dificuldade em incluir em seu plano de ensino, um modelo teórico para explicar a velocidade de uma reação química. Observa-se que ele escolheu trabalhar somente o primeiro período do desenvolvimento histórico da cinética química, onde só são abordados os aspectos macroscópicos do estudo da velocidade de uma reação química.

\section{P7}

\section{Fase inicial}

Para a professora o ensino de cinética química é importante:

Porque os conhecimentos sobre Cinética Química envolvem vários conceitos como ocorrem a formação das substâncias, 
fatores que interferem na cinética como temperatura, pressão e concentração dos reagentes e a utilização dos catalisadores. (Instrumento 1,questão 3, Apêndice II).

Quanto ao conteúdo que é importante ensinar, ela aponta: "Acredito que tudo seja importante. A construção de todos os conceitos e dos fatores determinantes e que interferem na cinética química". Conteúdo que ela normalmente aborda em suas aulas: colisões efetivas, energia de ativação, fatores que influenciam na velocidade das reações: temperatura, pressão, concentração e sup. de contato. Utilização de catalisadores.(MES1)

Um dos conteúdos que ela indica que tem maior dificuldade em ensinar é: "Diferenciar as energias de ativação", porque, segundo ela é difícil para o aluno a interpretação das etapas em que a reação pode ocorrer: “

Para demonstrar os fatores que influenciam a velocidade de uma reação química: concentração, ela aponta: "Já utilizei práticas de como demonstrar a interferência da temperatura e as superfícies de contato na velocidade de uma reação química, experimento com comprimidos efervescentes".

Quando questionada por que o experimento é importante no ensino de cinética química sua resposta é: "Os experimentos ilustram os conceitos trabalhados em sala de aula e despertam o interesse dos alunos para 0 aprendizado".

Em relação ao papel da História da Ciência (Instrumento 1,questão 9, Apêndice II), a professora considera que a sua inclusão no ensino: "Pode ajudar porque através da história podemos desvendar como foram construídos os conceitos teórica e experimentalmente" (categoria C4 da HQ).

Em seu ensino atual sobre cinética química ela afirma trabalhar com a História da Ciência. Essa foi a única professora desse grupo de professores que afirmou usar História da Química em suas aulas.

Em relação a sua imagem sobre a natureza da ciência (instrumento 2, Apêndice VII), a professora escolheu as seguintes afirmações: 
- O conhecimento é construído com base em teorias que orientam a observação, em outras palavras, uma observação depende da teoria. $(R)$

- Toda investigação científica começa pela observação rigorosa do fenômeno que se estuda. (E/I).

- O conhecimento científico se gera graças à capacidade que os seres humanos possuem para propor problemas e imaginar possíveis soluções aos mesmos. (R)

- Através do experimento, o investigador comprova se sua hipótese de trabalho é verdadeira ou falsa. (E/I)

- Teorias científicas são derivadas, de um modo rigoroso, de fatos adquiridos pela observação e pela experimentação. (E/l)

Pela análise das respostas da professora, observa-se que o modelo do ensino inicial está baseado, principalmente, nos aspectos submicroscópicos da cinética química (MES1). Este modelo inicial pode ser caracterizado, principalmente pela perspectiva filosófica empirista/indutivista (E/I).

\section{Fase intermediária}

Quanto à atividade 6 (quarto encontro, Apêndice $\mathrm{XI}$ ), a professora não mostrou ter o entendimento de como se dá a variação da velocidade de uma reação com o tempo, justificando que: “ $A$ velocidade de formação do ácido esterificado se mantém com o decorrer do tempo" (modelo de aumento constante - MAC; Cakmakci et al, 2005). A sua explicação de como se dá a influência da temperatura na velocidade da reação nesse mesmo exercício é:

Na temperatura ambiente a porcentagem de ácido
esterificado formado é menor e o tempo da duração da
experiência é maior. Na experiência realizada a $100^{\circ} \mathrm{C}$, a
porcentagem de ácido esterificado formado é maior e o
tempo de duração da experiência é menor. Não existe uma
constante em relação ao tempo e a quantidade formada.

Portanto, percebe-se que em suas explicações não aparece um modelo explicativo, nem termos relativos a partículas (MEM).

$\mathrm{Na}$ atividade experimental 3, sobre o efeito da temperatura na velocidade de uma reação (quarto encontro, Apêndice XII ), sua explicação não inclui termos relacionados a partículas: "Quanto maior a temperatura, maior a velocidade da 
reação". Quando, na mesma atividade se pedia uma explicação com o uso de um modelo de partículas para explicar por que a transformação é mais lenta quando realizada em água gelada, o professor escreveu: " $A$ água gelada diminui $O$ choque, colisões, entre as partículas". Portanto, a professora indica termos relacionados a um modelo explicativo, nesse caso a teoria das colisões (MES1).

No próximo exercício sobre gráficos (quinto encontro, Apêndice $X V$ ) a professora desenhou o seguinte gráfico:

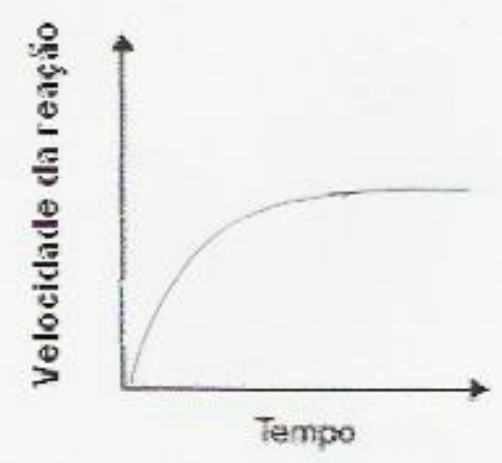

Figura 4.17 A variação da velocidade de uma reação em função do tempo segundo P7.

Percebe-se que o modelo de seu gráfico refere-se ao modelo de aumento constante - MAC (Cakmakci et al,2005). Sua justificativa para esse modelo é:
A ideia é que com o passar do tempo a velocidade aumenta e se estabiliza, pois no inicio existe a interação entre $A$ e $B$ acontecendo onde haverá maior concentração dos reagentes e após a formação do produto $\mathrm{C}$ a transformação atingirá o equilíbrio, estabilizando a velocidade em relação ao tempo. A princípio quando a transformação química se dá o número de choques entre os reagentes $\mathrm{A}$ e $\mathrm{B}$ é maior por estar em maior quantidade, interferindo também na velocidade. (grifo nosso)

Nas explicações da professora a ideia de que a velocidade de reação vai aumentando ficando constante e atingindo o equilíbrio, aparece tanto na atividade 6 como também no exercício 1. No caso do exercício 1 a reação genérica representada não indicava a ocorrência de equilíbrio químico (no caso a seta dupla). No instrumento inicial, quando questionados sobre quais conceitos relativos à cinética química os professores possuíam dificuldade em ensinar, 
muitos destes apontaram que tinham dificuldade em trabalhar com o equilíbrio químico. Percebe-se aqui uma confusão na interpretação desses conceitos que são distintos, a velocidade de uma reação e o estado de equilíbrio químico.

Em relação ao uso de artigos sobre a História da Química (atividade 1, primeiro encontro, Apêndice IIII), a professora indicou como iria utilizar essa estratégia no ensino: "Pode ser utilizados para explicar o princípio dos conceitos da química. De onde surgiram as primeiras hipóteses e investigações para chegar a formação do conceito". (categoria C3 da História da Química)

A sua ideia sobre o papel da $\mathrm{HQ}$, portanto, está relacionada à origem dos conhecimentos científicos. As vantagens dessa estratégia: "Mostrar como é feito o trabalho das ciências, todos os avanços, erros e conflitos". A professora não indicou haver desvantagens nessa estratégia.

No segundo encontro, os professores leram um documento oficial sobre $O$ papel da HQ no ensino de ciências (atividade 2, Apêndice Vl). A professora concordou com a ideia defendida no documento, Justificando: "Sim, pois assim facilitaria a compreensão dos alunos sobre o trabalho da ciência e de todo o processo investigativo" (categoria $\mathrm{C} 4$ ).

Ela aponta como uma dificuldade em abordar a Historia da Ciência no ensino: "Hoje já trabalho com a proposta curricular da CENP e não sinto dificuldades em trabalhar HC, a HC serve para auxiliar a traduzir a realidade da natureza feita pelo homem, portanto podendo sofre modificações, falhas e revisões" (categoria C2).

$\mathrm{Na}$ atividade 4 (terceiro encontro, Apêndice IX), a professora construiu o seguinte mapa conceitual: 


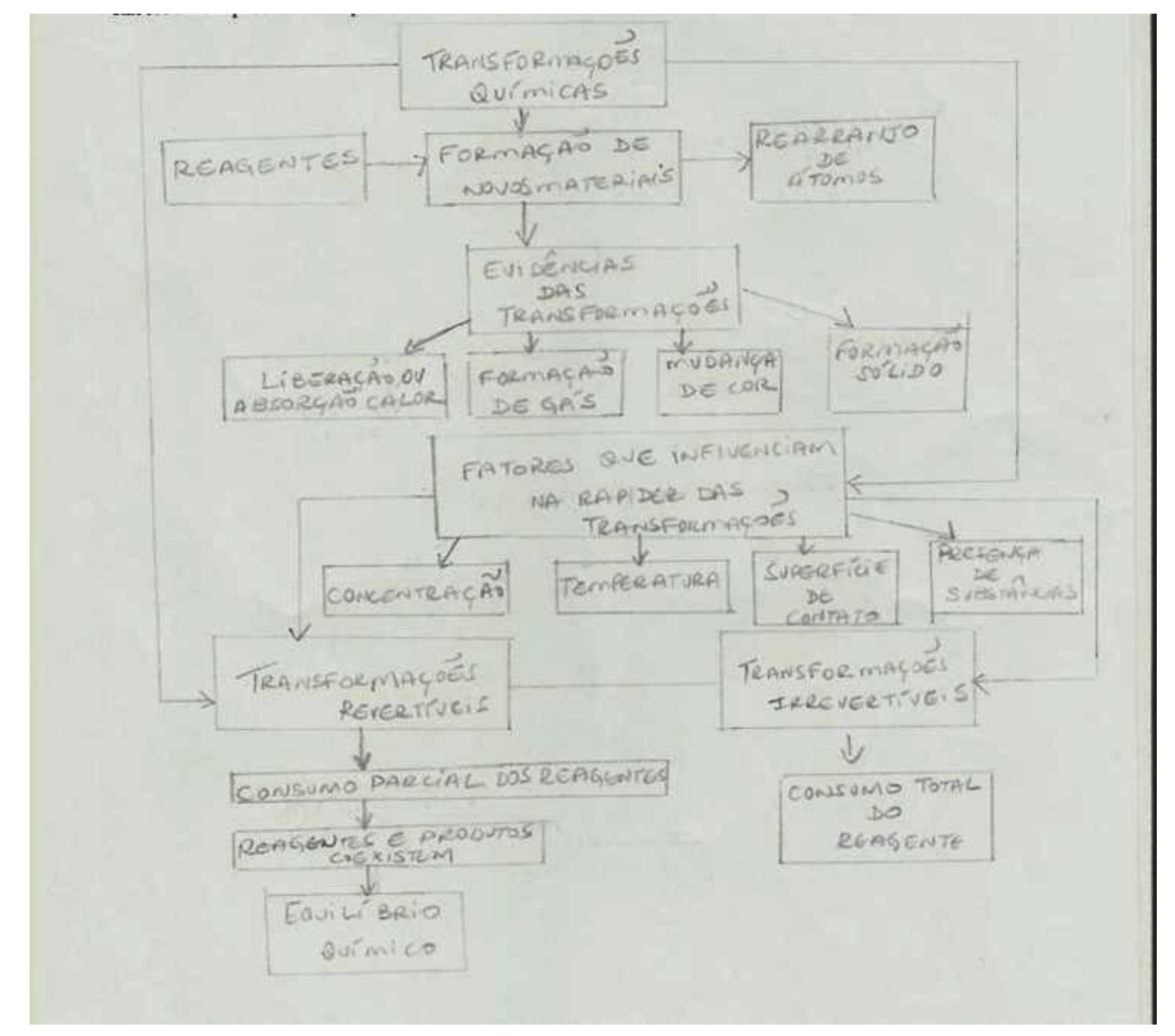

Figura 4.18 Mapa conceitual sobre imagem da ciência elaborado pela professora P7.

No mapa acima observa-se que a professora não aponta as ideias sobre a natureza da ciência que ela espera que seus alunos construam, mas sim faz a relação entre os conceitos envolvidos no tema cinética química. Pode-se inferir que faltou a essa professora o entendimento sobre o tema natureza da ciência, ou sobre o objetivo da atividade proposta.

Sua imagem sobre a natureza da ciência, após a discussão (instrumento 3, Apêndice XIV) no quinto encontro é coerente com a perspectiva filosófica racionalista:

A ciência procura explicar os fenômenos da natureza através da capacidade que os seres humanos possuem para propor problemas e imaginar possíveis soluções. $O$ 
conhecimento científico é construído com base em teorias que orientam a observação para explicar os fatos, portanto, por estar em constante desenvolvimento e construção, não sendo um conhecimento pronto, podendo ser questionado e reformulado.

Pela análise das respostas da professora, observa-se que o modelo do ensino intermediário está baseado, principalmente, nos aspectos submicroscópicos da cinética química (MES1). Seu modelo de ensino é marcado pela perspectiva filosófica e racionalista $(R)$.

\section{Fase final}

$\mathrm{Na}$ avaliação final (oitavo encontro, Apêndice XIX) a professora apontou em relação à superação das dificuldades sobre o ensino de cinética química: "Com o curso tivemos o aprimoramento do entendimento desses conteúdos, construindo o conhecimento através da História da Ciência".

Quanto à superação das dificuldades sobre o uso da História da Química: "Sim, pois nos foram fornecidos fontes de consulta, textos e experimentos que podem ser utilizados no ensino de cinética química.".

Sobre quais aspectos relacionados à sua prática a professora refletiu através do curso, ela respondeu que "o caminho que estou seguindo através da nova Proposta Curricular está correto e a contextualização é fundamental na prática de nossas aulas".

\section{Plano de ensino}

Em relação ao plano de ensino (folha de atividade 8, Apêncice XVII) dessa professora, podem-se observar no quadro a seguir as habilidades e competências em relação aos conceitos de cinética química, História da Química e a visão sobre a natureza da ciência que ela pretende que seus alunos desenvolvam:

Tema Habilidade e competências

Análise

Conceitos da Saber reconhecer e utilizar a linguagem química; Identificar MEM cinética variáveis relevantes e regularidades; Saber interpretar para química poder discutir a influência da variação da temperatura, do estado de agregação e da concentração sobre a rapidez das 
transformações químicas.

Visão sobre a natureza da ciência História da Química
Compreender a ciência e a tecnologia como partes integrantes da cultura humana contemporânea, Reconhecer o papel dos modelos explicativos da ciência.

Analisar e interpretar textos científicos, Saber estabelecer relações, reconhecer e avaliar a construção histórica e o desenvolvimento da ciência.

Quadro 4.13 Habilidades e competências indicadas no plano de ensino da professora P7.

Em relação aos outros tópicos do plano dessa professora:

- Objetivos:

$\mathrm{CQ}$ : propiciar ao aluno reconhecer e utilizar a linguagem química, identificar variáveis relevantes e regularidades, para poder discutir a influência da variação da temperatura, do estado de agregação e da concentração sobre a rapidez das transformações químicas através da articulação de experimentos, reconhecendo que é possível alterar a rapidez com que uma transformação química ocorre;

HFC: propiciar ao aluno analisar e interpretar textos científicos, saber estabelecer relações, reconhecendo o papel dos modelos explicativos da ciência, para que possa compreender a ciência e a tecnologia como partes integrantes da cultura humana contemporânea, reconhecendo e avaliando sua construção histórica e seu desenvolvimento.

- Conteúdos:

Variáveis que podem modificar a rapidez de uma transformação química, concentração, temperatura, estado de agregação. Definição de isomeria óptica, princípio de funcionamento do polarímetro e polarização rotatória. Substâncias opticamente ativas, ou que possuem atividade óptica, substâncias dextrogiras e levogiras.

\section{- Estratégias:}

$\mathrm{CQ}$ : dois experimentos com questões no inicio e no final dos experimentos. 
$\mathrm{HQ}$ : leitura e análise de texto (breve história do desenvolvimento do polarímetro) com questões para orientar a discussão; experimento (polarímetro); aula expositiva: conceitos de isomeria óptica; experimento virtual.

- Sequencia das atividades:

Aula 1: Experimento-Influência da concentração dos reagentes na velocidade da reação (raspas de zinco e ácido clorídrico $6 \mathrm{~mol}$. L -1);

Aula 2: Experimento-Influência da temperatura na velocidade de reação(comprimido efervescente em água em diferentes temperaturas);

Aula 3 - Leitura e Análise do texto: Breve história do desenvolvimento do Polarímetro e montagem de um polarímetro com filtro polarizador para análise de brilho de uma solução de açúcar em relação a água destilada. (obs. texto e experimento utilizado no curso de formação continuada)

Aula 4- Conceitos de Isomeria Óptica;

Aula 5: Experimento Virtual: Nesta aula os alunos vão desenvolver o conceito de quiralidade irão montar um polarímetro e testar soluções verificando o desvio da luz polarizada; 6ª̂Aula: Avaliação.

Pela análise do plano de ensino dessa professora percebe-se que seu modelo de ensino não inclui um modelo teórico (MEP), pois e não indica nenhum modelo teórico para o entendimento dos fatores que influem na velocidade de uma reação química.

Em relação a História da Química, ela inclui o texto sobre a história do desenvolvimento do polarímetro no seu plano de ensino, percebe-se que o objetivo dessa atividade, como ela aponta é o de:

Propiciar ao aluno analisar e interpretar textos científicos, saber estabelecer relações, reconhecendo o papel dos modelos explicativos da ciência, para que possa compreender a ciência e a tecnologia como partes integrantes da cultura humana contemporânea, reconhecendo e avaliando sua construção histórica e seu desenvolvimento. (plano de ensino, P7) 
Portanto, no plano dessa professora a História da Química é abordada com a finalidade de possibilitar o desenvolvimento dos conceitos químicos (GilPérez,1993), nesse caso, o entendimento do polarímetro.

Pode-se analisar a imagem sobre a natureza da ciência dessa professora na sequência do seu plano de ensino, principalmente no que se refere ao papel da experimentação, que nesse caso é o de desenvolver a teoria em sala de aula. Portanto, pode-se inferir que sua imagem é coerente com a perspectiva filosófica racionalista.

No quadro a seguir podem-se observar, nos três momentos do curso de formação, os modelos de ensino dessa professora:

\begin{tabular}{|c|c|c|c|c|}
\hline ETAPA & INSTRUMENTOS & $\begin{array}{l}\text { CINÉTICA } \\
\text { QUÍMICA }\end{array}$ & $\begin{array}{l}\text { HISTÓRIA DA } \\
\text { QUÍMICA }\end{array}$ & $\begin{array}{l}\text { IMAGEM DA } \\
\text { CIÊNCIA }\end{array}$ \\
\hline \multirow{2}{*}{ INÍCIO } & INSTRUMENTO 1 & MES1 & C4 & \\
\hline & INSTRUMENTO2 & & & $E / I$ \\
\hline \multirow{7}{*}{ DURANTE } & ATIVIDADE 1 & & C3 & \\
\hline & ATIVIDADE 2 & & $\mathrm{C} 2, \mathrm{C} 4$ & \\
\hline & ATIVIDADE 4 & & & - \\
\hline & ATIVIDADE 6 & MEM & & \\
\hline & INSTRUMENTO 3 & & & $\mathrm{R}$ \\
\hline & EXPERIMENTO 3 & MES1 & & \\
\hline & EXERCICIO 1 & MES1 & & \\
\hline \multirow{2}{*}{ FINAL } & ATIVIDADE 8 & MEM & $\mathrm{C} 3, \mathrm{C} 4$ & $R$ \\
\hline & PLANO DE ENSINO & MEP & $\mathrm{C} 3, \mathrm{C} 4$ & $\mathrm{R}$ \\
\hline
\end{tabular}

Quadro 4.14 Modelos de ensino de cinética química do professor P7, nas diferentes etapas do curso de formação. 


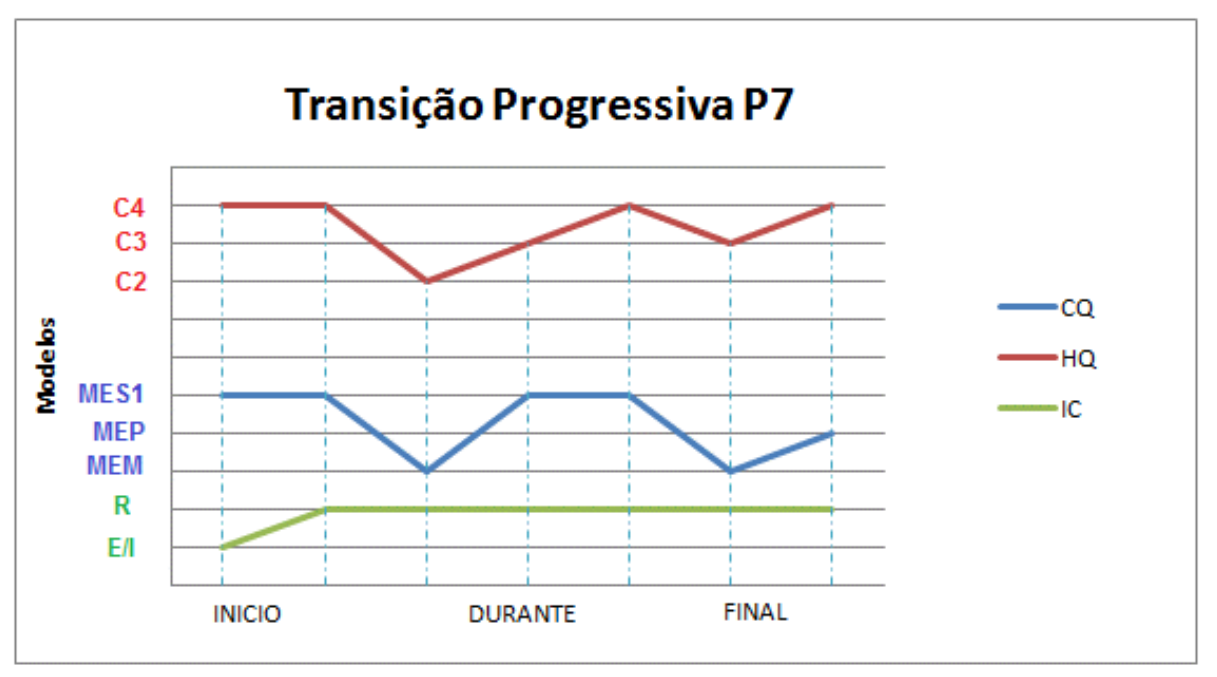

Figura 4.19 Transição progressiva da professora P7 nas três fases da pesquisa, em relação aos seguintes aspectos de seu modelo de ensino: $C Q$ : cinética química, $\mathrm{HQ}$ : História da Química e IC: imagem da ciência.

Observa-se que o curso de formação continuada facilitou a transição progressiva nos aspectos relacionados a sua imagem sobre a natureza da ciência, que no inicio do curso era referente à perspectiva $E / I$, passando a ser racionalista $(R)$ na fase intermediária, mantendo-se assim até na fase final:

Propiciar ao aluno analisar e interpretar textos científicos,
saber estabelecer relações, reconhecendo o papel dos
modelos explicativos da ciência, para que possa
compreender a ciência e a tecnologia como partes
integrantes da cultura humana contemporânea,
reconhecendo e avaliando sua construção histórica e seu
desenvolvimento. (plano de ensino, P7).

Em relação ao entendimento relacionado ao tema cinética química, embora a professora, na abordagem sobre a isomeria, trabalhe com um modelo que envolvem comportamento das partículas, por exemplo, a explicação da isomeria óptica com carbono assimétrico, em relação aos conceitos da cinética química ela não aborda a teoria das colisões e nem a teoria do estado de transição, portanto, optou-se caracterizar o modelo final dessa professora como pseudomicroscópico (MEP). 
P8

Fase inicial

Para o professor o ensino de cinética química é importante por que (Instrumento 1, Apêndice II):

Os alunos praticam todos os dias, sem saber, atividades que envolvem as velocidades das reações, por exemplo, ao se alimentar, a mastigação é um fator para aumentar a superfície de contato, os catalisadores naturais e artificiais, as pressões utilizadas para cozimento dos alimentos e a temperatura para auxiliar no entendimento da cinética.

Quanto ao conteúdo que é importante ensinar, ele aponta: "Aquele que o aluno consegue vivenciar, enxergar, por exemplo, a temperatura, como um fator que acelera a velocidade da reação.

O conteúdo que normalmente ensina é: "Rede pública: Fatores que afetam a velocidade, prática: temperatura na dissolução de um sal de fruta. Rede pública técnica: teoria e prática normal". (MEM)

Para este professor um dos conteúdos que ele indica que tem maior dificuldade em ensinar é: "A constante de equilíbrio". Porque, segundo ele: " $O$ aluno não consegue relacionar o número (Keq) com reagentes e produtos em equilíbrio".

Quanto à experimentação ele não usa na rede pública. Quando questionado por que o experimento é importante no ensino de cinética química sua resposta é: "O aluno enxerga, vê, acompanha".

O professor não usa História da Química no ensino de cinética química, contudo, considera que a sua inclusão no ensino facilitaria: "A comparação do inicio com o atual pode ser utilizado como grau de evolução da humanidade”.(categoria $\mathrm{C} 2$ da $\mathrm{HQ}$ )

Em relação a sua imagem sobre a natureza da ciência (instrumento 2, Apêndice VII), o professor escolheu as seguintes afirmações:

- O conhecimento científico é o conhecimento provado (E/I) 
- Toda investigação científica começa pela observação rigorosa do fenômeno que se estuda. (E/I).

- Através do experimento, o investigador comprova se sua hipótese de trabalho é verdadeira ou falsa. (E/I)

- O método científico é um conjunto de etapas de atividades práticas e mentais que sem duvida alguma levará a um conhecimento verdadeiro. (E/I)

- As hipóteses dirigem o processo de investigação científica. (R)

- Teorias científicas são derivadas, de um modo rigoroso, de fatos adquiridos pela observação e pela experimentação. (E/I)

Pela análise das respostas do professor, observa-se que nessa fase inicial seu modelo de ensino está baseado nos aspectos macroscópicos da cinética química (MEM). Este modelo inicial de ensino é marcado principalmente, pela perspectiva filosófica empirista/indutivista (E/I).

\section{Fase intermediária}

Quanto à atividade 6 (quarto encontro, Apêndice XI), o professor mostrou ter um entendimento parcial de como se dá a variação da velocidade de uma reação com o tempo, já que, para ele a velocidade diminui até um ponto em que fica constante: "A velocidade diminui. Através de uma exponencial, aumentando a velocidade rapidamente no inicio e após atingir uma certa quantidade de éster formado, esta velocidade diminui até atingir um equilíbrio".

Nessa mesma atividade a sua explicação de como se dá a influência da temperatura na velocidade da reação é: "Aumentando a temperatura para $100^{\circ} \mathrm{C}$ além de aumentar o rendimento do produto formado, nota-se uma diminuição do tempo total do processo", portanto, percebe-se que em suas explicações não aparece um modelo explicativo, nem termos relacionados a partículas.

$\mathrm{Na}$ atividade experimental 3, sobre o efeito da temperatura na velocidade de uma reação (quarto encontro, Apêndice XII ), sua explicação não inclui termos relacionados a partículas: "Temperaturas maiores, velocidade de reação maior. Temperatura menor, velocidade de reação menor". Quando, na mesma atividade se pedia uma explicação com o uso de um modelo de partículas para explicar 
porque a transformação é mais lenta quando realizada em água gelada, o professor escreveu: "O movimento caótico ou browniano é menor diminuindo os choques, ficam menor a velocidade de reação". O professor usa o termo choques, contudo, fica difícil relacionar a sua explicação está relacionada à teoria das colisões, portanto, escolheu-se indicar sua resposta como MEP.

No próximo exercício sobre gráficos (exercício 1, quinto encontro, Apêndice $\mathrm{XV}$ ) o professor fez o seguinte desenho:

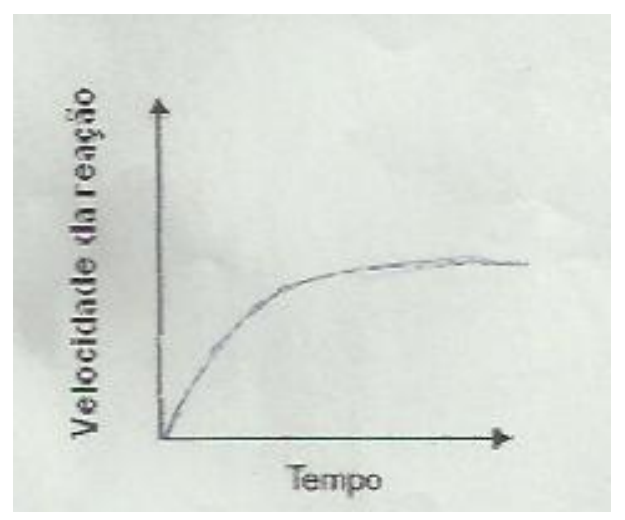

Figura 4.20 A variação da velocidade de uma reação em função do tempo segundo P8.

Percebe-se que o modelo de seu gráfico refere-se ao modelo de aumento constante - MAC (categoria Cakmakci et al,2005). Sua justificativa para esse modelo é:

No início a velocidade de reação é igual a zero, pois, só temos reagente e lógico nenhum produto formado. Com o passar do tempo há sim consumo da concentração do reagente $A$, este fato pode ser notado com a inclinação negativa da curva, quando neste momento a velocidade da reação é proporcional ao consumo do reagente na unidade de tempo. $v=d[A] / d t$. A curva hipérbole equilátera mostra que o consumo de reagente é acintosa no inicio, tendendo a uma constante de velocidade quando o equilíbrio é atingido, nesse exato momento dizemos que o equilíbrio é dinâmico microscopicamente.

Nas explicações do professor, a ideia de que a velocidade de reação vai aumentando ficando constante e atingindo o equilíbrio, aparece tanto na atividade 6 como também no exercício 1. Observa-se que sua explicação está somente relacionada aos aspectos macroscópicos da velocidade dessa reação química. 
Em relação ao uso de artigos sobre a História da Química (atividade 1, primeiro encontro, Apêndice III), o professor indicou como iria utilizar essa estratégia no ensino: "Através da leitura dos artigos, observação e imaginação desde o macro até o mundo microscópico".

As vantagens dessa estratégia: "Os alunos poderiam visualizar as macropartículas indo para as micropartículas, através de sucessivas soluções e diluições. Nem sempre os alunos tem ao alcance um laboratório a disposição".

No segundo encontro, os professores leram um documento oficial sobre o papel da HQ no ensino de ciências (atividade 2, Apêndice $\mathrm{VI}$ ). O professor concordou com a ideia defendida no documento, justificando: "É evidente que tudo tem um marco histórico, se você consegue reunir essas evidências em um planejamento, a atividade estará de acordo com o pressuposto". (categoria C3 da $H Q)$.

Ele aponta como uma dificuldade em abordar a historia da ciência $(\mathrm{HC})$ no ensino: "O tempo, número de aulas, mas se a cada capitulo fosse feita uma menção histórica daquele assunto, acredito que seja possível aplicar a HC, teríamos que ter uma proposta curricular que já nos atendesse".

$\mathrm{Na}$ atividade 4 (terceiro encontro, Apêndice IX), o professor construiu o seguinte mapa conceitual: 


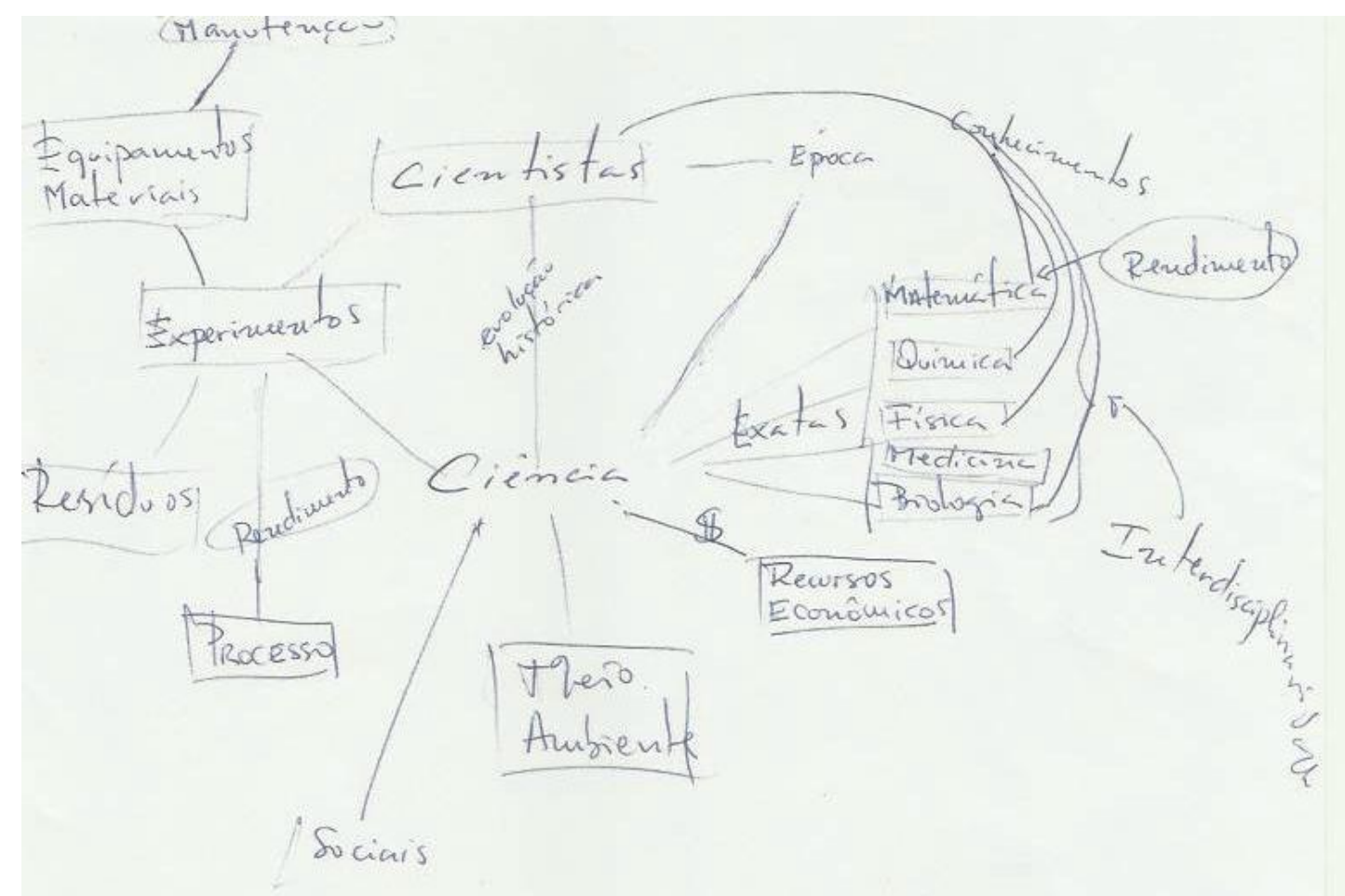

Figura 4.21 Mapa conceitual sobre a imagem da ciência elaborado pelo professor P8.

No mapa acima observa-se que o professor aponta as ideias sobre a natureza da ciência relacionadas principalmente à perspectiva filosófica racionalista $(R)$ : a ciência esta relacionada à sociedade, ao ambiente e aos recursos econômicos, onde os cientistas de uma determinada época, elaboram conhecimentos que estão ligados a outras áreas (interdisciplinaridade). Contudo, percebe-se que a experimentação está relacionada à maneira como os cientistas desenvolvem a ciência, no caso indicado no mapa, pela experimentação (perspectiva $\mathrm{E} / \mathrm{I}$ ).

Sua imagem sobre a natureza da ciência, após a discussão (instrumento 3, Apêndice XIV) no quinto encontro pode ser caracterizada como sendo coerente com a perspectiva filosófica empirista/indutivista:

A ciência é uma palavra que pode dar algumas derivações, por exemplo: você está ciente de...? Qual é a sua ciência sobre...? Então ao meu entender ciência significa conhecimento de alguma coisa em torno, tal como, política, química, física, biologia, matemática, etc. A ciência se desenvolve através de estudos práticos e teóricos ou em ordem inversa, mas acredito que o estudo prático, na 
maioria das vezes, é o primordial, por sua vez, o conhecimento científico é construído por observações, hipóteses, resultado e conclusão. (Grifo nosso)

Pela análise das respostas do professor, observa-se que seu modelo de ensino, nessa fase intermediária está baseado, principalmente, nos aspectos pseudomicroscópicos da cinética química (MEP). Este modelo é marcado pela perspectiva filosófica empirista/indutivista (E/l)

\section{Fase final}

$\mathrm{Na}$ avaliação final (oitavo encontro, Apêndice XIX) o professor apontou em relação à superação das dificuldades sobre o ensino de cinética química:

Se você trabalhar com o experimento, como foi proposto, vai ajudar a superar essas dificuldades caso contrário o aluno não vai se interessar pelo blá blá diário, cansado? Interesse por outra disciplina? Com fome? Problemas em casa? E vai aí afora. Trabalhando o experimento, você consegue mobilizar o aluno e uma vez feito isso, o resto, ele desenvolve. Para desenvolver a teoria da colisão e do complexo ativado, lançaria mão das simulações dos sites sugeridos pelo curso que foi dado.

Quanto à superação das dificuldades sobre o uso da História da Química:

Sem dúvida que algumas dificuldades foram superadas, pois o essencial é você na hora de trabalhar possuir o texto a ser aplicado. Acredito que se colocarmos o texto na apostila (caderno do aluno) vai ajudar o professor a tratar da história da ciência com mais enfoque. Não podemos esquecer das bibliografias para pesquisa, onde uma tratativa maior do assunto pode ser dado.

A respeito de quais aspectos relacionados à sua prática o professor refletiu através do curso, ele apontou que:

A História da Ciência é uma forma rica de levar ao aluno toda uma evolução, do antigo ao atual e lançando uma interrogação do futuro, portanto, o que eu não vinha fazendo regularmente no meu plano de ensino, dar mais ênfase à história da ciência, devo adicionar para os próximos planos.

\section{$\underline{\text { Plano de ensino }}$}

Em relação ao plano de ensino (folha de atividade 8, Apêncice XVII) desse professor, podem-se observar no quadro a seguir as habilidades e competências 
em relação aos conceitos de cinética química, a História da Química e a visão sobre a natureza da ciência que ele pretende que seus alunos desenvolvam:

\begin{tabular}{|c|c|c|}
\hline Tema & Habilidade e competências & Análise \\
\hline $\begin{array}{l}\text { Conceitos } \\
\text { da cinética } \\
\text { química }\end{array}$ & $\begin{array}{l}\text { Ler e interpretar textos de interesse científico e tecnológico; } \\
\text { Interpretar e utilizar diferentes formas de representação } \\
\text { (tabelas, gráficos, expressões, ícones etc...); Exprimir-se } \\
\text { oralmente com correção e clareza, usando a terminologia } \\
\text { corrente; Produzir textos adequados para relatar experiências, } \\
\text { formular dúvidas ou apresentar conclusões; Utilizar as } \\
\text { tecnologias básicas de redação e informação; Identificar } \\
\text { variáveis relevantes e selecionar os procedimentos necessários } \\
\text { para a producão, análise e interpretacão de resultados. }\end{array}$ & MEM \\
\hline $\begin{array}{l}\text { Visão } \\
\text { sobre a } \\
\text { natureza } \\
\text { da ciência }\end{array}$ & $\begin{array}{l}\text { Ler e interpretar modelos adquiridos pelos cientistas. } \\
\text { Desenvolver modelos explicativos para a ciência atual; } \\
\text { Interpretar a evolução da ciência com o cientista através do } \\
\text { tempo; Compreender os códigos da época; Interpretar e criticar } \\
\text { resultados a partir de experimentos. }\end{array}$ & $E / I$ e $R$ \\
\hline $\begin{array}{l}\text { História da } \\
\text { Química }\end{array}$ & $\begin{array}{l}\text { Traçar cronologicamente a evolução da ciência; Interpretar o } \\
\text { conhecimento científico atrelado à que época; Identificar cada } \\
\text { modelo ao seu idealizador e traçar o perfil do cientista com sua } \\
\text { época. }\end{array}$ & $\begin{array}{l}\mathrm{C} 3 \mathrm{e} \\
\mathrm{C} 4\end{array}$ \\
\hline
\end{tabular}

Quadro 4.15 Habilidades e competências indicadas no plano de ensino do professor P8.

Em relação aos outros tópicos do plano desse professor:

- Objetivos:

Entendimento da velocidade de uma reação fazendo referência à cinemática da física; fatores que afetam a velocidade de reação: temperatura, pressão, tamanho da partícula, isto é. superfície de contato, catalisadores e concentração dos reagentes.

- Conteúdos:

Atmosfera como fonte de materiais; produção de amônia; nitrogênio: matéria prima na obtenção de alguns materiais; perturbação do estado de equilíbrio químico; o que o ser humano introduz na atmosfera, hidrosfera e biosfera. Os parâmetros que serão destacados são aqueles que afetam a velocidade da reação, tais como: Temperatura, pressão, tamanho da partícula, isto e, superfície de contato, catalisadores e concentração dos reagentes.

Estratégias: 
CQ: Leitura de textos (os textos serão os que já existem no livro adotado e mais da apostilado estado), vídeo, discussão dos textos. Apresentação de trabalhos feitos em casa ( $\mathrm{O}$ trabalho de acompanhamento da velocidade de dissolução do comprimido efervescente, modificando a temperatura e o tamanho da superfície); Exercícios individuais e em grupo (Os exercícios são do caderno e do livro adotado)

HFC: Textos do caderno do Estado: Processo Haber Boch. Uma aula: trabalhar com a cronologia do tempo onde há um envolvimento dos cientistas, mas não posso perder muito tempo, pois não tenho muitas aulas.

- Sequência:

Esse conteúdo será levado ao aluno na forma teórica, experimentalmente utilizando a solubilidade do sal de fruta efervescente em pó e na forma inteira (comprimido) em temperaturas diferentes, na combustão de serragem e pedaço de madeira, vídeo da reação em cadeia, citando ainda o cotidiano do aluno, desde a cozinha, banheiro, digestão, o processo de degradação do meio ambiente, formação do petróleo e do álcool. No final deste processo o aluno deve ter as competências e as habilidades indicadas na proposta (Obs. Proposta Curricular de São Paulo, 2011). Sequência:

1. Aula teórica e prática

2. Leitura de textos e Vídeo (reação em cadeia)

3. Discussão dos textos

4. Apresentação de trabalhos feitos em casa (Exercícios individuais e em grupo)

Pela análise do plano de ensino desse professor percebe-se que seu modelo de ensino não inclui um modelo teórico (MEM), pois ele não indica nenhum modelo teórico para o entendimento da velocidade de uma reação química, focalizando seu ensino somente nos fatores que podem afetar a velocidade.

Em relação à História da Química, embora ele aponte o uso do texto do caderno do Estado de São Paulo, para esse professor essa estratégia não tem a finalidade de ensinar os conceitos químicos, e sim mostrar a sua origem: "Processo Haber Boch. Uma aula: trabalhar com a cronologia do tempo onde há 
um envolvimento dos cientistas, mas não posso perder muito tempo, pois não tenho muitas aulas" (plano de ensino, P8).

Pode-se perceber que a imagem sobre a natureza da ciência desse professor, na sequencia do seu plano de ensino, é coerente com a perspectiva filosófica empirista/indutivista.

No quadro a seguir podem-se observar, nos três momentos do curso de formação, os modelos de ensino desse professor:

\begin{tabular}{|c|c|c|c|c|}
\hline ETAPA & INSTRUMENTOS & $\begin{array}{l}\text { CINÉTICA } \\
\text { QUÍMICA }\end{array}$ & $\begin{array}{c}\text { HISTÓRIA DA } \\
\text { QUÍMICA }\end{array}$ & $\begin{array}{c}\text { IMAGEM DA } \\
\text { CIÊNCIA }\end{array}$ \\
\hline \multirow{2}{*}{ INÍCIO } & INSTRUMENTO 1 & MEM & $\mathrm{C} 2$ & \\
\hline & INSTRUMENTO 2 & & & $E / I$ \\
\hline \multirow{7}{*}{ DURANTE } & ATIVIDADE 1 & & $\mathrm{C} 4$ & \\
\hline & ATIVIDADE 2 & & C3 & \\
\hline & ATIVIDADE 4 & & & $E / I, R$ \\
\hline & ATIVIDADE 6 & MEM & & \\
\hline & INSTRUMENTO 3 & & & $\mathrm{R}$ \\
\hline & EXPERIMENTO 3 & MEP & & \\
\hline & EXERCICIO 1 & MEP & & \\
\hline \multirow{2}{*}{ FINAL } & ATIVIDADE 8 & MEM & $\mathrm{C} 3, \mathrm{C} 4$ & $E / I, R$ \\
\hline & PLANO DE ENSINO & MEM & $\mathrm{C} 3$ & $E / I$ \\
\hline
\end{tabular}

Quadro 4.16 Modelos de ensino de cinética química do professor P8, nas diferentes etapas do curso de formação.

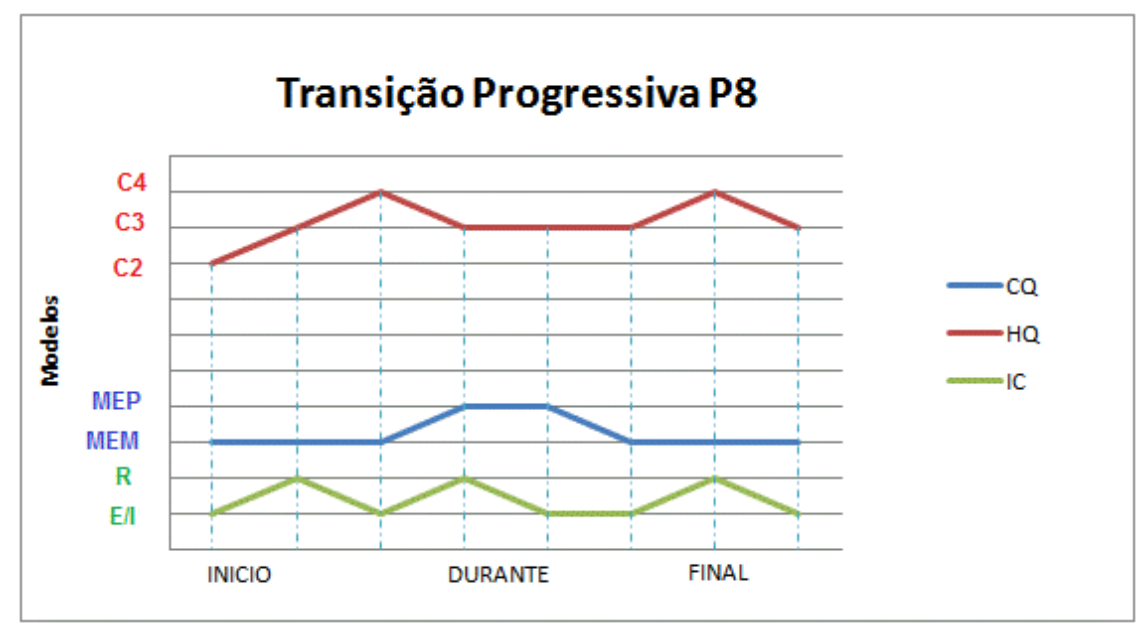

Figura 4.22 Transição progressiva do professor P8 nas três fases da pesquisa, em relação aos seguintes aspectos de seu modelo de ensino: $C Q$ : cinética química, $\mathrm{HQ}$ : História da Química e IC: imagem da ciência. 
Em relação à História da Química, embora para esse professor somente tenha a função de mostrar a origem do conhecimento científico, ele a incluiu em seu plano de ensino, o que não ocorria no seu modelo de ensino inicial, o que pode revelar uma mudança no seu entendimento sobre o papel da HQ no ensino de cinética química:

\begin{abstract}
A história da ciência é uma forma rica de levar ao aluno toda uma evolução, do antigo ao atual e lançando uma interrogação do futuro, portanto, o que eu não vinha fazendo regularmente no meu plano de ensino, dar mais ênfase à história da ciência, devo adicionar para os próximos planos (avaliação final, Apêndice XIX).
\end{abstract}

Percebeu-se durante o curso, que esse professor tinha grande dificuldade em interpretar graficamente a velocidade de uma reação química, afirmando sempre que esta tinha valor igual a zero no inicio (MAC,categoria Cakmakci et al,2005). Isso pode ser observado em seu plano onde ele aponta em seus objetivos:

$$
\begin{aligned}
& \text { Levar ao aluno o conhecimento da cinética química, fazendo } \\
& \text { referencias a cinemática onde o movimento em relação ao } \\
& \text { tempo faz referencias no campo da Física e paralelamente } \\
& \text { na Química o consumo de reagentes em relação ao tempo } \\
& \text { avalia o processo em função da velocidade de reação (P8, } \\
& \text { plano de ensino). }
\end{aligned}
$$

Ao fazer essa comparação da cinética química com a cinética da física, ele pode estar reforçando no aluno a ideia de que no inicio da transformação química a velocidade é igual a zero. Segundo Bektasli e Cakmakci (2011), o problema é que o conceito de velocidade não é exclusivo de uma única disciplina. Basicamente o termo "velocidade" tem um significado similar na física e na química, mas o uso e a terminologia deste conceito são diferentes para cada domínio. Assim, na química o termo "taxa" (velocidade) pode ser definida como a mudança da concentração de um reagente em particular, ou produto por unidade de tempo. Por outro lado na física "velocidade" é usado para a quantidade de deslocamento em certo período de tempo.

Em relação à imagem sobre a natureza da ciência desse professor, embora na fase inicial e intermediária tenham sido identificadas algumas características 
relacionadas a perspectiva filosófica racionalista, sua imagem revelou ser fortemente influenciada pela perspectiva empirista/indutivista, principalmente em relação a grande importância que esse professor dá ao papel da observação e do experimento na construção do conhecimento científico.

P9

\title{
Fase inicial
}

Para esta professora o ensino de cinética química é importante: "Porque o aluno tem que saber como as reações acontecem, e que muitas vezes, necessita delas no seu dia a dia”.

Conteúdo que ela normalmente aborda em suas aulas:

\begin{abstract}
Não ensino nada, pois quando o currículo era proposto pelo professor, eu não conseguia chegar a esse conteúdo. Agora com a proposta curricular de SP, muitas vezes só consigo terminar a apostila 1, pois os alunos tem tentas dificuldades em realizar as atividades concretas, imagina trabalhar com 0 "abstrato"(instrumento 1, Apêndice II).
\end{abstract}

Ela considera difícil abordar todo o conteúdo de cinética química (instrumento 1, Apêndice II).

Quanto à experimentação ela não usa esse recurso em suas aulas. Quando questionada por que o experimento é importante no ensino de cinética química sua resposta foi: "Ajuda muito, porque os alunos poderão "ver" a experiência, ou seja, realizar o concreto para ele próprio tirar suas conclusões".

Em relação à História da Ciência, embora ela considere importante a sua inclusão no ensino, "Primeiro vai me ajudar como professora a descobrir algumas coisas que eu mesma nem conheço. Depois se a professora tem mais conhecimento sobre o assunto, poderá despertar nos alunos, o interesse pela $H Q$ à qual acho que muitas vezes nem damos muita "bola"', ela afirma não usar em suas aulas, pois, segundo ela: acho que sei pouquíssimo sobre a HQ. (categoria C1 da História da Química).

Em relação a sua imagem sobre a natureza da ciência (instrumento 2, Apêndice VII), a professora escolheu as seguintes afirmações: 
- O conhecimento científico se gera graças à capacidade que os seres humanos possuem para propor problemas e imaginar possíveis soluções aos mesmos. (R)

- Teorias científicas são derivadas, de um modo rigoroso, de fatos adquiridos pela observação e pela experimentação. (E/l)

Pela análise das respostas da professora, como ela não aborda cinética química, não foi possível indicar esse aspecto no seu modelos de ensino. Os únicos aspectos que foram identificados desse modelo foi a sua imagem da ciência que esta relacionada tanto a perspectiva filosófica empirista/indutivista $(E / I)$ como a perspectiva racionalista $(R)$, e o seu entendimento sobre o papel da História da Química no ensino (categoria C1).

\section{Fase intermediária}

Quanto à atividade 6 (quarto encontro, Apêndice XI), a professora não mostrou ter o entendimento de como se dá a variação da velocidade de uma reação com o tempo, justificando que: "A velocidade aumenta" (modelo de aumento - MA (Cakmakci et al, 2005). A sua explicação de como se dá a influência da temperatura na velocidade da reação nesse mesmo exercício é: "Podemos concluir que o fator tempo e temperatura estão influenciando a reação", portanto, percebe-se que em suas explicações não aparece um modelo teórico.

$\mathrm{Na}$ atividade experimental 3, sobre o efeito da temperatura na velocidade de uma reação (quarto encontro, Apêndice XII ), sua explicação não inclui termos relacionados a partículas: "Quanto maior a temperatura mais rápido se dissolve 0 comprimido". Quando, na mesma atividade se pedia uma explicação com o uso de um modelo de partículas para explicar por que a transformação é mais lenta quando realizada em água gelada, o professor escreveu: " $A$ água gelada diminui o choque, colisões, entre as partículas". Portanto, a professora indica termos relacionados a um modelo explicativo, a teoria das colisões (MES1).

No próximo exercício sobre gráficos (quinto encontro, Apêndice $X V$ ) a professora desenhou o seguinte gráfico: 


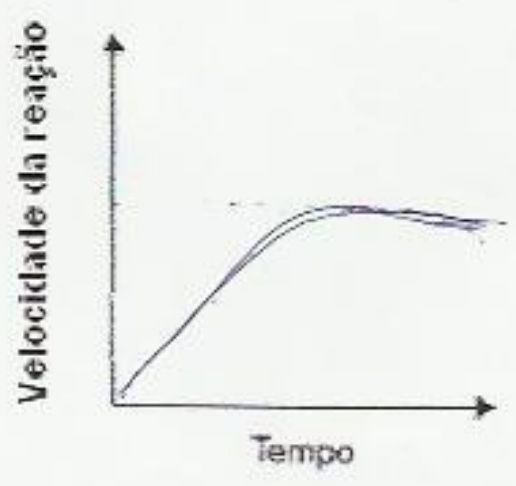

Figura 4.23 A variação da velocidade de uma reação em função do tempo segundo P9.

Percebe-se que o modelo de seu gráfico (fig.4.23) refere-se ao modelo de aumento constante - MAC (categoria Cakmakci et al, 2005). Sua justificativa para esse modelo é: "Acho que no inicio da reação a velocidade é alta, pois é quando os reagentes estão formando os produtos, em determinado momento há o equilíbrio entre reagentes e produtos e por isso a velocidade torna-se constante".

Pode-se observar que a sua explicação sobre o seu gráfico não inclui um modelo teórico.

A professora não realizou a atividade sobre o uso de artigos sobre a História da Química (atividade 1, primeiro encontro, Apêndice III).

No segundo encontro, os professores leram um documento oficial sobre o papel da $H Q$ no ensino de ciências (atividade 2, Apêndice VI). A professora concordou com a ideia defendida no documento, Justificando: "Sim, porém sempre tinha a visão de que a história da ciência se resumia a pequenos trechos (em destaque) nos livros didáticos do ensino médio. Porque mesmo na faculdade, pouco se vê sobre a história da ciência”.

Ela aponta como uma dificuldade em abordar a historia da ciência no ensino: "A maior dificuldade partiria da própria professora "eu", por falta de domínio sobre o assunto". 
Em relação ao mapa conceitual (atividade 4, Apêndice IV), a professora não construiu um esquema mas sim escreveu uma relação de ideias sobre a natureza da ciência que ela espera que seus alunos construam. Elas são:

- Que a ciência em si não está pronta e nem acabada;

- Que o método científico baseia-se muitas vezes em tentativas e erros ("que podemos sim, errar");

- A experimentação é apenas parte do processo, pois temos também que fundamentarmos em teorias que já foram elaboradas, e porque não, muitas vezes questionálas;

- E o principal: A curiosidade de tentar investigar ou mesmo "entender" o mundo no qual estamos inseridos e como podemos "cuidar dele" de forma mais eficaz.

Em relação a essas afirmações, pode-se afirmar que estas são coerentes com a perspectiva filosófica racionalista.

Sua imagem sobre a natureza da ciência, após a discussão (instrumento 3 , Apêndice XIV) no quinto encontro é:

A ciência é um conjunto de observações e investigações sobre o "mundo" em que estamos inseridos. Ela se desenvolve através da curiosidade do ser humano. $\underline{\mathrm{O}}$ conhecimento científico é construído através de práticas mentais, observações da natureza, matéria, etc, movido pela curiosidade de solucionar um problema ou não; $E$ isso ocorre não necessariamente nessa ordem. (grifo nosso)

Pela análise das respostas da professora, observa-se que suas ideias estão baseadas, principalmente, nos aspectos macroscópicos da cinética química (MEM). Este modelo é marcado pela perspectiva filosófica racionalista $(R)$, e a sua ideia sobre o papel da $\mathrm{HQ}$ no ensino não ficou evidente nessa fase.

\section{Fase final}

$\mathrm{Na}$ avaliação final (oitavo encontro, Apêndice XIX) a professora apontou em relação à superação das dificuldades sobre o ensino de cinética química: "Acabamos revendo o conteúdo de uma nova forma e para mim agora "aprendi" cinética química de forma significativa". 
Com relação a superação das dificuldades sobre o uso da História da Química: "Experimentos sim, textos e fontes que você separou para nós. Mas para procurarmos sozinhos é muito difícil”.

Quanto aos aspectos relacionados à sua prática o professor refletiu através do curso sobre:

Tudo. Que eu nem imaginava como a História da Ciência é linda, eu desconhecia a história completamente. Que eu tinha uma visão de ciência "misturada" entre o empirismo e o racionalismo. E agora eu quero que meu aluno tenha uma visão racionalista da ciência. $E$ que eu tenho que me "policiar" ao fazer meu plano para que fique bem claro, inclusive para as coordenadoras pedagógicas que não são da área.

\section{Plano de ensino}

Em relação ao plano de ensino (folha de atividade 8, Apêncice XVII) dessa professora, podem-se observar no quadro a seguir as habilidades e competências em relação aos conceitos de cinética química, História da Química e a visão sobre a natureza da ciência que ela pretende que seus alunos desenvolvam:

\begin{tabular}{|c|c|c|}
\hline Tema & Habilidade e competências & Análise \\
\hline $\begin{array}{l}\text { Conceitos da } \\
\text { cinética } \\
\text { química }\end{array}$ & $\begin{array}{l}\text { "O que é. Fatores que alteram a velocidade de uma } \\
\text { reação química. Observar. Analisar uma reação química. } \\
\text { Entender como ocorre a quebra de uma ligação química } \\
\text { e a formação de novas substâncias. Interpretar gráficos." }\end{array}$ & MES2 \\
\hline $\begin{array}{l}\text { Visão sobre a } \\
\text { natureza da } \\
\text { ciência }\end{array}$ & $\begin{array}{l}\text { A ciência não é estática. Que são necessários, as vezes, } \\
\text { várias "pessoas" erraram para que uma possa acertar, ou } \\
\text { que outros vão se baseando em estudos de outros } \\
\text { cientistas e aperfeiçoando as suas técnicas. Visão } \\
\text { racionalista. }\end{array}$ & $\mathrm{R}$ \\
\hline $\begin{array}{l}\text { História da } \\
\text { Química }\end{array}$ & $\begin{array}{l}\text { Analisar como foi sendo desenvolvidas as teorias que } \\
\text { usamos hoje. Verificar o quanto é complexo para que } \\
\text { uma teoria possa ser aceita e que não é apenas uma } \\
\text { pessoa que a faz e sim varias pessoas desenvolvem a } \\
\text { mesma pesquisa em diferentes lugares até que ela fosse } \\
\text { aceita. }\end{array}$ & C4 \\
\hline
\end{tabular}

Quadro 4.17 Habilidades e competências indicadas no plano de ensino da professora P9.

Em relação aos outros tópicos do plano dessa professora: 
- Objetivo:

Trabalhar com o conteúdo "Cinética Química" abordando a História da Ciência. Tentar construir uma visão racionalista no ensino da ciência para que os alunos possam diferenciar o senso comum do senso crítico; bem como identificar que o conhecimento científico não é estático, nem construído por apenas uma única pessoa; que as teorias científicas são válidas enquanto "dão conta" de resolver as práticas dos seres humanos e que podem ser perfeitamente substituídas por outras quando não conseguem mais dar explicações a vários fatos.

- Conteúdos:

O que é Cinética Química? Quais foram os primeiros cientistas a falar e trabalhar com cinética química? Conceitos de velocidade de uma reação química. Fatores que alteram a velocidade de uma reação (temperatura, superfície de contato, pressão e catalisador). Enfatizar mais o fator temperatura; por achar que é mais fácil para a visualização macroscópica do aluno. Trabalhar com a elaboração, construção e leitura de gráficos de cinética.

\section{- Estratégias:}

Questionário inicial (ideias prévias); texto (100 anos de Nobel -Jacobus H. van't Hoff); experimento (comprimido efervescente, analisando somente o fator temperatura), gráficos e pesquisa.

\section{- Sequência:}

1ㄹ Aula: Levantamento de conhecimentos prévios; começar com a pergunta na lousa "O que é Cinética Química?". Como os alunos ainda não estudaram o assunto, eu irei questioná-los se eles já viram: "uma palha de aço enferrujar?"; "uma fruta apodrecer depois de ficar vários dias na fruteira?"; "um antiácido efervescer?". Depois explicarei que essas situações citadas, que ocorrem no dia-a-dia, são várias reações químicas que acontecem, porém com maior ou menor velocidade. E que o estudo das velocidades das reações químicas é dado pela cinética química. Em seguida farei mais perguntas: Hoje em dia nós sabemos e conseguimos identificar, calcular, etc., todos os fatores que ocorrem nas reações químicas. Mas e antigamente, quando se dispunha de poucos recursos de materiais laboratoriais, não havia computadores, etc. Como os cientistas fizeram para "identificar"; "experimentar" e "formular" a teoria da cinética química? Será 
que foi apenas um cientista que formulou toda a teoria ou foram vários? Será que todos os fatores foram descobertos de uma vez só ou alguns fatores foram identificados primeiro e outros depois? O que estava acontecendo no "Mundo" na época em que a teoria foi elaborada? Irei pedir que eles respondam mesmo sem saber todas essas perguntas e irei listando as respostas dadas por eles na lousa (pode ser que "saiam" respostas corretas ou as mais absurdas porém como eles ainda não pesquisaram sobre o assunto a professora fará anotações do jeito que eles responderem).

Em seguida irei distribuir cópias do texto: 100 anos de Nobel - Jacobus Henricus Van’t Hoff para se lido na aula (se possível irei tirar cópias para cada aluno; se não, irei tirar poucas cópias e pedirei que eles façam a leitura em grupo). Após a leitura do texto sobre Van't Hoff, irei pedir que eles façam uma pesquisa para tentar responder corretamente as questões citadas acima.

$2^{\text {a }}$ Aula: Iremos fazer uma roda de conversa sobre o texto lido e ouvir as respostas dos alunos para as perguntas que foram feitas na aula anterior de acordo com as pesquisas que eles fizeram. Irei listar na lousa novamente as respostas que eles deram na aula anterior, antes de fazer a pesquisa e ao lado colocarei as respostas para as mesmas perguntas, porém, agora com a pesquisa feita. Irei fazer um comparativo com eles; para ver o que eles sabiam antes ou não e o que eles aprenderam com as suas pesquisas (vou pedir que eles façam as anotações, da listagem que a professora escreveu na lousa, no caderno).

Em seguida, pedirei que eles discutam por alguns minutos, sobre a importância de analisarmos os fatos históricos envolvidos no conceito de uma teoria, para que possamos entendê-la melhor. Eles terão que expressar suas opiniões. Essa roda de conversa mais debate terá que durar uns 20 min, dependendo da classe, pois, na sequência irei passar na lousa os conceitos de velocidade de uma reação química e os fatores que alteram a mesma (temperatura, superfície de contato, pressão e catalisador).

Passarei uma lição de casa com o tema: elaboração de um texto com o título "Por que é importante estudar sobre a História da Ciência?" que deverá ser entregue na aula seguinte.

3a Aula: Recolher a lição de casa; entregar uma cópia de uma lista de exercício sobre cinética química para se entregue na aula seguinte (lição de casa). 
Aula prática: realização do experimento com o comprimido efervescente, (experimento de demonstração, com material providenciado pela professora, realizado dentro de sala de aula, pois a escola não possui laboratório), analisando somente o fator temperatura: água gelada, água quente e água a temperatura ambiente. Explicação e montagem de um relatório de laboratório.

4ª Aula: Explicação sobre a construção de um gráfico de cinética química. Construção de um gráfico de cinética química temperatura $x$ tempo (feito no caderno). Recolhimento das avaliações escritas: Lista de Exercícios (individual), Relatório de Laboratório (grupo), Gráfico (individual).

No plano de ensino da professora não está claro se ao trabalhar com o fator temperatura ela irá usar um modelo teórico para explicar essa influência, portanto, considerou-se que ela irá somente abordar os aspectos macroscópicos (MEM).

Em relação à História da Química para essa professora essa estratégia tem a finalidade de ensinar e entender como os conceitos químicos foram elaborados: “...Em seguida, pedirei que eles discutam por alguns minutos, sobre a importância de analisarmos os fatos históricos envolvidos no conceito de uma teoria, para que possamos entendê-la melhor". (Categoria C4 da HQ), como também a origem desses conhecimentos (categoria C3 da HQ):

Como os cientistas fizeram para "identificar"; "experimentar" e "formular" a teoria da cinética química? Será que foi apenas um cientista que formulou toda a teoria ou foram vários? Será que todos os fatores foram descobertos de uma vez só ou alguns fatores foram identificados primeiro e

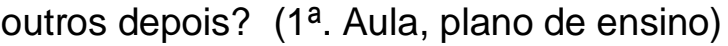

Pode-se perceber que a imagem sobre a natureza da ciência dessa professora, no objetivo de seu plano de ensino, é coerente com a perspectiva filosófica racionalista:

Tentar construir uma visão racionalista no ensino da ciência para que os alunos possam diferenciar o senso comum do senso crítico; bem como identificar que o conhecimento científico não é estático, nem construído por apenas uma única pessoa; que as teorias científicas são válidas enquanto "dão conta" de resolver as práticas dos seres humanos e que podem ser perfeitamente substituídas por 
outras quando não conseguem mais dar explicações a vários fatos.

Contudo, na sequência de seu plano percebem-se ideias que são coerentes com a perspectiva filosófica empirista/indutivista, como por exemplo, na primeira aula: Como os cientistas fizeram para "identificar"; "experimentar" $e$ "formular" a teoria da cinética química? ... (grifo nosso), onde podem ser observadas as etapas do método cientifico: observar (identificar), experimentar e elaborar a teoria.

No quadro a seguir podem-se observar, nos três momentos do curso de formação continuada, os modelos de ensino dessa professora:

\begin{tabular}{|c|l|c|c|c|}
\hline \multirow{2}{*}{ ETAPA } & INSTRUMENTOS & CINÉTICA QUÍMICA & HISTÓRIA DA QUÍMICA & $\begin{array}{c}\text { IMAGEM DA } \\
\text { CIÊNCIA }\end{array}$ \\
\hline \multirow{4}{*}{ INÍCIO } & INSTRUMENTO 1 & - & C1 & \\
\cline { 2 - 5 } & INSTRUMENTO 2 & & - & E/I, R \\
\hline \multirow{5}{*}{ DURANTE } & ATIVIDADE 1 & & - & \\
\cline { 2 - 5 } & ATIVIDADE 2 & & & $\mathrm{R}$ \\
\cline { 2 - 5 } & ATIVIDADE 4 & & & $\mathrm{R}$ \\
\cline { 2 - 5 } & ATIVIDADE 6 & MEM & & \\
\cline { 2 - 5 } & INSTRUMENTO 3 & & & $\mathrm{R}$ \\
\cline { 2 - 5 } & EXPERIMENTO 3 & MES1 & & E/I, R \\
\cline { 2 - 5 } & EXERCICIO 1 & MEM & & \\
\hline \multirow{2}{*}{ FINAL } & ATIVIDADE 8 & MES2 & C3, C4 & \\
\cline { 2 - 5 } & PLANO DE ENSINO & MEM & & \\
\hline
\end{tabular}

Quadro 4.18 Modelos de ensino de cinética química do professor P9 nas diferentes etapas do curso de formação. 


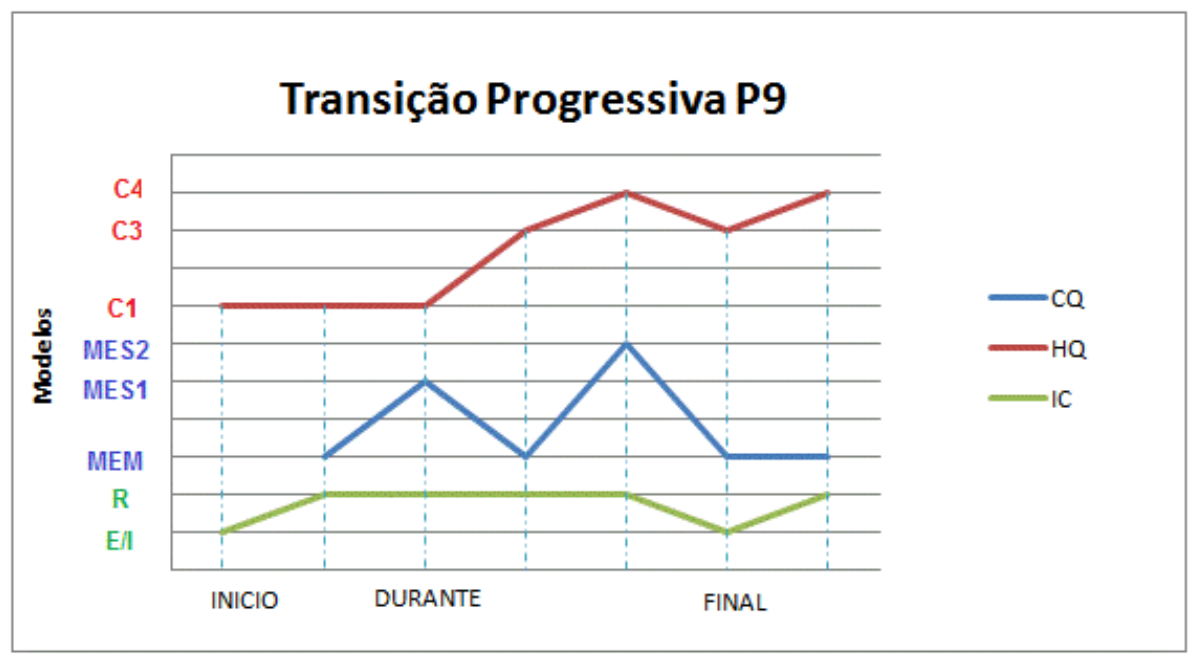

Figura 4.24 Transição progressiva da professora P9 nas três fases da pesquisa, em relação aos seguintes aspectos de seu modelo de ensino: $\mathrm{CQ}$ : cinética química, $\mathrm{HQ}$ : História da Química e IC: imagem da ciência.

No gráfico acima pode ser observado que o curso de formação continuada facilitou a transição progressiva em dois aspectos analisados, a História da Química e Imagem sobre a natureza da ciência, pois a professora começou a apresentar ideias relacionadas à perspectiva filosófica racionalista. Contudo, em relação à cinética química, percebe-se a dificuldade da professora em usar um modelo teórico no seu plano de ensino. Embora nos objetivos de seu plano (atividade 8, Apêndice VIII), ela tenha incluído conceitos ligados a teoria do estado de transição: "Entender como ocorre a quebra de uma ligação química e a formação de novas substâncias", durante a sequência de suas aulas ela não informa como irá trabalhar com esse conteúdo.

A ideia de um método científico único aparece novamente nas ideias dessa professora. Segundo Oki e Moradillo (2009), isso pode estar relacionado a formação desses professores, pois, muitos currículos da licenciatura seguem o modelo tradicional, no qual não há articulação entre o ensino de História das Ciências por disciplinas especificas e conteúdos da filosofia da ciência. 


\section{P10}

Fase inicial

Para esta professora o ensino de cinética química é importante: "Porque dessa forma ,o aluno entende que não pode ir misturando tudo, aleatoriamente, e entende, por exemplo, o perigo de uma explosão em determinada ação.".

Conteúdo que ela normalmente aborda em suas aulas: "Não ensino não me sinto segura, exibo um filme com o tema e a explicação".

Ela conteúdo de cinética química que considera difícil abordar: "Equilíbrio químico, porque é abstrato para o aluno”.

Quanto à experimentação ela não usa esse recurso em suas aulas. Normalmente usa filmes retirados do "youtube". Quando questionada por que o experimento é importante no ensino de cinética química sua resposta é: "Ajuda, mas principalmente à noite o tempo é muito curto e duas aulas por semana é muito pouco".

Em relação à História da Ciência $(\mathrm{HC})$, embora ela considere importante a sua inclusão no ensino, "Porque dessa forma os alunos conseguem entender como os cientistas chegaram as suas conclusões e principalmente entender que ninguém vai ao laboratório para descobrir tal coisa. Entender que a partir da observação ele vai tirando conclusões e observando fatos", ela afirma não usar em suas aulas.(categoria $\mathrm{C} 4$ da $\mathrm{HQ}$ )

Em relação a sua imagem sobre a natureza da ciência (instrumento 2, Apêndice VII), a professora escolheu todas as afirmações do instrumento.

Pela análise das respostas da professora, em relação ao seu ensino de cinética química, não foi possível indicar esse aspecto no seu modelos de ensino. Os únicos aspectos que foram identificados desse modelo foi a sua imagem da ciência que esta relacionada tanto a perspectiva filosófica empirista/indutivista $(E / I)$ como a perspectiva racionalista $(R)$, e o seu entendimento sobre o papel da História da Química no ensino (categoria C4). 


\section{Fase intermediária}

Quanto à atividade 6 (quarto encontro, Apêndice $\mathrm{XI}$ ), a professora não mostrou ter o entendimento de como se dá a variação da velocidade de uma reação com o tempo, justificando que: "A velocidade aumenta" (modelo de aumento - MA (Cakmakci et al, 2005). Sua explicação de como se dá a influência da temperatura na velocidade da reação nesse mesmo exercício é: " $A$ temperatura possui forte influência", portanto, percebe-se que em suas explicações não aparece um modelo teórico, nem o uso de termos relacionados a partículas (MEM).

A professora não realizou a atividade experimental 3 (quarto encontro, Apêndice XII), como também não fez o próximo exercício sobre gráficos (exercício 1, quinto encontro, Apêndice XV), por ter faltado ao encontro.

Em relação à História da Química (atividade 1, primeiro encontro, Apêndice III), a professora indicou como iria utilizar essa estratégia no ensino: "Mostrar a evolução das ideias, dos pensamentos. Mostrar que as ideias dependem de um determinado contexto" ( categorias C2 e C3 da HQ)

No segundo encontro, os professores leram um documento oficial sobre 0 papel da HQ no ensino de ciências (atividade 2, Apêndice VI). A professora concordou com a ideia defendida e justificou: "Sim, proporcionar ao aluno descobrir como tudo ocorreu e a partir daí tirar suas próprias conclusões, permite uma escalada para a construção dos diferentes saberes" ( categorias C3 e C4 da $\mathrm{HQ})$

Ela aponta como uma dificuldade em abordar a historia da ciência no ensino o pouco tempo de aula.

$\mathrm{Na}$ atividade 4 (terceiro encontro, Apêndice IX), a professora construiu o seguinte mapa conceitual: 


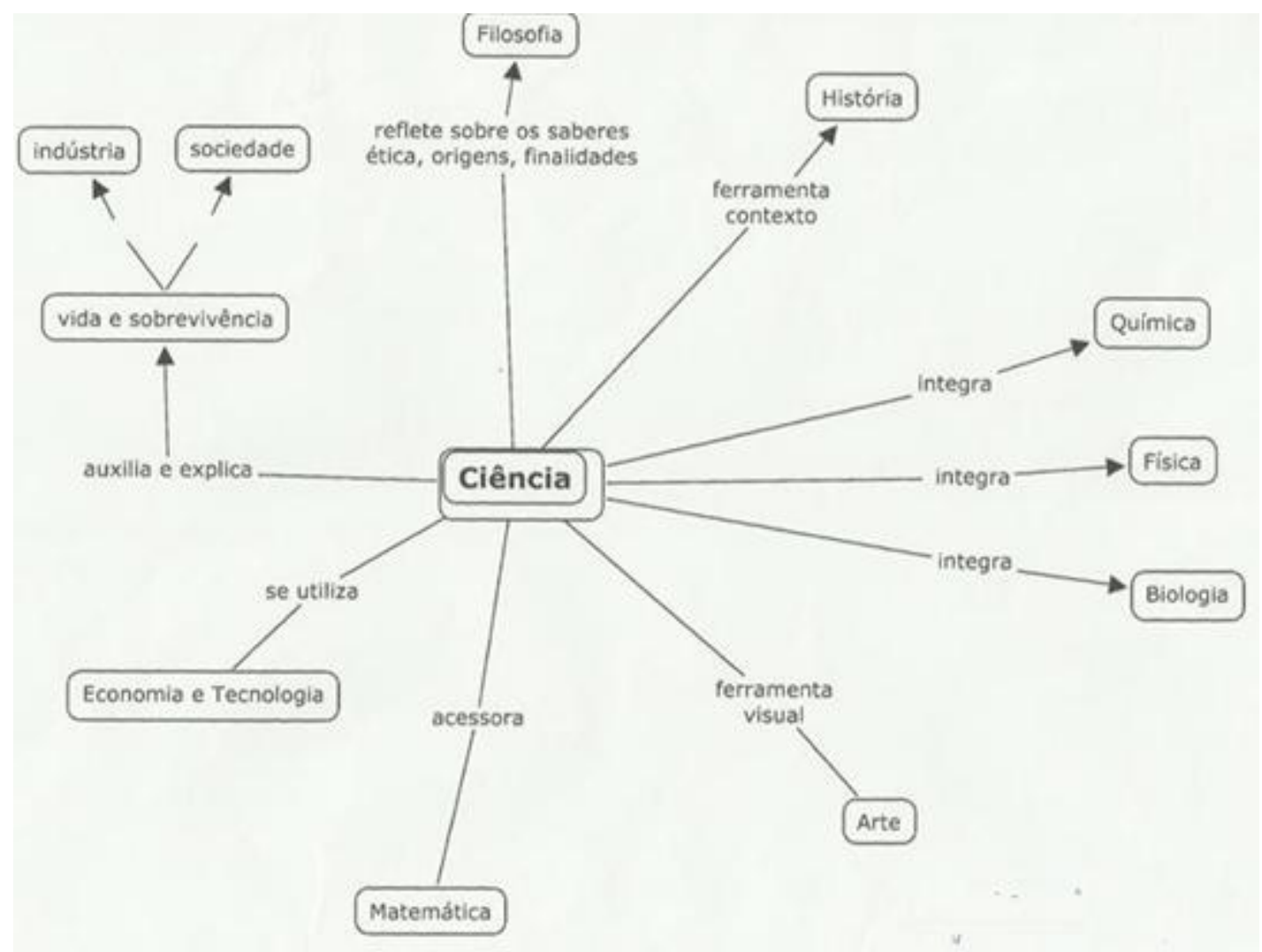

Figura 4. 25 Esquema sobre a imagem da ciência elaborado pela professora P10.

Em seu esquema a professora relaciona a ciência a várias áreas de conhecimento inclusive à filosofia e à história. Pode-se inferir que estas relações, que fazem parte da imagem sobre a natureza dessa professora, são coerentes com a perspectiva filosófica racionalista $(R)$

Sua imagem sobre a natureza da ciência, após a discussão (instrumento 3 , Apêndice XIV) no quinto encontro é: "Ciência é o estudo de um fenômeno ou fato em que aproveitamos todas as observações, conhecimentos pré-aprendidos, teorias desenvolvidas, esquemas mentais, para construir o conhecimento de forma efetiva na resolução de problemas relacionados à natureza". (perspectiva racionalista)

Pela análise das respostas da professora, verifica-se que esta fase está baseada, principalmente, nos aspectos macroscópicos da cinética química (MEM). Observa-se que esse modelo sofre influência das ideias que pertencem à perspectiva racionalista $(\mathrm{R})$. Para essa professora a história da química pode 
facilitar 0 entendimento de onde vieram as ideias e conhecimentos que possuímos atualmente (categoria C3), como também ajudar os alunos a entender como um determinado conceito foi construído (categoria $\mathrm{C} 4$ ).

\section{Fase final}

Na avaliação final (oitavo encontro, Apêndice XIX) a professora apontou em relação à superação das dificuldades sobre o ensino de cinética química: "Principalmente por mim, porque não tive esses ensinamentos na faculdade. Eu aprendi aqui, com vocês".

Com relação à superação das dificuldades sobre o uso da História da Química: "Sim, acredito que essas dificuldades foram superadas, mas sem o auxilio inicial eu não conseguira".

Sobre quais aspectos relacionados à sua prática a professora refletiu através do curso, ele respondeu que refletiu sobre: "Simplificação dos conteúdos de cinética direcionados aos alunos do ensino médio. Englobando a História torna o conhecimento mais próximo e visível do aluno".

Plano de ensino:

Em relação ao plano de ensino (folha de atividade 8, Apêncice XVII) dessa professora, podem-se observar no quadro a seguir as habilidades e competências em relação aos conceitos de cinética química, História da Química e a visão sobre a natureza da ciência, que ela pretende que seus alunos desenvolvam:

\begin{tabular}{|c|c|c|}
\hline Tema & Habilidade e competências & Análise \\
\hline $\begin{array}{l}\text { Conceitos } \\
\text { da cinética } \\
\text { química }\end{array}$ & $\begin{array}{l}\text { Reconhecer que ela está presente em todas as reações (lentas ou } \\
\text { rápidas). Reconhecer os fatores que influem na cinética: } \\
\text { temperatura, superfície de contato, concentração, uso de catalisador } \\
\text { e pressão. Comparar o uso de aditivos e conservantes no sentido de } \\
\text { acelerar ou retardar um processo de transformação química. Ser } \\
\text { capaz de escolher os melhores métodos e sua respectiva aplicação. } \\
\text { Ser capaz de analisar e decidir o consumo de produtos alimentícios. } \\
\text { Inteirar-se dos seus direitos enquanto consumido. Fazer com que o } \\
\text { aluno veja e comprove através de experimentos simples, alguns } \\
\text { fatores que podem influenciar nas velocidades das transformações } \\
\text { químicas. }\end{array}$ & MEM \\
\hline
\end{tabular}


Visão

sobre a

natureza

Visão de ciência através do racionalismo

$\mathrm{R}$

da ciência

História da Analisar os métodos e compará-los com os mais antigos,

Química comparando tecnologias.

Quadro 4.19 Habilidades e competências indicadas no plano de ensino da professora P10.

Em relação aos outros tópicos do plano dessa professora:

- Objetivo:

Usando o tema conservação de alimentos, mostrar as dificuldades a respeito da deterioração, o uso dos conservantes e métodos para diminuir as reações a fim de conservar os alimentos por um período maior de tempo.

- Conteúdos:

CQ: Fatores que influenciam na rapidez de uma reação: Temperatura, superfície de contato, concentração, pressão e catalisadores.

HFC: Valorizar o conhecimento dos povos antigos quanto às técnicas de conservação de alimentos; valorizar os progressos das ciências e suas aplicações como bem estar do ser humano.

- Estratégias:

Texto (conservação de alimentos), simulações (Labivirt- Conservação de alimentos) e atividades experimentais (Explosão de Cores: corantes nos alimentos e Experiência da Maçã: http://www.youtube.com/watch?v=Elm7OQpfHFw).

- Sequência:

1. Esboçar Gráficos que mostrem a variação ao longo do tempo da quantidade de reação e de produtos de uma reação;

2. Atentar aos rótulos de produtos industrializados, quanto a sua conservação;

3. Manusear materiais caseiros a fim de comparar a rapidez das transformações da aparência, de acordo com a temperatura e o tempo. Por exemplo: carne moída e inteira, maçã inteira e cortada ao meio;

4. Valorizar o conhecimento dos povos antigos quanto às técnicas de conservação de alimentos;

5. Utilizar dados experimentais, como por exemplo: Explosão de cores ou comprimidos efervescentes, a fim de determinar as leis da cinética química em um processo;

6. Apontar os princípios científicos que estão no nosso dia a dia; Investigar experimentalmente o que vem a ser a conservação de alimentos. Por exemplo, a experiência da maçã;

7. Valorizar os progressos das ciências e suas aplicações como bem estar do ser humano; 
8. Fazer um elo entre esse aprendizado e os direitos do consumidor.

Em relação à História da Química para essa professora essa estratégia tem a finalidade de informar como determinadas técnicas de conservação de alimentos foram elaboradas (categoria C3):

Valorizar o conhecimento dos povos antigos quanto às técnicas de conservação de alimentos; valorizar os progressos das ciências e suas aplicações como bem estar o ser humano." (plano de ensino, P10)

No quadro a seguir podem ser observados, nos três momentos do curso de formação continuada, os modelos de ensino dessa professora:

\begin{tabular}{|c|c|c|c|c|}
\hline ETAPA & INSTRUMENTOS & $\begin{array}{l}\text { CINÉTICA } \\
\text { QUÍMICA }\end{array}$ & $\begin{array}{l}\text { HISTÓRIA DA } \\
\text { QUÍMICA }\end{array}$ & $\begin{array}{l}\text { IMAGEM DA } \\
\text { CIÊNCIA }\end{array}$ \\
\hline \multirow{2}{*}{ INÍCIO } & INSTRUMENTO 1 & - & C4 & \\
\hline & INSTRUMENTO 2 & & & $E / I, R$ \\
\hline \multirow{7}{*}{ DURANTE } & ATIVIDADE 1 & & $\mathrm{C} 2, \mathrm{C} 3$ & \\
\hline & ATIVIDADE 2 & & $\mathrm{C} 3, \mathrm{C} 4$ & \\
\hline & ATIVIDADE 4 & & & $\mathrm{R}$ \\
\hline & ATIVIDADE 6 & MEM & & \\
\hline & INSTRUMENTO 3 & & & $\mathrm{R}$ \\
\hline & EXPERIMENTO 3 & - & & \\
\hline & EXERCICIO 1 & - & & \\
\hline \multirow{2}{*}{ FINAL } & ATIVIDADE 8 & MEM & $\mathrm{C3}$ & $\mathrm{R}, \mathrm{E} / \mathrm{I}$ \\
\hline & PLANO DE ENSINO & MEM & C3 & $\mathrm{R}$ \\
\hline
\end{tabular}

Quadro 4.20 Modelos de ensino de cinética química do professor P10 nas diferentes etapas do curso de formação.

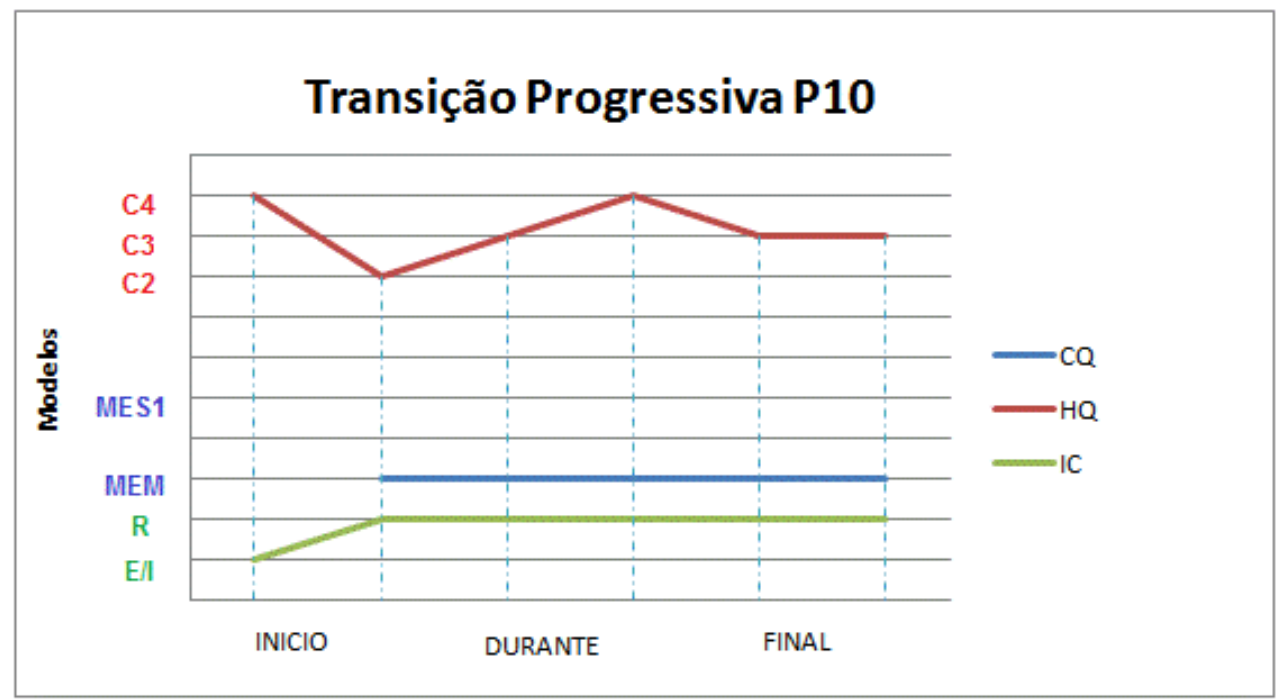


Figura 4.26 Transição progressiva da professora P10 nas três fases da pesquisa, em relação aos seguintes aspectos de seu modelo de ensino: $C Q$ : cinética química, $H Q$ : História da Química e IC: imagem da ciência.

Percebe-se, que o curso de formação continuada pode ter facilitado a transição progressiva nos aspectos relacionados à sua imagem sobre a natureza da ciência e ao entendimento do papel da História da Química no ensino (fig, 4.26). Contudo, em relação ao papel da experimentação, as ideias dessa professora ainda são coerentes com a perspectiva empirista/indutivista: "Fazer com que o aluno veja e comprove através de experimentos simples, alguns fatores que podem influenciar nas velocidades das transformações químicas (quadro 4.19).

Em relação a cinética química, a professora continuou somente com o modelo macroscópico. Essa dificuldade na transição do modelo, em relação a cinética química, pode ser devida a não realização de duas atividades, nas quais os modelos foram discutidos durante o curso de formação.

Em relação às estratégias de ensino, em seu plano a professora indicou o uso de textos, experimentos e simulações, como também incluiu a elaboração de gráficos, portanto, pode-se inferir que o curso proporcionou a essa professora 0 conhecimento de novas maneiras de se abordar a cinética química. Contudo, a abordagem histórica, segundo Pozo e Crespo (2009) não proporcionou a professora oportunidade de incluir atividades que utilizam procedimentos que sejam próximos aos que utiliza um cientista em suas pesquisas (formular e comprovar hipóteses, medir, contrastar modelos, etc), mas somente de incluir outros procedimentos específicos já não da ciência, mas da aprendizagem escolar, como ler e compreender os textos, decodificar os gráficos, entre outros.

\section{P11}

\section{Fase inicial}

Respostas as questões referentes ao instrumento 1 (Apêndice II): 
Quanto à importância da cinética química, a professora justifica que "Uma parte do conteúdo do ensino das velocidades de reações pode contribuir no seu cotidiano".

O que para ela é importante ensinar: "Infelizmente no ensino estadual abordo muito pouco, me apego mais à parte que considero mais fácil para eles que são os fatores que aceleram a velocidade de reação".

O que ela ensina: "Faço uma abordagem sobre os fatores, no ensino particular também abordo a teoria das colisões, um pouco de cálculo de velocidade e catalisadores". (MES1)

Sua maior dificuldade: Teoria das colisões (colisões efetivas e não efetivas), porque, segundo ela: "Vejo que para o aluno (principalmente do estado) fica um pouco abstrato".

Quanto às estratégias usadas pela professora em suas aulas, embora ela tenha colocado a importância da cinética no cotidiano do aluno, em suas aulas ela não utiliza exemplos de aplicações desse conhecimento.

A atividade experimental que realiza é a do comprimido efervescente, para todos os fatores que interferem na velocidade de uma reação química. Como justificativa para o uso do experimento ela coloca que: "Eles têm a oportunidade de vivenciar a teoria. Porém, nem sempre é possível devido ao tempo".

A professora em suas aulas, sobre o tema cinética química, não aborda a História da Ciência embora ela considere que seja importante: é importante, porém é uma estratégia que ainda uso "muito pouco".

Analisando-se sua imagem sobre a natureza da ciência, as afirmações que ela assinalou no instrumento 2 (Apêndice VII), são todas aquelas que se referem à perspectiva empirista/Indutivista.

Pode-se perceber a perspectiva empirista/indutivista na justificativa da professora quando ela indica que com o experimento: "Eles têm a oportunidade de vivenciar a teoria", ou seja, o experimento aqui teria a função de comprovar a teoria já vista em sala de aula. 
Pela análise das respostas da professora, observa-se que ela, no seu ensino, inclui um modelo teórico para explicar a influência dos fatores na velocidade de uma reação química, a teoria das colisões (MES1), embora, ela aponte que em suas aulas nas escolas estaduais ela não inclua essa explicação. Este modelo inicial de ensino pode ser caracterizado pelas ideias da perspectiva filosófica empirista/indutivista (E/I). Em relação ao aspecto entendimento do papel da História da Química no ensino, não foi possível identificar, nas respostas das atividades, as ideias dessa professora.

\section{Fase intermediária}

Quanto à atividade 6 (quarto encontro, Apêndice XI), a professora mostrou ter o entendimento de como se dá a variação da velocidade de uma reação com o tempo, justificando que a velocidade "Diminui com o tempo" (modelo científico MC; Cakmakci et al, 2005). A sua explicação de como se dá a influência da temperatura na velocidade da reação nesse mesmo exercício é: "A reação numa temperatura maior é mais rápida", portanto, percebe-se que em suas explicações não aparece um modelo explicativo (MEM).

$\mathrm{Na}$ atividade experimental 3, sobre o efeito da temperatura na velocidade de uma reação (quarto encontro, Apêndice XII ), sua explicação não inclui termos relacionados a partículas: "quanto maior a temperatura maior a rapidez da transformação". Quando, na mesma atividade se pedia uma explicação com o uso de um modelo de partículas para explicar por que a transformação é mais lenta quando realizada em água gelada, o professora escreveu: "O número de choques efetivos será menor a uma temperatura mais baixa. Uma maior temperatura significa maior energia cinética, disponibilizando um maior número de espécies químicas para entrar em reação". Portanto, a professora inclui termos relacionados a um modelo teórico, a teoria das colisões, em sua explicação (MES1).

No próximo exercício sobre gráficos (exercício 1, quinto encontro, Apêndice $\mathrm{XV}$ ) a professora não soube responder deixando sua folha em branco. 
Em relação à História da Química (atividade 1, primeiro encontro, Apêndice II), a professora indicou como iria utilizar essa estratégia no ensino: "Fazer pequenos resumos de artigos para suscitar a curiosidade dos alunos pelo tema que seria abordado". (categoria C1 da HQ)

As vantagens para ela seriam: "Propicia aos alunos ficarem mais familiarizados com as pessoas que participaram da história". (categoria C3 da $\mathrm{HQ})$

No segundo encontro, os professores leram um documento oficial sobre 0 papel da HQ no ensino de ciências (atividade 2, Apêndice Vl). A professora concordou com a ideia defendida no documento justificando:

Sim, porém se eu fosse utilizar deste texto eu faria uma síntese das ideias mais importantes para passá-las aos alunos, porque acho que eles talvez achassem o texto na íntegra um pouco difícil e os confundiriam (principalmente os alunos do estado).

Para ela a maior dificuldade em trabalhar com a HQ seria:

Teria que ter conhecimento de materiais que abordassem essa história em diversos momentos e talvez simplifica-la para passa-la de forma sintética para os alunos (até devido ao tempo). Teria que passá-la de maneira introdutória de no máximo 10 minutos. Tenho alguma dificuldade em conseguir esse material. Nas minhas aulas tenho passado alguns tópicos como: desenvolvimento de modelos atômicos, processo de produção de amônia e estudo da tabela periódica.

A professora não realizou a atividade 4, relativa ao mapa conceitual sobre a imagem da ciência.

$\mathrm{Na}$ atividade realizada sobre as diferenças entre as duas perspectivas filosóficas, empirista/indutivista e racionalista (instrumento 3, Apêndice XIV) no quinto encontro, a professora escreveu:

Ciência são questões que nos intrigam e que nos levam a investigar fatos e por vezes a experimentação, com isso reelaboramos ideias e construímos teorias. A ciência é abrangente precisamos nos apossar de todas as ferramentas possíveis de outras áreas. 
Pela análise das respostas da professora, observa-se que seu modelo de ensino nessa fase está baseado nos aspectos microscópicos da cinética química (MES1). Este modelo é marcado principalmente pela perspectiva filosófica racionalista $(\mathrm{R})$. Para essa professora a história da química pode facilitar o entendimento de onde vieram as ideias e conhecimentos que possuímos atualmente (categoria C3), como também despertar a curiosidades dos alunos para o assunto que irá ser abordado (categoria C1).

\section{Fase final}

$\mathrm{Na}$ avaliação final (oitavo encontro, Apêndice XIX) a professora apontou em relação à superação das dificuldades sobre o ensino de cinética química: "sim, porém ainda sinto dificuldade em abordar com os alunos a questão de ordem de reação".

Com relação à superação das dificuldades sobre o uso da História da Química: "A falta de materiais, textos e fontes, sim. Falta agora aplicar minhas ideias, verificar se as ideias que tenho são válidas, se deu certo ou não, reavaliadas. Sinto ainda alguma dificuldade por ser uma coisa nova".

Sobre quais aspectos relacionados à sua prática a professora refletiu através do curso, ela respondeu que: "Estou refletindo sobre a ordem do conteúdo a ser dado para que contemple as ideias que venho tendo sobre a visão da ciência".

\section{Plano de ensino}

Em relação ao plano de ensino (folha de atividade 8, Apêncice XVII) dessa professora, podem-se observar no quadro a seguir as habilidades e competências em relação aos conceitos de cinética química, História da Química e a visão sobre a natureza da ciência e que ela pretende que seus alunos desenvolvam:

Tema

Conceitos da cinética
Habilidade e competências

Compreender os fatores que levam a variar a velocidade de uma reação química e até o que leva uma reação ocorrer. Transpor esses conceitos para interpretar gráficos. Avaliar a
Análise

MEM 


\begin{tabular}{lll}
\hline química & $\begin{array}{l}\text { importância desses conceitos para uma indústria e na ação de } \\
\text { remédios. }\end{array}$ & $\mathrm{R}$ \\
$\begin{array}{l}\text { Visão sobre } \\
\text { a natureza } \\
\text { da ciência }\end{array}$ & $\begin{array}{l}\text { Constatar que os estudos relacionados à compreensão dos } \\
\text { fenômenos químicos, no caso da velocidade da reação, foram } \\
\text { construídos passo a passo por varias teorias que no decorrer } \\
\text { do tempo foram se completando. Perceber que esses estudos } \\
\text { foram resultados de experimentos que levaram muito tempo } \\
\text { para serem avaliados. }\end{array}$ & \\
História da & $\begin{array}{l}\text { Reconhecer o desenvolvimento histórico que levaram os } \\
\text { diversos cientistas ao conhecimento que se tem hoje sobre os } \\
\text { Química }\end{array}$ & C3 \\
\hline
\end{tabular}

Quadro 4.21 Habilidades e competências indicadas no plano de ensino da professora P11.

Em relação aos outros tópicos do plano dessa professora:

- Objetivos:

HFC: Conhecer alguns processos históricos que levaram ao conhecimento que se tem hoje sobre a influência da concentração na rapidez da reação e conhecer alguns cientistas que colaboraram nesse processo.

$C Q:$ Perceber que toda reação necessita de um certo tempo para se completar. Avaliar a influência da concentração de reagentes na otimização de processos na indústria química. Perceber as relações quantitativas que expressam a rapidez de uma transformação química, reconhecendo, selecionando ou propondo procedimentos experimentais que permitam o estabelecimento das relações matemáticas existentes. Compreender como se mede a rapidez da reação, calculando a taxa de variação ao longo da quantidade de algum reagente ou produto.

- Conteúdos:

Efeito da concentração sobre a rapidez de reações: aspectos qualitativos e quantitativos. Fatores que influenciam a velocidade das transformações: temperatura e superfície de contato. Teoria das colisões. Energia de ativação. Complexo ativado. Lei da velocidade.

- Estratégias:

Questões orais sobre a abordagem prévia sobre o assunto. Pesquisas (história da cinética química), mapa conceitual do desenvolvimento do estudo sobre a velocidade da reação de acordo com a concentração. Interpretação de gráficos e tabelas. Manusear materiais caseiros. Experimentação (comprimido efervescente, fígado cru). Utilizar dados 
experimentais cinéticos adequados a fim de perceber como a concentração atua na rapidez da reação.

- Sequência:

1. Experimento: Fatores que influenciam a velocidade das transformações: conservação de alimentos

2. Experimento: Fatores que influenciam a velocidade das transformações: temperatura e superfície de contato.

3. Fatores que influenciam a velocidade das transformações: concentração temperatura e superfície de contato/ Teoria das colisões.

4. Catalisadores; exercícios (apostila).

5. Lei da velocidade; Exercícios (análise de gráficos).

6. Contexto histórico; Resolução de exercícios.

7. Aplicação de questionário sobre imagens da ciência.

8. Atividade de avaliação final.

No conteúdo a professora aponta que irá abordar modelos teóricos para explicar a influência dos fatores na velocidade de uma reação.

Em relação à História da Química para essa professora essa estratégia tem a finalidade somente de informar a origem dos conceitos químicos (categoria C3): “Conhecer alguns processos históricos que levaram ao conhecimento que se tem hoje sobre a influência da concentração na rapidez da reação e conhecer alguns cientistas que colaboraram nesse processo". (plano de ensino, P11)

Em relação a imagem sobre a natureza da ciência, no plano de ensino a imagem que ela quer que seus alunos desenvolvam, pode-se inferir que se refere a perspectiva racionalista, pois existe a preocupação da professora de mostrar a ciência como uma construção humana.

No quadro a seguir podem ser observados, nos três momentos do curso de formação, os modelos de ensino dessa professora: 


\begin{tabular}{|c|c|c|c|c|}
\hline ETAPA & INSTRUMENTOS & $\begin{array}{l}\text { CINÉTICA } \\
\text { QUÍMICA }\end{array}$ & $\begin{array}{l}\text { HISTÓRIA DA } \\
\text { QUÍMICA }\end{array}$ & $\begin{array}{c}\text { IMAGEM DA } \\
\text { CIÊNCIA }\end{array}$ \\
\hline \multirow{2}{*}{ INÍCIO } & INSTRUMENTO 1 & MES1 & - & \\
\hline & INSTRUMENTO 2 & & & $E / I$ \\
\hline \multirow{7}{*}{ DURANTE } & ATIVIDADE 1 & & $\mathrm{C} 1$ & \\
\hline & ATIVIDADE 2 & & $\mathrm{C} 3$ & \\
\hline & ATIVIDADE 4 & & & - \\
\hline & ATIVIDADE 6 & MEM & & \\
\hline & INSTRUMENTO 3 & & & $\mathrm{R}$ \\
\hline & EXPERIMENTO 3 & MES1 & & \\
\hline & EXERCICIO 1 & - & & \\
\hline \multirow{2}{*}{ FINAL } & ATIVIDADE 8 & MEM & C3 & $\mathrm{R}$ \\
\hline & PLANO DE ENSINO & MES1, MES2 & C3 & $\mathrm{R}$ \\
\hline
\end{tabular}

Quadro 4.22 Modelos de ensino de cinética química do professor P11 nas diferentes etapas do curso de formação.

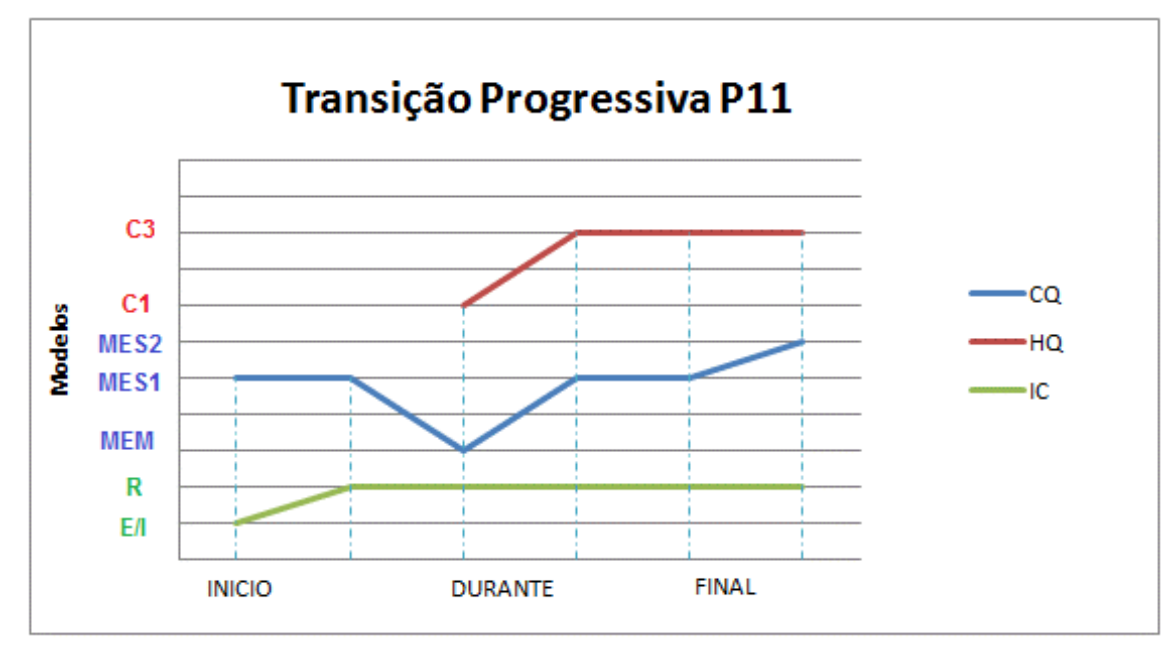

Figura 4.27 Transição progressiva da professora P11 nas três fases da pesquisa, em relação aos seguintes aspectos de seu modelo de ensino: $C Q$ : cinética química, $H Q$ : História da Química e IC: imagem da ciência.

Na figura 4.27 verifica-se a transição progressiva da professora P11 em relação aos seus modelos de ensino. Percebe-se que em relação a cinética química, a professora, embora em duas atividades (6 e 8) não tenha indicado um modelo teórico, no seu plano de ensino ela escolheu trabalhar com as ideias pertencentes aos modelos MES1 e MES2, contudo, na sua sequencia de ensino não aparece como irá ser abordada a teoria do estado de transição. 
Em relação a História da Química, percebe-se que seu objetivo é o de fornecer informações para seus alunos e informar a origem de um determinado conhecimento, ela não é abordada em sala de aula com o objetivo de ensinar os conceitos relacionados à cinética química.

\section{P12}

\section{Fase inicial}

Respostas as questões referentes ao instrumento 1 (Apêndice II):

Para esta professora o ensino de cinética química é importante: "Porque as reações químicas estão presentes no nosso cotidiano. Algumas são desejáveis outras não. Sabendo do modo como elas ocorrem podemos interrompê-las, acelera-las ou retardar o seu acontecimento".

Quanto ao conteúdo que é importante ensinar, ela aponta: "São as transformações que podem ocorrer com a matéria e o gasto de energia para que ocorra". Conteúdo que ela normalmente aborda em suas aulas: Reações químicas. Tipos e velocidades das reações. (MEM)

Um dos conteúdos que ela indica que tem maior dificuldade em ensinar é: "A interação que ocorre entre os átomos para que as reações aconteçam". Porque, segundo ela: "Me parece que os alunos não conseguem pensar na matéria descontínua".

Quanto à experimentação é usada para demonstrar os fatores que influenciam a velocidade de uma reação química: concentração: "Concentração: Ataque de um ácido a um metal; Superfície de contato: sorrisol; Temperatura: dicromato de amônio e magnésio". Quando questionada por que o experimento é importante no ensino de cinética química sua resposta é que: "O experimento prova a teoria".

Em relação à História da Ciência, embora ela considere importante a sua inclusão no ensino, "Porque é importante saber quando, onde e porque a 
curiosidade sobre determinado assunto começou e até onde ela fez com que a ciência avançasse” (categoria C3 da HQ), ela afirma não usar em suas aulas.

Em relação a sua imagem sobre a natureza da ciência (instrumento 2, Apêndice VII), a professora escolheu as seguintes afirmações:

- A ciência tem evoluído historicamente mediante a acumulação sucessiva das teorias verdadeiras.(E/I)

- O conhecimento é construído com base em teorias que orientam a observação, em outras palavras, uma observação depende da teoria.(R)

- Toda investigação científica começa pela observação rigorosa do fenômeno que se estuda.(E/l)

- O conhecimento científico se gera graças à capacidade que os seres humanos possuem para propor problemas e imaginar possíveis soluções aos mesmos.(R)

- Através do experimento, o investigador comprova se sua hipótese de trabalho é verdadeira ou falsa.(E/I)

- As hipóteses dirigem o processo de investigação científica.(R)

Pela análise das respostas da professora, observa-se que a fase inicial está baseada nos aspectos macroscópicos da cinética química (MEM). Este modelo inicial de ensino é marcado tanto pela perspectiva filosófica empirista/indutivista (E/I) como a perspectiva racionalista. Para essa professora a história da química pode facilitar o entendimento de onde vieram as ideias e conhecimentos que possuímos atualmente (categoria C3).

\section{Fase intermediária}

Quanto à atividade 6 (quarto encontro, Apêndice XI), a professora mostrou ter o entendimento de como se dá a variação da velocidade de uma reação com o tempo, justificando que: "É mais rápida inicialmente. $A$ velocidade diminui com o passar do tempo" (modelo científico - MC; Cakmakci et al, 2005). A sua explicação de como se dá a influência da temperatura na velocidade da reação nesse mesmo exercício é: "É mais rápida em temperatura mais elevada $\left(100^{\circ} \mathrm{C}\right)$. A temperatura influi na reação, altera sua velocidade.", portanto, percebe-se que em suas explicações não aparece um modelo explicativo (MEM) 
$\mathrm{Na}$ atividade experimental 3, sobre o efeito da temperatura na velocidade de uma reação (quarto encontro, Apêndice XII ), sua explicação não inclui termos relacionados a partículas: "Temperaturas maiores, mais rápida a reação". Quando, na mesma atividade se pedia uma explicação com o uso de um modelo de partículas para dizer por que a transformação é mais lenta quando realizada em água gelada, a professora escreveu: "Maior temperatura partículas com mais energia". Portanto, a professora inclui termos relacionados ao comportamento das partículas, contudo, não faz referência aos choques entre essas partículas. (MEP)

No próximo exercício sobre gráficos (exercício 1, quinto encontro, Apêndice $\mathrm{XV}$ ) a professora desenhou o seguinte:

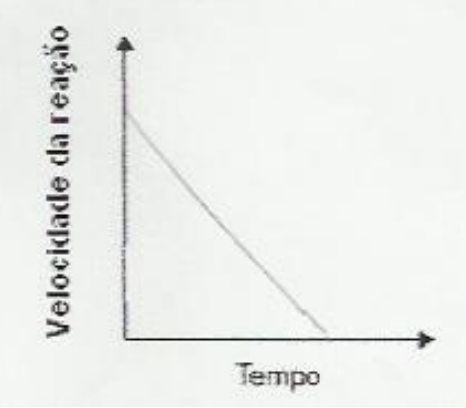

Figura 4.28 A variação da velocidade de uma reação em função do tempo segundo P12.

Percebe-se que o modelo de seu gráfico refere-se ao modelo decréscimo MD (Cakmakci et al,2005), pois, embora ela indique que a velocidade diminui com o tempo, em seu desenho indica que a velocidade diminui até chegar a zero. Sua justificativa para esse modelo, contudo, é coerente com o modelo científico: " $A$ velocidade da reação diminui porque a concentração de A diminuiu. Quando temos menos reagentes os choques entre moléculas diminui fazendo com que a reação fique mais lenta" (MES1).

Em relação ao uso de artigos sobre a História da Química (atividade 1, primeiro encontro, Apêndice III), a professora indicou como utilizaria essa estratégia: "Relacionar os conteúdos apresentados com artigos que falem sobre $o$ momento histórico, econômico e filosófico que marcavam o período de sua descoberta e a sua aceitação pela sociedade." (categoria C3 da HQ). 
Vantagens em se utilizar essa estratégia no ensino:

Apresentar a ciência dentro de um contexto histórico facilita o entendimento, dá mais sentido para a busca dos cientistas, esclarece de que forma ocorrem os avanços e transformações das ideias com o passar do tempo e de que maneira isso altera de forma concreta a nossa realidade.

No segundo encontro, os professores leram um documento oficial sobre 0 papel da HQ no ensino de ciências (atividade 2, Apêndice Vl). A professora concordou com a ideia defendida no documento justificando: "Sim, porque dessa forma não teremos apenas uma transposição didática dos conteúdos e sim a formação de elos com os contextos que Ihes são significativos". (categoria C3, $\mathrm{HQ})$

Para ela a maior dificuldade em trabalhar com a $\mathrm{HQ}$ seria: "A maior dificuldade está na falta de conhecimento dos professores que também não tiveram contato com a História da Ciência".

$\mathrm{Na}$ atividade 4 (terceiro encontro, Apêndice IX), a professora construiu o seguinte mapa conceitual:

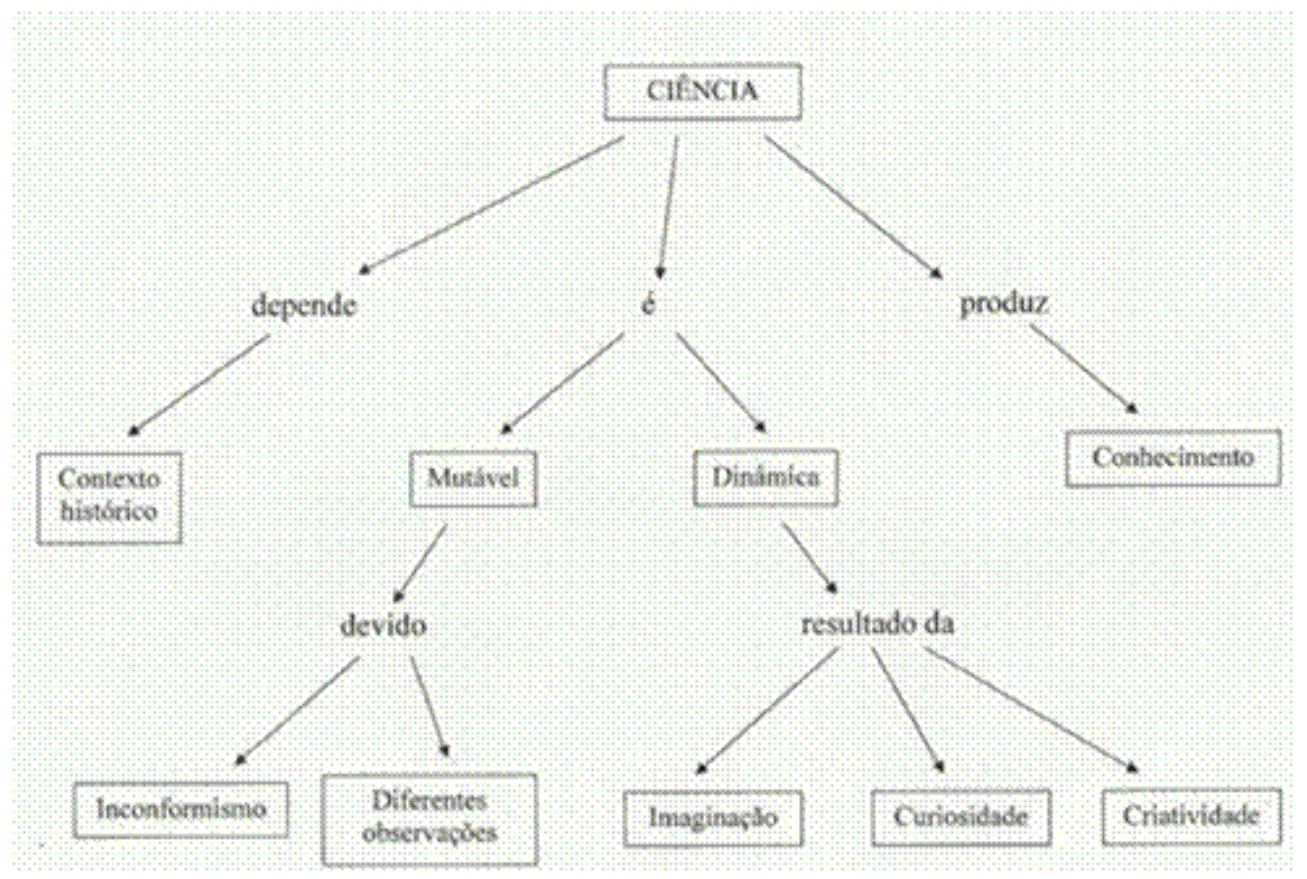

Figura 4.29 Mapa conceitual sobre a imagem da ciência elaborado pela professora P12. 
Em seu mapa, a professora relaciona a ciência a muitas ideias ligadas à perspectiva filosófica racionalista: a ciência é mutável, dinâmica e que depende de um contexto histórico.

$\mathrm{Na}$ atividade realizada (instrumento 3, Apêndice XIV) no quinto encontro, a professora escreveu:

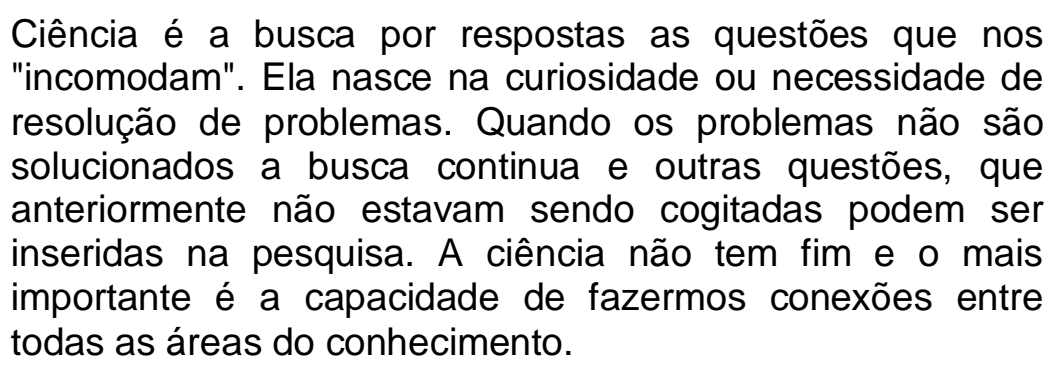

Pela análise das respostas da professora, observa-se que a fase intermediária está baseada, principalmente, nos aspectos microscópicos da cinética química (MES1), Este modelo é marcado principalmente pela perspectiva filosófica racionalista $(R)$. Como na fase inicial, o papel da $H Q$ no ensino para essa professora continua sendo o de pode facilitar o entendimento de onde vieram as ideias e conhecimentos que possuímos atualmente (categoria C3).

\section{Fase final}

$\mathrm{Na}$ avaliação final (oitavo encontro, Apêndice XIX) a professora apontou em relação à superação das dificuldades sobre o ensino de cinética química: "Porque eu voltei a estudar mais profundamente o conteúdo e comecei a aprender a origem desses estudos o que vai fazer com que eu possa transmitir com mais segurança a cinética para meus alunos”.

Com relação à superação das dificuldades sobre o uso da História da Química: "Sim, porque os materiais apresentados durante as aulas e o caminhos propostos mostraram a possibilidade de novos caminhos para o ensino de cinética com o auxílio da História da Ciência".

Sobre quais aspectos relacionados à sua prática a professora refletiu através do curso, ela respondeu que: "Uso dos textos históricos como 
motivadores da curiosidade e construção de conceitos científicos. Contextualização".

\section{$\underline{\text { Plano de ensino }}$}

Em relação ao plano de ensino (folha de atividade 8, Apêncice XVII) dessa professora, podem-se observar no quadro a seguir as habilidades e competências quanto aos conceitos de cinética química, história da química e a visão sobre a natureza da ciência, que ela pretende que seus alunos desenvolvam:

$\begin{array}{lll}\text { Tema Habilidade e competências } & \text { Análise }\end{array}$

\begin{tabular}{|c|c|c|}
\hline $\begin{array}{l}\text { Conceitos } \\
\text { da cinética } \\
\text { química }\end{array}$ & $\begin{array}{l}\text { Compreender que as interações entre matéria e energia em um } \\
\text { certo tempo resultam em modificações de forma ou natureza } \\
\text { da matéria, considerando aspectos qualitativos e } \\
\text { macroscópicos. Identificar as transformações químicas pela } \\
\text { percepção de mudanças na natureza dos materiais ou da } \\
\text { energia, associando-as a uma dada escala de tempo. } \\
\text { Reconhecer e compreender fenômenos envolvendo interações } \\
\text { e transformações químicas, identificando propriedades e } \\
\text { invariantes. }\end{array}$ & MEM \\
\hline $\begin{array}{l}\text { Visão sobre } \\
\text { a natureza } \\
\text { da ciência }\end{array}$ & $\begin{array}{l}\text { Construir uma visão sistematizada das diferentes linguagens e } \\
\text { campos de estudo da química estabelecendo conexões, entre } \\
\text { seus diferentes temas e contextos; Adquirir compreensão no } \\
\text { mundo no qual a química é parte integrante, através dos } \\
\text { problemas que ela consegue resolver e dos fenômenos que } \\
\text { podem ser descritos por seus conceitos e modelos; Articular o } \\
\text { conhecimento químico e o de outras áreas no enfrentamento } \\
\text { de situações-problema. }\end{array}$ & $\mathrm{R}$ \\
\hline $\begin{array}{l}\text { História da } \\
\text { Química }\end{array}$ & $\begin{array}{l}\text { Reconhecer e compreender a ciência e a tecnologia química } \\
\text { como criação humana inserida na história e na sociedade em } \\
\text { diferentes épocas. Perceber o papel desempenhado pela } \\
\text { química no desenvolvimento tecnológico ao logo da história e a } \\
\text { complexa relação entre ciência e tecnologia ao longo da } \\
\text { história. }\end{array}$ & C3 \\
\hline
\end{tabular}

Quadro 4.23 Habilidades e competências indicadas no plano de ensino da professora P12.

Em relação aos outros tópicos do plano dessa professora:

- Objetivos:

HFC: Compreender como o contexto histórico, econômico e cultural se inter-relacionam e influenciam o desenvolvimento de um novo processo químico; 
CQ: analisar dados para entender que existem transformações químicas que não se completam segundo as previsões estequiométricas; entender o que acontece em sistemas e processos químicos a partir de dados apresentados em tabelas e em descrições de experimentos; valorizar o controle de variáveis em processos de investigação.

- Conteúdos:

CQ: Variáveis que podem modificar a rapidez de uma transformação química: concentração, temperatura, pressão, estado de agregação, catalisador, reações reversíveis e não reversíveis, equilíbrio químico.

HFC: Texto sobre história da ciência: 100 anos de Nobel- Jacobus Henricus van’t Hoff.

- Estratégias:

Texto sobre História da Ciência- leitura e debate, atividades práticas de investigação, exercícios teóricos.

- Sequência:

1.Texto sobre história da ciência (100 anos de Nobel- Jacobus Henricus van't Hoff), leitura e debate;

2. Aula expositiva: variáveis que poder modificar a rapidez de uma Transformação Química;

3. Atividades práticas de investigação (experimentos: Influência da temperatura na energia cinética das moléculas; acendendo o palito de fósforo no óleo; fatores que afetam a velocidade de uma reação (concentração); Reações reversíveis e irreversíveis; equilíbrio químico);

4. Exercícios teóricos.

No desenvolvimento do conteúdo a professora não trabalha com modelos teóricos para explicar a velocidade e a influência dos fatores na velocidade de uma reação (MEM).

Em relação à História da Química para essa professora essa estratégia tem a finalidade de verificar como um determinado contexto pode influenciar o desenvolvimento dos conceitos químicos (categoria C4, HQ): "Compreender como 
o contexto histórico, econômico e cultural se inter-relacionam e influenciam o desenvolvimento de um novo processo químico". (plano de ensino, P12). Contudo, o texto que ela selecionou, aborda a vida de um cientista e a sua contribuição para a cinética química (categoria $\mathrm{C} 3, \mathrm{HQ}$ ).

Em seu plano de ensino observa-se que a imagem sobre a natureza da ciência é coerente com as ideias da perspectiva filosófica racionalista $(R)$ : "Compreender como o contexto histórico, econômico e cultural se inter-relacionam e influenciam o desenvolvimento de um novo processo químico".

No quadro a seguir podem ser observados, nos três momentos do curso de formação, os modelos de ensino dessa professora:

\begin{tabular}{|c|c|c|c|c|}
\hline ETAPA & INSTRUMENTOS & $\begin{array}{l}\text { CINÉTICA } \\
\text { QUÍMICA }\end{array}$ & $\begin{array}{l}\text { HISTÓRIA DA } \\
\text { QUÍMICA }\end{array}$ & $\begin{array}{l}\text { IMAGEM DA } \\
\text { CIÊNCIA }\end{array}$ \\
\hline \multirow{2}{*}{ INÍCIO } & INSTRUMENTO 1 & MEM & C3 & \\
\hline & INSTRUMENTO2 & & & $E / I$ \\
\hline \multirow{7}{*}{ DURANTE } & ATIVIDADE 1 & & $\mathrm{C} 3$ & \\
\hline & ATIVIDADE 2 & & C3 & \\
\hline & ATIVIDADE 4 & & & $R$ \\
\hline & ATIVIDADE 6 & MEM & & \\
\hline & INSTRUMENTO 3 & & & $\mathrm{R}$ \\
\hline & EXPERIMENTO 3 & MEP & & \\
\hline & EXERCICIO 1 & MES1 & & \\
\hline \multirow{2}{*}{ FINAL } & ATIVIDADE 8 & MEM & $\mathrm{C3}$ & $\mathrm{R}$ \\
\hline & PLANO DE ENSINO & MEM & C3, C4 & $\mathrm{R}$ \\
\hline
\end{tabular}

Quadro 4.24 Modelos de ensino de cinética química do professor P12 nas diferentes etapas do curso de formação. 


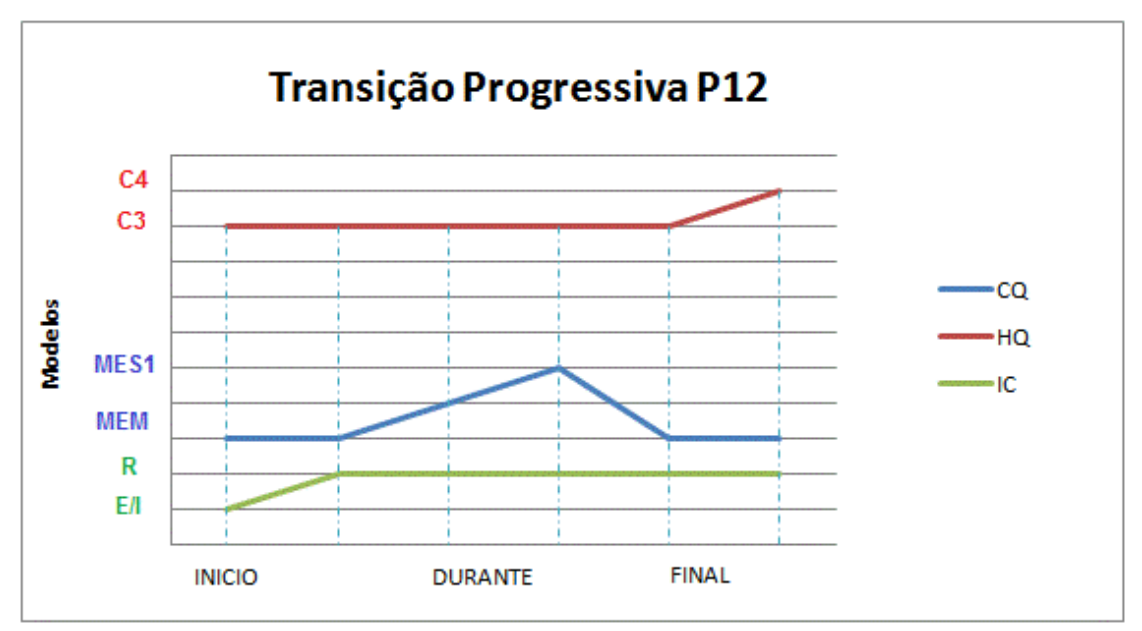

Figura 4.30 Transição progressiva da professora $\mathrm{P} 12$ nas três fases da pesquisa, em relação aos seguintes aspectos de seu modelo de ensino: $C Q$ : cinética química, $H Q$ : História da Química e IC: imagem da ciência.

$\mathrm{Na}$ figura 4.30 pode ser observada a transição progressiva da professora em relação aos seus modelos de ensino. Percebe-se que em relação a cinética química, a professora, embora no exercício 1 tenha indicado um modelo teórico, no seu plano de ensino ela escolheu não trabalhar com as ideias pertencentes ao modelos submiscroscópico (MES1 ou MES2). Em relação a História da Química, percebe-se que seu objetivo é o, principalmente, de fornecer informações para seus alunos e informar a origem de um determinado conhecimento.

Percebe-se a dificuldade da professora, como a de outros professores que já foram analisados anteriormente, de abordar a História da Química com o objetivo de ensinar os conceitos químicos envolvidos no tema.

\section{P13}

\section{Fase inicial}

Respostas às questões referentes ao instrumento 1 (Apêndice II):

Segundo a professora no ensino de cinética química: "É importante visualizar o movimento das partículas na interação química".

Quanto ao conteúdo, ela aponta que é importante ensinar: 
Quando uma reação química deve ocorrer lentamente ou rapidamente. É importante essa situação, pois o aluno como aplicador dos conhecimentos adquiridos, pode atuar nas escolhas que faz, criticamente, beneficiando ou prejudicando as coisas.

O conteúdo que ela normalmente aborda em suas aulas: $O$ que é cinética química, importância de conhecer e "enxergar" uma reação química, Influência das variáveis: pressão, temperatura, concentração e catalisadores. Como aplicar esse conhecimento em situações reais. (MEM)

Para esta professora um dos conteúdos que tem maior dificuldade em ensinar é: "Estudo sobre equilíbrio químico". Porque, segundo ela: "Falta-me bagagem, conhecimento para ensinar. É um conteúdo árduo, pois aprendemos o lado matemático/abstrato, sem uma aplicação lógica".

Quanto à experimentação a professora usa sugestões do caderno do Estado de São Paulo (comprimido efervescente). Quando questionada por que o experimento é importante no ensino de cinética química sua resposta é que: "Enxergar torna real o aprendizado. Mais concreto".

Em relação à História da Ciência, embora ela considere importante a sua inclusão no ensino, "Demais. É necessário conhecer a origem de qualquer tema que queremos desenvolver, isto é, como a química foi/deve ser vista desde o primórdio da civilização humana para atuar, aplicando corretamente (em todos os sentidos, ético/social/ambiental/político), o conhecimento químico, a construção de um futuro melhor" (categoria $\mathrm{C} 3$ da $\mathrm{HQ}$ ), ela afirma não usar em suas aulas, porque, segundo ela: "Não sei trabalhar nesse contexto".

Em relação a sua imagem sobre a natureza da ciência (instrumento 2, Apêndice VII), a professora escolheu as seguintes afirmações:

- O conhecimento científico é o conhecimento provado (E/I)

- A ciência tem evoluído historicamente mediante a acumulação sucessiva das teorias verdadeiras.(E/I)

- O conhecimento é construído com base em teorias que orientam a observação, em outras palavras, uma observação depende da teoria.(R) 
- Os cientistas explicam os fatos por meio de teorias que já estavam em suas cabeças antes da observação dos fatos.(R)

- Toda investigação científica começa pela observação rigorosa do fenômeno que se estuda.(E/I)

- O conhecimento científico se gera graças à capacidade que os seres humanos possuem para propor problemas e imaginar possíveis soluções aos mesmos.(R)

- $\quad$ As hipóteses dirigem o processo de investigação científica.(R)

- As teorias determinam quais experimentos são considerados legítimos e como eles devem ser conduzidos. Em outras palavras, não existem experimentos independentes de teorias. $(\mathrm{R})$

Pela análise das respostas da professora, observa-se que suas ideias iniciais estão baseadas, principalmente, nos aspectos macroscópicos da cinética química (MEM). Este modelo inicial de ensino é marcado principalmente pela perspectiva filosófica racionalista $(R)$. Em relação a História da Química, percebese que seu objetivo é o, principalmente, de fornecer informações para seus alunos e informar a origem de um determinado conhecimento (categoria $\mathrm{C} 3, \mathrm{HQ}$ ).

\section{Fase intermediária}

Quanto à atividade 6 (quarto encontro, Apêndice $\mathrm{XI}$ ), a professora não mostrou ter o entendimento de como se dá a variação da velocidade de uma reação com o tempo, justificando que: "Aumenta a medida que o tempo passa. $O$ tempo é um fator que deve ser considerado nesse processo. Pode-se dizer que a interação entre as moléculas reagentes (choque efetivo) não ocorre instantaneamente" (modelo de aumento - MA; Cakmakci et al, 2005). A sua explicação de como se dá a influência da temperatura na velocidade da reação nesse mesmo exercício é: "Quanto maior a temperatura mais colisões efetivas, mais velocidade (choque entre as moléculas reagentes), maior porcentagem de éster formada", portanto, percebe-se que em suas explicações que aparece um modelo teórico (ideia relativa a teoria das colisões). (MES1)

$\mathrm{Na}$ atividade experimental 3, sobre o efeito da temperatura na velocidade de uma reação (quarto encontro, Apêndice XII ), sua explicação também inclui termos relacionados a partículas: "Promove maior agitação da moléculas, numa 
temperatura maior". Quando, na mesma atividade pedia-se uma explicação com o uso de um modelo de partículas para explicar por que a transformação é mais lenta quando realizada em água gelada, a professora escreveu: " $O$ movimento desordenado, com choques (energia cinética menor), das moléculas será mais lento". (MES1)

A professora deixou o exercício 1 (quinto encontro, Apêndice XV) em branco.

Em relação ao uso de artigos sobre a História da Química (atividade 1, primeiro encontro, Apêndice III), a professora indicou como utilizaria essa estratégia: "Trabalhando ludicamente através da produção de história em quadrinhos".

Vantagens em se utilizar essa estratégia no ensino: "Abordagem "simplista" dos acontecimentos químicos que atravessam a história da humanidade". (categoria $\mathrm{C} 3, \mathrm{HQ}$ )

No segundo encontro, os professores leram um documento oficial sobre o papel da $H Q$ no ensino de ciências (atividade 2, Apêndice VIII). A professora concordou com a ideia defendida no documento justificando: "Sim, claro, pois quando se entende a história do objeto de estudo, tudo tem sentido, lógica, significação".

Para ela a maior dificuldade em trabalhar com a HQ seria: "Não fomos preparados para ministrar esse tipo de conhecimento. Observando o perfil do alunado que temos (cultura do imediato) e dependendo da abordagem estes podem não receber com bons olhos o aspecto histórico do conhecimento".

$\mathrm{Na}$ atividade 4 (terceiro encontro, Apêndice IX), a professora construiu o seguinte mapa conceitual: 


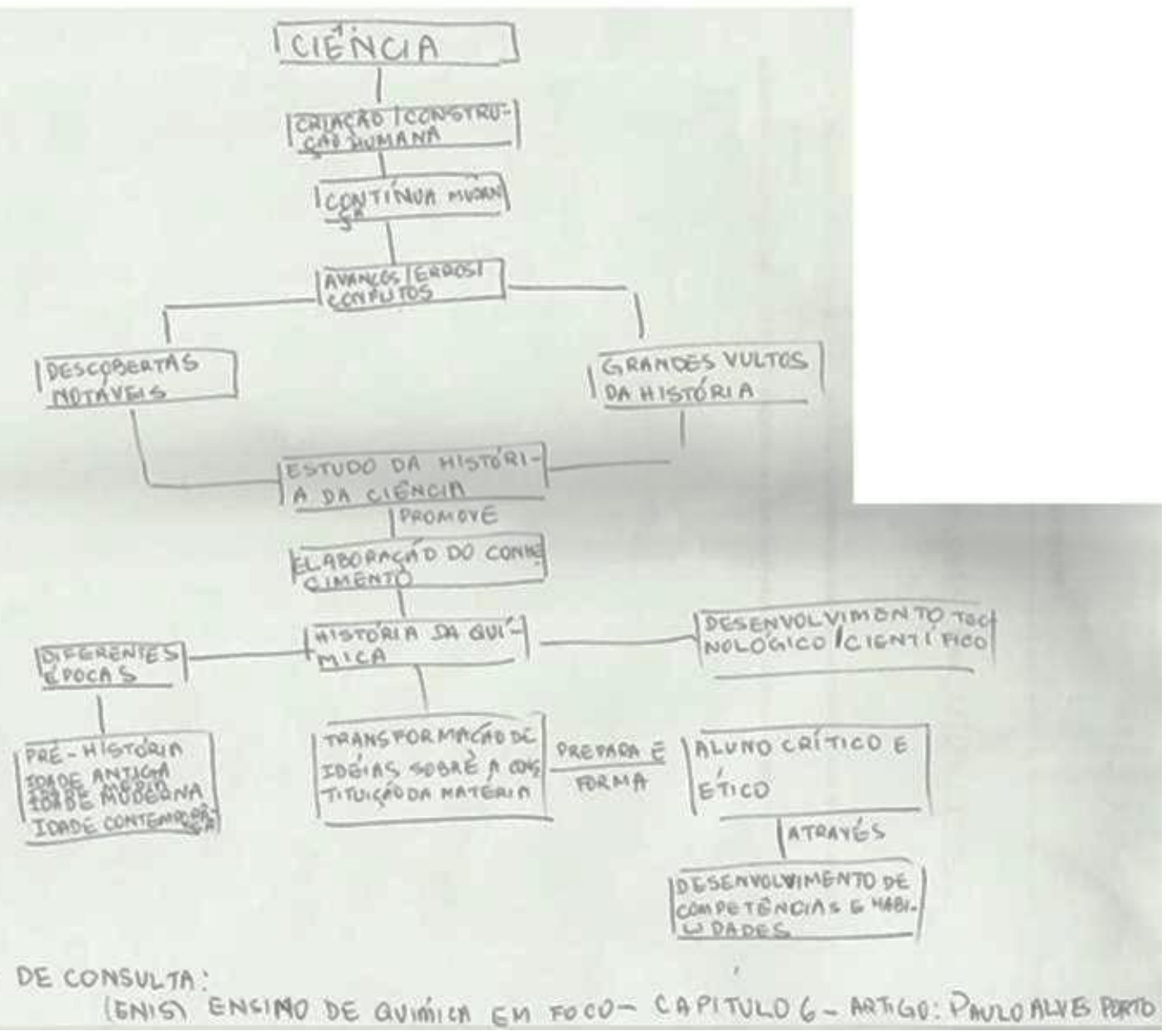

Figura 4.31 Mapa conceitual sobre a imagem da ciência elaborado pela professora P13.

Em seu mapa a professora relaciona a ciência a muitas ideias ligadas à perspectiva filosófica racionalista: que a ciência é uma construção humana, em contínua mudança, que se desenvolve através de erros e acertos e que depende de um contexto histórico.

$\mathrm{Na}$ atividade realizada (instrumento 3, Apêndice XIV) no quinto encontro, a professora escreveu:

Ciência é um acúmulo de conhecimento que vão sendo adquiridos a partir de erros e tentativas, frutos da criação humana. Toda descoberta científica tem como pontapé inicial uma ideia/teoria pré-concebida, a partir da qual o conhecimento vai sendo consolidado, testando hipóteses, ora descartando as ideia pré concebidas, ora aproveitandoas, construindo de uma maneira não linear, mas abrangente, o conhecimento científico. 
Pela análise de suas respostas, observa-se que o núcleo teórico de seu modelo de ensino, nessa fase intermediária é coerente com a teoria das colisões (MES1), onde nas explicações da professora já aparece a ideia relativa à teoria das colisões. Este modelo é marcado pela perspectiva filosófica racionalista (R). Em relação a História da Química, percebe-se que seu objetivo é o, principalmente, de fornecer informações para seus alunos e informar a origem de um determinado conhecimento (categoria C3, HQ), contudo, em seu mapa conceitual a professora indique que: "O estudo da História da ciência promove a elaboração do conhecimento"

\section{Fase final}

$\mathrm{Na}$ avaliação final (oitavo encontro, Apêndice XIX) a professora apontou que em relação à superação das dificuldades sobre o ensino de cinética química: "O material que recebemos é de um valor imensurável. Por deficiência acadêmica a assimilação ficou a desejar (falha minha)."

Quanto à superação das dificuldades sobre o uso da História da Química: "Sim, mas ainda temos um longo caminho a percorrer pois, foi dado o pontapé inicial para "consolidar" os conhecimentos adquiridos, à medida que novos horizontes vão se abrindo".

Sobre quais aspectos relacionados à sua prática a professora refletiu através do curso, ela respondeu que:
A necessidade da abordagem histórica sobre cinética química para dar mais significado aos conteúdos científicos. Adequação de experimento/simulação para "visualização" da influência da temperatura, pressão e catalisador na velocidade de uma transformação química.

\section{Plano de Ensino}

Em relação ao seu plano de ensino (folha de atividade 8, Apêncice XVII), podem-se observar no quadro a seguir as habilidades e competências em relação aos conceitos de cinética química, a História da química e a visão sobre natureza da ciência, que ela pretende que seus alunos desenvolvam: 


\begin{tabular}{llc} 
Tema & Habilidade e competências & Análise \\
\hline $\begin{array}{l}\text { Conceitos } \\
\text { da cinética } \\
\text { química }\end{array}$ & $\begin{array}{l}\text { Construir conhecimento científico a partir da análise } \\
\text { de textos que os fundamentara historicamente. }\end{array}$ & - \\
$\begin{array}{l}\text { Visão } \\
\text { sobre a } \\
\text { natureza } \\
\text { da ciência }\end{array}$ & $\begin{array}{l}\text { Desenvolver o senso crítico sobre a construção ao } \\
\text { longo da história da humanidade, que foi } \\
\text { acontecendo através dos acertos/tentativas/erros } \\
\text { sobre ideias "preconcebidas". }\end{array}$ & $\mathrm{R}$ \\
$\begin{array}{l}\text { História da } \\
\text { Química }\end{array}$ & $\begin{array}{l}\text { Desenvolver a competência leitora sobre a } \\
\text { construção histórica do conhecimento científico, } \\
\text { humanístico/artístico. }\end{array}$ & C4 \\
\hline
\end{tabular}

Quadro 4.25 Habilidades e competências indicadas no plano de ensino da professora P13.

Em relação aos outros tópicos do plano dessa professora:

- Objetivos:

HFC: Introduzir os alunos ao estudo da cinética química, através de uma abordagem histórica e contextualizada. Levar os alunos a compreenderem que o conhecimento científico que estão adquirindo é fruto do trabalho de pesquisadores que por tentativas, erros e acertos a partir de ideias "preconcebidas" nos deixam legados imensos de descobertas e por ser a ciência "uma construção humana em contínua mudança", novas descobertas ocorrem/ocorrerão pela mão "hábil" do homem.

CQ: Realização de experimentos demonstrativos/investigativos para que os alunos percebam a relação intrínseca que existe entre várias ciências. Quantitativamente, qualitativamente do macroscópico para o microscópico.

- Conteúdos:

$\mathrm{CQ}$ : construção do significado; Fatores que podem modificar a velocidade da ocorrência de uma transformação química (TQ) como temperatura, pressão, superfície de contato, concentração dos participantes de uma TQ, catalisador; colisão efetiva/choque frontal/energia de ativação.

HFC: Produção da amônia pelo processo Haber-Bosch, Biografia de Gilbert Lewis, Jacobus Henricus van't Hoff e Svante August Ahrrhenius. 
- Estratégias:

Leitura e interpretação de textos fornecidos pelo professor e/ou trazido pelos alunos sobre a síntese da Amônia pelo processo Haber-Bosch, 100 anos de Nobel. Pesquisa extra sala /dinâmica em U, discussão aberta sobre as biografias solicitadas. Utilização do Datashow para apresentar simulações de experimentos. Experimentos demonstrativos/investigativos. Resolução de exercícios.

- Sequência:

1aㅡ AULA: Aplicação de questionário prévio;

$2^{\mathrm{a}}$ AULA: Os textos (síntese de Amônia e 100 de Nobel) e biografias (solicitados com antecedência e distribuídos em 5 grandes grupos) serão discutidos abertamente cada grupo sendo representado por um relator que irá expor à sala o entendimento do grupo sobre o tema pesquisado/estudado promovendo, assim, um amplo debate a respeito de como os conhecimentos químicos foram sendo construídos ao longo da história da humanidade e, como finalização desta etapa, construir uma linha de tempo.

$3^{a}$ AULA: Apresentação em Power Point, de uma simulação sobre a influência da pressão e temperatura na ocorrência de uma transformação química. Discussão posterior. Realização de um experimento podendo ser demonstrativo para melhor fixação da influência da temperatura na ocorrência de uma transformação química.

4 AULA: Experimento: Montagem e funcionamento do Chafariz de Amônia "possibilitando a descrição e os conflitos que acompanham a elaboração de um processo científico", fazendo uso de materiais de baixo custo. Discussão posterior.

5 AULA: Resolução de exercícios (contemplando questões objetivas, discursivas, análise e construção de gráficos) sobre os conteúdos científicos.

6ª AULA: Aplicação de questionário (pós). Vale a mesma redação das questões prévias.

7ªULA: Elaboração de mapa conceitual para verificar a apreensão dos conteúdos trabalhados.

No desenvolvimento do conteúdo o professora trabalha com modelos teóricos para explicar a velocidade e a influência dos fatores na velocidade de uma reação (MES1): 
Construção do significado; Fatores que podem modificar a velocidade da ocorrência de uma TQ como temperatura, pressão, superfície de contato, concentração dos participantes de uma TQ, catalisador; colisão efetiva/choque

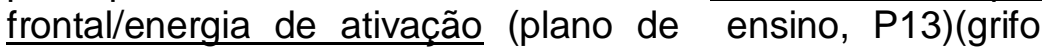
nosso)

Em relação à História da Química para ela essa estratégia tem a finalidade de trabalhar como um determinado contexto pode influenciar o desenvolvimento da cinética química (categoria C4): "Introduzir os alunos ao estudo da cinética química, através de uma abordagem histórica e contextualizada". (plano de ensino, $P 13)$

No plano de ensino da professora observa-se que a imagem sobre a natureza da ciência é coerente com as ideias da perspectiva filosófica racionalista:

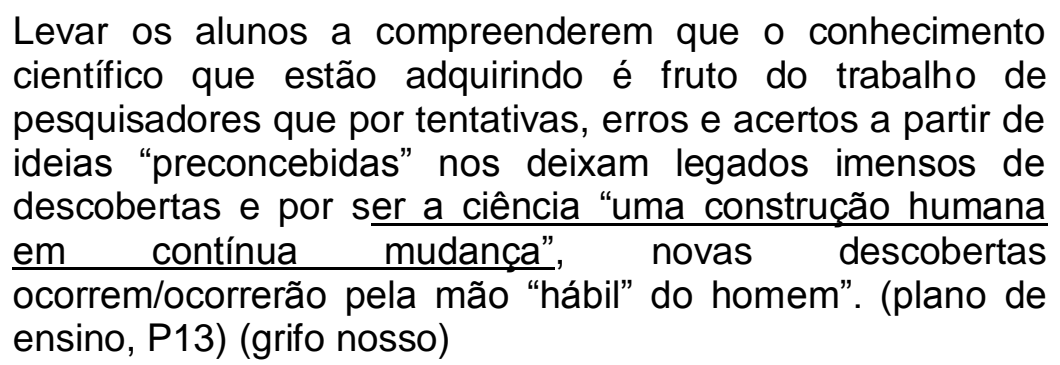

No quadro a seguir, podem ser observados, nos três momentos do curso de formação continuada, os modelos de ensino dessa professora:

\begin{tabular}{|c|c|c|c|c|}
\hline ETAPA & INSTRUMENTOS & $\begin{array}{l}\text { CINÉTICA } \\
\text { QUÍMICA }\end{array}$ & $\begin{array}{l}\text { HISTÓRIA DA } \\
\text { QUÍMICA }\end{array}$ & $\begin{array}{l}\text { IMAGEM DA } \\
\text { CIÊNCIA }\end{array}$ \\
\hline \multirow{2}{*}{ INÍCIO } & INSTRUMENTO 1 & MEM & C3 & \\
\hline & INSTRUMENTO 2 & & & $\mathrm{R}$ \\
\hline \multirow{7}{*}{ DURANTE } & ATIVIDADE 1 & & $\mathrm{C} 3$ & \\
\hline & ATIVIDADE 2 & & C4 & \\
\hline & ATIVIDADE 4 & & & $\mathrm{R}$ \\
\hline & ATIVIDADE 6 & MES1 & & \\
\hline & INSTRUMENTO 3 & & & $\mathrm{R}$ \\
\hline & EXPERIMENTO 3 & MES1 & & \\
\hline & EXERCICIO 1 & - & & \\
\hline \multirow{2}{*}{ FINAL } & ATIVIDADE 8 & - & $\mathrm{C4}$ & $\mathrm{R}$ \\
\hline & PLANO DE ENSINO & MES1 & C4 & $\mathrm{R}$ \\
\hline
\end{tabular}

Quadro 4.26 Modelos de ensino de cinética química do professor P13 nas diferentes etapas do curso de formação. 


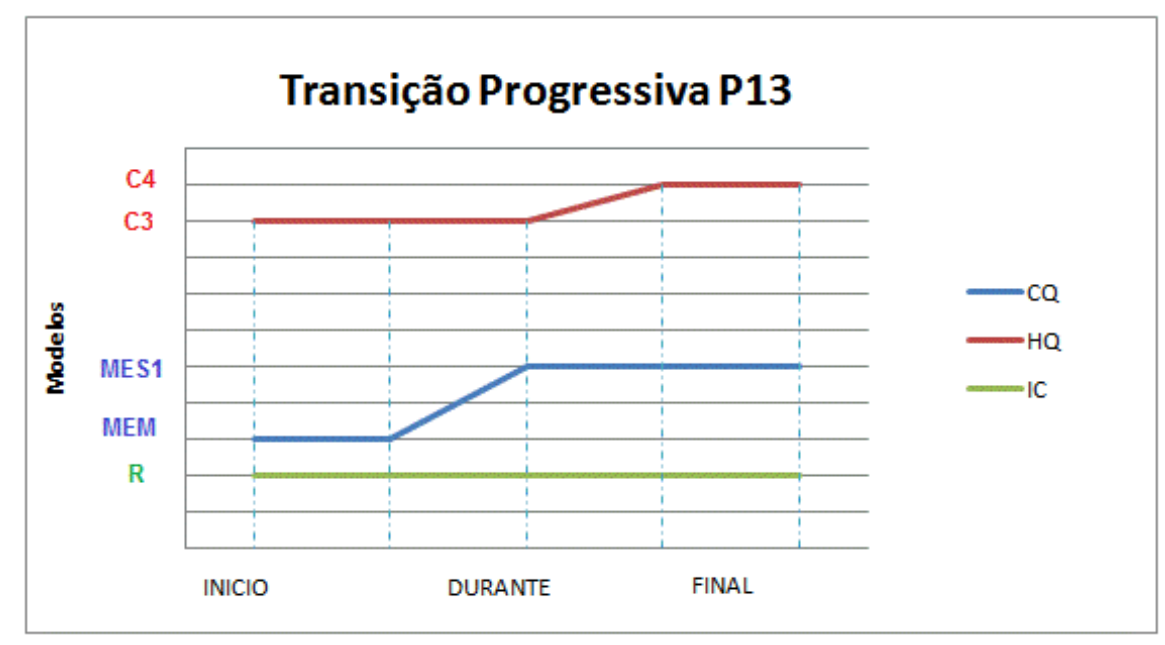

Figura 4.32 Transição progressiva da professora P13 nas três fases da pesquisa, em relação aos seguintes aspectos de seu modelo de ensino: $C Q$ : cinética química, $\mathrm{HQ}$ : História da Química e IC: imagem da ciência.

Pode-se inferir então que o curso de formação continuada facilitou a transição progressiva nos aspecto relacionados à cinética química e à História da Química. A sua imagem sobre a natureza que já no inicio do curso era coerente com a perspectiva racionalista, manteve-se assim, até na elaboração do seu plano de ensino

\section{P14}

\section{Fase inicial}

Respostas as questões referentes ao instrumento 1 (Apêndice II):

Para o professor o ensino de cinética química é importante: "Para sua compreensão no meio em que vive. Principalmente compreender a produção industrial em especial, o fator econômico, como chefe de toda a produção".

Quanto ao conteúdo que é importante ensinar, ele aponta: "O estudo da influência da temperatura em uma reação química", pois, segundo ele: "Possibilita uma discussão ampla em sala de aula". 
O conteúdo que normalmente ensina é: "Fatores que influenciam a velocidade de uma reação, importância econômica na produção". (MEM)

Para este professor um dos conteúdos que ele indica que tem maior dificuldade em ensinar é: "A influência da superfície de contato".

Quanto à experimentação ele usa a influência de certos fatores na velocidade de uma reação química (Concentração: pedaços de metais e ácidos em diferentes concentrações; Superfície de contato: Comprimido efervescente; Temperatura: ácidos em diferentes temperaturas; Catalisador: reação da batata com água oxigenada). Quando questionado por que o experimento é importante no ensino de cinética química sua resposta é: "Facilita a compreensão dos fenômenos químicos, por exemplo, de uma "visualização" das evidências de uma transformação química".

Em suas aulas ele aborda aplicações da cinética química: "Mostro a importância na produção industrial, ambiental, etc".

Em relação à História da Química, embora ele considere importante a sua inclusão no ensino, "Ajuda o aluno a entender toda a trajetória da ciência e que esta não é pronta e acabada. Ajuda o aluno na elaboração de suas hipóteses" (categorias $\mathrm{C} 2$ e $\mathrm{C} 4$ da $\mathrm{HQ}$ ), ele afirma não usar em suas aulas.

Em relação a sua imagem sobre a natureza da ciência (instrumento 2, Apêndice VII), o professor escolheu as seguintes afirmações:

- O conhecimento científico é o conhecimento provado (E/I)

- O conhecimento é construído com base em teorias que orientam a observação, em outras palavras, uma observação depende da teoria.(R)

- Os cientistas explicam os fatos por meio de teorias que já estavam em suas cabeças antes da observação dos fatos.(R)

- O conhecimento científico se gera graças à capacidade que os seres humanos possuem para propor problemas e imaginar possíveis soluções aos mesmos.(R)

- As hipóteses dirigem o processo de investigação científica.(R) 
- Teorias científicas são derivadas, de um modo rigoroso, de fatos adquiridos pela observação e pela experimentação. (E/l)

- As teorias determinam quais experimentos são considerados legítimos e como eles devem ser conduzidos. Em outras palavras, não existem experimentos independentes de teorias. $(\mathrm{R})$

Pela análise das respostas do professor, observa-se que suas ideias iniciais estão baseadas nos aspectos macroscópicos da cinética química (MEM). Este modelo inicial de ensino é marcado principalmente, pela perspectiva filosófica racionalista $(\mathrm{R})$.

\section{Fase intermediária}

Quanto à atividade 6 (quarto encontro, Apêndice XI), o professor mostrou ter entendimento de como se dá a variação da velocidade de uma reação com o tempo, justificando que: "A velocidade de formação do éster diminui com o tempo. O que explica esta diminuição é devido à diminuição da quantidade de reagentes" (modelo científico - MC; Cakmakci et al,2005). Sua explicação de como se dá a influência da temperatura na velocidade da reação nesse mesmo exercício é: "Para atingir uma certa porcentagem de éster do ácido requer um tempo maior em temperatura ambiente. Concluímos que a temperatura é um fator importante na cinética", portanto, percebe-se que em suas explicações não aparece um modelo explicativo. (MEM)

O professor não realizou a atividade experimental 3, sobre o efeito da temperatura na velocidade de uma reação (quarto encontro, Apêndice XII ).

No próximo exercício sobre gráficos (quinto encontro, Apêndice XV) 0 professor desenhou o seguinte gráfico: 


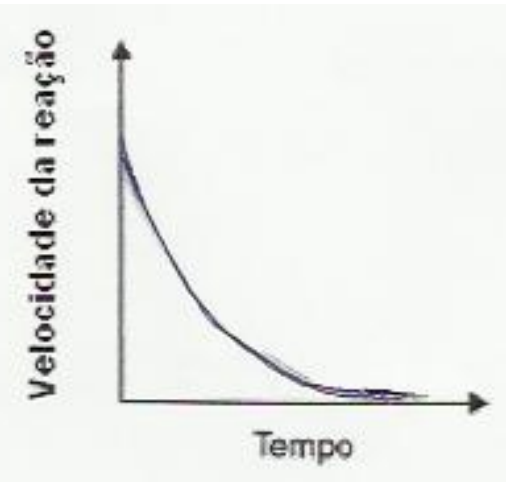

Figura 4.33 A variação da velocidade de uma reação em função do tempo segundo P14.

Percebe-se que o modelo de seu gráfico refere-se ao modelo científico MC (categoria Cakmakci et al,2005). Sua justificativa para esse modelo é:

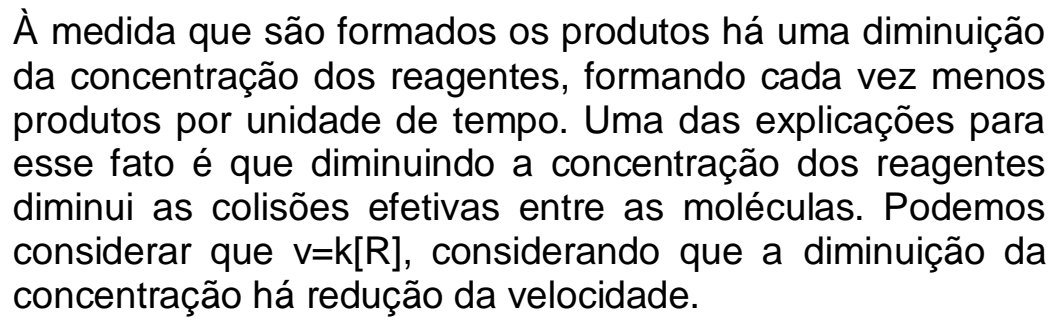

Portanto, ele usa em sua explicação ideias relativas a teoria das Colisões: "...Uma das explicações para esse fato é que diminuindo a concentração dos reagentes diminui as colisões efetivas entre as moléculas." (MES1)

Em relação ao uso de artigos sobre a História da Química (atividade 1, primeiro encontro, Apêndice III), o professor indicou como utilizaria essa estratégia: "Podem ser utilizados como base para uma boa discussão em sala de aula".

Vantagens em se utilizar essa estratégia no ensino: "Irá favorecer ao aluno a compreensão que a química como ciência foi construída pelo homem, e como qualquer atividade humana está sujeita a conflitos, caráter provisório".

No segundo encontro, os professores leram um documento oficial sobre 0 papel da $\mathrm{HQ}$ no ensino de ciências (atividade 2, Apêndice VI). O professor concordou com a ideia defendida no documento justificando:

Sim, pois a concretização destas ideias pelo aluno, entendo ser um recurso instrucional frutífero para motivá-los para o 
estudo de ciências, pois permite o seu encorajamento para a exposição da ideias, elaboração de hipóteses, de sua investigações no campo da ciência.

Para ele a maior dificuldade em trabalhar com a HQ seria: "O maior desafio encontrado pelo professor entendo estar na dificuldade de aproximar 0 conhecimento científico elaborado pelos cientistas nas diferentes épocas ao universo cognitivo do aluno".

$\mathrm{Na}$ atividade 4 (terceiro encontro, Apêndice IX), o professor construiu o seguinte mapa conceitual:

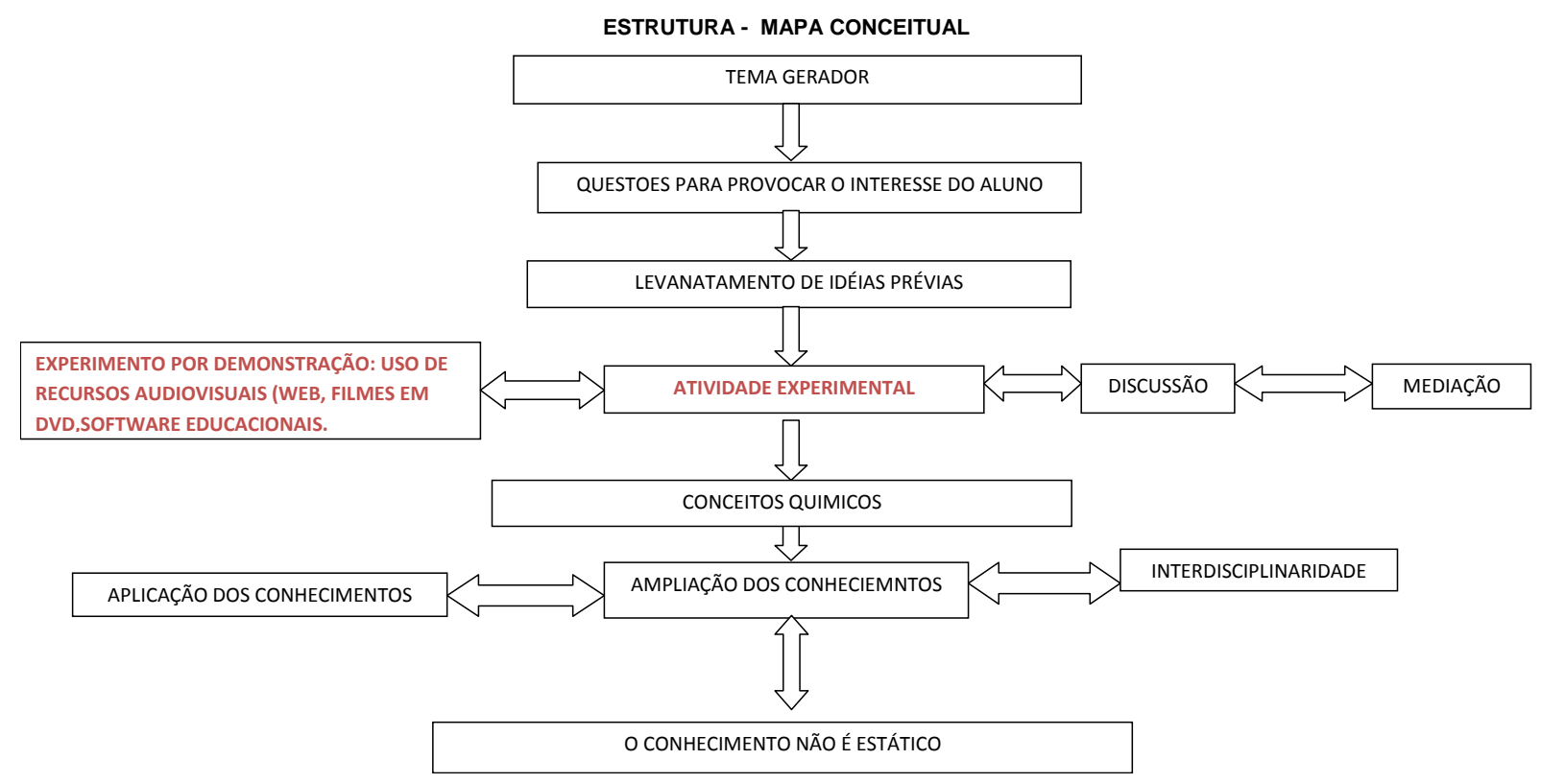

Figura 4.34 Mapa conceitual sobre a imagem da ciência elaborado pelo professor P14.

Em seu mapa o professor indica não a imagem da ciência que ele espera que seus alunos construam, mas sim uma sequência de atividades. Contudo ele aponta um item relativo à imagem da ciência que é: o conhecimento não é estático, essa ideia esta relacionada à perspectiva filosófica racionalista $(R)$.

$\mathrm{Na}$ atividade realizada (instrumento 3, Apêndice XIV) no quinto encontro, o professor escreveu:

A ciência é o conjunto de teorias elaboradas pelo homem capaz de explicar determinados fenômenos. Esta foi desenvolvida com a contribuição de diversos atores, que, através do registro destas sucessivas descobertas ao longo 
da história, a ciência continuará em constante evolução, através das gerações.

Pela análise das respostas do professor, observa-se que suas ideias nessa fase intermediária estão baseadas, principalmente, nos aspectos relativos à teoria da colisão (MES1). Este modelo é marcado principalmente pela perspectiva racionalista $(R)$. Em relação a $H Q$, o seu papel no ensino seria o de o aluno poder vivenciar etapas da produção do conhecimento científico, categoria C4:”... pois permite o seu encorajamento para a exposição da ideias, elaboração de hipóteses, de sua investigações no campo da ciência" (atividade 2)

\section{Fase final}

$\mathrm{Na}$ avaliação final (oitavo encontro, Apêndice XIX) o professor apontou em relação à superação das dificuldades sobre o ensino de cinética química:

A dinâmica do curso permitiu uma discussão aprofundada dos fatores que afetam a velocidade de uma transformação química, pois mostrou as buscas de diferentes metodologias experimentais, (não tratou o experimento como fato isolado, como é geralmente apresentado no livro didático), ou seja, as explicações teóricas para os resultados experimentais foi um fator importante para a compreensão de tais fenômenos. Destaco também, como uma grande contribuição neste processo de formação, as discussões referentes à importância dos fatos experimentais no desenvolvimento dos modelos científicos da época e suas contribuições para a construção dos modelos na atualidade.

Com relação à superação das dificuldades sobre o uso da História da Química: "Sim. Os experimentos realizados, sugestões/simulações de experimentos na plataforma web, as dicas de leitura e principalmente as discussões sobre o tema, com base no material literário, acrescentou muito a minha formação".

Sobre quais aspectos relacionados à sua prática o professor refletiu através do curso, ele escreveu que:

Há uma necessidade de aprimorar, diversificar o meu plano de aula. Está clara a necessidade de busca de novas metodologias para contemplar as diferentes necessidades e propensões dos alunos na abordagem do tema em questão. Neste aspecto, não posso mais planejar as minhas 
atividades tendo como referência apenas os livros didáticos convencionais do ensino médio, mas buscar recursos diversificados.

\section{Plano de ensino:}

Em relação ao plano de ensino (folha de atividade 8, Apêncice XVII) desse professor, podem-se observar no quadro a seguir as habilidades e competências em relação aos conceitos de cinética química, à História da química e à visão sobre a natureza da ciência, que ele pretende que seus alunos desenvolvam:

\begin{tabular}{|c|c|c|}
\hline Tema & Habilidade e competências & Análise \\
\hline $\begin{array}{l}\text { Conceitos } \\
\text { da cinética } \\
\text { química }\end{array}$ & $\begin{array}{l}\text { Elaborar hipóteses. Registrar observações. Conhecer } \\
\text { fenômenos. Estabelecer relações para assimilar conceitos. } \\
\text { Descobrir resultados. }\end{array}$ & MEM \\
\hline $\begin{array}{l}\text { Visão sobre } \\
\text { a natureza } \\
\text { da ciência }\end{array}$ & $\begin{array}{l}\text { Conhecer e analisar fatos criticamente. Evidenciar o caráter } \\
\text { provisório do conhecimento científico. Compreender o } \\
\text { papel do pensamento divergente para a investigação } \\
\text { científica (pensamento crítico). Construção de uma imagem } \\
\text { não deformada do trabalho científico. }\end{array}$ & $\mathrm{R}$ \\
\hline $\begin{array}{l}\text { História da } \\
\text { Química }\end{array}$ & $\begin{array}{l}\text { Evidenciar relações mútuas que vinculem a ciência } \\
\text { (tecnologia e sociedade). Ciência como herança cultural. } \\
\text { Entendimento do processo da criação científica. Que } \\
\text { posam entender a linguagem da ciência moderna. }\end{array}$ & $\mathrm{C} 4$ \\
\hline
\end{tabular}

Quadro 4.27 Habilidades e competências indicadas no plano de ensino do professor P14.

Em relação aos outros tópicos do plano:

- Objetivos:

CQ: Analisar na prática, a variável temperatura e sua influência na velocidade de reação nos parâmetros da equação de Arrhenius através de um experimento. Determinar a energia de ativação a partir da variação da constante de velocidade com a temperatura com os dados apresentados no experimento.

HFC: Apresentar aos alunos numa perspectiva histórica, as descrições concernentes à construção dos conceitos e modelos da Cinética Química ao longo da história; Estimular o interesse dos alunos pelas disciplinas científicas, ao quebrar a monotonia dos programas de ensino estritamente direcionados para aspectos técnicos; Favorecer o 
contato dos alunos com indagações, evidências, argumentos que estimulem a mudança conceitual; Melhorar a aprendizagem de conceitos, hipóteses, teorias, modelos e leis propostas pela Ciência; Suscitar a admiração pelas realizações da Ciência e incentivar o aluno a se tornar um futuro cientista; Caracterizar a Ciência como parte integrante da herança cultural das sociedades contemporâneas; llustrar as dificuldades, discussões e resistências desenvolvidas para estabelecer diferentes metodologias experimentais para medir e representar velocidade de reação.

- Conteúdo:

Fatores que afetam a velocidade de uma reação química; energia de ativação; teoria das colisões, etc; Justificativa: Dentre os conteúdos abordados em Cinética Química nos livros didáticos adotados no ensino médio está uma abordagem qualitativa das velocidades das reações, levando em consideração os fatores que as influenciam. Porém, a abordagem é feita apenas com dados experimentais passando a impressão de algo puramente empírico que não podem ser modelados teoricamente e/ou molecularmente.

Os modelos científicos, sua história e a utilização da experimentação são considerados importantes para o ensino e aprendizagem dos estudantes, ao possibilitar a construção do conhecimento científico.

As considerações da categoria História dos conceitos da Cinética Química podem contribuir para a construção de uma imagem da atividade científica, mostrando as buscas de diferentes metodologias experimentais utilizadas para compreender a velocidade de reação química. Portanto, a Equação de Arrhenius, que descreve a constante de velocidade, torna-se um meio importante para a compreensão do andamento das reações e de como os fatores externos e internos ao sistema podem influenciar o seu andamento.

- Estratégias:

Levantamento prévio de ideias; Leitura e interpretação do texto com abordagem histórica; experimentação; exercícios; gráficos.

- Sequência:

Inicialmente serão discutidas com os alunos algumas ideias que conhecem sobre a cinética. Questionamentos como: obtenção dos produtos químicos; exemplos de 
reações rápidas e lentas; contribuição das reações em processos industriais distintos: fabricação de remédios, plásticos; Rendimentos/Custos.

Em seguida será apresentada à turma uma seleção, proposta, de textos históricos sobre passagens marcantes da história da cinética química e dos momentos que julgamos mais convenientes para sua apresentação, evidenciando as relações mútuas que vinculam a ciência, tecnologia e sociedade. A preocupação de mostrar aos alunos uma visão moderna de ciência, ou seja, mostrar a ciência não mais como um conjunto de conhecimentos isolados, como normalmente é apresentada nos livros didáticos, mas sim, como um construto de um grupo de pessoas que tem por objetivo resolver determinados problemas de sua época.

Neste plano iremos dar ênfase os estudos realizados por Svante Arrhenius que 1889 determinou experimentalmente a importância do efeito da temperatura na rapidez de uma transformação química. Determinando a sua famosa equação.

Após esta discussão inicial será proposto uma atividade experimental onde a proposta é determinar experimentalmente o efeito da temperatura na velocidade da reação, a energia de ativação e o fator de frequência da reação entre hidrogenossulfito de sódio e iodato de potássio. Permitindo que o aluno construa generalizações (Análise dos parâmetros da equação de Arrhenius, em uma atividade em grupo) reconhecendo as variáveis nas transformações químicas a partir dos dados coletados. Que possam entender o que é e como se determina a energia de ativação a partir da variação da constante de velocidade com a temperatura com os dados apresentados no experimento.

Portanto, percebe-se no desenvolvimento do conteúdo que o professor trabalha com um modelo teórico para explicar a velocidade e a influência dos fatores na velocidade de uma reação (MES1).

Em relação à História da Química para esse professor essa estratégia tem a finalidade de que os alunos entendam o desenvolvimento histórico dos conceitos relacionados à cinética química (categoria C4):"Apresentar aos alunos numa perspectiva histórica, as descrições concernentes à construção dos conceitos e modelos da Cinética Química ao longo da história" (plano de ensino, P14) 
Também em seu plano observa-se que a imagem sobre a natureza da ciência é coerente com as ideias da perspectiva filosófica racionalista:

A preocupação de mostrar aos alunos uma visão moderna de ciência, ou seja, mostrar a ciência não mais como um conjunto de conhecimentos isolados, como normalmente é apresentada nos livros didáticos, mas sim, como um construto de um grupo de pessoas que tem por objetivo resolver determinados problemas de sua época. (plano de ensino, P14)(grifo nosso)

No quadro a seguir, podem ser observados, nos três momentos do curso de formação, os modelos de ensino desse professor:

\begin{tabular}{|c|c|c|c|c|}
\hline ETAPA & INSTRUMENTOS & $\begin{array}{l}\text { CINÉTICA } \\
\text { QUÍMICA }\end{array}$ & $\begin{array}{l}\text { HISTÓRIA DA } \\
\text { QUÍMICA }\end{array}$ & $\begin{array}{l}\text { IMAGEM DA } \\
\text { CIÊNCIA }\end{array}$ \\
\hline \multirow{2}{*}{ INÍCIO } & INSTRUMENTO 1 & MEM & $\mathrm{C} 2, \mathrm{C} 4$ & \\
\hline & INSTRUMENTO 2 & & & $\mathrm{R}$ \\
\hline \multirow{7}{*}{ DURANTE } & ATIVIDADE 1 & & $\mathrm{C} 2, \mathrm{C} 4$ & \\
\hline & ATIVIDADE 2 & & C 4 & \\
\hline & ATIVIDADE 4 & & & $\mathrm{R}$ \\
\hline & ATIVIDADE 6 & MEM & & \\
\hline & INSTRUMENTO 3 & & & $\mathrm{R}$ \\
\hline & EXPERIMENTO 3 & - & & \\
\hline & EXERCICIO 1 & MES1 & & \\
\hline \multirow[b]{2}{*}{ FINAL } & ATIVIDADE 8 & MEM & $\mathrm{C} 4$ & $\mathrm{R}$ \\
\hline & $\begin{array}{l}\text { PLANO DE } \\
\text { ENSINO }\end{array}$ & MES1 & C4 & $\mathrm{R}$ \\
\hline
\end{tabular}

Quadro 4.28 Modelos de ensino de cinética química do professor P14 nas diferentes etapas do curso de formação.

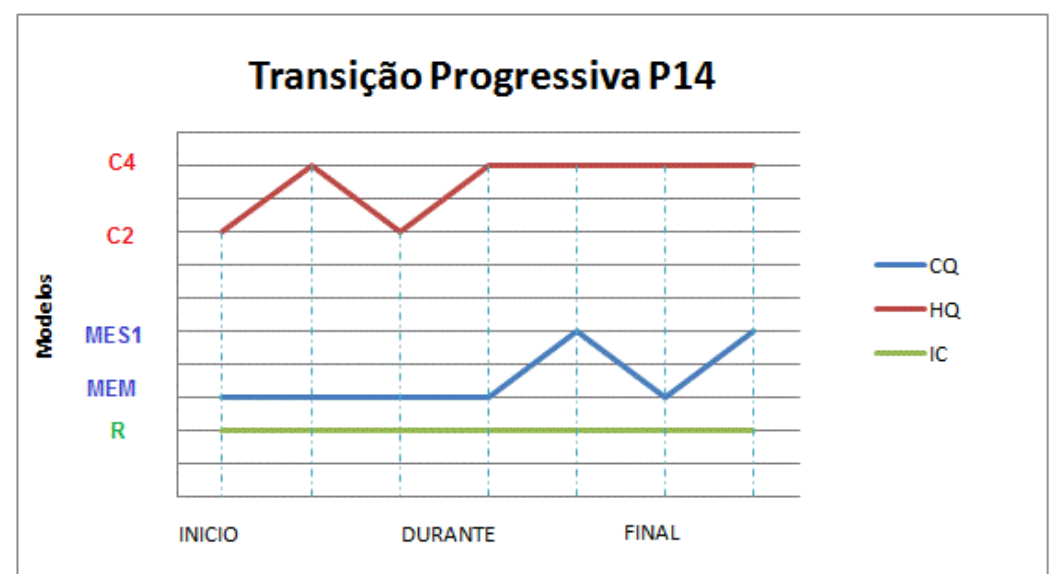


Figura 4.35 Transição progressiva do professor P14 nas três fases da pesquisa, em relação aos seguintes aspectos de seu modelo de ensino: $C Q$ : cinética química, $H Q$ : História da Química e IC: imagem da ciência.

Na figura acima se observa que o curso de formação continuada facilitou a transição progressiva nos aspectos relacionados à cinética química (mudou do MEM para MES1), como também na inclusão de novas estratégias para o ensino desse tema, como, por exemplo, atividades para construção de gráficos e textos.

Sua imagem sobre a natureza da ciência que no inicio do curso era coerente com a perspectiva racionalista permaneceu a mesma até o final. No seu plano aparece a ideia de que a História da Química pode ajudar os alunos a construírem uma imagem da ciência coerente com a perspectiva racionalista:

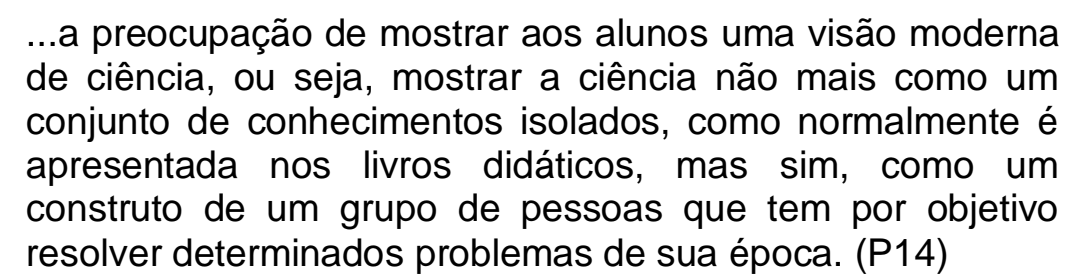

Isso, segundo Del Pino et al (2006), pode ajudar os alunos construírem a imagem de ciência como uma construção humana, coletiva, fruto do trabalho de muitas pessoas, para evitar a ideia de uma ciência feita basicamente por gênios, em sua maioria homens.

Além de ajudar na construção da imagem da ciência, percebe-se no plano de ensino desse professor, a preocupação de abordar a História da Química com o objetivo de ensinar conceitos científicos (Gil-Pérez,1993).

\section{P15}

Fase inicial

Respostas as questões referentes ao instrumento 1 (Apêndice II):

Quanto à importância da cinética química, a professora justifica que com esse conhecimento os alunos podem compreender melhor como ocorrem as transformações químicas. Quanto ao conteúdo que é importante ensinar, ela 
afirma que tudo tem importância: "...desde compreender porque existe afinidade entre as partículas, até estudar os efeitos que favorecem sua interação e de que forma isso ocorre."

Contudo, devido ao pequeno número de aulas de química, no ensino médio, a professora concentra seu ensino nos fatores que influem na velocidade (concentração, temperatura, superfície de contato) e quando possível na atuação dos catalisadores.(MEM)

Para esta professora um dos conteúdos que ela indica que tem maior dificuldade em ensinar é a Lei da velocidade de uma transformação química, porque, em suas palavras: "É difícil quando precisamos expressar na equação matemática um determinado fenômeno".

Pode-se observar, pela justificativa da professora, que ela pensa na Lei da velocidade de uma reação como sendo obtida a partir de uma equação matemática, e não que essa relação matemática é estabelecida por dados experimentais, como é na realidade. Um dos aspectos que é pouco discutido no ensino médio é o caráter empírico da cinética química, por exemplo, é pouco discutido que a lei de uma velocidade, assim como a ordem de uma reação, são determinadas experimentalmente. Contudo, no ensino de química, em especial no que diz respeito à cinética química, nos PCNs (1999) já se encontra essa ideia:

Estabelecidas essas relações e ampliando-as, é preciso que se percebam as relações quantitativas que expressam a rapidez de uma transformação química, reconhecendo, selecionando ou propondo procedimentos experimentais que permitem o estabelecimento das relações matemáticas existentes, como a lei da velocidade.(p.33)(grifo nosso)

Quanto às estratégias usadas pela professora em suas aulas, como aplicação desse conhecimento, ela cita a importância da cinética para o sistema produtivo, no controle do custo final dos produtos, como também o relaciona com situações do cotidiano:

Compreendendo a maneira como os fatores interferem na velocidade das reações, podemos 'manipular" uma transformação da matéria de maneira que ela possa ter uma aplicação prática, Por exemplo, se eu sei que o aumento da 
superfície de contato acelera o apodrecimento da carne, eu procuro não picá-la antes de guardá-la.

A atividade experimental que realiza é para que os alunos entendam a influência da temperatura e superfície de contato, na velocidade de reação (experimento dissolução de comprimido efervescente, triturado e inteiro, em água em diferentes temperaturas). Para ela as atividades experimentais: "Permitem vivenciar o conteúdo"

Em relação à História da Ciência, embora ela considere importante a sua inclusão no ensino, "Pois ajuda a compreender como uma determinada ideia evolui e acredito que isso ajude na construção do conhecimento" ela afirma não usar em suas aulas.(categoria $\mathrm{C} 4 \mathrm{da} \mathrm{HQ}$ )

A professora em suas aulas, também não utiliza os textos sobre 0 desenvolvimento histórico do processo Haber-Bosch que estão presentes no caderno do aluno (São Paulo, 2011) no ensino de cinética química, excluindo de suas aulas qualquer aspecto histórico relacionado ao tema. As justificativas dadas por ela, assim como também por outros professores, é os textos são de difícil compreensão para o aluno e que também o número de aulas de química e o tempo disponível não permitem que se aplique esse tipo de atividade, leitura e interpretação de textos.

Analisando-se a sua imagem sobre a ciência, embora a professora considere que o conhecimento científico seja gerado graças à capacidade que os seres humanos possuem para propor problemas e imaginar possíveis soluções aos mesmos, a maneira como que esse conhecimento é construído está ligada a seguir, fielmente, as etapas do método científico, onde a observação tem muita importância, pois, é a partir dela que se elaboram as teorias e onde o papel do experimento é o de comprovar se estas teorias estão corretas ou não (categoria 3 -E/I, quadro 3.3).

Pode-se perceber a perspectiva empirista/indutivista na justificativa da professora quando ela indica que o experimento: "permite vivenciar o conteúdo", 
ou seja, o experimento aqui teria a função de comprovar a teoria já vista em sala de aula.

Seu modelo de ensino, nessa fase inicial, pode ser caracterizado como modelo de ensino macroscópico (MEM), pois ela aborda somente os fatores que influenciam a velocidade de uma reação química, e isso pode ser observado nos experimentos que ela utiliza. Este modelo inicial de ensino é marcado fortemente pela perspectiva filosófica empirista/indutivista (E/I). Em relação a História da Química para essa professora essa estratégia tem a finalidade de que os alunos entendam o desenvolvimento de um conhecimento científico (categoria C4).

\section{Fase intermediária}

Quanto à atividade 6 (quarto encontro, Apêndice XI), a professora mostrou ter o entendimento de como se dá a variação da velocidade de uma reação com o tempo, justificando que: " $A$ velocidade de formação do éster diminui a medida que são consumidos os reagentes." (modelo científico - MC; Cakmakci et al,2005).

A sua explicação de como se dá a influência da temperatura na velocidade da reação nesse mesmo exercício é: "Podemos concluir que o fator tempo e temperatura estão influenciando a reação.", portanto, percebe-se que em suas explicações não aparece um modelo explicativo (MEM).

$\mathrm{Na}$ atividade experimental 3, sobre o efeito da temperatura na velocidade de uma reação (quarto encontro, Apêndice XII ), sua explicação inclui termos relacionados a partículas: "O aumento da temperatura aumenta o movimento das partículas, fazendo com que haja maior quantidade de moléculas com energia suficiente para reagir, isto é, com energia superior a de ativação".

Quando, na mesma atividade se pedia uma explicação com o uso de um modelo de partículas para explicar por que a transformação é mais lenta quando realizada em água gelada, a professora escreveu: "Moléculas sem energia suficiente para colidir, não resultando em complexo ativado". Portanto, a professora inclui termos relacionados a modelos teóricos (MES1 e MES2) 
No próximo exercício sobre gráficos (exercício 1, quinto encontro, Apêndice $\mathrm{XV}$ ) a professora desenhou o seguinte gráfico:

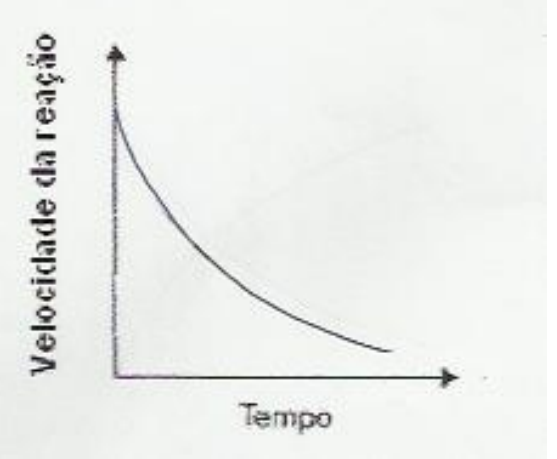

Figura 4.36 A variação da velocidade de uma reação em função do tempo segundo P15.

Percebe-se que o modelo de seu gráfico refere-se ao modelo científico MC (categoria Cakmakci et al, 2005). Sua justificativa para esse modelo é:

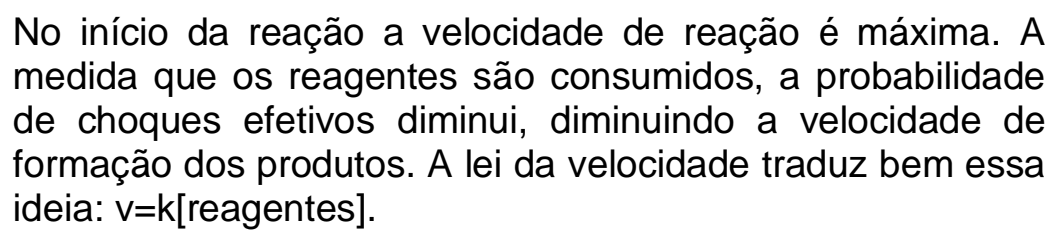

Em sua resposta, a professora usa a ideia de probabilidade de choques efetivos para explicar como se dá a variação da velocidade de uma reação, ideia esta que pertence à teoria das colisões (MES1).

Em relação ao uso de artigos sobre a História da Química (atividade 1, primeiro encontro, Apêndice III), a professora indicou como utilizaria essa estratégia:

Como instrumento para ajudar na compreensão de como o conhecimento científico foi construído, despertando no aluno a consciência de que os benefícios da ciência que desfrutamos hoje é fruto da dedicação de varias gerações de cientistas. (grifo nosso, categoria $\mathrm{C} 4$ )

No segundo encontro, os professores leram um documento oficial sobre o papel da HQ no ensino de ciências (atividade 2, Apêndice VI). A professora concordou com a ideia defendida no documento. Para ela a maior dificuldade em trabalhar com a HQ seria: "O desenvolvimento do conhecimento químico envolve 
o conhecimento de outras ciências que nem sempre o aluno tem um bom domínio".

Na figura 1 está representado o mapa da professora analisada nesse trabalho (atividade 4, terceiro encontro, Apêndice IX).

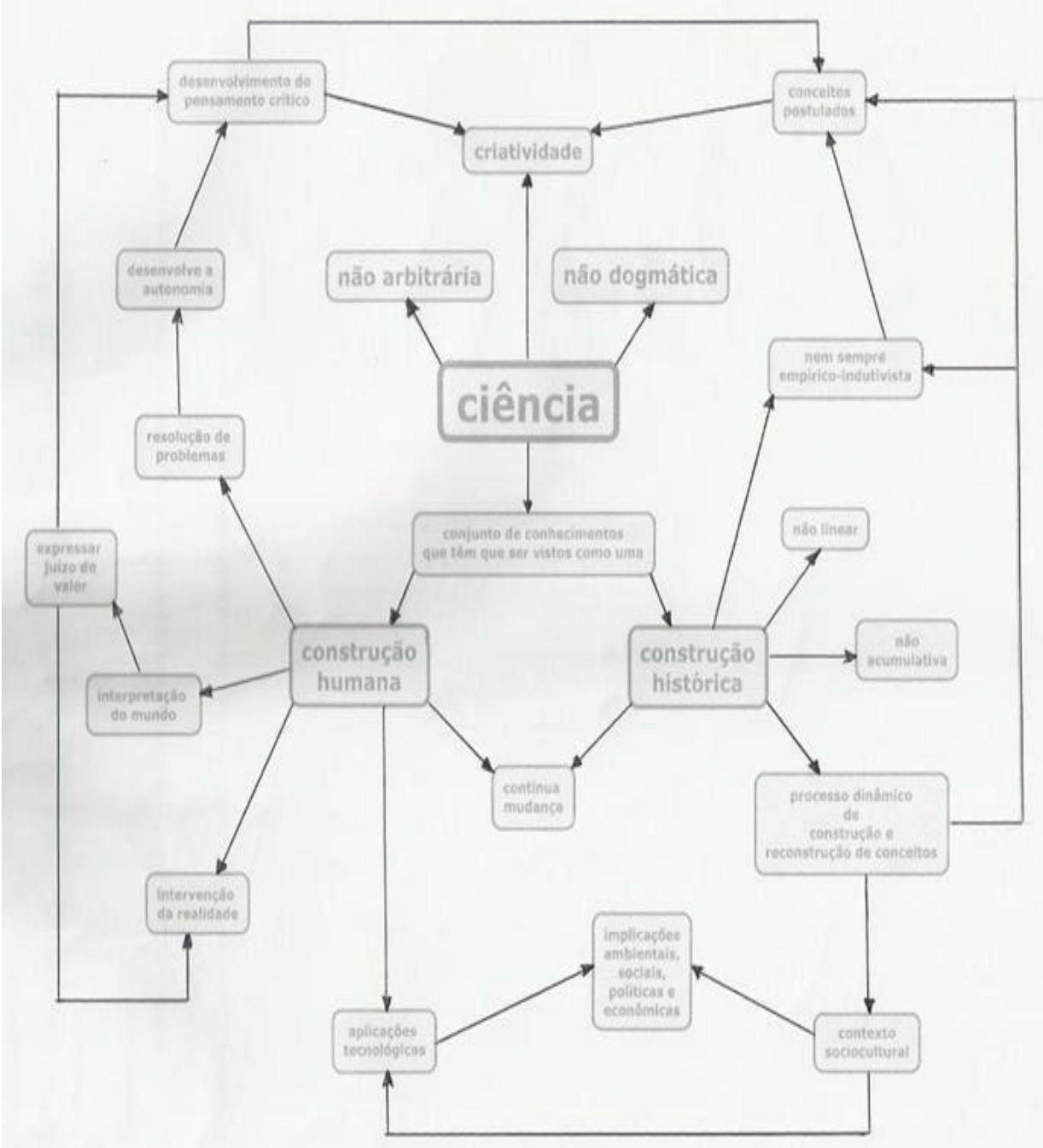

Figura 4.37 Mapa conceitual da professora P15 sobre a visão de ciência que ela espera que seus alunos construam.

Pode-se observar, no mapa conceitual, que a perspectiva filosófica representada é a racionalista (quadro 3.3). O desenvolvimento da ciência, seguindo-se uma linha do mapa, por exemplo, é caracterizado como sendo não 
linear, não acumulativo e que nem sempre se desenvolve seguindo-se um método científico (empírico/indutivista), mas também através da criatividade.

$\mathrm{Na}$ atividade realizada (instrumento 3, Apêndice XIV) no quinto encontro, a professora escreveu:

Ciência é um conjunto de conhecimentos que nos permite compreender o mundo que nos cerca, intervir na realidade e resolver problemas. O conhecimento científico é construído continuadamente, e está intimamente relacionado a um contexto sociocultural. Não depende apenas de uma observação rígida de um fenômeno e nem sempre pode ser comprovada experimentalmente.

As ideias de que a ciência "está intimamente relacionado a um contexto sociocultural", e de que a construção do conhecimento científico: "Não depende apenas de uma observação rígida de um fenômeno e nem sempre pode ser comprovada experimentalmente", estão relacionadas a uma visão de ciência contemporânea (perspectiva racionalista), contudo, observa-se no texto da professora, uma ideia relacionada à perspectiva filosófica empirista/indutivista (quadro I): "O conhecimento científico é construído continuadamente"

Pela análise das respostas da professora, observa-se que o modelo de ensino nessa fase já começa apresentar aspectos submicroscópicos da cinética química, como, por exemplo, a probabilidade de choque efetivo, que está presente na Teoria das Colisões, como também o conceito de energia de ativação. Portanto podemos caracterizar esse modelo de ensino predominantemente como MES1. Este modelo intermediário de ensino é caracterizado, principalmente pela perspectiva filosófica racionalista $(R)$.

\section{Fase final}

No final do curso foi aplicado um instrumento, uma avaliação, na qual os professores tinham que indicar se suas dificuldades em relação ao ensino de cinética química e em relação à História da Ciência tinham sido superadas, após passarem pelo curso. 
A professora apontou em relação à cinética química: "As dificuldades relativas aos conceitos de cinética química foram superadas, mas principalmente, ajudou a compreender a evolução dos conceitos relacionados à cinética química".

E em relação à História da Química:

Sim, pois tivemos acesso a esses materiais e na elaboração do plano de ensino, foi possível explorar as estratégias para colocar esse material na prática. Nunca havia abordado história da cinética em minhas aulas. Pretendo incluir esse conteúdo na minha prática.

\section{Plano de Ensino}

Em relação ao plano de ensino (folha de atividade 8, Apêncice XVII) dessa professora, podem-se observar no quadro abaixo as habilidades e competências em relação aos conceitos de cinética química, à História da química e à visão sobre a natureza da ciência que ela pretende que seus alunos desenvolvam:

\begin{tabular}{llc} 
Tema & Habilidade e competências & Análise \\
\hline $\begin{array}{l}\text { Conceitos da } \\
\text { cinética } \\
\text { química }\end{array}$ & $\begin{array}{l}\text { Compreender as diferenças de significado entre } \\
\text { "velocidade" e "rapidez"; Interpretar tabelas e gráficos; } \\
\text { Interpretar o resultado do experimento demonstrativo. }\end{array}$ & MEM \\
$\begin{array}{l}\text { Visão sobre a } \\
\text { natureza da } \\
\text { ciência }\end{array}$ & $\begin{array}{l}\text { Compreender que a ciência é um conjunto de } \\
\text { conhecimentos não acabados, em contínua mudança e que } \\
\text { depende da colaboração de vários cientistas. }\end{array}$ & $\mathrm{R}$ \\
$\begin{array}{l}\text { História da } \\
\text { Química }\end{array}$ & $\begin{array}{l}\text { Compreender que os conhecimentos científicos são frutos } \\
\text { de uma construção humana e uma construção histórica e } \\
\text { intimamente relacionados a um contexto sociocultural. }\end{array}$ & $\mathrm{C} 4$ \\
& $\begin{array}{l}\text { Compreender que a elaboração de um conceito percorre } \\
\text { um longo caminho de erros e acertos. }\end{array}$ & \\
\hline
\end{tabular}

Quadro 4.29 Habilidades e competências indicadas no plano de ensino da professora P15.

Em relação aos outros tópicos do plano dessa professora:

- Objetivos:

$\mathrm{CQ}$ : compreender os fatores e leis que influem na velocidade ou "rapidez" das transformações químicas, assim como os eventos microscópicos que se desenrolam durante essas transformações. Compreender as diferenças de significado entre 
"velocidade" e "rapidez" de uma transformação química, através da análise de um experimento demonstrativo. Interpretar tabelas e gráficos de [reagentes] x Tempo numa transformação química. HFC: Compreender que os conhecimentos científicos são uma construção humana e uma construção histórica em contínua mudança.

- Conteúdo:

Introdução à Cinética Química; Rapidez das Transformações Químicas; Introdução à Teoria das Colisões.

\section{- Estratégias:}

CQ: Levantamento prévio de ideias; experimentação (experimento demonstrativo: ácido clorídrico e solução aquosa de amônia, ambos concentrados, em um tubo de vidro); exercícios; gráficos. HFC: leitura e discussão de um texto, elaborado por ela a partir do material que foi fornecido pelo curso de formação.

\section{Sequência:}

AULA 1: Levantamento Prévio de Ideias; AULA 2: Leitura e interpretação do texto. Um breve histórico sobre Cinética Química; AULA 3 e 4: Experiência: Rapidez ou velocidade?;AULA 5: Interpretação de um Modelo microscópico.

Após a leitura do texto, em sala de aula, os alunos tinham que responder as questões propostas pela professora. As questões estão relacionadas tanto ao desenvolvimento histórico da cinética química, a filosofia da ciência, quanto ao entendimento de conceitos relacionados à cinética, como pode-se observar em algumas dessas questões:

1. Podemos atribuir apenas a van't Hoff (Prêmio Nobel de Química-1901) os conhecimentos de cinética química que temos hoje? Por quê?;2. É correto afirmar que a ciência é um conjunto de conhecimentos isolados e acabados?

No quadro a seguir, podem ser observados, nos três momentos do curso de formação, os modelos de ensino dessa professora: 


\begin{tabular}{|c|c|c|c|c|}
\hline ETAPA & INSTRUMENTOS & $\begin{array}{l}\text { CINÉTICA } \\
\text { QUIIMICA }\end{array}$ & $\begin{array}{l}\text { HISTÓRIA DA } \\
\text { QUÍMICA }\end{array}$ & $\begin{array}{l}\text { IMAGEM DA } \\
\text { CIÊNCIA }\end{array}$ \\
\hline \multirow{2}{*}{ INÍCIO } & INSTRUMENTO 1 & MEM & $\mathrm{C4}$ & \\
\hline & INSTRUMENTO 2 & & & $E / I$ \\
\hline \multirow{7}{*}{ DURANTE } & ATIVIDADE 1 & & C4 & \\
\hline & ATIVIDADE 2 & & - & \\
\hline & ATIVIDADE 4 & & & $\mathrm{R}$ \\
\hline & ATIVIDADE 6 & MEM & & \\
\hline & INSTRUMENTO 3 & & & $E / I, R$ \\
\hline & EXPERIMENTO 3 & MES1, MES2 & & \\
\hline & EXERCICIO 1 & MES1 & & \\
\hline \multirow{2}{*}{ FINAL } & ATIVIDADE 8 & MEM & $\mathrm{C} 2, \mathrm{C} 4$ & $R$ \\
\hline & PLANO DE ENSINO & MES1 & C4 & $\mathrm{R}$ \\
\hline
\end{tabular}

Quadro 4.30 Modelos de ensino de cinética química da professora P15 nas diferentes etapas do curso de formação.

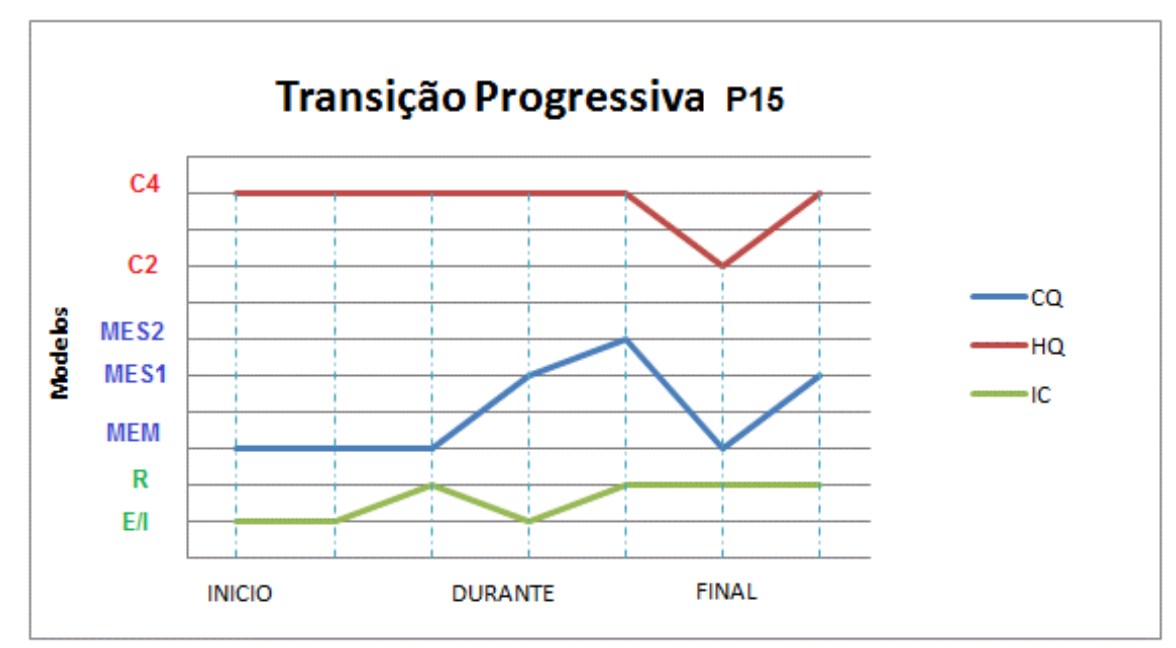

Figura 4.38 Transição progressiva da professora P15 nas três fases da pesquisa, em relação aos seguintes aspectos de seu modelo de ensino: $C Q$ : cinética química, $\mathrm{HQ}$ : História da Química e IC: imagem da ciência.

No gráfico acima observa-se que o curso de formação continuada facilitou a transição progressiva nos aspectos relacionados a cinética química e a imagem sobre a natureza da ciência dessa professora. A sua imagem sobre a natureza que já no inicio do curso era coerente com a perspectiva racionalista, manteve-se assim, até a fase final.

Em relação ao papel da História da Química no ensino, percebe-se que a preocupação da professora está principalmente em que seus alunos entendam o 
processo de construção do conhecimento. Verifica-se no seu plano de ensino, que os conceitos químicos serão abordados a partir do desenvolvimento histórico da cinética química (Gil-Pérez (1993).

\section{P16}

\section{Fase inicial}

Respostas às questões referentes ao instrumento 1 (Apêndice II):

Para a professora o ensino de cinética química é importante: "Porque é através do conhecimento teórico (conceitual) que o aluno irá compreender melhor o que ocorre no seu cotidiano, esta relação conhecimento e vivência é que será significativa para ele".

O conteúdo que ela normalmente aborda em suas aulas: Conceito de cinética química, fatores que influenciam, onde é aplicada na vida do aluno, qual a sua importância na vida produtiva.(MEM)

Para esta professora um dos conteúdos que ela indica que tem maior dificuldade em ensinar é: "Equilíbrio químico". Porque, segundo ela: "É abstrato, o aluno não consegue visualizar o processo".

Quanto à experimentação é usada para demonstrar os fatores que influenciam a velocidade de uma reação química: Superfície de contato: Comprimido efervescente; Pressão: seringa impulsionando o êmbolo/gases ;Temperatura: água quente/fria; Catalisador: Massa plástica utilizada na vedação de carros, calhas. Quando questionada por que o experimento é importante no ensino de cinética química sua resposta é: "Facilita e aproxima o conceito teórico do conteúdo para o entendimento e compreensão do aluno".

Em relação à História da Ciência, embora ela considere importante a sua inclusão no ensino, "Porque ajuda a compreensão de como tudo iniciou a química que hoje ai está, presente no nosso dia-a-dia para melhorar a nossa qualidade de vida", ela afirma não usar em suas aulas. (categoria C3 da HQ) 
Em relação a sua imagem sobre a natureza da ciência (instrumento 2, Apêndice VII), a professora escolheu as seguintes afirmações:

- O conhecimento é construído com base em teorias que orientam a observação, em outras palavras, uma observação depende da teoria.(R)

- Toda investigação científica começa pela observação rigorosa do fenômeno que se estuda.(E/l)

- O conhecimento científico se gera graças à capacidade que os seres humanos possuem para propor problemas e imaginar possíveis soluções aos mesmos.(R)

- O método científico é um conjunto de etapas de atividades práticas e mentais que sem duvida alguma levará a um conhecimento verdadeiro.(E/I)

- As hipóteses dirigem o processo de investigação científica.(R)

- As teorias determinam quais experimentos são considerados legítimos e como eles devem ser conduzidos. Em outras palavras, não existem experimentos independentes de teorias. $(\mathrm{R})$

Pela análise das respostas da professora, observa-se que essa fase inicial está baseada, principalmente, nos aspectos macroscópicos da cinética química (MEM). Este modelo inicial de ensino é marcado principalmente pela perspectiva filosófica racionalista.

\section{Fase intermediária}

Quanto à atividade 6 (quarto encontro, Apêndice XI), a professora mostrou ter o entendimento de como se dá a variação da velocidade de uma reação com o tempo, justificando que: " $A$ velocidade diminui. $A$ velocidade de formação do éster no inicio do processo houve aumento de formação do produto com espaço de tempo menor e com o passar do tempo houve uma diminuição de formação de produto, devido à diminuição da concentração de reagente". (modelo científico MC; Cakmakci et al,2005).

A sua explicação de como se dá a influência da temperatura na velocidade da reação nesse mesmo exercício é: "Com o aumento da temperatura o equilíbrio é atingido num tempo mais curo, uma vez que o aumento da energia favorece $o$ número de choques efetivos." (grifo nosso), portanto, percebe-se que em suas explicações aparece um modelo teórico (MES1). 
$\mathrm{Na}$ atividade experimental 3, sobre o efeito da temperatura na velocidade de uma reação (quarto encontro, Apêndice XII ), sua explicação não inclui termos relacionados a partículas: "Quanto maior a temperatura, maior a velocidade da reação". Quando, na mesma atividade se pedia uma explicação com o uso de um modelo de partículas para explicar por que a transformação é mais lenta quando realizada em água gelada, o professor escreveu: "Menor temperatura da solução, menor é o movimento das partículas". Portanto, a professora dá uma explicação usando termos relacionados a partículas (MEP).

A professora não realizou a atividade do gráfico (exercício 1, quinto encontro, Apêndice XV), deixando sua folha em branco.

A professora não realizou a atividade 1 (primeiro encontro, Apêndice II), sobre o uso de artigos da História da Ciência.

No segundo encontro, os professores leram um documento oficial sobre o papel da HQ no ensino de ciências (atividade 2, Apêndice Vl). A professora concordou com a ideia defendida no documento, justificando: "Sim, pois torna $O$ ensino e a aprendizagem mais significativa para o aluno, bem como a contextualização dos conceitos químicos". (categoria C4, da História da Química)

Para ela a maior dificuldade em trabalhar com a HQ seria:

Fazer a transposição didática dos conteúdos químicos, para a realidade dos nossos alunos. Acesso aos textos da historia da ciência relacionado aos conceitos químicos. Estratégias e metodologias diferenciadas para se trabalhar a história da ciência no ensino de química.

A professora não fez o mapa conceitual (atividade 4, terceiro encontro, Apêndice IX).

$\mathrm{Na}$ atividade realizada (instrumento 3 , Apêndice XIV) no quinto encontro, a professora escreveu: "O conhecimento científico é construído por um conjunto de atividades práticas e mentais, de fatos adquiridos pela observação, hipóteses, experimentação e elaboração de teoria".

Pela análise das respostas da professora, observa-se que o seu modelo de ensino nessa fase intermediária está baseado, principalmente, nos aspectos 
microscópicos da cinética química (MEP). Este modelo é marcado pela perspectiva racionalista (E/I), pois nela a ênfase ao método cientifico, que se inicia pela observação (quadro 3.3).

\section{Fase final}

$\mathrm{Na}$ avaliação final (oitavo encontro, Apêndice XIX) a professora apontou em relação à superação das dificuldades sobre o ensino de cinética química: "aprofundamento dos conhecimentos científicos em relação à cinética química".

Com relação à superação das dificuldades sobre o uso da História da Química:

$$
\begin{aligned}
& \text { Sim, pois a medida que as aulas foram transcorrendo fui } \\
& \text { percebendo que você foi nos subsidiando com suas } \\
& \text { orientações para nos dar suporte para transpor nossas } \\
& \text { dificuldades. Claro que sempre vamos encontrar entraves } \\
& \text { em nosso caminho, porem, houve uma "clarificação" em } \\
& \text { nosso conhecimento para a nossa formação. }
\end{aligned}
$$

Sobre quais aspectos relacionados à sua prática a professora refletiu através do curso, ela respondeu que: "No aspecto da abordagem dos conteúdos de química. Na metodologia do ensino de química, contextualizando com a história da ciência, para tornar a aprendizagem significativa”.

\section{Plano de ensino}

Em relação ao seu plano de ensino (folha de atividade 8, Apêncice XVII), podem-se observar no quadro a seguir as habilidades e competências em relação aos conceitos de cinética química, à História da química e à visão sobre a natureza da ciência que ela pretende que seus alunos desenvolvam:

Tema

Habilidade e competências

Análise

Conceitos da Recorrer aos conhecimentos desenvolvidos sobre as variáveis MEM

cinética que podem afetar a rapidez do processo de deterioração dos

química alimentos para a elaboração de propostas de intervenção na

Visão sobre sociedade.

a natureza

da ciência 
História da

Fortalecer o ensino de Cinética química, introduzindo a história formação cidadã.

Quadro 4.31 Habilidades e competências indicadas no plano de ensino da professora P16.

Em relação aos outros tópicos do plano dessa professora:

- Objetivos:

CQ: Reconhecer o papel da Química no sistema produtivo, analisando a importância do estudo relacionado à Cinética Química e sua utilização no cotidiano, para que o homem possa melhorar a qualidade de vida.

HFC: Relacionar dados da História da Ciência com os conceitos da química, para que o aluno chegue a conclusões sobre as variáveis que podem alterar a rapidez com que uma transformação química ocorre.

- Conteúdo:

CQ: Fatores que influenciam a rapidez de uma reação: Temperatura e Concentração, choque entre partículas, teoria das colisões, energia de ativação e complexo ativado;

HFC: Desenvolvimento Histórico da Cinética Química - Período: 1850-1935.

- Estratégias:

Experimentação investigativa (concentração e temperatura); leitura e interpretação de textos.

- Sequência:

1ํㅡㄹ aula: 1-Experimento 1 - Influência da temperatura na velocidade da reação. Experimentação Investigativa: antes de iniciar a aula experimental, deve-se instigar os alunos, questionando-os a fim de resgatar os seus conhecimentos prévios, relacionando os conteúdos a serem trabalhados. 2-Questões para o aluno responder e discutir com o grupo, após realização do experimento. 3-Leitura de texto referente ao conteúdo: Temperatura (Química \& Sociedade - Editora Nova Geração - Págs. 395 e 397);

$2^{\text {a }}$ Aula:1-Experimento 2 - Influência da concentração dos reagentes na velocidade da reação. 2-Questões para o aluno responder e discutir com o grupo, após realização do 
experimento. 3-Leitura de textos referente ao conteúdo: Concentração (Química \& Sociedade - Editora Nova Geração - Págs. 395 e 397).

$3^{\text {a }}$ Aula: a)Leitura e discussão com os alunos sobre a bibliografia e história do cientista que participou da evolução do estudo da Cinética Química, particularmente sobre a sua atuação em Amsterdã, quando foi publicado seu livro "Études de dynamique chimique" em 1884, uma das mais importantes obras de química de todos os tempos; b)Fazer um paralelo com os dois textos da História da Ciência já discutidos em grupo, com as atividades propostas nas aulas anteriores (experimentos e leitura complementar referente aos conteúdos: Temperatura e Concentração - Química \& Sociedade - Editora Nova Geração - Págs.395 e 397).c). A discussão com o grupo e a mediação do professor, deve levar o aluno à reflexão na questão da relação entre a história da ciência e os conteúdos da cinética desenvolvidos nas aulas de química, para que o conhecimento adquirido possa subsidiar o aluno no seu desenvolvimento e na sua ação perante a sociedade em que vive.

4․ Aula: a-Retomada dos conceitos químicos abordados nas aulas anteriores sobre a Influência da temperatura e concentração na rapidez ou retardamento das reações, destacando a interação e o choque entre as partículas, a energia de ativação e o complexo ativado no processo da transformação química. b-Produção individual de um texto sobre os conceitos químicos elaborados da Cinética Química - Influência de fatores que interferem na rapidez das reações. (grifo nosso)

No desenvolvimento do conteúdo, observando-se o texto acima grifado, a professora trabalha com modelos teóricos para explicar a velocidade e a influência dos fatores na velocidade de uma reação (MES2).

Em relação à História da Química para essa professora essa estratégia tem a finalidade de que os alunos entendam o desenvolvimento dos conceitos relacionados à cinética química, como também conhecer os cientistas envolvidos nessa construção (categorias C3 e C4 da HQ).

Em relação à natureza da ciência, pode-se observar em seu plano de ensino, uma visão próxima a da perspectiva filosófica racionalista no que diz respeito à ideia de que o conhecimento científico é visto como uma construção humana: 
Leitura e discussão com os alunos sobre a bibliografia e história do cientista que participou da evolução do estudo da Cinética Química........ A discussão com o grupo e a mediação do professor, deve levar o aluno à reflexão na questão da relação entre a história da ciência e os conteúdos da cinética desenvolvidos nas aulas de química, para que o conhecimento adquirido possa subsidiar o aluno no seu desenvolvimento e na sua ação perante a sociedade em que vive ( $3^{\underline{a}}$ aula do plano, P16).

No quadro a seguir, podem ser observados, nos três momentos do curso de formação, os modelos de ensino dessa professora:

\begin{tabular}{|c|c|c|c|c|}
\hline ETAPA & INSTRUMENTOS & $\begin{array}{l}\text { CINÉTICA } \\
\text { QUÍMICA }\end{array}$ & $\begin{array}{l}\text { HISTÓRIA DA } \\
\text { QUÍMICA }\end{array}$ & $\begin{array}{c}\text { IMAGEM DA } \\
\text { CIÊNCIA }\end{array}$ \\
\hline \multirow{2}{*}{ INÍCIO } & INSTRUMENTO 1 & MEM & $\mathrm{C} 3$ & \\
\hline & INSTRUMENTO 2 & & & $\mathrm{R}$ \\
\hline \multirow{7}{*}{ DURANTE } & ATIVIDADE 1 & & - & \\
\hline & ATIVIDADE 2 & & $\mathrm{C} 4$ & \\
\hline & ATIVIDADE 4 & & & - \\
\hline & ATIVIDADE 6 & MES1 & & \\
\hline & INSTRUMENTO 3 & & & $E / I$ \\
\hline & EXPERIMENTO 3 & MEP & & \\
\hline & EXERCICIO 1 & - & & \\
\hline \multirow{2}{*}{ FINAL } & ATIVIDADE 8 & MEM & $\mathrm{C} 3, \mathrm{C} 4$ & \\
\hline & PLANO DE ENSINO & MES2 & $\mathrm{C} 4$ & $\mathrm{R}$ \\
\hline
\end{tabular}

Quadro 4.32 Modelos de ensino de cinética química do professor P16 nas diferentes etapas do curso de formação.

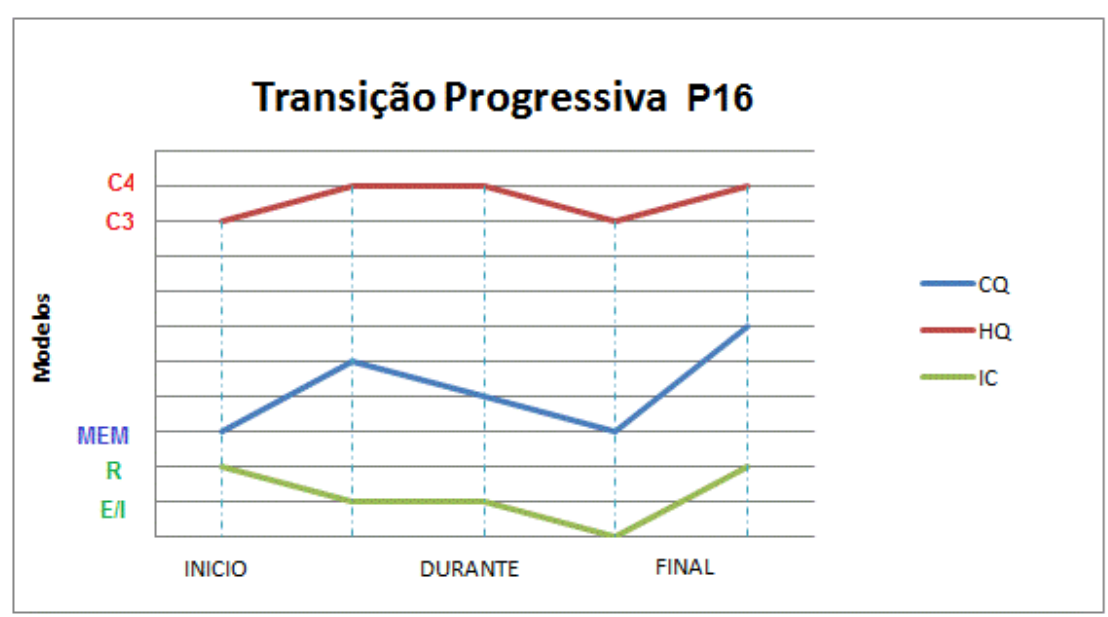


Figura 4.39 Transição progressiva da professora P16 nas três fases da pesquisa, em relação aos seguintes aspectos de seu modelo de ensino: $C Q$ : cinética química, $H Q$ : História da Química e IC: imagem da ciência.

Na figura acima observa-se que o curso de formação continuada facilitou a transição progressiva em relação ao entendimento do papel da $\mathrm{HQ}$ no ensino e a cinética química. Contudo, em relação a sua imagem sobre a natureza da ciência, percebe-se que para essa professora ainda existem dificuldades no seu entendimento. Segundo Níaz (2009), isso ocorre porque o processo de entendimento da natureza da ciência é complexo, mesmo para os pesquisadores em ensino de ciências, portanto, é plausível sugerir que os professores participantes do curso tenham também tenham tido dificuldades no seu entendimento.

\section{P17}

\section{Fase inicial}

Respostas as questões referentes ao instrumento 1 (Apêndice II):

A professora $\mathrm{P} 17$, não justificou porque é importante aprender cinética química no ensino médio. Quanto ao conteúdo que é importante ensinar ela aponta:

$$
\begin{aligned}
& \text { Reações químicas que ocorrem no nosso organismo, } \\
& \text { durante o processo digestivo, os ataques corrosivos } \\
& \text { proporcionados pela ação de intempéries, utilização de } \\
& \text { antiácidos, enfim, temas que são corriqueiros e comuns no } \\
& \text { dia a dia, os quais eles possam correlacionar. Em adição } \\
& \text { concentração e soluções. (MEM) }
\end{aligned}
$$

A professora não estava lecionando no período em que participou do curso de formação, assim, ao invés de considera-se o conteúdo que ela leciona, será considerado, nessa fase inicial, como resposta o conteúdo que ela considera importante ensinar sobre cinética química. 
Para ela, o conteúdo que indica que tem maior dificuldade em ensinar é: "Algo que os alunos não possam ver acontecendo e que não seja simples correlacionar com o dia a dia". Porque, segundo ela: "É abstrato".

Quando questionada por que o experimento é importante no ensino de cinética química sua resposta é que: "Nesse instante o aluno visualiza, armazena e concretiza o conteúdo ministrado".

Em relação à História da Ciência, embora ela considere importante a sua inclusão no ensino, "Quando se conhece a origem dos acontecimentos, facilita no processo de aprendizagem, porque é neste momento em que o aluno capta a aplicação do que você esta ensinando e consequentemente a sua devida importância", ela afirma não usar em suas aulas. (categoria C3 da HQ)

Em relação a sua imagem sobre a natureza da ciência (instrumento 2, Apêndice VII), a professora escolheu as seguintes afirmações:

- O conhecimento científico é o conhecimento provado (E/I)

- O conhecimento científico se gera graças à capacidade que os seres humanos possuem para propor problemas e imaginar possíveis soluções aos mesmos. (R)

- Através do experimento, o investigador comprova se sua hipótese de trabalho é verdadeira ou falsa.(E/l)

- Ao realizar uma observação o cientista não deve sofrer a influência de teorias prévias sobre o problema investigado.(E/l)

Pela análise das respostas da professora, observa-se suas ideias estão relacionadas, principalmente, aos aspectos macroscópicos da cinética química (MEM). Este modelo inicial de ensino é marcado principalmente pela perspectiva filosófica empirista/indutivista (E/I).

\section{Fase intermediária}

Quanto à atividade 6 (quarto encontro, Apêndice XI), a professora mostrou não ter o entendimento de como se dá a variação da velocidade de uma reação com o tempo, justificando que: "A velocidade aumenta. Com o aumento do tempo (h) a quantidade (\%) de ácido esterificado foi aumentando, devido ao aumento da 
temperatura da reação a velocidade aumentou consideravelmente". (modelo de aumento - MA; Cakmakci et al,2005).

Sua explicação de como se dá a influência da temperatura na velocidade da reação nesse mesmo exercício é: "Que a temperatura é fator determinante na velocidade da reação e consequentemente a produção de ácido esterificado", portanto, percebe-se que em suas respostas não aparece um modelo explicativo (MEM).

A professora não realizou a atividade experimental 3 , sobre o efeito da temperatura na velocidade de uma reação (quarto encontro, Apêndice XII).

A professora não fez o exercício 1 sobre gráficos (quinto encontro, Apêndice XV)

Em relação ao uso de artigos sobre a História da Química (atividade 1, primeiro encontro, Apêndice III), a professora indicou como utilizaria essa estratégia: "Através de aula expositiva como seminários, onde o tema a ter abordado seria demonstrado pelos alunos".

Vantagens em se utilizar essa estratégia no ensino: "Estão relacionadas ao poder de assimilação rápido do conteúdo a ser ministrado e a origem do conteúdo, ou seja, baseado na História da Química" (grifo nosso). (categoria C3).

No segundo encontro, os professores leram um documento oficial sobre 0 papel da HQ no ensino de ciências (atividade 2, Apêndice Vl). A professora concordou com a ideia defendida no documento. Para ela a maior dificuldade em trabalhar com a HQ seria: "O desafio é fazer com que esta prática sempre ocorra de maneira lúdica e entusiasmada.".

Em relação a atividade de elaboração do mapa conceitual (atividade 4, terceiro encontro, Apêndice IX) a professora elaborou o seguinte mapa: 


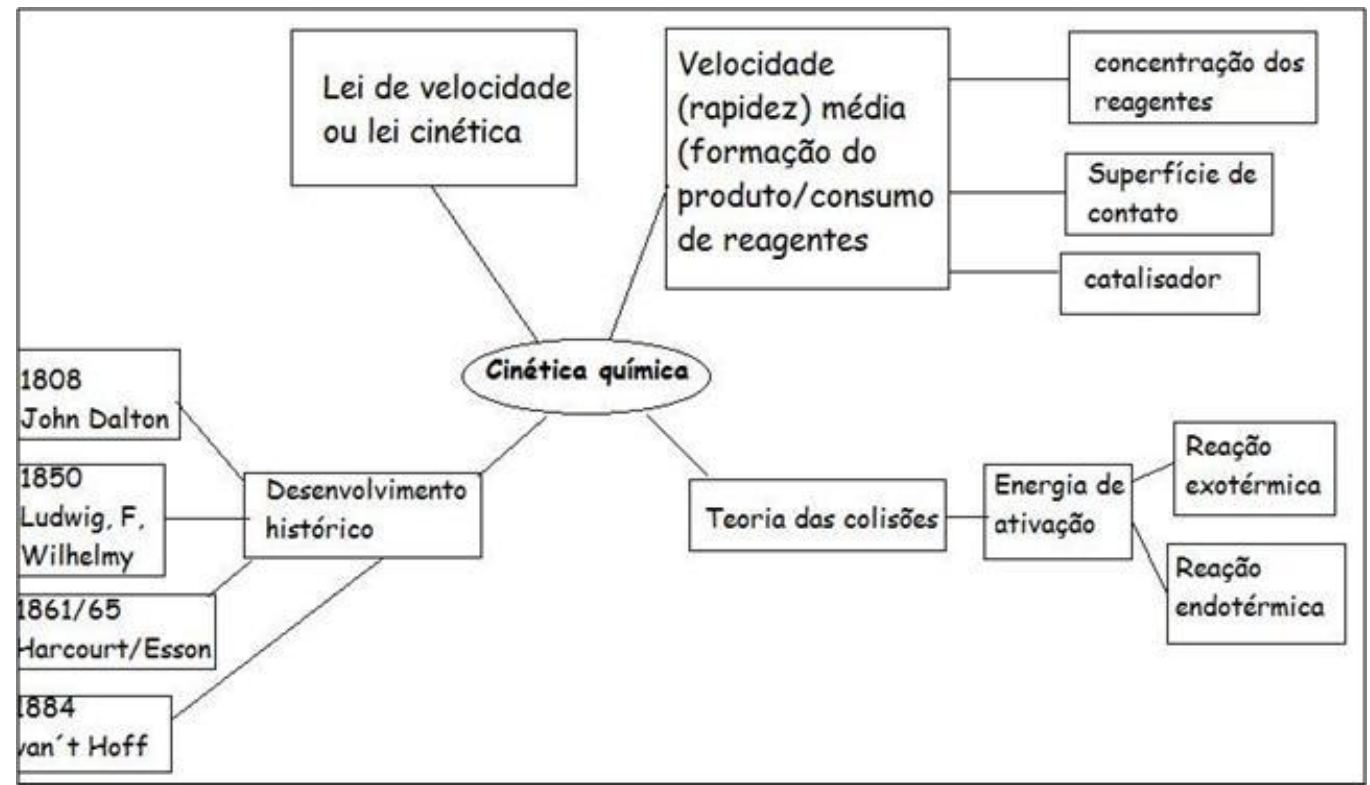

Figura 4.40 Mapa conceitual da professora P17 sobre a visão de ciência que ela espera que seus alunos construam.

Em seu mapa observa-se que a professora, não aponta as ideias sobre a natureza da ciência que ela espera que seus alunos construam, mas sim faz uma relação entre os conceitos envolvidos no tema cinética química e os nomes de alguns cientistas que participaram do desenvolvimento da cinética química.

Na atividade realizada (instrumento 3, Apêndice XIV) no quinto encontro, a professora escreveu:

A ciência é o pilar principal da construção do conhecimento científico, no qual baseia-se, na maioria das vezes, em ideias e teorias com o intuito de compreensão e expansão do conhecimento intelectual, experimental e sobretudo a comprovação de fatos. (perspectiva E/l, quadro 3.3)

A partir da análise das respostas da professora, observa-se que o seu modelo de ensino nessa fase intermediária está baseado, principalmente, nos aspectos macroscópicos da cinética química (MEM). Este modelo é marcado pela perspectiva filosófica empirista/indutivista (E/I).

\section{Fase final}

$\mathrm{Na}$ avaliação final (oitavo encontro, Apêndice XIX) a professora apontou em relação à superação das dificuldades sobre o ensino de cinética química: "As 
aulas práticas auxiliaram e o material didático apresentado juntamente com as discussões".

Com relação à superação das dificuldades sobre o uso da História da Química: "Sim, principalmente quanto ao acesso aos materiais disponibilizados por vocês, bem como as fontes para consulta. O que fica hoje é o desafio de contextualizar isto de maneira prática ao aluno".

Sobre quais aspectos relacionados à sua prática a professora refletiu através do curso, ela respondeu que: "A contextualização do tema que você irá abordar junto ao aluno. "deixar passar em branco" a História da Ciência é uma negligência, uma vez que pude perceber a importância que tem e como amplia a visão".

\section{Plano de ensino:}

Em relação ao seu plano de ensino (folha de atividade 8, Apêncice XVII), podem-se observar no quadro a seguir as habilidades e competências em relação aos conceitos de cinética química, a História da química e a visão sobre a natureza da ciência, que ela pretende que seus alunos desenvolvam:

Tema

Habilidade e competências

Análise

Conceitos da cinética

química

Compreender a correlação das variáveis de temperatura, MEM concentração, tamanho do corpo de prova com a velocidade da reação.

Visão sobre a Contextualização dos conceitos e a importância de teorias natureza da anteriores para a continuidade e construção da ciência; $A$ ciência ciência é dinâmica. Conhecimento na linha do tempo.

História da Correlacionar fatos históricos com o desenvolvimento da Química cinética, a importância e o porquê da criação de determinada teoria.

Quadro 4.33 Habilidades e competências indicadas no plano de ensino da professora P17.

Em relação aos outros tópicos do plano dessa professora:

- Objetivos: 
$\mathrm{CQ}$ : Verificar fatores que podem estar diretamente associados à velocidade de uma reação química utilizando como instrumento a conservação de alimentos e o cotidiano do aluno; Através da conservação dos alimentos possa compreender a Cinética química;

HFC: Abordar os principais cientistas relacionados a historia da cinética química. Através da história o aluno possa contextualizar os conceitos e a importância de teorias anteriores para a continuidade e construção da ciência e perceber o conhecimento em uma linha do tempo e que a ciência é dinâmica.

- Conteúdo:

Introdução a cinética química, fatores que podem estar diretamente associados à velocidade de uma reação química.

\section{- Estratégias:}

Questionário para levantamento do conhecimento prévio do aluno sobre a conservação dos alimentos. Experimento sobre conservação de alimento (Investigação através de experimento); Discussões referentes ao experimento utilizando o material distribuído com o conteúdo do tema; questionário empregado antes e após a realização do experimento; simulações (Apresentar material interativo como recurso complementar para contribuição no entendimento do tema abordado). Mapa conceitual.

- Sequência:

Aula 01: Principal desafio nesta aula é Instigar o aluno quanto ao caráter investigativo à possibilidade de relacionar experimentos com a cinética química. Aplicação de questionário para mapeamento do conhecimento do aluno referente ao tema a ser abordado. Preparação de amostras para realização do experimento. Realização do experimento;

Aula 02: Discutir com o grupo o questionário respondido previamente realizando comparação entre os resultados obtidos após os três dias de observações; Comparar os resultados obtidos entre os grupos; Contextualizar os conceitos vivenciados através dos experimentos realizados versus conceitos relacionados à cinética química (vide: material fornecido pelo professor como apoio;) a fim de sistematizar os conteúdos.

Aula 03: Abordar os principais cientistas relacionados a história da cinética química; Através de discussões, explanar ao aluno a importância da visão de ciência para o 
desenvolvimento do conhecimento, sobretudo demonstrando a evolução e contextualização através do mapa conceitual (fig. 4.40).

Aula 04: Apresentar material interativo como recurso complementar para contribuição no entendimento do tema abordado; Apresentar diagramas de resumo sobre a cinética química; Aplicar novamente o questionário; Obter feedback dos alunos quanto a metodologia utilizada para exposição do tema cinética química, com o intuito da melhoria continua e construtivista do ensino da química utilizando abordagens relacionadas ao cotidiano do aluno.

No seu plano a professora não trabalha com modelos teóricos para explicar a velocidade e a influência dos fatores na velocidade de uma reação (MEM), mas sim tem a preocupação de enfocar o cotidiano:

Verificar fatores que podem estar diretamente associados à velocidade de uma reação química utilizando como instrumento a conservação de alimentos e o cotidiano do aluno; Através da conservação dos alimentos possa compreender a Cinética química. (plano de ensino, P17)(grifo nosso)

Em relação à História da Química para ela, essa estratégia tem a finalidade de que os alunos entendam a origem dos conceitos relacionados à cinética química, e compreendam o caráter dinâmico da ciência (categorias C2 e C3):

Abordar os principais cientistas relacionados a historia da cinética química. Através da história 0 aluno possa contextualizar os conceitos e a importância de teorias anteriores para a continuidade e construção da ciência e perceber o conhecimento em uma linha do tempo e que a ciência é dinâmica. (plano de ensino, P17)

No quadro a seguir, podem ser observados, nos três momentos do curso de formação, os modelos de ensino dessa professora:

\begin{tabular}{|c|l|c|c|c|}
\hline \multirow{2}{*}{ ETAPA } & INSTRUMENTOS & CINÉTICA QUÍMICA & HISTÓRIA DA QUÍMICA & $\begin{array}{l}\text { IMAGEM DA } \\
\text { CIÊNCIA }\end{array}$ \\
\hline \multirow{2}{*}{ INÍCIO } & INSTRUMENTO 1 & MEM & C3 & \\
\cline { 2 - 5 } & INSTRUMENTO 2 & & & E/I \\
\hline \multirow{5}{*}{ DURANTE } & ATIVIDADE 1 & & C3 & \\
\cline { 2 - 5 } & ATIVIDADE 2 & & - & - \\
\cline { 2 - 5 } & ATIVIDADE 4 & & & E/I \\
\cline { 2 - 5 } & ATIVIDADE 6 & MEM & & \\
\cline { 2 - 5 } & INSTRUMENTO 3 & & \multicolumn{2}{|c}{} \\
\cline { 2 - 5 } & EXPERIMENTO 3 & - & \multicolumn{2}{c}{} \\
\hline
\end{tabular}




\begin{tabular}{|l|l|c|c|c|}
\cline { 3 - 4 } \multicolumn{2}{c|}{} & EXERCICIO 1 & - & \multicolumn{1}{c|}{} \\
\hline \multirow{2}{*}{ FINAL } & ATIVIDADE 8 & MEM & C3 & R, E/I \\
\cline { 2 - 5 } & PLANO DE ENSINO & MEM & C2,C3 & $R$ \\
\hline
\end{tabular}

Quadro 4.34 Modelos de ensino de cinética química do professor P17 nas diferentes etapas do curso de formação.

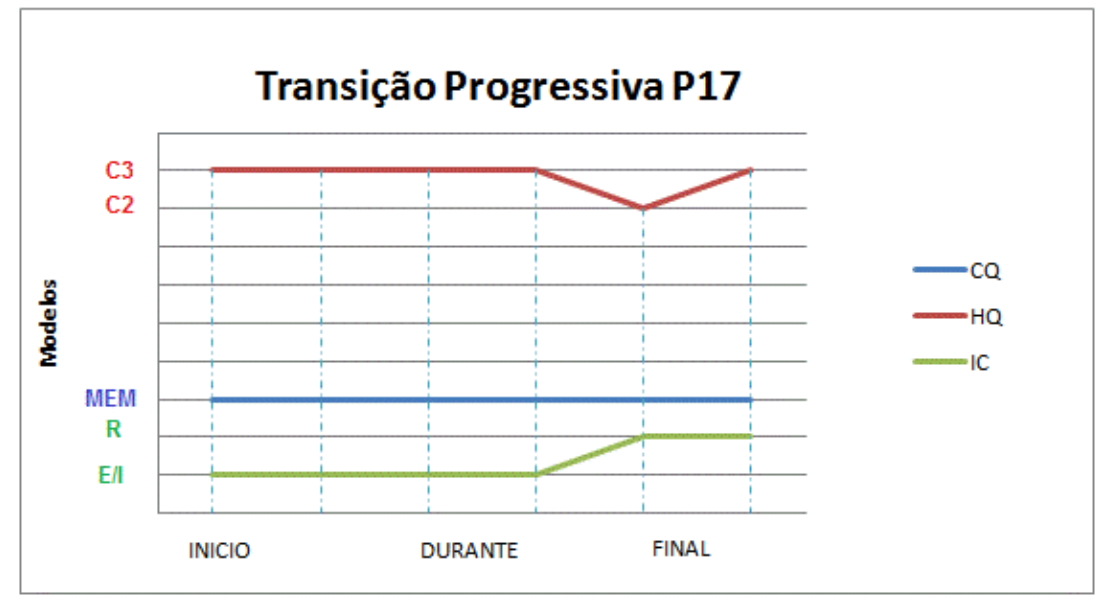

Figura 4.41 Transição progressiva da professora P17 nas três fases da pesquisa, em relação aos seguintes aspectos de seu modelo de ensino: $\mathrm{CQ}$ : cinética química, $\mathrm{HQ}$ : História da Química e IC: imagem da ciência.

Pela análise da figura acima percebe-se que o curso de formação continuada facilitou a transição progressiva em relação ao seu entendimento do papel da História da Química no ensino de cinética química, mesmo assim, para essa professora a História da Química ainda não foi aborda com o objetivo de se ensinar os conceitos químicos, mas sim de informar aos alunos a origem desses conhecimentos.

Em relação a sua imagem sobre a natureza da ciência, observa-se no plano a sua intenção de trabalhar com as ideias do experimento investigativo, ideias que são coerentes com a perspectiva filosófica racionalista, como também a de mostrar a ciência como sendo uma construção humana.

\section{P18}

Fase inicial 
Respostas às questões referentes ao instrumento 1 (Apêndice II):

Para a professora o ensino de cinética química é importante: "Porque o aluno precisa entender que além das transformações químicas ocorrerem, elas também têm velocidades em que isso acontece e é um conceito que está relacionado com o dia a dia".

O conteúdo que ela normalmente aborda em suas aulas: Velocidade de reação, deslocamento de equilíbrio, equilíbrio em meio aquoso.(MEM)

Em relação ao que ensina, o aspecto mais importante é: "Velocidade das reações, equilíbrio químico, fatores que alteram as velocidades das reações. Porque, da mesma forma que temos reações que ocorrem instantaneamente, temos as não instantâneas e o aluno não associa essas diferenças na ocorrência".(MEM)

Para esta professora um dos conteúdos que ela indica que tem maior dificuldade em ensinar é: " $A$ ocorrência da reação e a duração em que ela ocorre e os fatores que reduzem ou aceleram essas velocidades".

Quanto à experimentação é usada para demonstrar os fatores que influenciam a velocidade de uma reação química: Superfície de contato e temperatura: Comprimido efervescente. Quando questionada por que o experimento é importante no ensino de cinética química sua resposta é: "Ajuda muito, porque parte do macroscópico para o micro".

Em relação à História da Ciência, embora ela considere importante a sua inclusão no ensino, "Acho que pode auxiliar porém, confesso que tenho que ler mais sobre História da Ciência" (categoria C1da HQ), ela afirma não usar em suas aulas.

Em relação a sua imagem sobre a natureza da ciência (instrumento 2, Apêndice VII), a professora escolheu as seguintes afirmações:

- A eficácia e a objetividade do trabalho científico consistem em seguir fielmente as fases ordenadas do método científico: observação, hipótese, experimentação e elaboração de teorias.(E/l) 
- Toda investigação científica começa pela observação rigorosa do fenômeno que se estuda.(E/I)

- O conhecimento científico se gera graças à capacidade que os seres humanos possuem para propor problemas e imaginar possíveis soluções aos mesmos.(R)

- Através do experimento, o investigador comprova se sua hipótese de trabalho é verdadeira ou falsa.(E/I)

- Ao realizar uma observação o cientista não deve sofrer a influência de teorias prévias sobre o problema investigado.(E/I)

- Teorias científicas são derivadas, de um modo rigoroso, de fatos adquiridos pela observação e pela experimentação.(E/I)

Pela análise das respostas da professora, observa-se que o seu modelo de ensino nessa fase inicial está baseado, principalmente, nos aspectos macroscópicos da cinética química (MEM). Este modelo inicial de ensino é marcado principalmente pela perspectiva filosófica empirista/indutivista (E/I)

\section{Fase intermediária}

Quanto à atividade 6 (quarto encontro, Apêndice XI), a professora mostrou ter entendimento de como se dá a variação da velocidade de uma reação com o tempo, justificando que: "A velocidade irá diminuindo com o tempo. Como a velocidade de reação depende da concentração e os reagentes estão sendo consumidos, a velocidade diminui”. (modelo científico - MC; Cakmakci et al,2005).

A sua explicação de como se dá a influência da temperatura na velocidade da reação nesse mesmo exercício é: "Podemos concluir que com o aumento da temperatura há uma aceleração da velocidade, e um rendimento em menor tempo e melhor.", portanto, percebe-se que em suas explicações não aparece um modelo explicativo (MEM).

$\mathrm{Na}$ atividade experimental 3, sobre o efeito da temperatura na velocidade de uma reação (quarto encontro, Apêndice XII ), sua explicação não inclui termos relacionados a partículas: "Quanto maior a temperatura mais rápido ocorre a reação". Quando, na mesma atividade se pedia uma explicação com o uso de um modelo de partículas para explicar por que a transformação é mais lenta quando 
realizada em água gelada, a professora escreveu: "Porque diminui a movimentação das partículas, diminuindo os choques efetivos, diminuindo assim o tempo de reação”. Portanto, a professora inclui termos relacionados a modelos teóricos (MES1).

No próximo exercício sobre gráficos (quinto encontro, Apêndice XV) a professora desenhou o seguinte:

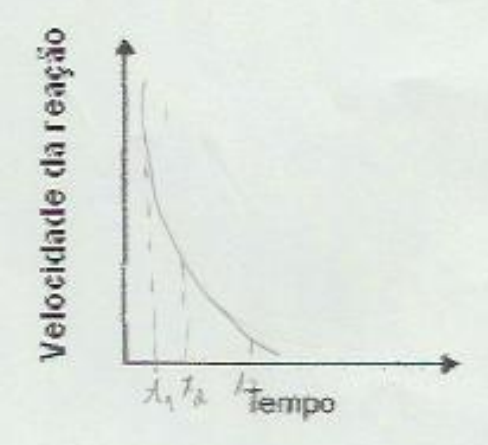

Figura 4.42 A variação da velocidade de uma reação em função do tempo segundo P18.

Percebe-se que o modelo de seu gráfico refere-se ao modelo científico MC (categoria Cakmakci et al,2005). Sua justificativa para esse modelo é:

No início está presente no sistema várias moléculas de $A$ e $B$, ou seja, facilitando colisões efetivas, iniciando, portanto, com velocidade alta, conforme vai diminuindo a concentração dos reagentes diminui também a velocidade de formação do produto.(MES1)

Em relação ao uso de artigos sobre a História da Química (atividade 1, primeiro encontro, Apêndice III), a professora indicou como utilizaria essa estratégia:

Uma discussão, trazendo a atenção e curiosidade dos alunos, fazendo uma dinâmica e trazê-los cada vez mais ao conhecimento da história da química. (categoria C1da $\mathrm{HQ)}$

Vantagens em se utilizar essa estratégia no ensino: "Participação maior dos alunos". 
No segundo encontro, os professores leram um documento oficial sobre 0 papel da HQ no ensino de ciências (atividade 2, Apêndice VI). A professora concordou com a ideia defendida no documento, justificando: "Sim, é plausível, pois mostra que a química não é uma ciência exata e que não é sempre que chegamos a resultados desejados".(Categoria C2 da HQ)

Para ela a dificuldade em abordar $\mathrm{HC}$ no ensino é:

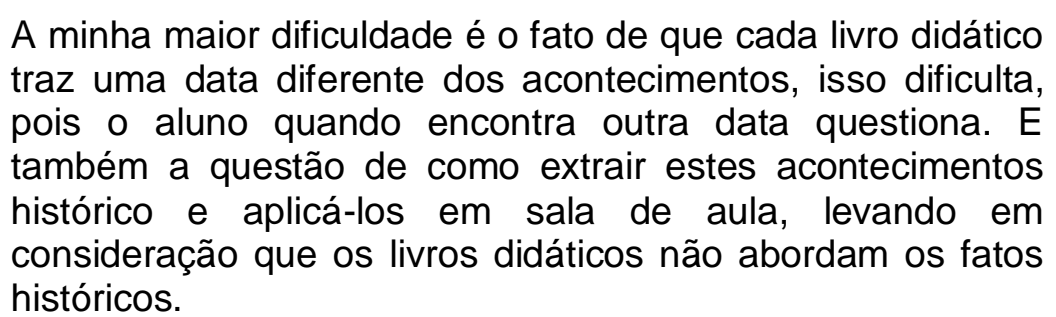

$\mathrm{Na}$ atividade 4 (terceiro encontro, Apêndice IX), a professora construiu o seguinte mapa conceitual:

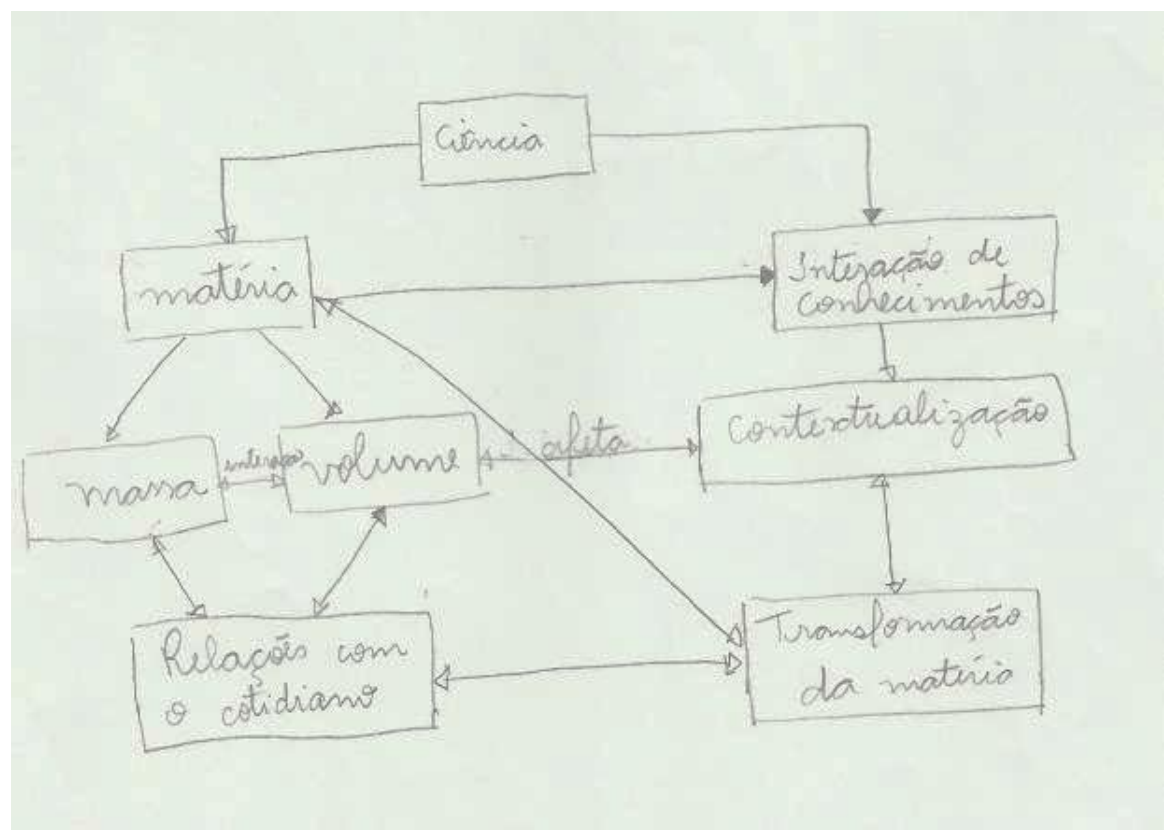

Figura 4.43 Mapa conceitual da professora P18 sobre a visão de ciência que ela espera que seus alunos construam.

Pode-se observar no mapa conceitual acima que a professora tenta relacionar conceitos relativos à ciência com a ideia de contextualização, sem, 
contudo, relacioná-los explicitamente, com ideias referentes à imagem da natureza da ciência.

$\mathrm{Na}$ atividade realizada (instrumento 3, Apêndice XIV) no quinto encontro, a professora escreveu:

É o desenvolvimento de fatos que auxiliam no entendimento
de leis, que se desenvolve através de experimentação e
observações. O conhecimento científico é $\begin{array}{llll}\text { construído } \\ \text { principalmente através da observação de }\end{array}$
experimentais. (grifo nosso)

Pela análise das respostas da professora, observa-se que o seu modelo de ensino nessa fase intermediária está baseado, principalmente, nos aspectos submicroscópicos da cinética química (MES1). Este modelo é marcado principalmente pela perspectiva filosófica empirista/indutivista (E/I).

\section{Fase final}

$\mathrm{Na}$ avaliação final (oitavo encontro, Apêndice XIX) a professora apontou em relação à superação das dificuldades sobre o ensino de cinética química: "Só depende de nós mesmos encarar esses tipos de dificuldades e gerar linguagens para seguir uma história para chegar ao mais moderno e atual, utilizando a História da Ciência”.

Com relação a superação das dificuldades sobre o uso da História da Química: "Sim, pude me questionar e melhorar minha visão para poder aplicar todo esse conhecimento na área de educação".

Sobre quais aspectos relacionados à sua prática a professora refletiu através do curso, ela respondeu que: "Que posso ir muito mais além, que eu era pequena para uma grande dimensão de conhecimentos e que sou capaz de buscar mais e mais".

\section{$\underline{\text { Plano de ensino }}$}

A professora não realizou a atividade 8 (Apêndice VIII).

Em relação aos tópicos do plano dessa professora:

- Objetivos: 
HFC: Criar uma visão mais aberta da ciência. Compreender a não linearidade dos fatos históricos. CQ: Interpretar gráficos. Relacionar as energias envolvidas. Compreender os fatores que interferem na velocidade da reação. Leitura e interpretação.

- Conteúdo: Velocidade de reação. Fatores que interferem na velocidade de reação.

- Estratégias:Experimentação, mapa conceitual, textos.

- Sequência:

1) Apresentar diversas situações em vídeos com diferentes tipos de reações e alteração de diversos parâmetros, como temperatura e concentração.

2) Solicitar para os alunos que relatem os experimentos vistos e analisem.

3) Solicitar que os alunos façam uma pesquisa e identifiquem reações semelhantes as apresentadas;

4) Com o material pesquisado dos alunos, analisar junto com eles e discutir os conceitos de velocidade de reação.

5) Conceituar velocidade de reação.

6) Elaborar um mapa conceitual.

7) Desenvolver experimentação para comprovação da velocidade de reação.

8) Apresentar trechos do texto "A primeira ideia de átomos" e instigando os alunos para discussão e compreensão do modelo atômico de Dalton.

9) Em seguida apresentar trechos do artigo científico "Os noventa anos de Les atomes" da química nova na escola.

10)Para fechamento e avaliação dos conceitos envolvidos, solicitar uma atividade experimental com explicações dos acontecimentos.

No seu plano a professora não trabalha com modelos teóricos para explicar a velocidade e a influência dos fatores na velocidade de uma reação (MEM).

Em relação à História da Química para ela essa estratégia tem a finalidade de que os alunos conheçam o desenvolvimento de uma teoria (categoria C4): "Apresentar trechos do texto "A primeira ideia de átomos" e instigando os alunos 
para discussão e compreensão do modelo atômico de Dalton”. (plano de ensino, P18)

Em seu plano de ensino, pode-se observar que sua imagem sobre a natureza da ciência é coerente com a perspectiva filosófica racionalista: "Criar uma visão mais aberta da ciência. Compreender a não linearidade dos fatos históricos" (plano de ensino, P18) (grifo nosso)

Contudo em relação ao papel da experimentação, a imagem da natureza da ciência da professora é coerente com a imagem da perspectiva empirista indutivista: "7) Desenvolver experimentacão para comprovação da velocidade de reação" (plano de ensino, P18) (grifo nosso).

No quadro a seguir, podem ser observados, nos três momentos do curso de formação, os modelos de ensino dessa professora:

\begin{tabular}{|c|c|c|c|c|}
\hline ETAPA & INSTRUMENTOS & $\begin{array}{l}\text { CINÉTICA } \\
\text { QUÍMICA }\end{array}$ & $\begin{array}{l}\text { HISTÓRIA DA } \\
\text { QUÍMICA }\end{array}$ & $\begin{array}{c}\text { IMAGEM DA } \\
\text { CIÊNCIA }\end{array}$ \\
\hline \multirow{2}{*}{ INÍCIO } & INSTRUMENTO 1 & MEM & $\mathrm{C} 1$ & \\
\hline & INSTRUMENTO 2 & & & $E / I$ \\
\hline \multirow{7}{*}{ DURANTE } & ATIVIDADE 1 & & $\mathrm{C} 1$ & \\
\hline & ATIVIDADE 2 & & $\mathrm{C} 2$ & \\
\hline & ATIVIDADE 4 & & & - \\
\hline & ATIVIDADE 6 & MEM & & \\
\hline & INSTRUMENTO 3 & & & $E / I$ \\
\hline & EXPERIMENTO 3 & MES1 & & \\
\hline & EXERCICIO 1 & MES1 & & \\
\hline \multirow{2}{*}{ FINAL } & ATIVIDADE 8 & - & - & - \\
\hline & PLANO DE ENSINO & MEM & $\mathrm{C} 4$ & $E / I, R$ \\
\hline
\end{tabular}

Quadro 4.35 Modelos de ensino de cinética química da professora P18 nas diferentes etapas do curso de formação. 


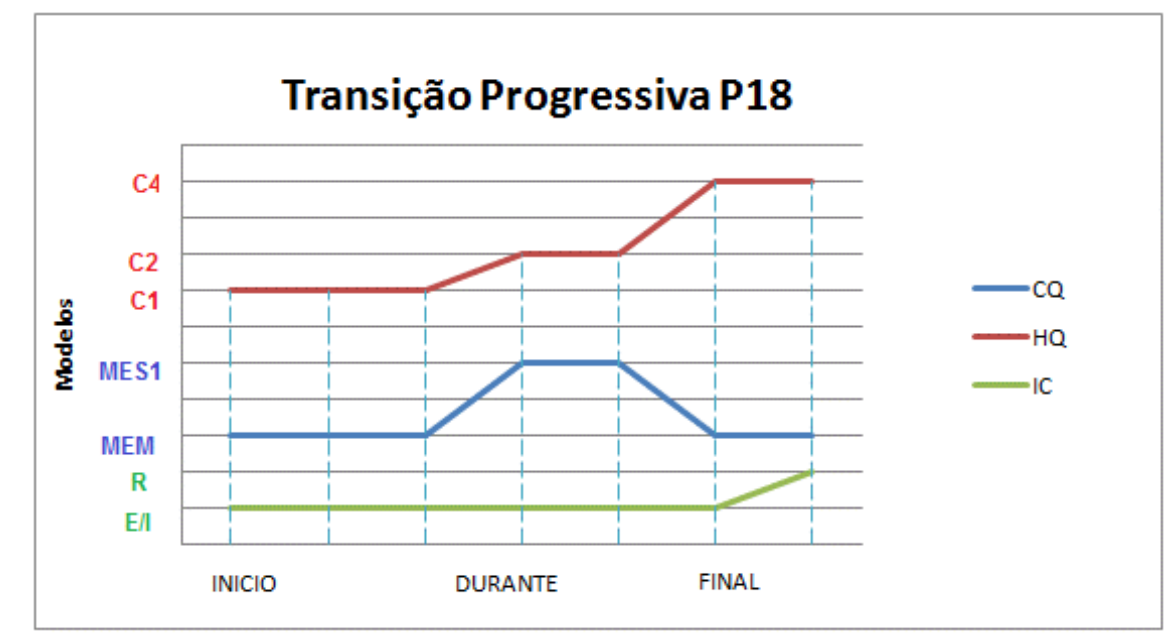

Figura 4.44 Transição progressiva da professora P18 nas três fases da pesquisa, em relação aos seguintes aspectos de seu modelo de ensino: $C Q$ : cinética química, $H Q$ : História da Química e IC: imagem da ciência.

Na figura 4.44 verifica-se que o curso facilitou a transição progressiva nos aspectos relacionados ao entendimento da história da química no ensino e a sua imagem sobre a natureza da ciência, pois no seu plano de ensino a professora começou a apresentar ideias que estão relacionadas à perspectiva filosófica racionalista. Contudo, percebe-se a dificuldade da professora em abordar em seu plano de ensino um modelo teórico para explicar a velocidade de uma reação química.

\section{P19}

\section{Fase inicial}

Respostas as questões referentes ao instrumento 1 (Apêndice II):

Para a professora o ensino de cinética química é importante, pois: "Colabora com o esclarecimento de alguns fatos do cotidiano".

Os conteúdos que ela normalmente aborda em suas aulas: fatores que influenciam a velocidade da reação, interação entre reagentes formando produtos, catalisadores. 
Em relação ao que ensina, o aspecto mais importante é: "Interação entre os reagentes e fatores que influenciam na velocidade de reação, porque, nesse assunto podemos usar exemplos do cotidiano para facilitar o aprendizado do aluno".(MEM)

Para esta professora os conteúdos que ela indica que tem maior dificuldade em ensinar são: "Os cálculos e a construção e leitura de gráficos, interpretação de problemas".

Quanto à experimentação ela usa para demonstrar os fatores que influenciam a velocidade de uma reação química: Concentração: ácido (muriático) mais carbonato de cálcio, acido acético mais carbonato de cálcio; Superfície de contato e temperatura: comprimido vitamina c, água quente/fria; Catalisador: "durepox" (massa plástica). Quando questionada por que o experimento é importante no ensino de cinética química sua resposta é: " $O$ experimento que eu aplico é de caráter investigativo. $O$ experimento é importante, pois facilita $O$ aprendizado, mas somente quando inserido nesse contexto".

Em relação à História da Química, embora ela considere importante a sua inclusão no ensino:

Acho muito importante, mas o problema é que nos falta
material, no livro didático, e também em outros materiais de
apoio para o professor. Trabalhar história em cinética, com
certeza facilita o aprendizado em sala, pois enriquece o
conhecimento, assim o professor pode fazer muito mais
analogias, pois sabemos perante a HQ que muitas
conquistas de conhecimento foram através de fenômenos
naturais do cotidiano. (grifo nosso) (categoria C4)

Ela afirma não usar História da Química em suas aulas.

Em relação à sua imagem sobre a natureza da ciência (instrumento 2, Apêndice VII), a professora escolheu as seguintes afirmações:

- A eficácia e a objetividade do trabalho científico consistem em seguir fielmente as fases ordenadas do método científico: observação, hipótese, experimentação e elaboração de teorias.(E/l)

- Toda investigação científica começa pela observação rigorosa do fenômeno que se estuda.(E/l) 
- Através do experimento, o investigador comprova se sua hipótese de trabalho é verdadeira ou falsa.(E/I)

- O método científico é um conjunto de etapas de atividades práticas e mentais que sem duvida alguma levará a um conhecimento verdadeiro.(E/I)

- As hipóteses dirigem o processo de investigação científica.(R)

Pela análise das respostas da professora, observa-se que o seu modelo de ensino nessa fase inicial está baseado, principalmente, nos aspectos macroscópicos da cinética química (MEM). Este modelo inicial de ensino é marcado, principalmente, pela perspectiva filosófica empirista/indutivista (E/I).

\section{Fase intermediária}

Quanto à atividade 6 (quarto encontro, Apêndice $\mathrm{XI}$ ), a professora mostrou não ter o entendimento de como se á da variação da velocidade de uma reação com o tempo, justificando que: "A velocidade aumenta. Devido a agitação das moléculas em aquecimento, pois conforme passa o tempo a energia térmica fornecida pelo aquecimento facilita a interação entre as moléculas". (Modelo de aumento - MA ;categoria Cakmakci et al, 2005).

Sua explicação de como se dá a influência da temperatura na velocidade da reação nesse mesmo exercício é: "Quanto mais dias maior a produção", portanto, percebe-se que na sua explicação não aparecem termos relacionados a partículas, embora ela use a ideia de movimento das moléculas para explicar a velocidade de uma reação (MEM).

$\mathrm{Na}$ atividade experimental 3, sobre o efeito da temperatura na velocidade de uma reação (quarto encontro, Apêndice XII ), sua explicação não inclui termos relacionados a partículas: "Quanto maior a temperatura mais rápido ocorre a reação". Quando, na mesma atividade se pedia uma explicação com o uso de um modelo de partículas para explicar por que a transformação é mais lenta quando realizada em água gelada, a professora escreveu: "Menor energia, menor interação entre partículas” (MEP).

A professora não realizou o exercício 1 sobre gráficos (quinto encontro, Apêndice $X V$ ), deixando a sua folha em branco. 
A professora não realizou a atividade relacionada ao uso de artigos sobre a História da Química (atividade 1, primeiro encontro, Apêndice III).

No segundo encontro, os professores leram um documento oficial sobre 0 papel da HQ no ensino de ciências (atividade 2, Apêndice VI). A professora concordou com a ideia defendida no documento, justificando: "As ideias são muito plausíveis, inserir a química de forma contextual, solidificando o conhecimento químico" (grifo nosso)(Categoria C3).

Para ela a dificuldade em abordar HC no ensino é: "Leitura e interpretação dos alunos. Reprodução de cópias. Número de alunos".

$\mathrm{Na}$ atividade 4 (terceiro encontro, Apêndice IX), a professora construiu o seguinte mapa conceitual:

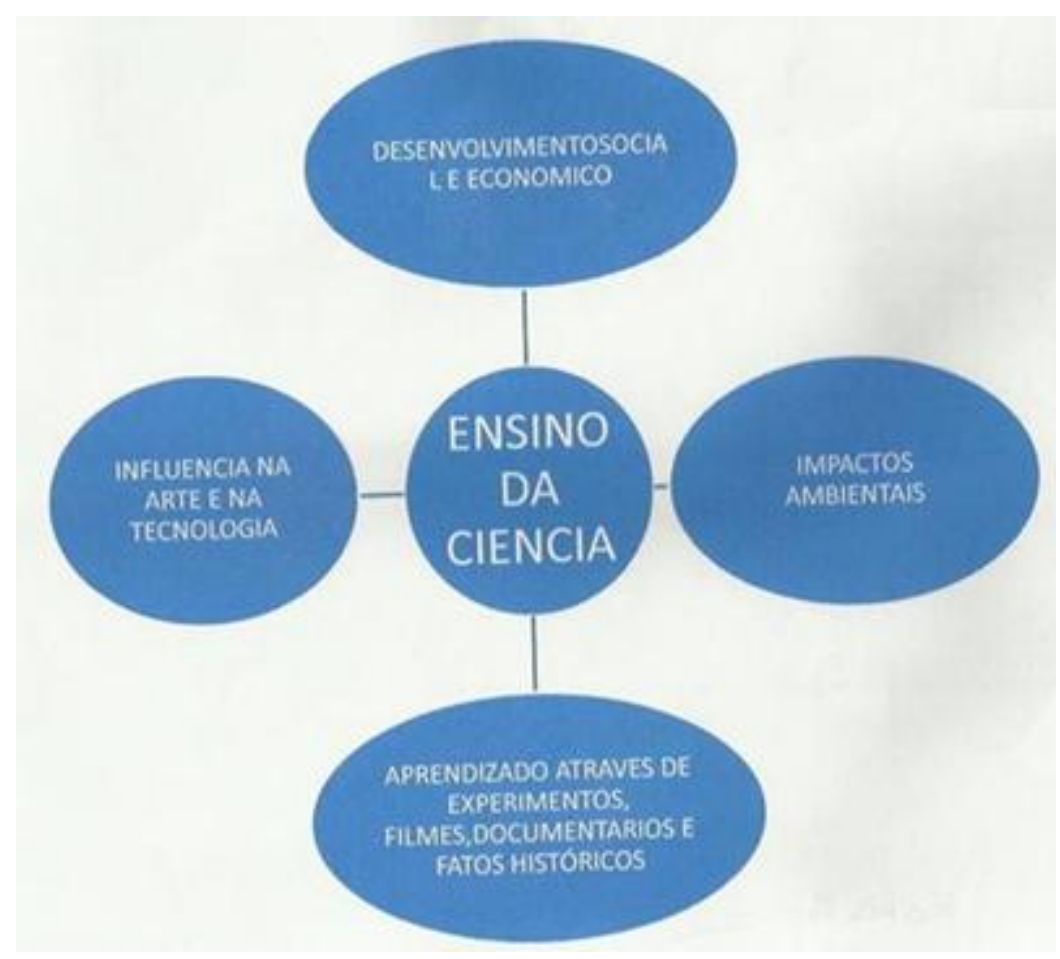

Figura 4.45 Mapa conceitual sobre a imagem da ciência elaborado pela professora P19.

Em seu mapa a professora relaciona o ensino de ciência a outras áreas de conhecimento, indica a sua influencia nos aspectos ambientais, por exemplo, como também indica algumas estratégias, como experimentos, filme, entre outras. 
Contudo, apenas pela leitura de seu mapa não foi possível usar as categorias elaboradas para identificar sua imagem sobre a natureza da ciência.

$\mathrm{Na}$ atividade realizada (instrumento 3 , Apêndice XIV) no quinto encontro, a professora escreveu:

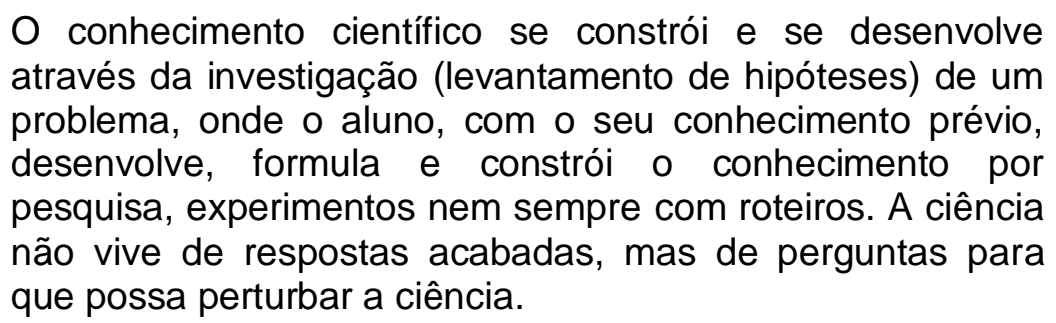

Pela análise das respostas da professora, observa-se que o seu modelo de ensino nessa fase intermediária está baseado, principalmente, nos aspectos pseudomicroscópicos da cinética química (MEP). Este modelo é marcado pela perspectiva filosófica racionalista $(\mathrm{R})$.

\section{Fase final}

$\mathrm{Na}$ avaliação final (oitavo encontro, Apêndice XIX) a professora apontou que as dificuldades sobre o ensino de cinética química foram superadas: "Pois temos mais segurança e mais materiais alternativos para poder sanar essas dificuldades".

Com relação à superação das dificuldades sobre o uso da História da Química: "Sim, pois tivemos novas ideias para trabalhar os conteúdos sem precisar desse material. Existem várias outras estratégias para trabalhar com os conteúdos históricos como nos exemplos( leitura de imagens, resumo de textos e experimentos com materiais fáceis)".

Sobre quais aspectos relacionados à sua prática a professora refletiu através do curso, ela respondeu que: " $A$ importância do ensino de história da ciência é fundamental para solidificar o ensino de química, através da história podemos enriquecer o conteúdo de química e motivar os alunos ao aprendizado".

\section{Plano de ensino}


Em relação ao seu plano de ensino (folha de atividade 8, Apêncice XVII), podem-se observar no quadro a seguir as habilidades e competências em relação aos conceitos de cinética química, a História da Química e a visão sobre a natureza da ciência, que ela pretende que seus alunos desenvolvam:

\begin{tabular}{llc} 
Tema & Habilidade e competências & Análise \\
\hline $\begin{array}{l}\text { Conceitos } \\
\text { da cinética }\end{array}$ & $\begin{array}{l}\text { Construção de gráficos; Relacionar a cinética química } \\
\text { química }\end{array}$ & MEM história e na sociedade; Observação dos resultados \\
& $\begin{array}{l}\text { com experimentos. Fazer analogias. Trazer o } \\
\text { conhecimento científico para situações do cotidiano. }\end{array}$ & \\
Interpretar os experimentos. & $\mathrm{R}$ \\
Visão & $\begin{array}{l}\text { Relações entre as ideias dos cientistas, percepção da } \\
\text { influencia da ciência na sociedade. Verificar que os }\end{array}$ & \\
sobre a & $\begin{array}{l}\text { natureza } \\
\text { conceitos não surgiram do nada. A ciência não é }\end{array}$ & \\
História da & estática. & Interpretar modelos históricos relacionando-os a cada \\
Química & época. Leitura e interpretação. Fazer relações com os & C2,C3 e C4 \\
& $\begin{array}{l}\text { experimentos da história e os atuais. Verificar a } \\
\text { construção do conhecimento numa linha do tempo. }\end{array}$ & \\
\hline
\end{tabular}

Quadro 4.36 Habilidades e competências indicadas no plano de ensino da professora P19.

Em relação aos outros tópicos do plano dessa professora:

\section{- Objetivos:}

CQ: Abordar o conteúdo de cinética química de forma contextualizada, fazendo com que a ciência torne mais próxima para o aluno. Desenvolver as habilidades e competências; HFC: Interpretar modelos históricos relacionados a cada época. Leitura/interpretação. Fazer relações com os experimentos da história antiga e atual. Verificar a construção do conhecimento numa linha do tempo. Percepção influência da ciência na sociedade. Relações entre as ideias dos cientistas. Verificar que os conceitos não surgiram do nada. A ciência não é estática.

- Conteúdo:

CQ: fatores que influenciam em uma transformação química (pressão, temperatura, concentração e superfície de contato). Enzimas, amido e açúcares, Catalisadores. Modelos atômicos que formam a matéria. Comportamento dos átomos em alta e baixa temperatura, alta e baixa pressão, alta e baixa concentração; HFC: Digestão química dos alimentos: descoberta da amilase pelo químico Francês Anselme Payen -1983. 
Descoberta da uréase pelo químico alemão James Summer-1926. Haber Boch uso de catalisador na produção da amônia.

- Estratégias:

Leitura de imagem de moléculas (Realizar com alunos leitura de imagem, para compreensão do comportamento das moléculas nos fatores que influenciam numa transformação química); Leitura de textos com informações históricas; Experimentos investigativos reação do fígado com água oxigenada; Vídeos de experimentos do site "pontociência"; Aulas expositivas com recurso de PowerPoint.

- Sequência:

Aula 1: Tema 1: Qual a importância da enzima numa reação química? Objetivo: Trabalhar com os alunos leitura/interpretação e produção de texto.

Aula 2:Tema 2: Como identificar uma transformação química e os fatores que alteram a transformação química. Objetivo: trabalhar com os alunos elaboração de conceitos a partir da observação e análise dos resultados em um experimento.

Aula 3:Tema 3: O que é uma transformação química e os fatores que influenciam a rapidez numa transformação. Objetivo: Realizar com alunos leitura de imagem, para compreensão do comportamento das moléculas nos fatores que influenciam numa transformação química.

Aula 4:Tema 4: Experimentos sobre os fatores que influenciam na transformação química. Objetivo: trabalhar com os alunos a observação de experimentos sobre cinéticas e comparar com os experimentos antigos. Avaliação: montagem de uma linha do tempo sobre cinética química e alguns fatos históricos.

Aula 5:Tema 5: Cinética química para todos. Objetivo: trabalhar com os alunos a interpretação dos conhecimentos científicos.

Pela análise do plano de ensino da professora P10, considerou-se que seu modelo é mais coerente com o modelo de ensino pseudomicroscópico (MEP): "Realizar com alunos leitura de imagem, para compreensão do comportamento das moléculas nos fatores que influenciam numa transformação química" (grifo nosso) (plano de ensino, P19) 
Em relação a História da Química para essa professora essa estratégia tem a finalidade de que os alunos entendam vários aspectos, como a ideia de ciência dinâmica, a origem e 0 desenvolvimento de um determinado conceito químico (categorias $\mathrm{C} 2, \mathrm{C} 3$ e $\mathrm{C} 4$ ).

Em seu plano de ensino, pode-se observar que sua imagem sobre a natureza da ciência é coerente com a perspectiva filosófica racionalista: "Percepção influência da ciência na sociedade. Relações entre as ideias dos cientistas. Verificar que os conceitos não surgiram do nada. A ciência não é estática".

Nos quadros a seguir, podem ser observados, nos três momentos do curso de formação, os modelos de ensino dessa professora:

\begin{tabular}{|c|l|c|c|c|}
\hline ETAPA & INSTRUMENTOS & CINÉTICA QUÍMICA & HISTÓRIA DA QUÍMICA & $\begin{array}{c}\text { IMAGEM DA } \\
\text { CIÊNCIA }\end{array}$ \\
\hline \multirow{2}{*}{ INÍCIO } & INSTRUMENTO 1 & MEM & C4 & E/I \\
\cline { 2 - 5 } & INSTRUMENTO 2 & & - & \\
\hline \multirow{5}{*}{ DURANTE } & ATIVIDADE 1 & & & \\
\cline { 2 - 5 } & ATIVIDADE 2 & & & - \\
\cline { 2 - 5 } & ATIVIDADE 4 & & & $\mathrm{R}$ \\
\cline { 2 - 5 } & ATIVIDADE 6 & MEM & & \\
\cline { 2 - 5 } & INSTRUMENTO 3 & & & $\mathrm{R}$ \\
\cline { 2 - 5 } & EXPERIMENTO 3 & MEP & & $\mathrm{R}$ \\
\cline { 2 - 5 } & EXERCICIO 1 & - & $\mathrm{C2,C3,C4}$ & \\
\hline \multirow{2}{*}{ FINAL } & ATIVIDADE 8 & MEM & C2,C3,C4 & \\
\cline { 2 - 5 } & PLANO DE ENSINO & MEP & & \\
\hline
\end{tabular}

Quadro 4.37 Modelos de ensino de cinética química da professora P19 nas diferentes etapas do curso de formação. 


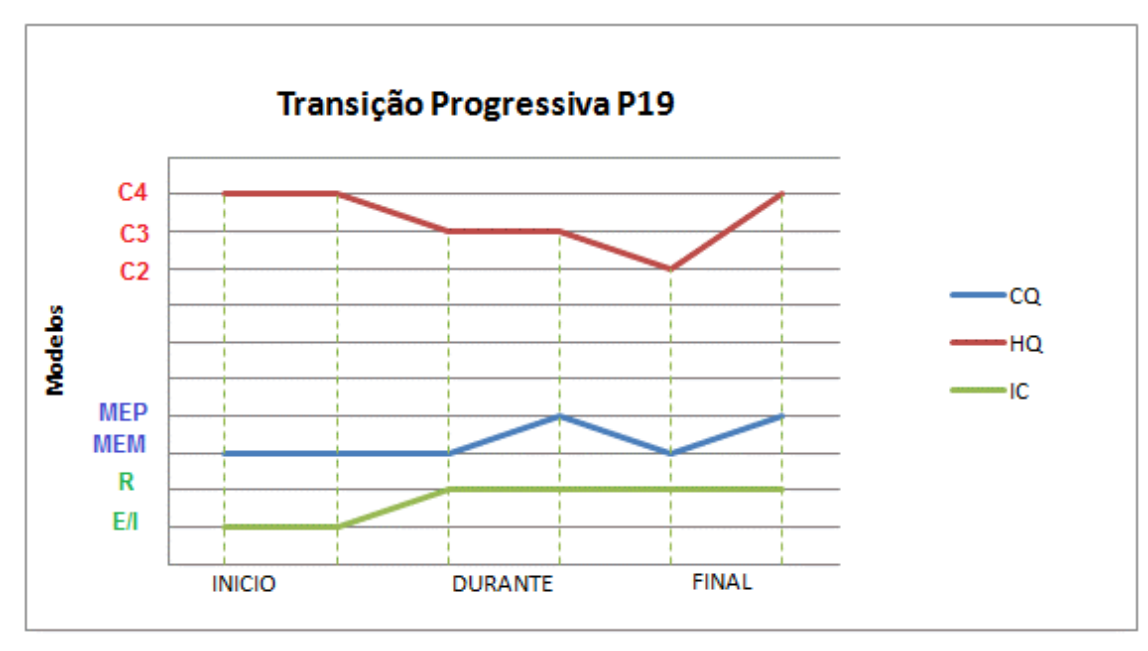

Figura 4.46 Transição progressiva da professora P19 nas três fases da pesquisa, em relação aos seguintes aspectos de seu modelo de ensino: $C Q$ : cinética química, $H Q$ : História da Química e IC: imagem da ciência.

Percebe-se pela análise da figura 4.46 que o curso de formação continuada facilitou a transição progressiva nos aspectos relacionados à Historia da química e sua imagem sobre a natureza da ciência.

Em relação à História da Química essa professora demonstrou ter um bom entendimento desta para o ensino de química, como pode ser observado no texto a baixo onde ela justifica, a escolha do seu tema:

Atualmente trabalhar o assunto de cinética química é uma reprodução dos conceitos já estabelecidos nos livros didáticos e em momento algum temos a história envolvida com o conteúdo programático.

Quando explicamos cinética química, percebemos que existe uma necessidade de incluir a história da cinética química de forma contextualizada, isso se deve ao fato dos nossos alunos buscarem explicações para os conteúdos apresentados a eles. A inclusão da história da cinética química facilita a compreensão do aluno para os assuntos que serão abordados sobre fatores que influenciam a rapidez de uma reação química e o uso de catalisador.

Portanto, a escolha de enzimas como tema gerador é um facilitador, pois podemos através dele introduzir os conteúdos de cinética química pela história da descoberta de uma enzima no processo digestivo" (plano de ensino, P19) (grifo nosso) 
Fase inicial

Respostas as questões referentes ao instrumento 1 (Apêndice II):

Para a professora o ensino de cinética química é importante: "Porque se trata do "movimento" entre as partículas e dessa "agitação" pode ou não ocorrer uma reação química, um fenômeno químico".

P20 é aluna do curso de licenciatura em química: "Ainda não dou aula, mas poderia falar acerca da importância no nosso cotidiano e até mesmo na parte economicamente viável dentro de uma indústria".

Em relação à cinética química o aspecto mais importante é: "Entender melhor a estrutura das partículas e transformá-las em algo macro que possui mobilidade e está em toda parte".(MEP)

Para esta professora um dos conteúdos em que ela indica que tem maior dificuldade é: "A bomba nuclear. Como um núcleo colide, surgimento de novas partículas, quantidade de energia envolvida e produzida, além do efeito posterior de destruição de uma bomba".

Quanto à experimentação ela indica exemplos de experimentos que são usados para demonstrar os fatores que influenciam a velocidade de uma reação química: Concentração: queima da palha de aço inteira e um pedaço de papel; Pressão: abrir um refrigerante quente; Superfície de contato.: comprimido efervescente pulverizado e inteiro na água; temperatura: lavar uma panela melhor usar água quente.

Quando questionada por que o experimento é importante no ensino de cinética química sua resposta é: "Porque não basta só teoria. Quando o aluno vê algo palpável ele se sente mais próximo e entende melhor o que estamos abordando".

Em relação à História da Ciência, embora ela considere importante a sua inclusão no ensino, "Para ver que não há uma verdade absoluta, uma teoria pode ser posteriormente rejeitada". (categoria $\mathrm{C} 2 \mathrm{~d}$ a $\mathrm{HQ}$ ). 
A professora não realizou a atividade sobre a imagem sobre a natureza da ciência (instrumento 2, Apêndice VII). Contudo, pode-se considerar que sua imagem inicial era coerente com a perspectiva filosófica empirista/indutivista:

Embora tenha chegado com a ideia de conhecimento
científico ser uma verdade absoluta, a ciência está
relacionada com a natureza e o conhecimento científico é
gerado da interação do homem com a natureza, da
exploração da mesma... (instrumento 3,Apêndice VI)(grifo
nosso)

Pela análise das respostas da professora, observa-se que suas ideias estão baseadas, principalmente, nos aspectos macroscópicos da cinética química, mas com o uso de termos relacionados às características microscópicas da matéria, como, por exemplo, movimento de moléculas. (MEP). Este modelo inicial de ensino é marcado pela perspectiva filosófica empirista/indutivista (E/I).

\section{Fase intermediária}

Quanto à atividade 6 (quarto encontro, Apêndice XI), a futura professora mostrou não ter o entendimento de como se á da variação da velocidade de uma reação com o tempo, justificando que: " $A$ velocidade aumenta. A temperatura de $100^{\circ} \mathrm{C}$ aumenta consideravelmente a porcentagem inicial de ácido esterificado quando comparado a temperatura ambiente, basta verificar que em $32 \mathrm{~h}$ de experiência corresponde praticamente a 368 dias a temperatura ambiente". (Modelo de aumento - MA ;categoria Cakmakci et al, 2005).

Sua explicação de como se dá a influência da temperatura na velocidade da reação nesse mesmo exercício é: "Conclui-se a influencia da temperatura como fator importante.", portanto, percebe-se que em suas explicações não aparece um modelo teórico, ou termos relacionados a partículas (MEM).

$\mathrm{Na}$ atividade experimental 3, sobre o efeito da temperatura na velocidade de uma reação (quarto encontro, Apêndice XII ), sua explicação inclui termos relacionados a partículas: "A temperatura influencia a partir do momento em que permite a maior colisão entre as partículas. Aumenta o choque, as colisões efetivas”. Quando, na mesma atividade se pedia uma explicação com o uso de um modelo de partículas para explicar por que a transformação é mais lenta 
quando realizada em água gelada, a professora escreveu: "Quando a água está gelada o tempo é maior porque é baixa a energia, basta lembrar o metabolismo humano a baixas temperaturas". Portanto, a professora inclui termos relacionados a modelos teóricos (MES1).

No próximo exercício sobre gráficos (quinto encontro, Apêndice XV) a professora desenhou o seguinte gráfico:

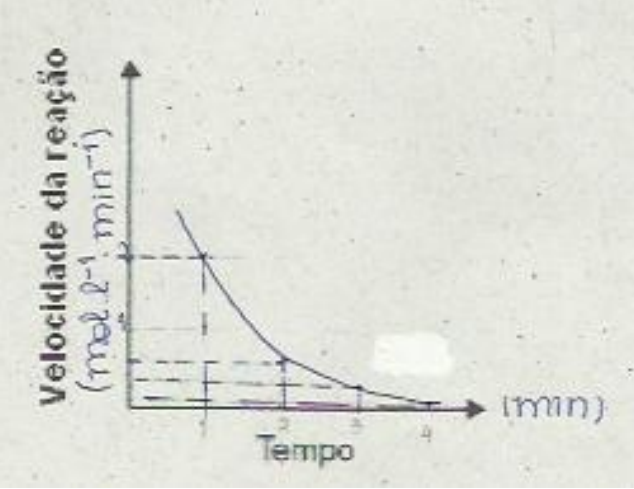

Figura 4.47 A variação da velocidade de uma reação em função do tempo segundo P20.

Percebe-se que o modelo de seu gráfico refere-se ao modelo científico MC (categoria Cakmakci et al,2005). Sua justificativa para esse modelo é: " $A$ medida em que ocorre a reação os reagentes são consumidos e forma-se novo produto. A velocidade diminui com o tempo à medida em que os reagentes são consumidos".(MEM)

Em relação ao uso de artigos sobre a História da Química (atividade 1, primeiro encontro, Apêndice III), a professora indicou como utilizaria essa estratégia: "Apagar a imagem negativa que as pessoas têm da química".

Vantagens em se utilizar essa estratégia no ensino: "Reconhecimento que a ciência não é uma verdade absoluta".

No segundo encontro, os professores leram um documento oficial sobre 0 papel da HQ no ensino de ciências (atividade 2, Apêndice Vl). A professora concordou com a ideia defendida no documento, justificando: "Plausível, porque visam a um questionamento crítico da ciência não como algo linear e acúmulo de conhecimentos, mas de acertos e erros". 
As dificuldades em abordar a História da Ciência são: "A maior dificuldade é ter de despertar o interesse do aluno por algo não mais aceito e até mesmo colocar em dúvida esse conhecimento".

$\mathrm{Na}$ atividade 4 (terceiro encontro, Apêndice IX), a professora construiu o seguinte mapa conceitual:

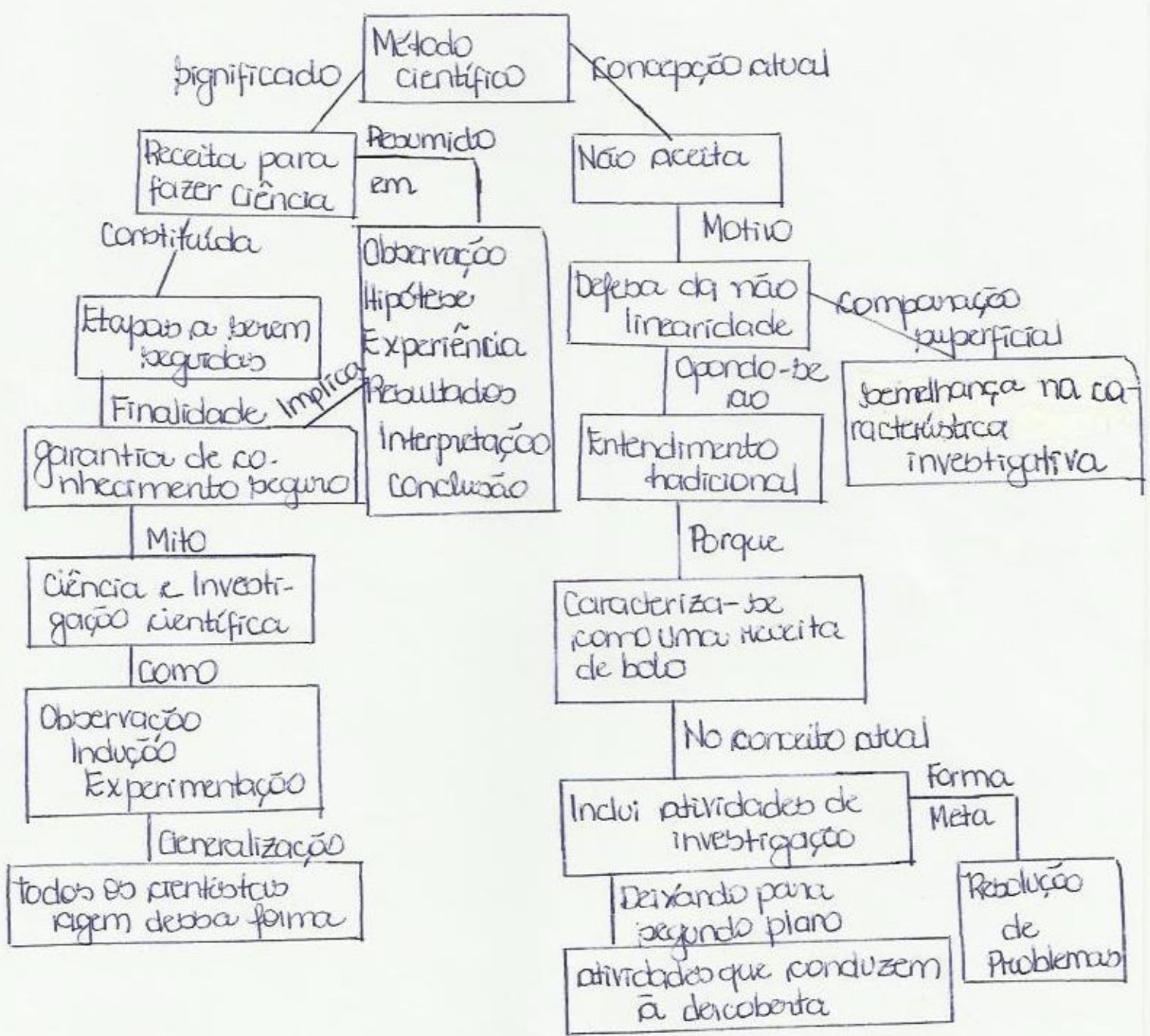

Figura 4.48 Mapa conceitual sobre a imagem da ciência elaborado pela professora P20.

Em seu mapa a professora faz uma comparação entre o método científico em relação às duas perspectivas a empirista/indutivista (lado esquerdo do mapa) e a perspectiva racionalista (lado direito). Pode-se inferir que a sua ideia sobre a 
natureza da ciência seja coerente com a perspectiva filosófica racionalista, pois ela afirma ser essa uma concepção atual sobre a imagem da cincia.

$\mathrm{Na}$ atividade realizada (instrumento 3, Apêndice XIV) no quinto encontro, a professora escreveu:

\begin{abstract}
Embora tenha chegado com a ideia de conhecimento científico ser uma verdade absoluta, a ciência está relacionada com a natureza e o conhecimento científico é gerado da interação do homem com a natureza, da exploração da mesma. O conhecimento científico não é algo unicamente verdadeiro que não pode ser refutado.
\end{abstract}

Pela análise das respostas da professora, observa-se que o seu modelo de ensino nessa fase intermediária está baseado, principalmente, nos aspectos macroscópicos da cinética química (MEM). Este modelo é marcado pela perspectiva filosófica racionalista $(\mathrm{R})$.

\title{
Fase final
}

$\mathrm{Na}$ avaliação final (oitavo encontro, Apêndice XIX) a professora apontou em relação à superação das dificuldades sobre o ensino de cinética química: "Superado talvez não seja apenas essa resposta, porque no curso aprendi muita coisa da qual eu não tinha conhecimento. Eu iniciei o curso apenas com aquelas ideias relacionadas à concentração, temperatura e colisões efetivas sem saber ao menos uma explicação e o que dirá quais as pessoas envolvidas e os motivos para investirem em suas pesquisas".

Com relação a superação das dificuldades sobre o uso da História da Química:

Com certeza, superei algumas dificuldades como apresentar a cinética química para os alunos. Agora posso dizer que conseguirei abordar melhor a matéria, assim como poderei trabalhar a leitura e interpretação de texto na química porque a química não deixa de ser uma interpretação, apesar de muitos a considerarem puramente exata.

Sobre quais aspectos relacionados à sua prática a professora refletiu através do curso, ela respondeu que: "Não tinha muita noção de como me comportar e abordar as matérias e agora me sinto mais preparada para enfrentar 
uma sala de aula. Obrigada por tudo, ainda mais que envolveu a história (amo ler) e desmitificou a lenda das exatas puras".

\section{$\underline{\text { Plano de ensino }}$}

Em relação ao plano de ensino (folha de atividade 8, Apêncice XVII) dessa professora, podem-se observar no quadro a seguir as habilidades e competências em relação aos conceitos de cinética química, a História da química e a visão sobre a natureza da ciência que ela pretende que seus alunos desenvolvam:

\section{Tema Habilidade e competências Análise}

\begin{tabular}{llc}
\hline $\begin{array}{l}\text { Conceitos } \\
\text { da cinética } \\
\text { química }\end{array}$ & $\begin{array}{l}\text { Não aceitar informações simples, ou seja, simplesmente } \\
\text { decorar sentenças em destaques nos livros. Conhecer os } \\
\text { responsáveis pela matéria que estão estudando e os motivos } \\
\text { que o levaram a pesquisar o assunto. }\end{array}$ & MEM \\
$\begin{array}{l}\text { Visão } \\
\text { sobre a }\end{array}$ & $\begin{array}{l}\text { uma coisa distante do seu plano real. Apagar a ideia da } \\
\text { natureza } \\
\text { da ciência }\end{array}$ & $\begin{array}{l}\text { ordem, regra a ser seguida e de que as ideias não surgem ao } \\
\text { acaso. }\end{array}$ \\
$\begin{array}{l}\text { História da } \\
\text { Química }\end{array}$ & $\begin{array}{l}\text { Relacionar certas aplicações com a necessidade do } \\
\text { fundo e sim, enxergar os fatos de maneira simultânea. } \\
\text { Pessoas pesquisando ao mesmo tempo sobre determinado } \\
\text { assunto. }\end{array}$ & C3 e C4 \\
\end{tabular}

Quadro 4.38 Habilidades e competências indicadas no plano de ensino da professora P20.

Em relação aos outros tópicos do plano dessa professora:

- Objetivos: Origem do nitrogênio e da cinética química.

- Conteúdo: Síntese da amônia; fatores que influenciam uma reação química, catalisadores.

- Estratégias: Pesquisa; aula expositiva.

\section{- Sequência:}

1. Sensibilização: mostrar o ciclo do hidrogênio e a composição atmosférica; 2. Problematização: pesquisa: a importância do nitrogênio. Início da cinética química; 3. Desenvolvimento: discussão sobre produção em larga escala da indústria em meio à guerra. 4. Síntese/metacognição: significado da síntese da amônia. Fatores que influenciam em uma reação química. Processos industriais (baixo custo, alto rendimento). 
No seu plano a professora não trabalha com modelos teóricos para explicar a velocidade e a influência dos fatores na velocidade de uma reação (MEM).

Em relação à História da Química para essa professora essa estratégia tem a finalidade de que os alunos entendam a origem de um determinado conceito químico (categoria C3): "Origem do nitrogênio e da cinética química" (plano de ensino, P20)

Em seu plano de ensino, observa-se que suas ideia sobre a natureza da ciência, são coerentes com a perspectiva filosófica racionalista.

No quadro a seguir, podem ser observados, nos três momentos do curso de formação, os modelos de ensino dessa professora:

\begin{tabular}{|c|c|c|c|c|}
\hline ETAPA & INSTRUMENTOS & $\begin{array}{l}\text { CINÉTICA } \\
\text { QUÍMICA }\end{array}$ & $\begin{array}{l}\text { HISTÓRIA DA } \\
\text { QUÍMICA }\end{array}$ & $\begin{array}{c}\text { IMAGEM DA } \\
\text { CIÊNCIA }\end{array}$ \\
\hline \multirow{2}{*}{ INÍCIO } & INSTRUMENTO 1 & MEP & $\mathrm{C} 2$ & \\
\hline & INSTRUMENTO 3 & & & - \\
\hline \multirow{7}{*}{ DURANTE } & ATIVIDADE 1 & & $\mathrm{C} 2$ & \\
\hline & ATIVIDADE 2 & & $\mathrm{C} 2$ & \\
\hline & ATIVIDADE 4 & & & $R$ \\
\hline & ATIVIDADE 6 & MEM & & \\
\hline & INSTRUMENTO 3 & & & $R$ \\
\hline & EXPERIMENTO 3 & MES1 & & \\
\hline & EXERCICIO 1 & MEM & & \\
\hline \multirow{2}{*}{ FINAL } & ATIVIDADE 8 & MEM & $\mathrm{C} 3, \mathrm{C} 4$ & $\mathrm{R}$ \\
\hline & PLANO DE ENSINO & MEM & $\mathrm{C3}$ & $\mathrm{R}$ \\
\hline
\end{tabular}

Quadro 4.39 Modelos de ensino de cinética química da professora P20 nas diferentes etapas do curso de formação. 


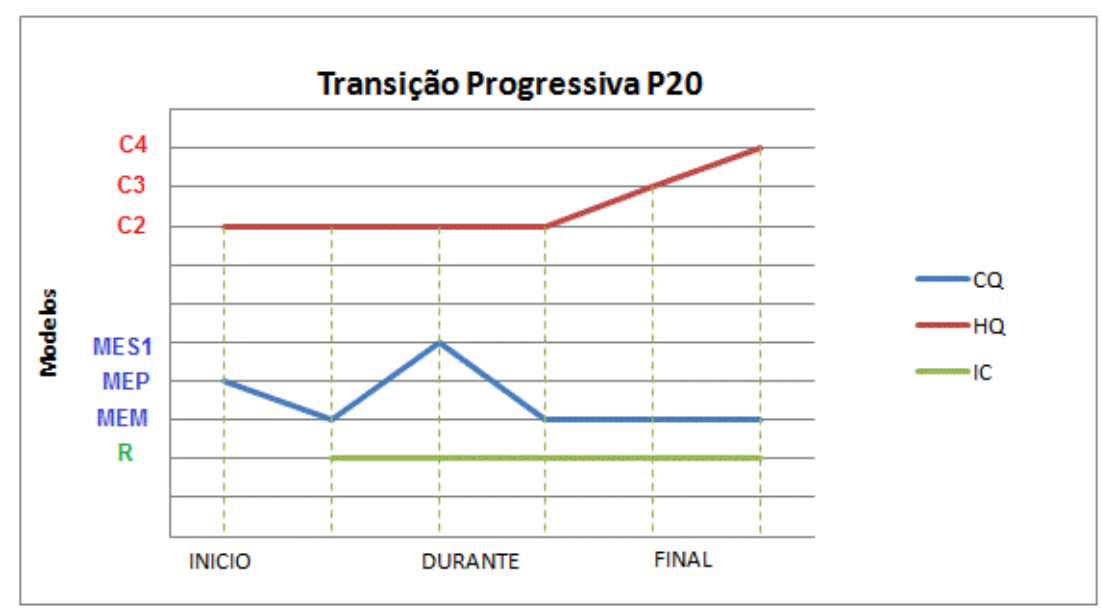

Figura 4.49 Transição progressiva da professora P20 nas três fases da pesquisa, em relação aos seguintes aspectos de seu modelo de ensino: $C Q$ : cinética química, $H Q$ : História da Química e IC: imagem da ciência.

Na figura acima percebe-se que o curso de formação continuada facilitou a transição progressiva nos aspectos relacionados ao seu entendimento do papel da História da Química no ensino e como também na sua imagem sobre a natureza da ciência. Em relação à cinética química, em suas explicações durante o curso, a futura professora somente usou um modelo teórico em uma única atividade (experimento 3 ).

Como foi observado anteriormente, muitos professores em seu plano de ensino, escolheram abordar apenas os aspectos relacionados ao modelo macroscópico, principalmente focalizando seu ensino na influência de certos fatores na velocidade de uma reação química.

Contudo, como apontam as autoras Justi e Ruas (1997), para a aprendizagem do tema cinética química é necessário o entendimento integrado de muitos conceitos fundamentais, como, o da natureza particular da matéria e o caráter interativo e dinâmico das reações químicas, e essa integração, segundo as autoras, é difícil para o aluno do ensino médio, o que cria um obstáculo para a aprendizagem.

Portanto, acredita-se nesse trabalho que os professores, no planejamento de suas atividades, poderiam dar oportunidades aos alunos para trabalharem com 
modelos explicativos, por exemplo a teoria das colisões, durante o ensino de cinética química.

\subsection{Transição progressiva das duas professoras após a aplicação do plano de ensino}

Como dados para essa etapa considerou-se, além das gravações em áudio e vídeo das aulas assistidas e das anotações da pesquisadora, os depoimentos das duas professoras, P11 e P15, realizados durante e após a aplicação dos planos de ensino.

\section{P11}

A professora P11 foi uma das professoras que aplicou seu plano sobre cinética química, na escola onde leciona, após concluir o curso de formação continuada. A professora leciona química para o ensino médio há 19 anos, na rede de ensino pública e particular. A escola em que aplicou foi a escola particular, que se localiza na região central da cidade de São Bernardo do Campo no Estado de São Paulo.

Não foi necessário, pedir a seus alunos que assinassem uma autorização para o uso das imagens e gravações em áudio e vídeo, pois, a direção da escola que já possuía essa autorização, autorizou então essa coleta de dados. No final do acompanhamento dessa professora, foi deixado com a direção da escola, uma cópia de todas as gravações feitas pela pesquisadora.

Atualmente, o ensino dessa professora sobre o tema cinética química é baseado no sistema apostilado adotado pelo colégio ${ }^{16}$. Ela desenvolveu seu plano

\footnotetext{
${ }^{16}$ Uno - Sistema de Ensino - Química. Módulo 15. Autores: Eduardo Leite do Canto, Tito Miragaia Peruzzo. Editora: Grupo Santillana.2010.
} 
de ensino em duas turmas do segundo ano do ensino médio, uma do período diurno e outra do período noturno. Nesse trabalho, foi feito acompanhamento somente da turma do período diurno. Período de aplicação do plano de ensino: 26/10/2010 à 01/12/2010. A sequência de suas aulas pode ser observada a seguir:

\section{Sequência Conteúdo desenvolvido}

Aula 1 Início dos estudos sobre cinética química.

Aula 2 Fatores que influenciam a velocidade das transformações: temperatura e superfície de contato.

Aula 3 Modelo para explicar a influencia da concentração temperatura e superfície de contato na velocidade das reações químicas: Teoria das colisões.

Aula 4 Lei da velocidade.

Aula 5 Exercícios (análise de gráficos).

Aula 6 Contexto histórico: apresentação da pesquisa-confecção de um mural.

Aula 7 Atividade de avaliação final.

\section{$11^{\text {a- }}$ Aula - Início dos estudos sobre cinética química}

Nessa aula a professora iria realizar uma demonstração de experimentos sobre a influência dos fatores que alteram a velocidade de uma reação, mas antes dos experimentos ela aplicou um questionário sobre os fatores que poderiam influenciar uma reação química (fig.4.50). O objetivo desse questionário, segundo a professora, era o de conhecer algumas ideias que os alunos já teriam sobre esse tema. Foi dado um tempo de dez minutos para os alunos responderem esse questionário.

\section{Questões de abordagem}

1. Na sua opinião qual ou quais seriam os fatores que alterariam a velocidade das reações químicas?

2. Você acha que é possivel mudar a velocidade de uma transformação química? Por que você acha isso?

3. O que interfere na rapidez com que a matéria orgânica se decompõe?

4. Por que os alimentos estragam?

5. Na sua casa são empregadas técnicas de conservação de alimentos?

Figura 4.50 Questionário elaborado pela professora P11 para levantamento das ideias iniciais dos alunos sobre cinética química. 
Através da análise desse questionário inicial (fig. 4.50) a professora pode observar que:

- Segundo os alunos, os fatores que alterariam a velocidade das reações são: temperatura, quantidade, pressão, substancias presentes, meio em que ocorre, volume, alteração na área de contato, catalisadores e estado físico.

- Em relação a decomposição da matéria orgânica, os fatores que podem interferir são: quantidade de bactérias no ar, temperatura do ambiente, falta de conservação do produto e umidade.

Como o laboratório da escola estava em reforma, a professora com um grupo de alunos do segundo ano do ensino médio, fez os experimentos tirando algumas fotos (fig. 4.51 e 4.52). Isso foi feito antes do início das aulas sobre cinética química.

$\mathrm{Na}$ primeira aula foram apresentados aos alunos dois experimentos, decomposição da matéria orgânica (anexo l) e a dissolução de comprimido efervescente (anexo II), com o objetivo de se discutir os fatores (temperatura, concentração e superfície de contato), que poderiam influir na velocidade de uma reação química.

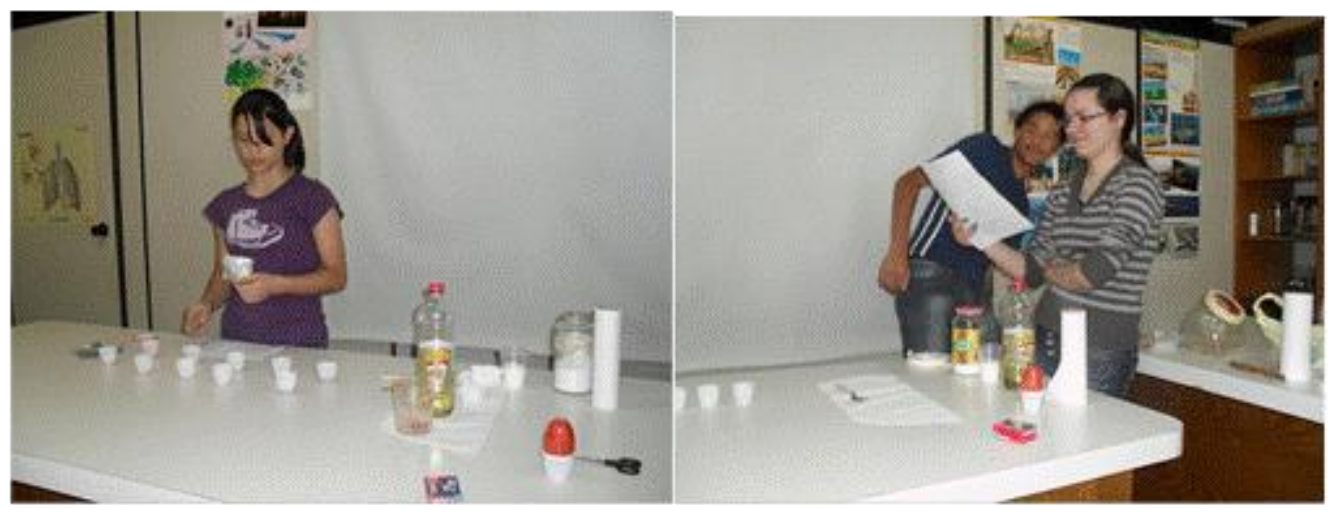

Figura 4.51 Imagens do experimento decomposição da matéria orgânica. 


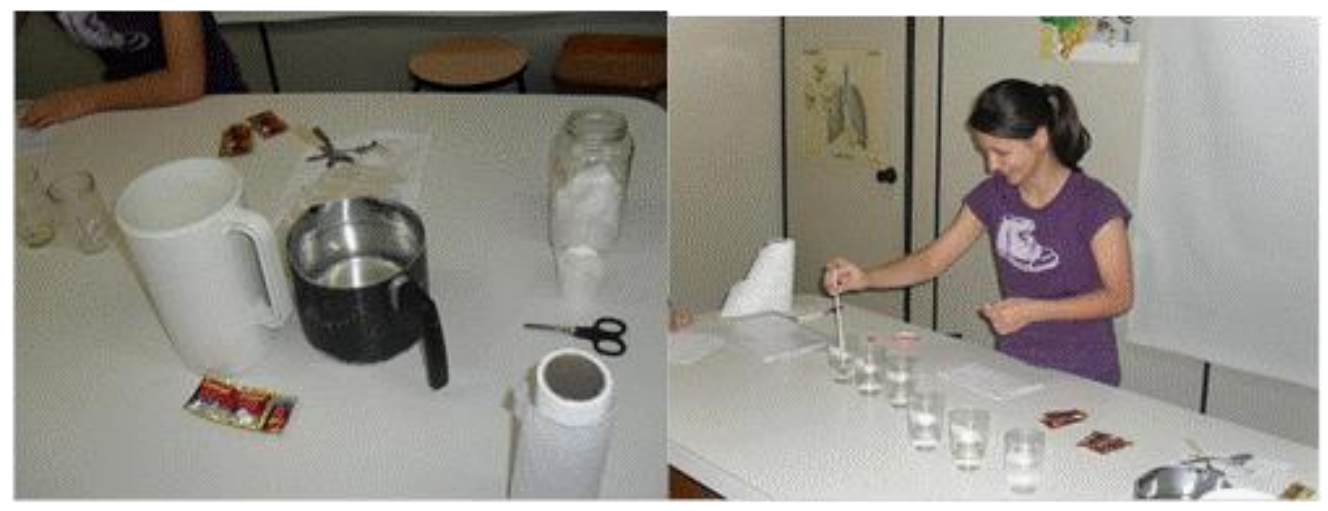

Figura 4.52 Imagens do experimento dissolução de comprimido efervescente.

Após visualizarem as fotos do experimento, a partir de uma apresentação elaborada por ela em Power point, a professora solicitou aos alunos, em relação ao experimento da decomposição da matéria orgânica, que comparassem os potinhos e indicassem em qual deles a decomposição da matéria orgânica foi mais lenta, justificando as suas respostas. Após terminarem, os alunos entregaram suas repostas escritas a professora.

No final da aula a professora solicitou aos alunos que pesquisassem sobre os principais acontecimentos e cientistas relacionados à cinética química. Ela não indicou aos alunos fontes para essa pesquisa.

2a aula: Fatores que influenciam a velocidade das transformacões: temperatura e superfície de contato

A professora iniciou essa aula discutindo com os alunos os fatores que puderam ser observados nos experimentos apresentados na aula anterior, que modificaram a velocidade das reações químicas, em seguida apresentou, um vídeo com o terceiro experimento (Prática 3- Por que alimentos estragam?, anexo III), onde foram discutidos principalmente a influência dos fatores temperatura e superfície de contato.

Após assistirem esse vídeo (disponível no site pontociência), os alunos receberam uma folha de atividade que foi realizada na própria aula. Nessa atividade os alunos tinham que: 
- Fazer uma síntese dos fatores que foram observados nos experimentos que alteraram as transformações químicas e

-Em referência aos alimentos, qual o principal fator que fez com que esses alimentos se degradassem mais rapidamente?

O objetivo da primeira e segunda aula era o de apresentar aos alunos os fatores que influenciam a velocidade de uma reação química a partir da discussão dos resultados obtidos nos experimentos.

3․ Aula - Modelo para explicar a influência da concentração temperatura e superfície de contato na velocidade das reações químicas: Teoria das colisões

Inicialmente foi feita a leitura, pela professora, da analise feita por ela das respostas dos alunos da atividade da aula anterior:

-Fatores que alteram a velocidade das reações:
temperatura, superfície de contato
concentração

-Em referencia aos alimentos: umidade, presença de água, concentração de oxigênio. (resumo, feito pela professora, das respostas dos alunos a folha de atividade da $2^{\text {a }}$. Aula)

Em seguida, ela fez uma síntese, no quadro negro, dos fatores que afetam a velocidade das transformações químicas (temperatura, concentração, superfície de contato e catalisador) com a introdução da ideia de colisões entre moléculas e do conceito de energia de ativação, através do questionamento: O que precisa para que a reação ocorra?

Em relação a teoria das colisões a professora indicou no quadro a seguinte relação, não fazendo nenhuma referência ao cientista que a elaborou: 


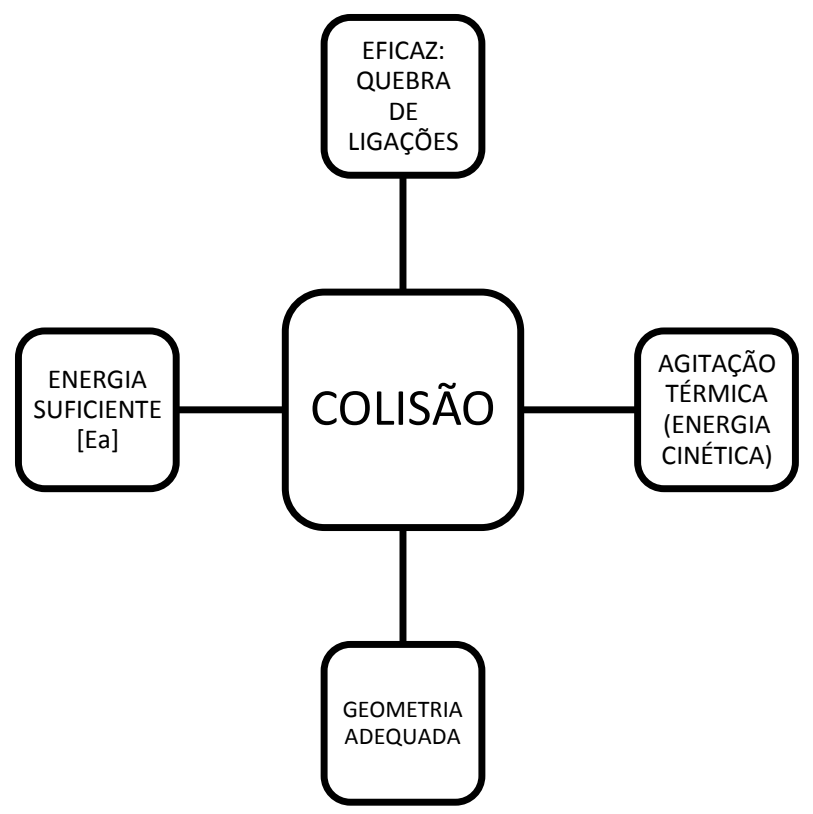

Para introduzir o conceito de energia de ativação, os alunos assistiram a um vídeo, que pertencia ao material apostilado usado no curso pela professora, sobre esse tema. Resumidamente o vídeo mostrava uma simulação onde eram exibidos gráficos de energia da ativação com e sem o efeito de catalisadores.

Percebe-se, que o modelo teórico que a professora usa para explicar a influência de certos fatores na velocidade de uma reação química é a teoria das colisões (MES1), contudo, sua explicação também está baseada na teoria do estado de transição (MES2), porque inclui a ideia de quebra e formação de ligações entre as moléculas.

\section{4⿳亠口冋. Aula - Lei da velocidade: quantificando a rapidez das reações}

Nessa aula foram apresentados, pela professora, no quadro negro, os conceitos de catalisador e lei de velocidade de uma reação química.

Os alunos assistiram a um vídeo da apostila (experimento da água oxigenada com o fígado de boi), para entender o efeito do catalisador na velocidade de uma reação química. Ao final da aula os alunos resolveram alguns exercícios da apostila sobre o tema.

O objetivo principal dessa aula, segundo a professora, foi o de fazer uma análise da equação da velocidade a partir de dados experimentais. A intenção 
aqui foi a de mostrar que: a velocidade de uma reação é determinada experimentalmente e que a velocidade de uma reação química não é constante.

É importante observar que antes de participar do curso de formação continuada a professora iniciava seu ensino por esse conteúdo, só que o enfoque era no cálculo da velocidade média de uma reação química, não realizando nenhuma atividade experimental ou questionamento com seus alunos.

Segundo ela: "Fiquei muito satisfeita com a mudança na abordagem e a inclusão dos experimentos, gostei mais de trabalhar dessa maneira e espero que talvez isso reflita na avaliação da aprendizagem dos alunos" (fala da professora no final da aula).

\section{$\underline{\text { 5a . Aula - Exercícios (análise de gráficos) }}$}

Nessa aula, os alunos resolveram uma lista de exercícios da apostila que envolvia os assuntos já abordados nas aulas anteriores como também exercícios com gráficos sobre a energia de ativação. Esses exercícios foram corrigidos na mesma aula pela professora no quadro negro.

O objetivo principal dessa aula foi o de que os alunos conseguissem interpretar gráficos da variação da velocidade de uma reação química em função do tempo.

\section{6⿳亠口冋. Aula: - Contexto histórico}

Nessa aula foi elaborado, pelos alunos com a ajuda da professora, um quadro com o material da pesquisa realizada pelos alunos (figura 4.53). Depois do quadro pronto foi feita uma discussão sobre o que os alunos encontraram, onde se tentou montar uma linha de tempo a partir do material que eles trouxeram para a aula.

Os alunos alegaram que tiveram muita dificuldade em encontrar os cientistas que trabalharam com a cinética química. 
Após essa discussão a professora apresentou aos alunos uma linha do tempo, elaborada por ela (anexo II). Essa linha de tempo foi elaborada a partir do material fornecido pelo curso de formação continuada.

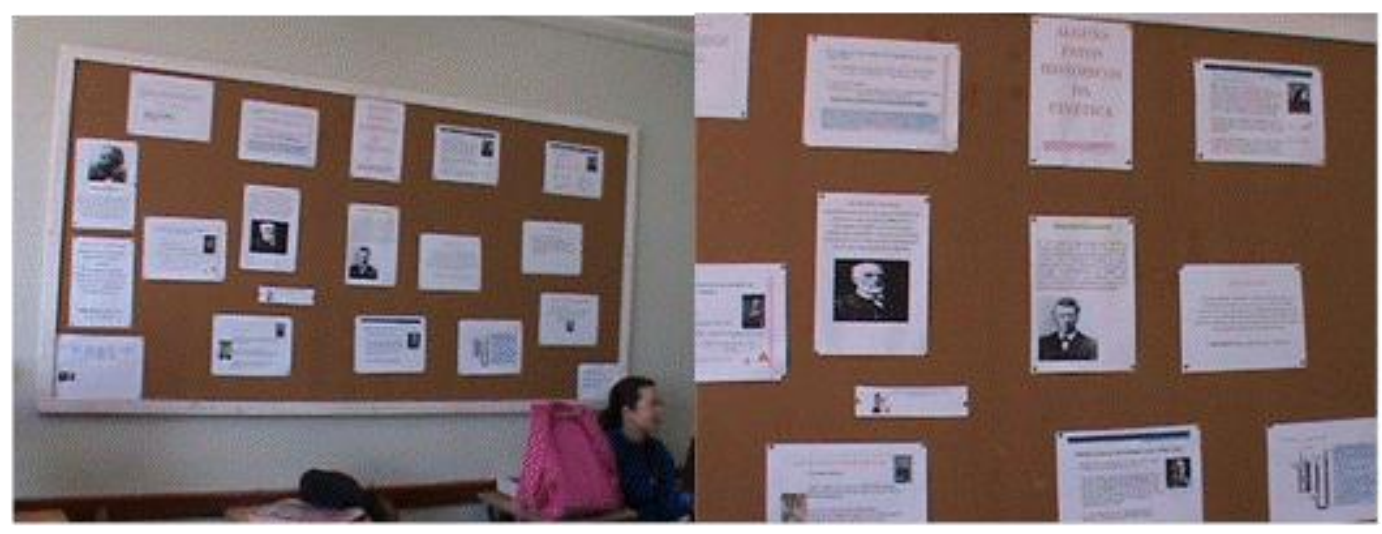

Figura 4.53 Imagens da pesquisa feita pelos alunos: "FATOS HISTÓRICOS DA CINÉTICA QUÍMICA".

O objetivo dessa aula foi o somente de indicar a origem de algumas das teorias da cinética química como também indicar os cientistas que participaram da elaboração dessas teorias em uma determinada época. A pesar do uso da linha de tempo, não foi discutido pela professora o caráter provisório das teorias, isto é, o caráter dinâmico da ciência.

\section{7a. Aula - Atividade de avaliação final}

Como atividade de avaliação, a professora aplicou uma prova que constava de questões objetivas e abertas retiradas de vestibulares como também da apostila dos alunos. As questões da prova estavam relacionadas ao conteúdo que foi desenvolvido durante as aulas (fatores que afetam a velocidade de uma reação, catalisadores e teoria das colisões).

Nessa avaliação, a professora incluiu um questionamento para verificar qual a opinião dos alunos sobre a sua própria aprendizagem do tema cinética química:

-Considerando o que você aprendeu, marque com um X. 


\begin{tabular}{|l|l|l|l|}
\hline Este módulo muito & Parcialmente & Pouco \\
\hline $\begin{array}{l}\text { Auxiliou-me a interpretar e esboçar gráficos } \\
\text { característicos do módulo }\end{array}$ & & & \\
\hline $\begin{array}{l}\text { Ajudou-me a compreender o efeito do fatores que } \\
\text { afetam a rapidez de reações }\end{array}$ & & & \\
\hline $\begin{array}{l}\text { As observações de experimentos me ajudaram a } \\
\text { compreender os fatores que afetam a velocidade das } \\
\text { reações. }\end{array}$ & & & \\
\hline
\end{tabular}

Quadro 4.40 Questão da avaliação final elaborada da professora P11

Outro ponto interessante é que ela incluiu, no final da avaliação, um fato histórico sobre a elaboração da lei da ação das massas ${ }^{17}$ (Fig. 4.54), contudo, a informação que constava nesse texto não era condizente com o que foi discutido durante o curso de formação continuada. Verifica-se que esse trecho só foi colocado na prova como um fato, uma curiosidade, não sendo solicitada nenhuma atividade aos alunos em relação a ele.

\section{Vocë sabia?}

- O fato de os noruegueses Guldberg e Waage terem enunciado a Lei da Ação das Massas no seu idioma retardou o reconhecimento de seus trabalhos por muitos anos. A Lei foi enunciada em 1863, mas ficou praticamente ignorada até ser publicada na Alemanha em 1899. Nessa época o químico alemão van't Hoff jă a havia descrito e ganho os créditos iniciais, os quais foram mais tarde reconhecidos como dos dois noruegueses que, além de amigos, eram cunhados.

Figura 4.54 Texto sobre a História da Cinética química incluído pela professora P11 na avaliação.

No quadro a seguir, podem ser observados os modelos de ensino dela do início do curso de formação continuada até a aplicação de seu plano de ensino:

${ }^{17}$ Segundo Laidler (1993), A lei de ação de massas de Guldberg e Waage está relacionada ao cálculo da constante de equilíbrio e não a lei de velocidade desenvolvida por van't Hoff. 


\begin{tabular}{|c|c|c|c|c|}
\hline ETAPA & INSTRUMENTOS & $\begin{array}{l}\text { CINÉTICA } \\
\text { QUÍMICA }\end{array}$ & $\begin{array}{l}\text { HISTÓRIA DA } \\
\text { QUÍMICA }\end{array}$ & $\begin{array}{l}\text { IMAGEM DA } \\
\text { CIÊNCIA }\end{array}$ \\
\hline \multirow{2}{*}{ INÍCIO } & INSTRUMENTO 1 & MES1 & - & \\
\hline & INSTRUMENTO 2 & & & $E / I$ \\
\hline \multirow{7}{*}{ DURANTE } & ATIVIDADE 1 & & $\mathrm{C} 1$ & \\
\hline & ATIVIDADE 2 & & $\mathrm{C3}$ & \\
\hline & ATIVIDADE 4 & & & - \\
\hline & ATIVIDADE 6 & MEM & & \\
\hline & INSTRUMENTO 3 & & & $R$ \\
\hline & EXPERIMENTO 3 & MES1 & & \\
\hline & EXERCICIO 1 & - & & \\
\hline \multirow{3}{*}{ FINAL } & ATIVIDADE 8 & MEM & $\mathrm{C3}$ & $\mathrm{R}$ \\
\hline & PLANO DE ENSINO & MES1, MES2 & $\mathrm{C3}$ & - \\
\hline & APLICAÇÃO PLANO & MES1, MES2 & $\mathrm{C3}$ & $\mathrm{R}$ \\
\hline
\end{tabular}

Quadro 4.41 Modelos de ensino de cinética química da professora P11 nas diferentes etapas do curso de formação e na aplicação de seu plano de ensino.

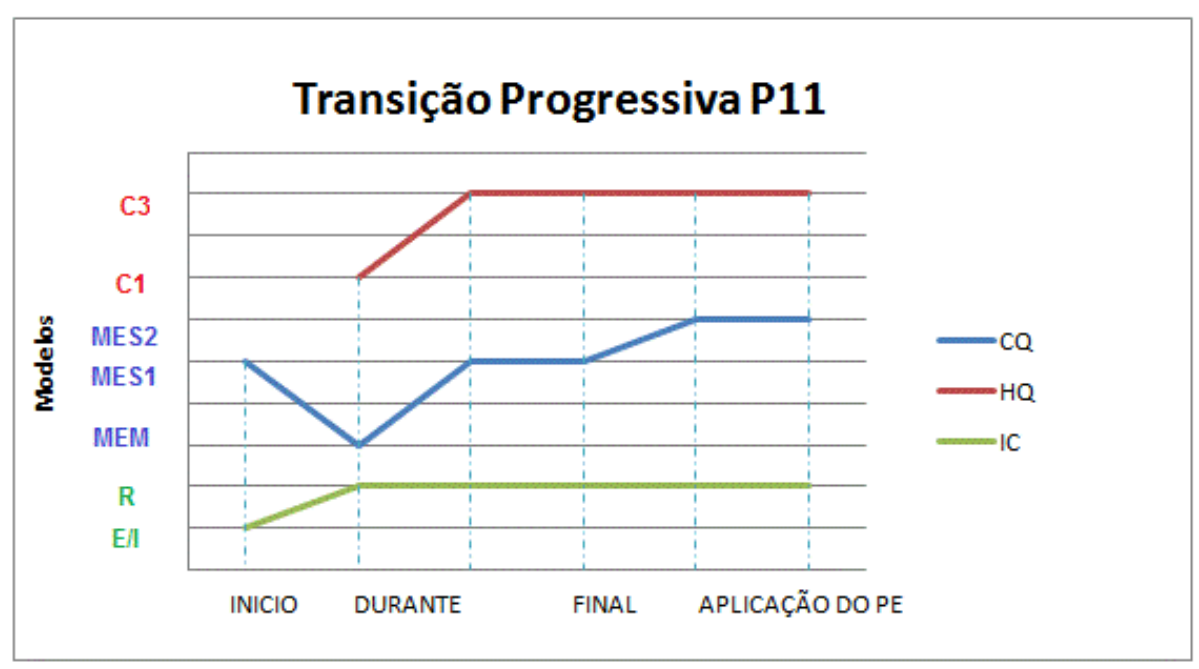

Figura 4.55 Transição progressiva da professora $\mathrm{P} 11$ nas quatro fases da pesquisa, em relação aos seguintes aspectos de seu modelo de ensino: $C Q$ : cinética química, $H Q$ : História da Química e IC: imagem da ciência.

Ao tomar como base a ideia de transição progressiva de Níaz (2009), observa-se que o curso facilitou a transição progressiva principalmente no entendimento dos conceitos reativos ao tema cinética química. O modelo de ensino, que inicialmente foi caracterizado como MEM (modelo de ensino macroscópico), passou a ser MES2 quando ela inclui no seu ensino ideias 
baseadas na teoria do estado de transição (quebra e formação de ligações entre as moléculas).

Em relação a imagem da natureza da ciência, pode-se perceber a preocupação da professora P11 de que seus alunos construam a ideia de que o conhecimento científico é uma construção humana (perspectiva racionalista).

Pela análise das aulas, percebe-se que a História da Química (HQ) não foi abordada com objetivo de se discutir o desenvolvimento dos conceitos químicos envolvidos na cinética química. Para ela, a $\mathrm{HQ}$ possui somente a finalidade de apresentar alguns nomes de cientistas que participaram do desenvolvimento da cinética química, como pode ser observado no detalhamento da 6 a. Aula.

Embora o papel da $\mathrm{HQ}$ no ensino de cinética química, para essa professora, seja somente o de mostrar a origem de determinado conhecimento científico, o que ficou mais evidente na aplicação de seu plano foi a mudança na abordagem dos conceitos, principalmente, na inclusão de atividades experimentais e na mudança na sequência de ensino dos conceitos, dentro do tema cinética química:

Pode ser que eu não tenha conseguido passar da forma que gostaria a desenvolvimento da cinética historicamente para eles, mas você me levou a ensinar cinética de uma ordem diferente do que está apresentada na apostila. Abordar primeiro experimentos que levem o aluno a deduzir e reconhecer os principais fatores que alteram a velocidade da reação (capítulo 02), depois abordar mecanismo de atuação de catalisador (capítulo 04), depois falar sobre cálculo de velocidade média (capítulo 01), abordar neste momento lei cinética.

Achei bem melhor. Com certeza o ano que vou vai ser ainda melhor, pois acho que vou mudar um pouco a ordem de abordagem da apostila para que possa dar cinética com um pouco mais de calma. (Trecho do depoimento da professora P11, dia 22 de novembro de 2010).

Contudo, pode-se perceber que a ideia de trabalhar com a $\mathrm{HQ}$, passou a fazer parte do planejamento do ensino dessa professora, mesmo em relação a outros conteúdos, como pode ser observado no seguinte trecho de seu depoimento: 
Pedi um trabalho aos meus alunos (aquela classe que você assistiu às aulas) estou dando equilíbrio químico para eles. Dividi a classe em 4 grupos e pedi que apresentassem um trabalho em Power Point com alguns temas diferenciados.

Resumidamente seria: um grupo deveria apresentar a biografia e os trabalhos de Haber e Bosch, o segundo deveria apresentar sobre a produção de amônia e relacionar com o acontecimento histórico da época e os princípios de Le Chatelier, o outro deveria apresentar e explicar alguns fatos do cotidiano sobre o que o equilíbrio químico pode explicar e o outro deveria pesquisar alguns experimentos de equilíbrio químico.

O primeiro grupo encarregado de apresentar sobre Haber e Bosch apresentou um tipo de documentário sobre eles, acharam um filme sobre a vida deles e inseriram fotos dos locais onde trabalharam e alguns equipamentos usados na época. Ficou nota dez, muito bom. Gostaria que você tivesse lá para ver (Trecho do depoimento da professora P11, 5 de março de 2011).

Percebe-se então, pela fala da professora, que ela passou a trabalhar com a História da Química de uma maneira diferente, mais integrada ao conteúdo que iria ser ensinado. Portanto, pode-se inferir que a História da Química passou a ter, segundo a ideia de Gil-Pérez (1993), o papel proporcionar o ensino de conceitos científicos.

\section{P15}

A escola em que a professora leciona e onde ela aplicou seu plano de ensino, é da rede pública e localiza-se no interior do Estado de São Paulo, na cidade de São José dos Campos. Antes de aplicar seu plano de ensino, a professora pediu que seus alunos assinassem uma autorização para o uso das imagens e gravações em áudio e vídeo (Apêndice I). Período de aplicação do plano de ensino: 15/03/2011 a 26/04/2011.

Normalmente seu ensino sobre o tema cinética química é baseado no caderno do professor e do aluno, que estão vinculados na Proposta Curricular do Estado de São Paulo (São Paulo, 2011). 


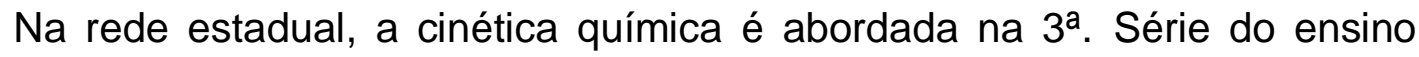
médio e em relação ao conteúdo especifico sobre esse tema são tratados conhecimentos sobre a cinética da transformação química e o controle da velocidade nas reações, que são importantes para compreender a síntese da amônia. A síntese da amônia foi escolhida pelos autores dos cadernos de química da Secretaria da Educação do Estado de São Paulo como tema por ser de grande importância social e econômica para o ser humano.

A professora aplicou seu plano em uma turma do $3^{a}$. Ano do ensino médio. Seguindo a seguinte sequência de ensino:

\section{Sequência Conteúdo desenvolvido}

Primeiro Ideias sobre ciência

encontro

Segundo Levantamento Prévio de Ideias dos alunos encontro

Terceiro encontro

Quarto encontro Um breve histórico sobre cinética química (segunda parte) Quinto encontro Atividade Experimental: "Rapidez ou Velocidade" Sexto encontro Interpretação do experimento com um modelo microscópico

- Primeiro encontro: atividade: "ideias sobre ciência":

Antes de aplicar seu plano de ensino, a professora aplicou um instrumento (instrumento 2, Apêndice VII), para detectar quais eram as ideias sobre a natureza da ciência que seus alunos possuíam (fig, 4.56). Este instrumento foi aplicado novamente no final das aulas sobre o tema cinética química. Essa atividade, segundo a professora:

Permitiu diagnosticar a visão que os alunos têm de ciência, e como ela possui afirmações que abordam tanto o ponto de vista empírico como o racionalista, exige uma reflexão profunda sobre o assunto e coloca o aluno diante da seguinte questão: $O$ que é ciência afinal? (trecho depoimento P15, 15/03/2011). 


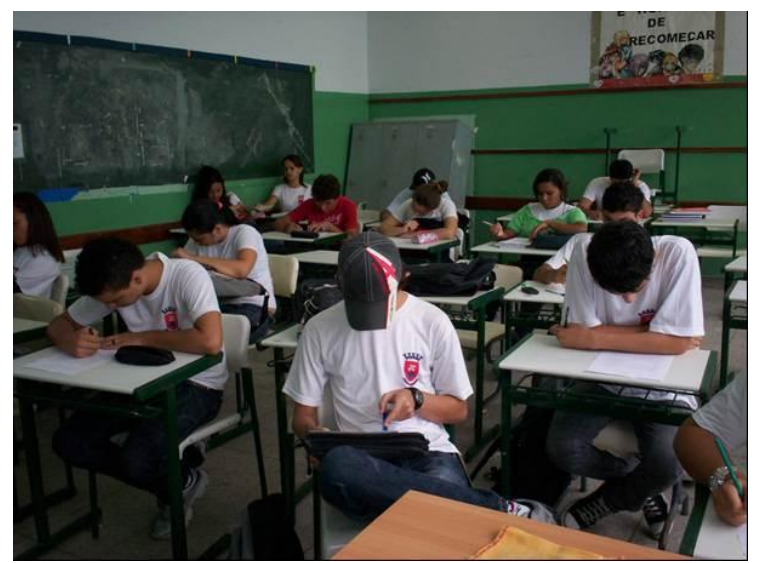

Figura 4.56 Imagem de alguns alunos durante a realização da primeira atividade (instrumento 2, Apêndice VII).

Em relação à imagem que a professora espera que seus alunos construam, a partir da aplicação de seu plano:

Gostaria que construíssem a imagem de ciência que desenvolvi no meu mapa conceitual. Entendam que a ciência progride por dedução e não por indução, voltada para a investigação e resolução de problemas. (trecho depoimento P15, 15/03/2011)

Percebe-se que as ideias da professora são coerentes com a perspectiva filosófica racionalista.

\section{Segundo encontro: Aula 1 - "Levantamento Prévio de Ideias"}

Nesse segundo encontro foi feita uma exposição de slides e a discussão dos mesmos, para que a professora pudesse diagnosticar algumas ideias dos alunos a respeito dos fatores que interferem na velocidade de uma transformação química, apesar de estes ainda não compreenderem bem como estes fatores atuam e como interferem na velocidade. Segundo a professora, apesar de a atividade tê-los levado à reflexão sobre o assunto, ela pode concluir que os conceitos apresentados por seus alunos terão que ser mais bem elaborados.

Através da análise do questionário a professora pode observar que:

$\checkmark$ Com relação ao conceito de Cinética Química: A maioria relacionou 0 termo com velocidade de transformação química. 
$\checkmark$ Com relação ao conceito de velocidade: Eles têm a noção de que a velocidade é algo que acontece em função do tempo, mas o que acontece exatamente eles não sabem. $\checkmark$ Com relação ao controle da velocidade: Eles concordam que é importante e que isto pode trazer algum tipo de benefício. Apenas alguns alunos não concordaram ou não entenderam a questão.

$\checkmark$ Com relação à identificação dos fatores: A maioria acredita que existe "alguma coisa por detrás da velocidade da transformação química", mas não compreendem como isto ocorre. (análise feita pela professora P15 das respostas dos alunos ao questionário, 22/03/2011)

\section{- Terceiro e quarto encontros: "Um breve histórico sobre cinética química"}

No terceiro encontro os alunos leram o texto sobre história da cinética química (Anexo $\mathrm{V}$ ) e a seguir foram questionados sobre os conceitos que o texto trazia e que eles desconheciam. A professora apresentou então em slides (PowerPoint) as principais ideias do texto, indicando os cientistas envolvidos na elaboração dessas ideias. A explicação destes e de outros conceitos foi feita, pela professora, à medida que os slides eram projetados, assim como a descrição dos eventos ligados à evolução histórica da cinética química.

Esse texto (anexo $\mathrm{V}$ ) foi elaborado pela professora a partir do material fornecido pelo curso de formação continuada e consistia de recortes de trabalhos de alguns cientistas envolvidos no estudo da cinética química. Pela leitura desse texto, verifica-se que o principal objetivo era o de informar a origem de alguns conhecimentos científicos. Contudo, nas questões propostas pela professora, percebe-se que ela pretendia que seus alunos construíssem alguns conceitos, como também pretendia discutir sobre a imagem da ciência (questões 1 e 2, anexo V).

No quarto encontro, em um primeiro momento, a professora fez algumas considerações sobre a aula anterior a fim de situá-los novamente no tema. $\mathrm{Na}$ sequência, foi lido um texto complementar que envolvia o conteúdo do texto anterior, mas com enfoque no desenvolvimento da ciência e no método científico. A seguir, os alunos reuniram-se em grupo para discutir e responder as questões (fig. 4.57). 
Esse texto complementar (Anexo $\mathrm{VI}$ ), que não constava inicialmente no seu plano, foi elaborado pela própria professora, porque esta sentiu que seus alunos tiveram dificuldades na identificação da perspectiva filosófica desse período de tempo estudado.

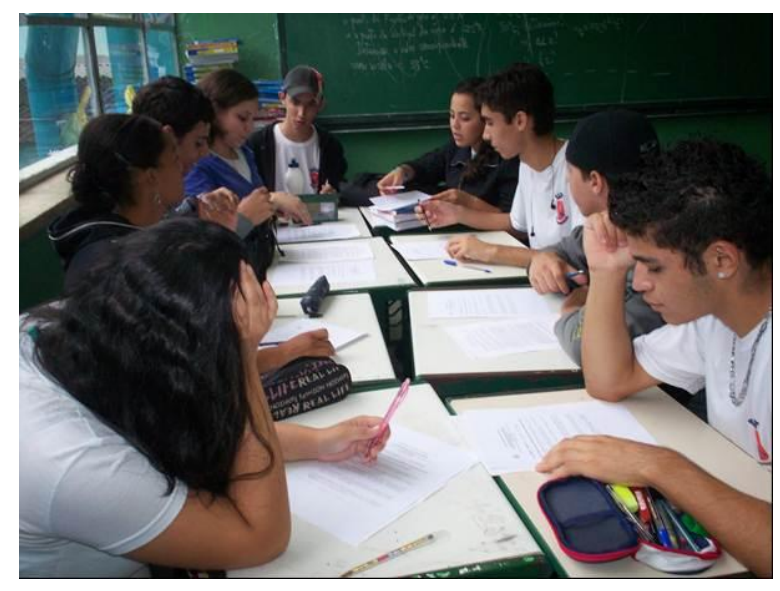

Figura 4.57 Imagem de alguns alunos respondendo as questões do texto sobre a história da cinética química.

Após a realização da atividade a reflexão que a professora faz é a de que:

Durante a realização desta atividade, pude perceber que os alunos estavam muito envolvidos com as questões e analisando as respostas do questionário, concluo que as ideias sobre ciência estão sendo construídas de maneira satisfatória. (depoimento da professora P15, 05/04/2011)

Verifica-se, pela fala da professora, que o trabalho com os textos sobre a história do desenvolvimento da cinética química, não teve somente o objetivo de informar aos alunos a origem de determinados conceitos químicos, mas também o objetivo que os alunos construíssem uma imagem de ciência mais próxima da ideias da perspectiva filosófica racionalista.

\section{- Quinto encontro: Atividade Experimental: "Rapidez ou Velocidade"}

Nesse encontro a professora realizou, por demonstração, o experimento da difusão gasosa (fig. 4.58). Antes da realização do experimento os alunos receberam o roteiro experimental com uma lista de exercícios para serem resolvidos durante a aula (anexo VII). 


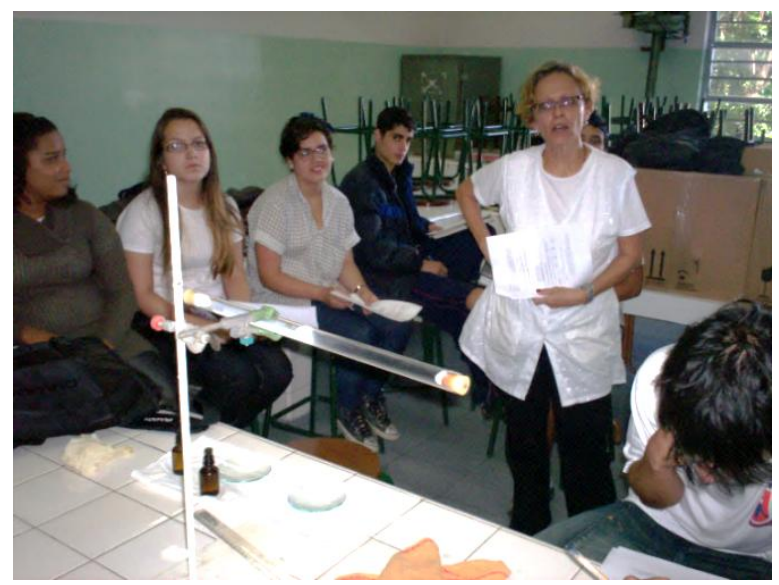

Figura 4.58 Imagem da aula experimental, difusão gasosa.

Um ponto interessante dessa atividade é que a professora preocupou-se em fazer a distinção entre o significado da velocidade na física e na química:

Quando falamos em "velocidade", logo lembramos o
conceito relacionado à física que a define como o
deslocamento de um corpo na unidade de tempo. Em
química, esse conceito tem um significado muito diferente,
por esta razão, adotaremos o termo "rapidez" ao invés de
velocidade quando estivermos tratando de transformações
químicas. (trecho do roteiro, anexo VII)

Nessa atividade, a professora também solicitou que seu alunos construíssem um gráfico da variação da concentração de um reagente em função do tempo (dada uma reação genérica) e que respondessem questões relacionadas a variação de velocidade dessa reação em função do tempo.

Reflexão da professora sobre essa atividade:

Os alunos da escola pública infelizmente não trazem uma boa bagagem, então, às vezes você precisa dar uma força, por exemplo, no gráfico, a concentração no eixo y e o tempo no eixo $x$, como analisar a variação de um em função do outro, e assim por diante. Eles começaram a resolver no laboratório e pediram para terminar em casa. Durante a aula, a medida que eu explicava a experiência pedi várias vezes que eles fossem imaginando como isto ocorria em nível submicroscópico, não sei se eles entenderam. (depoimento da professora P15, 12/04/2011) 
O principal objetivo dessa aula era que os alunos, a partir da atividade experimental, fossem construindo um modelo de partícula para explicar o que estava ocorrendo durante a reação química.

- Sexto encontro: "Interpretação do experimento com um modelo microscópico"

Em sala de aula, a professora pediu que seus alunos realizassem uma atividade (anexo VIII) que se referia à interpretação, em termos submicroscópicos, da reação química que foi estudada no experimento da difusão gasosa, realizado no encontro anterior.

Os objetivos dessa atividade, segundo a professora, eram o de:

Auxiliar na construção dos conceitos relacionados à Teoria das Colisões e o professor deverá mediar esta construção fornecendo elementos necessários e explorando a ideia de que as colisões que originam os produtos só ocorrem quando as partículas possuem energia suficiente e orientação certa.

Que o aluno elabore um modelo no qual houve algumas colisões efetivas, portanto, formação de algumas moléculas de produto. (comentários da professora sobre a atividade, anexo VIII)

Percebe-se então, que o objetivo era que os alunos construíssem o modelo da teoria das colisões para explicar essa reação química.

Após essa atividade, a professora apresentou seu mapa conceitual (Figura 4.37, p 240), sobre a visão de ciência. A intenção de mostrar o mapa conceitual era a de discutir com os alunos, algumas ideias que ela achava importante sobre a natureza da ciência. Os principais pontos discutidos foram:

$\checkmark$ O contexto em que os estudos iniciais foram desenvolvidos (por que estudar o açúcar?).

$\checkmark$ A não linearidade do desenvolvimento da ciência.

$\checkmark$ O papel da criatividade na ciência.

$\checkmark$ Refutar a ideia de existe somente um único método científico 
Após a apresentação do mapa conceitual foi aplicado novamente o instrumento 3 (Apêndice III), para poder identificar se houve alguma mudança em relação as ideias de seus alunos sobre a natureza da ciência.

Pode-se se perceber a preocupação da professora com a construção da imagem de ciência de seus alunos, pois durante todos os encontros, ela provoca discussões com seus alunos sobre esse tema.

A professora P15 não aplicou uma avaliação final como fez a professora $\mathrm{P} 11$, seus alunos foram avaliados pelas atividades que eles realizaram durante $\mathrm{o}$ ensino desse tema.

No quadro a seguir, podem ser observados os modelos de ensino dessa professora:

\begin{tabular}{|c|c|c|c|c|}
\hline ETAPA & INSTRUMENTOS & $\begin{array}{l}\text { CINÉTICA } \\
\text { QUÍMICA }\end{array}$ & $\begin{array}{l}\text { HISTÓRIA DA } \\
\text { QUÍMICA }\end{array}$ & $\begin{array}{l}\text { IMAGEM DA } \\
\text { CIÊNCIA }\end{array}$ \\
\hline \multirow{2}{*}{ INÍCIO } & INSTRUMENTO 1 & MEM & C4 & \\
\hline & INSTRUMENTO 2 & & & $E / I$ \\
\hline \multirow{7}{*}{ DURANTE } & ATIVIDADE 1 & & C4 & \\
\hline & ATIVIDADE 2 & & - & \\
\hline & ATIVIDADE 4 & & & $\mathrm{R}$ \\
\hline & ATIVIDADE 6 & MEM & & \\
\hline & INSTRUMENTO 3 & & & $E / I, R$ \\
\hline & EXPERIMENTO 3 & MES1, MES2 & & \\
\hline & \begin{tabular}{|l|} 
EXERCICIO 1 \\
\end{tabular} & MES1 & & \\
\hline \multirow{3}{*}{ FINAL } & ATIVIDADE 8 & MEM & $\mathrm{C} 2, \mathrm{C} 4$ & $\mathrm{R}$ \\
\hline & PLANO DE ENSINO & MES1 & $\mathrm{C} 4$ & $\mathrm{R}$ \\
\hline & APLICAÇÃO PLANO & MES1 & $\mathrm{C} 2, \mathrm{C} 3, \mathrm{C} 4$ & $R$ \\
\hline
\end{tabular}

Quadro 4.42 Modelos de ensino de cinética química da professora P15 nas diferentes etapas do curso de formação e na aplicação de seu plano de ensino. 


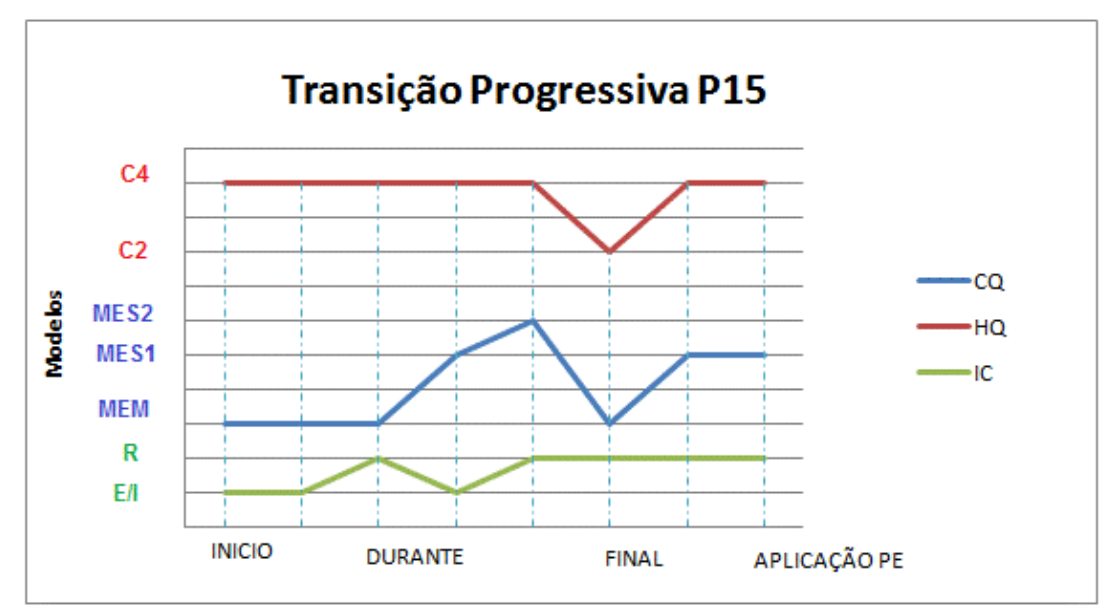

Figura 4.59 Transição progressiva da professora P15 nas quatro fases da pesquisa, em relação aos seguintes aspectos de seu modelo de ensino: $C Q$ : cinética química, $H Q$ : História da Química e IC: imagem da ciência.

Ao tomar como base a ideia de transição progressiva de Níaz (2009), observa-se que o curso facilitou a transição progressiva principalmente no entendimento dos conceitos reativos ao tema cinética química, como também no entendimento do papel da História da Química no ensino. O modelo de ensino, que inicialmente foi caracterizado como MEM (modelo de ensino macroscópico), passou a ser MES1 quando ela inclui no seu ensino, a teoria das colisões, trabalhando com esse modelo na interpretação dos resultados da atividade experimental (anexo VIII).

Em relação à Historia da Química, percebe-se que a professora P15 passa a dar mais importância a ela no seu ensino, com a melhor compreensão de seu potencial, tanto para ajudar seus alunos na construção de um determinado conhecimento científico, como também a de proporcionar uma discussão sobre a imagem da natureza da ciência.

Comparando-se as duas professoras, P11 e P15, percebe-se que as maiores diferenças entre elas estão no entendimento do papel da História da Química no ensino de cinética química e na preocupação em se discutir com seus alunos sobre a natureza da ciência. A professora P15, além de aplicar um instrumento para conhecer as ideias dos seus alunos sobre a natureza da ciência 
antes e após o ensino, também se preocupou, durante suas aulas, com que seu alunos construíssem uma imagem da ciência coerente com a perspectiva filosófica racionalista, isso pode ser observado nas atividades realizadas, como por exemplo, os textos sobre o desenvolvimento histórico da cinética química e a discussão sobre o seu mapa conceitual.

Acredita-se nesse trabalho que as discussões e atividades, que ocorreram durante os encontros do curso de formação continuada, proporcionaram uma melhor compreensão sobre a natureza da ciência. Portanto, esse grupo de professores puderam ficar cientes de que seu ensino não é neutro e que eles acabam sempre influenciando a construção da imagem de ciência de seus alunos.

Em relação a cinética química, percebe-se que as duas professoras escolheram abordar aspectos relacionados a um modelo submicroscópico, não focalizando seu ensino somente na influência de certos fatores na velocidade de uma reação química.

Segundo van Driel (2002), a noção de velocidade de reação requer que os alunos entendam que é preciso tempo para uma reação química ocorrer, e que esse tempo é influenciado por fatores como a temperatura do sistema e as concentrações das substâncias reagentes. Segundo o autor, um modelo simples de colisão entre partículas pode ser útil para explicar as influências observáveis em termos corpusculares. Contudo, as professoras incluíram em suas explicações, além da ideia de colisões, outros conceitos, como o de energia de ativação, orientação espacial adequada e de quebra de ligações (professora P11) que permitem um melhor entendimento da influência desses fatores na velocidade de uma reação química. 


\section{Conclusões e Considerações}

A partir da análise do processo de transição progressiva dos modelos de ensino, desse grupo de professores, foram encontrados os seguintes resultados:

- A transição progressiva dos modelos de ensino ocorre mais facilmente em relação às estratégias de ensino, do que em relação a mudança do núcleo teórico do modelo (modelos explicativos da cinética química), esta é muito mais difícil de ocorrer.

Quinze professores, no inicio curso de formação continuada, apontaram que em suas aulas normalmente só abordavam os aspectos macroscópicos (MEM) no ensino de cinética química, contudo, após o curso de formação, apenas sete professores indicaram, em seu plano de ensino final, modelos teóricos (MES1 ou MES2) relacionados ao estudo da velocidade de uma reação química (figura 4.60).

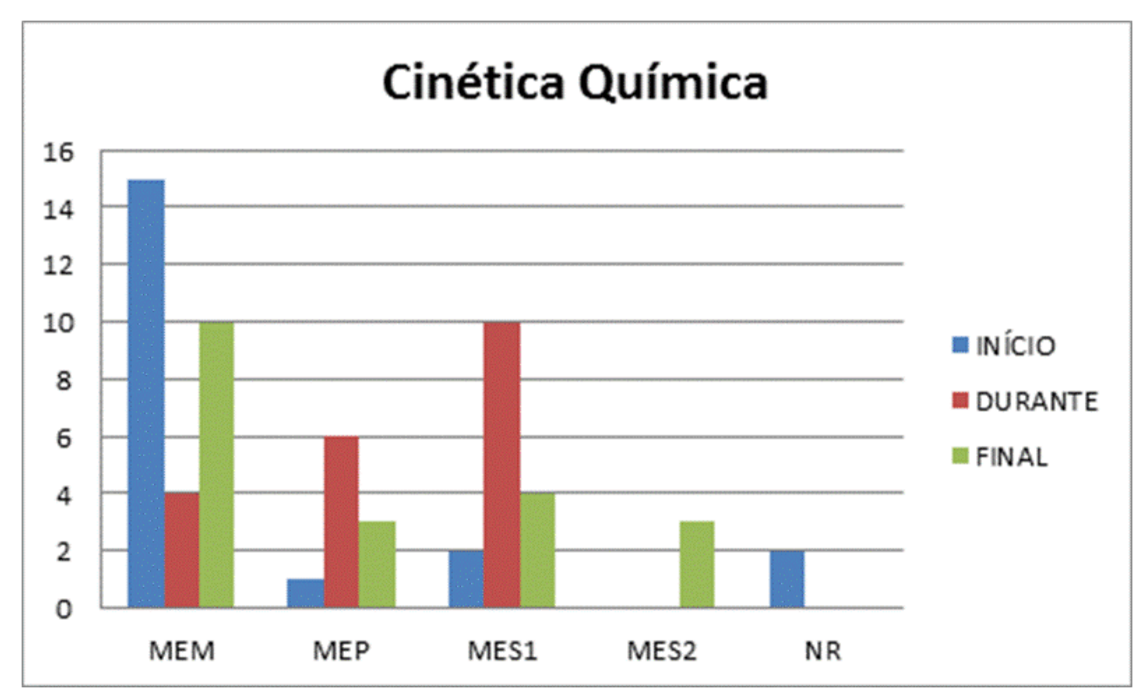

Figura 4.60 Transição progressiva dos professores nas 3 fases da pesquisa, em relação aos seguintes aspectos de seu modelo de ensino: CQ: cinética química. Nota: MEM: modelo de ensino macroscópico; MEP: modelo de ensino pseudomacroscópico; MES1: modelo de ensino submicroscópico 1;MES2: modelo de ensino submicroscópico 2; NR: não respondeu.

- Uma das atividades que facilitou a transição progressiva desses professores em relação ao entendimento da cinética química foi a 
realização do experimento 3 (Influência da temperatura e da superfície de contato na velocidade de reação de comprimidos efervescentes com a água, apêndice XII).

Essa atividade foi desenvolvida no quarto encontro do curso de formação, após a apresentação dos estudos referentes ao efeito da temperatura na velocidade das reações químicas (texto 2 da reconstrução histórica), onde, após a realização do experimento foi solicitado aos professores que explicassem, utilizando um modelo de partículas, por que a transformação é mais lenta quando realizada em temperatura mais baixa.

Nesse momento nove professores que no início do curso tinham o modelo MEM usaram em suas respostas o modelo da teoria das colisões para explicar o efeito da temperatura (MES1), seis professores que também possuíam o modelo MEM inicialmente responderam a essa questão usando termos relacionados a partículas (MEP), dois professores que no inicio do curso já possuíam um modelo submicroscópico (MES1), usaram esse modelo em suas explicações. Três professores não realizaram essa atividade.

- Percebeu-se que o uso do modelo está relacionado a atividade proposta, pois neste trabalho os professores somente usaram um modelo teórico (submicroscópico) em suas explicações quando isso foi explicitamente solicitado.

Isto está de acordo com o que foi encontrado no estudo de Cakmakci, Leach e Donnelly (2006), que quando é dada uma dica teórica, os alunos são mais propensos a usar termos científicos e modelos teóricos em suas explicações.

- Uma das dificuldades encontradas pelos professores durante o curso foi a elaboração de gráficos para representar os dados experimentais referentes a variação da velocidade de uma reação química em função do tempo.

Oito professores não realizaram a atividade, sendo que desse grupo, seis estavam presentes no dia do encontro, contudo, deixaram suas atividades sem 
responder. Pode-se inferir então que essa dificuldade não é somente dos alunos do ensino médio ou da graduação, conforme apontam Cakmakci et al (2005), os professores também encontram dificuldade em trabalhar com diferentes formas de representações, e isso é necessário no caso da cinética química.

- Entre as estratégias que os professores escolheram para abordar o tema cinética química, a experimentação foi a mais apontada, principalmente para demonstrar a influência dos fatores que podem alterar a velocidade de uma reação (temperatura, concentração, entre outros). Contudo, outras estratégias foram escolhidas no plano de ensino final, como o uso de gráficos, textos, mapas conceituais e simulações.

Percebeu-se neste trabalho a importância de discutir com os professores 0 uso de diferentes estratégias para o ensino de cinética química, possibilitando assim formas diferentes de abordar os conceitos presentes nesse tema.

- Treze professores, no início do curso, entendiam que no ensino, o papel da experimentação era o de comprovação de teorias:

Os experimentos ilustram os conceitos trabalhados em sala de aula e despertam o interesse dos alunos para 0 aprendizado.(P7, instrumento 1, apêndice 2).

Eles têm a oportunidade de vivenciar a teoria. Porém, nem sempre é possível devido ao tempo. (P11, instrumento 1, apêndice 2).

O experimento prova a teoria. ( $\mathrm{P} 12$, instrumento 1, apêndice 2).

Segundo Níaz (p. 3, 2008), essa visão empirista/indutivista da ciência já recebeu críticas do próprio Lakatos:

Um breve olhar sobre o desenvolvimento das teorias químicas e sua relação com as experiências, você descobre que a sabedoria convencional sobre a natureza empírica da química está errada. A história da química não pode ser usada para doutrinar estudantes em métodos baconianos. (NIAZ, 2008 apud LAKATOS, 1978, p. 290).

Após o curso de formação continuada, pode-se verificar que essa visão, sobre o papel da experimentação, foi modificada, somente quatro professores mantiveram essa ideia no seu plano final. Isso pode ser devido ao entendimento, 
desses professores, do desenvolvimento histórico dos conceitos científicos relacionados ao tema cinética química, onde foram discutidos vários experimentos e o seu papel na construção do entendimento desses conceitos.

- O curso de formação continuada facilitou a transição progressiva em relação à Imagem da natureza da ciência da maioria dos professores (fig. 4.61).

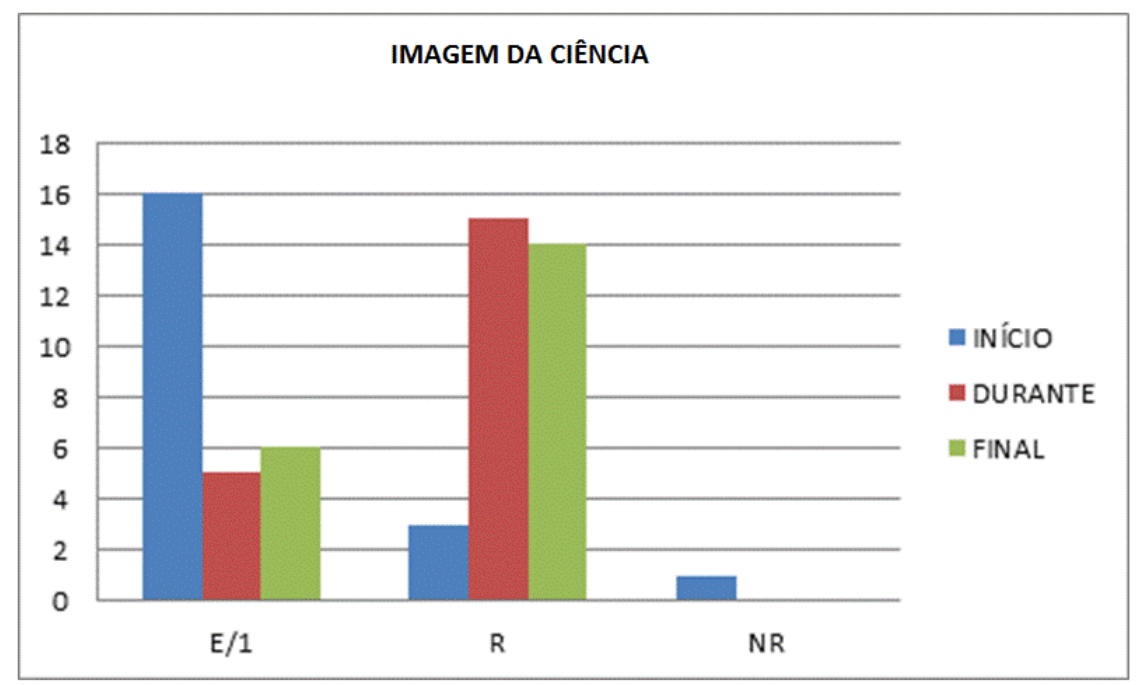

Figura 4.61 Transição progressiva dos professores nas 3 fases da pesquisa, em relação aos seguintes aspectos de seu modelo de ensino: Imagem da natureza da ciência (IC).Nota: E/l:empirista/indutivista; R: racionalista; NR:não respondeu.

Isso pode ser devido às discussões sobre esse tema que ocorreram durante o curso de formação continuada, como também a maneira com que o desenvolvimento histórico da cinética química foi apresentado a esses professores. Sempre se procurou enfatizar o caráter dinâmico da ciência como também a ideia de que esse conhecimento foi uma construção humana e que surgiu sempre que se procurava uma solução para algum problema encontrado na espoca em que foi elaborado. Segundo Níaz (2009), a discussão sobre a natureza da ciência é algo complexo e que depende das oportunidades que os professores tenham para fazer reflexões sobre diversas situações relacionadas a ela. 
- Em relação ao entendimento do papel da História da Química no ensino de ciências houve, durante o curso de formação, uma grande variação por parte dos professores dessa compreensão (fig. 4.62).

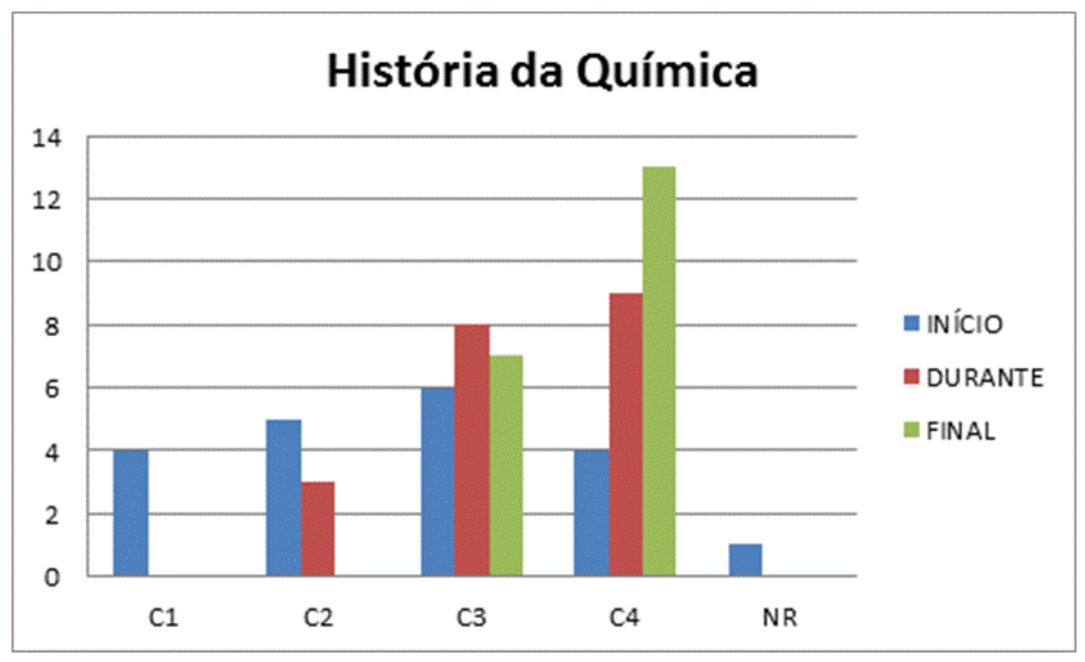

Figura 4.62 Transição progressiva dos professores nas 3 fases da pesquisa, em relação aos seguintes aspectos de seu modelo de ensino: História da Química (HQ). Nota: C1: Interesse pela química;C2: O caráter dinâmico da ciência; C3: A origem do conhecimento científico; C4: A construção do conhecimento científico; NR:não respondeu.

Contudo, embora metade desses professores inicialmente tivessem ideias que pertenciam às categorias $\mathrm{C} 1$ (Interesse pela química) ou C2 ( $\mathrm{O}$ caráter dinâmico da ciência), ao final do curso essas duas categorias não foram mais encontradas.

- O grupo de professores que ao final do curso possuía uma imagem empirista/indutivista da ciência foram aqueles que teve maior dificuldade de aceitar a ideia de que a História da Química pode ajudar os alunos a entender como um determinado conceito foi construído (categoria C4).

- Os professores que ao final do curso possuíam o modelo de ensino submicroscópico (MES1 e MES2), também apresentaram uma visão de ciência coerente com a perspectiva filosófica racionalista e foram os que compreenderam melhor o papel da História da Química no ensino de cinética Química. 
- A abordagem histórica da cinética química a partir de sua reconstrução histórica, permitiu aos professores um melhor entendimento do papel da História da Química no ensino de ciências, como também favoreceu, juntamente com outras atividades direcionadas a discussão sobre a natureza da ciência, a construção de uma imagem de ciência mais coerente com a aceita atualmente.

A partir da análise dos planos de ensino percebe-se que, apesar de os professores possuírem um melhor entendimento do papel da História da Química no ensino de ciências, poucos abordam a História da Química como com o objetivo de desenvolver os conceitos científicos.

- O processo de elaboração, reelaboração e aplicação dos planos de ensino, (principalmente no caso das duas professoras P11 e P15), com a supervisão da pesquisadora, mostrou-se ser de fundamental importância para o entendimento e incorporação da História da Química no ensino de cinética química, como também deixou evidente as maiores dificuldades que os professores apresentaram nesse processo.

Acredita-se neste trabalho que os professores teriam menos dificuldades em abordar conjuntamente esses três aspectos, cinética química, Historia da Química e filosofia da ciência em seus planejamentos, se o curso de formação tivesse uma duração maior, menos conteúdos e informações e mais oportunidades de discussões, conforme apontaram alguns professores na avaliação final.

Contudo, o acompanhamento desses professores, em relação a mudança nos seus modelos de ensino, mostrou a importância e a necessidade da participação desses em cursos de formação continuada, pois, esse contexto facilita a interação, a troca de experiências e o contato com uma série de conhecimentos que vem sendo desenvolvidos pela academia na área de ensino de ciências.

A partir dos resultados encontrados neste trabalho, visualizando-se o que seria importante levar em consideração em um curso de formação continuada, 
voltado para a abordagem histórica de um determinado conceito químico, pode-se destacar:

$\checkmark$ Ter sempre a preocupação com o entendimento do conteúdo que é apresentado durante o curso, Identificar os pontos de maior dificuldade de entendimento e tentar modificar o rumo do curso em função dessas dificuldades, com o objetivo de superá-las.

$\checkmark$ Deve ser feito um trabalho em tempo suficiente para que o professor, além de tomar contato com os assuntos a serem tratados em um curso de formação, possa ter experiências com os diversos aspectos tratados, de maneira a estabelecer relações conceituais mais duradouras, bem como em tempo suficiente para que considere essas experiências em sua prática docente.

Esses são alguns pontos que surgiram da reflexão feita sobre o curso de formação e que seriam, com certeza, levados em consideração pela pesquisadora em uma nova experiência de formação continuada. 


\section{Referências Bibliográficas}

Alfonso-GOldFARB, A. M. O que é História da Ciência. Coleção Primeiros Passos. São Paulo: Brasiliense, 1994.

BARDIN, L. Análise de Conteúdo. Edições 70. Lisboa. 1977.

BEKTASLI, B. \& CAKMAKCI, G. Consistency of students' ideas about the concept of rate across different contexts. Education and Science; 36(162), 273-287. 2011.

BELTRAN, N. O. Ideias em movimento. Química Nova na Escola. 5,p. 14-7, 1997.

BRASIL. S.E.M.T. Parâmetros Curriculares Nacionais: ensino médio. Brasília: MEC, SEMTEC. 1999

CACHAPUZ, A.; PRAIA, J. Y JORGE, M. Ciência, Educação em Ciência e Ensino das Ciências. Lisboa: Ministério da Educação, pp.59-94, 2002.

.Da educação em ciência às orientações para o ensino das ciências: um repensar epistemológico. Ciência \& Educação, v. 10, n. 3, p. 363-381, 2004.

CAKMAKCI, G., DONNELLY, J \& LEACH, J. A cross-sectional study of the understanding of the relationships between concentration and reaction rate among Turkish secondary and undergraduate students. In K. Boersma \& O. de Jong \& H. Eijkelhof \& M. Goedhart (Eds.). Research and the Quality of Science Education. Dordrecht: Springer. pp. 483-497, 2005.

Students' Ideas about Reaction Rate and its Relationship with Concentration or Pressure. International Journal of Science Education. 28:15, pp. 1795-1815. 2006.

CARVALHO, A. M. P.; GIL-PÉREZ, D. Formação de professores de ciências: tendências e inovações. São Paulo: Cortez . Coleção questões da nossa época, 8모 edição, 2006.

DEL PINO,J.C.; LOGUERCIO, R.Q. "Contribuições da História e da Filosofia da Ciência para a construção do conhecimento científico em contextos de formação 
profissional de química”. Disponível em: http://www.iq.ufrgs.br/aeq/producao/delpino/ACTA 2.pdf (acessado em 08 de julho de 2010).

DOMINGUES, A. M.; DUARTE, M. C.; A história da ciência no ensino básico: uma intervenção pedagógica no tema "origem da vida". Boletín das ciencias, Ano 21, №. 66 , pp. 127-128, 2008.

GAGLIARDI, J.R. Cómo utilizar la historia de las ciencias en la enseñanza del as ciencias. Enseñanza de las Ciencias, 6 (3), 291-296. 1988.

GIL- PÉREZ, D. Contribución de la historia y la filosofía de las ciencias al desarrollo de um modelo de enseñanza/aprendizaje como investigación. Enseñanza de las Ciencias, 11(2), 197-212, 1993.

GIL- PÉREZ, D; MONTORO, I. F.; ALÍS, J. C.; PRAIA, J.; CACHAPUZ. Para uma imagem não deformada do Trabalho científico. Ciência \& Educação, v.7, n.2, p.125-153, 2001.

GONZÁlEZ, A. M.; Historia de la ciencia: una posible contribución a la formación de los profesores. p. 345-360. La formacion del profesorado de ciencias y matematicas en España y Portugal. Lorenzo J. Blanco Nieto;Vicente Mellado Jiménez.(Coord.), $1994 . \quad$ Disponível em: http://www1.unex.es/eweb/liblanco/documentos/Blanco-Mellado-Final.pdf (acessado em 21/12/2010)

JUSTI, R.; Models in the Teaching of Chemical Kinetics. Tese de Doutorado. University of Reading; p. 1997.

JUSTI, R; RUAS,R.M.; Aprendizagem de química: reprodução de pedaços isolados de conhecimento? Química Nova na Escola. № 5, p. 24-27, 1997.

KAYA, Ebru e GEBAN, Ömer. Facilitating Conceptual Change in Rate of Reaction Concepts Using Conceptual Change Oriented Instruction. Education and Science, Vol. 37,. No 163. p. 226-225. 2012. 
KOLOMUÇ, Ali; TEKIN, Seher. Chemistry Teachers' Misconceptions Concerning Concept of Chemical Reaction Rate. Eurasian J. Phys. Chem. Educ. 3(2), p. 84101, 2011.

LAKATOS, I.; História da ciência e suas reconstruções racionais. Biblioteca de filosofia contemporânea. Edições 70. 1998.

LAKATOS, I.; Falsificação e metodologia dos programas de investigação científica.. Biblioteca de filosofia contemporânea. Edições 70; p.54-64. 1999.

MARTORANO, A. A. S; As concepções de ciência dos livros didáticos de química, dirigidos ao ensino médio, no tratamento da cinética química no período de 1929 a 2004. Dissertação de mestrado. Universidade de São Paulo, 2007.

MARTORANO, S. A. A., MARCONDES, M. E. R. As concepções de ciência dos livros didáticos de Química, dirigidos ao Ensino Médio, no tratamento da cinética química no período de 1929 a 2004. Investigações em Ensino de Ciências (UFRGS), v.14, p.341 - 355, 2009.

MELLADO, V.; CARRACEDO, D.; Contribuciones de la Filosofía de la Ciencia a la Didática de las Ciencias. Historia y Epistemología de las Ciencias. Enseñanza de las Ciencias, 11(3), p.331-339; 1993.

MELO, E. S. N.; MELO, J. R. F.; Softwares de simulação no ensino de química. Uma representação social na prática docente. ETD - Educação Temática Digital. Campinas, v.6, n.2, p.43-52, jun. 2005.

NÍAZ, M.; Progressive transitions in chemistry teachers' understanding of nature of science based on historical controversies. Science \& Education. (18). p.43-65, 2009.

.Teaching general Chemistry. A History of science approach. Nova Publishers. New York. p. 3-18. 2008.

NÍAZ, M.\& RODRIGUEZ, M.A. Teaching Chemistry as Rhetoric of Conclusions or Heuristic Principles - A History and Philosophy of Science Perspective. 
Chemistry Education: Researche and Practice in Europe; (1); p.315-322. 2000.

OKI, M. C. M.; MORADILLO, E. F.; O ensino de história da química: contribuindo para a compreensão da natureza da ciência. Ciência e Educação. vol.14, no.1. Bauru, p.67-88, 2008.

PÉREZ, L. F. M. Concepciones alternativas de professores de química em formacion, com respecto a cinética química y estratégia de enseñanza y aprendizaje. Dissertação de mestrado. Universidade Pedagógica Nacional. Bogotá. 2006.

PRAIA, J.; CACHAPUZ, A. Un análisis de las concepciones acerca de la naturaleza del conocimiento científico de los profesores portugueses de la enseñanza secundaria. Enseñanza de las Ciências, vol 12, ㄲo 3, p. 350-354. 1994.

PORTO, P. A. História e Filosofia da Ciência no Ensino de Química: Em busca dos objetivos educacionais da atualidade. Ensino de química em foco. Editora Unijuí, p.160-180, 2010.

POZO, J. I.; CRESPO, M. A. G.; Aprendizagem e o ensino de ciências. Do conhecimento cotidiano ao conhecimento científico. Editora Artmed. 5‥ ed., p. 46-76, 2009.

QUÍLEZ, J.. A historical approach to the development of chemical equilibrium through the evolution of the affinity concept: some educational suggestions. Chemistry education: research and practice. Vol. 5, No. 1, p. 69-87. 2004.

REZENDE, Flávio S.; FERREIRA, Luciana N. A.; QUEIROZ, Salete L. Concepções a respeito da construção do conhecimento científico: uma análise a partir de textos produzidos por estudantes de um curso superior de química. Revista Electrónica de Enseñanza de las Ciencias. Vol. 9. №3,p. 596-617. 2010.

MARTINS,M. C.; ROSA, K. A inserção de história e filosofia da ciência no currículo de licenciatura em física da universidade federal da bahia: uma visão de 
professores universitários. Investigações em Ensino de Ciências. V12(3), p.321-337, 2007.

PORLÁN, R; RUIZ, C., SILVA,C.; MELLADO,V. Construcción de mapas cognitivos a partir del cuestionario INPECIP. Aplicación al estudio de la evolución de las concepciones de una profesora de secundaria entre 1993 y 2002. Revista Electrónica Enseñanza de las Ciencias, 4 (1). 2005.

SAITO, F.; TRINDADE, L. S. P.; BELTRAN, M. H. R. História da Ciência e Ensino: ações e reflexões na construção de interfaces. Anais do XV Encontro Nacional de Ensino de Química (XV ENEQ) - Brasília, DF, Brasil - 21 a 24 de julho de 2010.Disponívem em: http://www.xveneq2010.unb.br/resumos/R0929-1.pdf

SÃO PAULO (Estado. Secretaria da Educação. CENP. Proposta Curricular para o Ensino de Química: 2ํgrau, p.54, 2011.

SCHNETZLER, R. P.; Concepções e alertas sobre formação continuada. Química Nova na Escola. № 16, Nov. p.15-20. 2002.

TAŞTAN, Özgecan; YALÇINKAYA;Eylem; BOZ, Yezdan. Pre-Service Chemistry Teachers' Ideas about Reaction Mechanism. Journal of Turkish science education. Volume 7, Issue 1, March. 2010.

VAN DRIEL, Jan H.; Students' corpuscular conceptions in the context of chemical equilibrium and chemical kinetics. Chemistry Education: Research and Practice in Europe. Vol. 3, No. 2, p. 201-213, 2002.

WANDERSEE,J.H; GRIFFARD,.B.; The History of Chemistry: Potential and Actual Contributions to Chemical Education. Chemical education: Towards Research-based practice. Kluwer Academic Publishers. p.29-46, 2002.

\section{Referências do texto do desenvolvimento histórico da cinética química}

DIAS, V. D. Cinética de Foto e Termoisomerização de Azocompostos em Matrizes Poliméricas. Dissertação de Mestrado. UNICAMP.Campinas.p.17.2004 
EYRING, H.; The Activated Complex and the Absolute Rate of Chemical Reactions. Chemical Reviews,17;p. 65-77;1935.

LAIDLER, K. J. ;The World of Physical Chemistry. p.233-283. Oxford Univ. Press; 1993.

LAIDLER, K. J.; KING, M. C. The development of Transition-State Theory. Journal Phys. Chemical. 87 ;p. 2657-2664; 1983.

LEWIS, W. C. McC. Studies in Catalysis. Part IX. The Calculation in Absolute Measure of Velocity Constants and Equilibrium Constants in Gaseous Systems. Journal of the Chemical Society, 113 p.471-491;1918.

MARTORANO, A. A. S; As concepções de ciência dos livros didáticos de química, dirigidos ao ensino médio, no tratamento da cinética química no período de 1929 a 2004. Dissertação de mestrado. Universidade de São Paulo, 2007.

PARTINGTON, J. R. A Short History of Chemistry. Ed. 3. Original London: Macmillan; New York: St Martin's Press, 1957. New York: Dover Publications, Inc., p.415, 1989.

OKI, M. Controvérsias sobre o atomismo no século XIX. Química Nova, Vol.32, 4, p.1072-1082. 2009.

SCHOR, H. H. Dinâmica de Reaçõess Químicas : de Boltzmann à Femtoquímica. Química Nova, 17 (5),p.483-488.1994.

SHORTER, J. A. G.; Vernon Harcourt. A founder of chemical kinetics and a friend of "Lewis Carrol”. Journal of Chemical Education. Vol 57 (6) ;p.411-416;1980.

\section{Referências na Internet}

http://web.lemoyne.edu/ giunta/arrlaw.html ARRHENIUS, Svante (1859-1927). Excerpt from: On the Reaction Velocity of the Inversion of Cane Sugar by Acids. Zeitschrift für Physikalische Chemie 4, 226- (1889) [as translated and published in 
Margaret H. Back \& Keith J. Laidler, eds., Selected Readings in Chemical Kinetics (Oxford: Pergamon, 1967)] (Acessado em 16 de Novembro de 2009).

http://rsbm.royalsocietypublishing.org/ BAWN, C. E. H. William Cudmore McCullagh Lewis. 1885-1956. Biogr. Mems Fell. R. Soc. 4, 192-203. 1958. (acessado em 5 de janeiro de 2010).

\section{http://openlibrary.org/b/OL7207026M/Physical chemistry and scientific thought}

LEWIS, W. C. McC. Physical chemistry and scientific thought. An Inaugural Lecture delivered, at the University of Liverpool on Friday, 16 January, p. 1-28; 1914. (Acessado em 30 de Novembro de 2009).

http://chimie.scola.acparis.fr/sitedechimie/hist chi/text origin/guldberg waage/Con cerning-Affinity.html. WAAGE and C.M. Guldberg. Studies Concerning Affinity. 1864. Henry I. Abrash, Tanslator. California State University, Northridge, CA. 91330. (Acessado em 29 de Agosto de 2009).

\section{http://dbhs.wvusd.k12.ca.us/webdocs/Equilibrium/Equilibrium-Constant.html.}

WAAGE and C.M. Guldberg. The Equilibrium Constant. 1864. (Acessado em 4 de Julho de 2009).

http://gallica.bnf.fr/ark:/12148/bpt6k91927k/f1.table. VAN'T HOFF, J. H.; Leçons de chimie physique professées à l'Université de Berlin. La dynamique chimique / par J. H. (Acessado em 22 de Agosto de 2009).

http://web.lemoyne.edu/ giunta/wilhelmy.html. WILHELMY, Ludwig Ferdinand .The Law By Which the Action of Acids on Cane Sugar Occurs. Excerpt from Poggendorf's Annalen der Physik und Chemie 81, 413-433, 499-526 (1850) [from Henry M. Leicester and Herbert S. Klickstein, eds., A Source Book in Chemistry, 1400-1900 (Cambridge, MA: Harvard, 1952). (Acessado em 16 de Novembro de 2009). 
APÊNDICES 


\section{APÊNDICE I - Autorização para a pesquisa}

Nome:

Tel:

Autorizo, gratuita e espontaneamente, a utilização pela pesquisadora Simone Alves de Assis Martorano, de minhas gravações de áudio e vídeo, para as finalidades descritas a seguir:

Publicação em tese de doutorado.

Publicação em revistas científicas.

Exposição em congressos científicos.

A utilização deste material não gera nenhum compromisso de ressarcimento, a qualquer preceito, por parte do pesquisador.

São Paulo, ,2010

Assinatura 


\section{APÊNDICE II- Instrumento 1}

Nome:

Data:

1. Você considera importante que o aluno do ensino médio, adquira conhecimentos sobre cinética química? Por que?

2. O que você acha importante ensinar sobre cinética química?

3. O que você normalmente ensina sobre cinética química?

4. Sobre os aspectos da cinética química que você ensina em suas aulas:

a. Qual você pensa ser o mais importante? Por que você acha isso?

b. Qual você considera o mais difícil de ser ensinado? Por que você acha isso?

5. Como você acha que um estudante que não pensa na matéria como descontínua interpreta o que você tenta ensinar sobre cinética química?

6. Você costuma usar aplicações para mostrar a relevância do estudo de cinética química? Se sim, quais?

7. Você usa atividades experimentais no ensino de cinética química? Se sim, complete a tabela abaixo:

\begin{tabular}{|l|l|}
\hline Tópico & Experimento usado \\
\hline $\begin{array}{l}\text { Influência da concentração na rapidez de uma } \\
\text { transformação química }\end{array}$ & \\
\hline $\begin{array}{l}\text { Influência da pressão na rapidez de uma } \\
\text { transformação química }\end{array}$ & \\
\hline $\begin{array}{l}\text { Influência da superfície de contato na rapidez } \\
\text { de uma transformação química }\end{array}$ & \\
\hline $\begin{array}{l}\text { Influência da temperatura na rapidez de uma } \\
\text { transformação química }\end{array}$ & \\
\hline $\begin{array}{l}\text { Influência do catalisador na rapidez de uma } \\
\text { transformação química }\end{array}$ & \\
\hline Outro: & Outro: \\
\hline
\end{tabular}

8. Você acha que os experimentos podem ajudar no ensino? Por que?

9. Você usa a história da química no ensino de cinética química? Se sim, complete a tabela abaixo:

\begin{tabular}{|l|l|}
\hline Tópico & $\begin{array}{l}\text { Fato ou personagem da história da } \\
\text { química usado }\end{array}$ \\
\hline $\begin{array}{l}\text { Influência da concentração na rapidez de uma } \\
\text { transformação química }\end{array}$ & \\
\hline $\begin{array}{l}\text { Influência da pressão na rapidez de uma } \\
\text { transformação química }\end{array}$ & \\
\hline $\begin{array}{l}\text { Influência da superfície de contato na rapidez } \\
\text { de uma transformação química }\end{array}$ & \\
\hline $\begin{array}{l}\text { Influência da temperatura na rapidez de uma } \\
\text { transformação química }\end{array}$ & \\
\hline $\begin{array}{l}\text { Influência do catalisador na rapidez de uma } \\
\text { transformação química }\end{array}$ & \\
\hline Outro: & Outra: \\
\hline
\end{tabular}

10. Você acha que a História da química pode ajudar no ensino? Por que? 


\section{APÊNDICE III - Folha de Atividade 1}

\section{Leitura e análise de artigo}

\section{Leitura base:}

CHAGAS, Aécio Pereira. Os noventa anos de Les Atomes. Química nova na escola. № 17 , maio 2003.

Objetivo: Leitura e analise de um texto que aborda as discussões sobre a aceitação da teoria atômica.

\section{Atividade:}

A partir da leitura do texto responda as seguintes questões:

1. Como era vista, pelos cientistas, no começo do século $X X$, a teoria atômica de Dalton introduzida no início do século XIX? Por que ela demorou, segundo o autor do artigo, para ser aceita?

2. Como você poderia utilizar artigos sobre a história da química nas suas aulas? Quais seriam as vantagens e a desvantagens? 


\section{APÊNDICE IV - Experimento 1}

Objetivo: Neste experimento vamos observar o que ocorre com a velocidade das reações quando se varia a concentração dos reagentes (adaptado de Salviano, 2007).

1. Como nós podemos alterar o tempo que uma transformação química leva para ocorrer?

\section{Materiais e Reagentes}

- 4 tubos de ensaio.

- Estante para tubos de ensaio.

- 2 conta - gotas;

- Caneta marcadora de vidro.

- Água destilada.

- Solução de $\mathrm{HCl}\left(6 \mathrm{molL}^{-1}\right)$.

- Raspas de zinco.

\section{Procedimento}

1. Numere, com a caneta marcadora de vidro, os tubos de ensaio de 1 a 4 .

2. Prepare os 4 tubos de ensaio de acordo com a tabela abaixo:

\begin{tabular}{|l|l|l|l|l|}
\hline Tubos de Ensaio & $\mathbf{1}$ & $\mathbf{2}$ & $\mathbf{3}$ & $\mathbf{4}$ \\
\hline HCl (gotas) & 9 & 9 & 9 & 9 \\
\hline Água (gotas) & 0 & 5 & 7 & 9 \\
\hline
\end{tabular}

3. Coloque uma placa (raspas) de zinco no tubo de ensaio 1 e observe a reação.

4. Repita as operações anteriores com os demais tubos de ensaio.

\section{Interpretando os Resultados}

- O que ocorre quando se adiciona gotas de água aos tubos de ensaio, contendo solução de $\mathrm{HCl}$ ?

- Em qual dos tubos de ensaio, o reagente $\mathrm{HCl}$ está presente em maior concentração? Explique.

- Em qual dos tubos de ensaio, o reagente $\mathrm{HCl}$ está presente em menor concentração? Explique.

- Visualmente, como você determinou o final da reação entre a raspa de zinco e a solução de $\mathrm{HCl}$ ?

- Qual reação foi mais rápida? Como podemos interpretar esse resultado? 


\section{APÊNDICE V - Experimento 2}

Adaptado de Olga Bagatin, Fernanda Ibanez Simplício, Silvana Maria de Oliveira Santin e Ourides Santin Filho. Rotação da luz polarizada: Abordagem histórica com proposta experimental. Química nova na escola. $N^{\circ} 21$, Maio. 2005Antes de realizar o experimento leia o texto abaixo:

\section{Breve história do desenvolvimento do polarímetro}

Em 1812, Jean Baptiste Biot observou que,

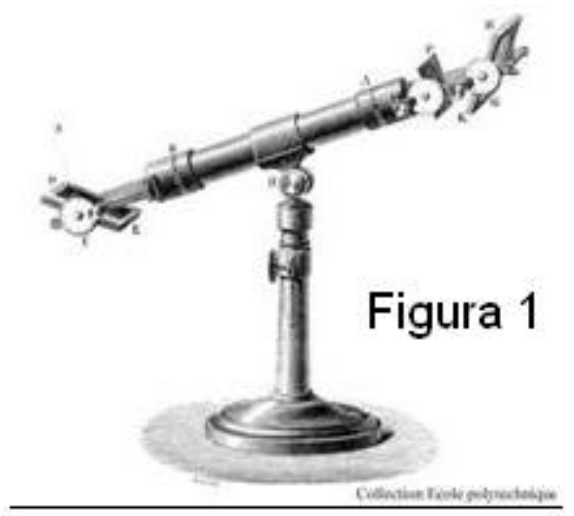
quando luz polarizada atravessava um cristal de quartzo convenientemente cortado, seu plano de polarização era rotacionado em um ângulo proporcional à espessura do cristal. Ele observou também que para alguns cristais a rotação ocorria para a direita e para outros a rotação era para a esquerda. Interessado no fenômeno, Biot estudou-o mais a fundo e percebeu efeitos similares quando a luz polarizada atravessava certos líquidos, como a terebintina e alguns óleos naturais (extrato de limão e louro). Mas, o mais surpreendente é que o mesmo efeito foi observado em soluções alcoólicas de cânfora, de alguns açúcares e de ácido tartárico. O que se constata nesses casos é que não são apenas cristais ou líquidos puros que causam rotação da luz, mas também soluções de algumas moléculas, o que indica que o fenômeno não se deve à estrutura cristalina ou a um arranjo especial do líquido, mas é decorrente da estrutura molecular em si, isto é, algumas moléculas exibem atividade óptica.

O desenvolvimento técnico e comercial dos polarímetros ocorreu de modo simultâneo na França e na Alemanha. $O$ instrumento mostrou ser um excelente aliado na análise de açúcares, em especial quando, em 1860, o governo da Prússia resolveu taxar e controlar a qualidade do açúcar refinado. Essa taxação foi rapidamente adotada por outros países, elevando a importância estratégica da boa qualidade das análises. Foi Biot que construiu o primeiro polarímetro (fig.1) especializado na análise de açúcares, o sacarímetro. Basicamente ele é um polarímetro comum, com escala indicando valores já corrigidos para percentual em massa de sacarose. Aplicações modernas do sacarímetro incluem especialmente a análise de alimentos. As indústrias têm que oferecer aos órgãos de saúde pública, laudos técnicos da composição dos alimentos que pretendem colocar no mercado. Amostras destes são enviadas a laboratórios credenciados que procedem a diversas análises, entre elas de composição e quantidade de açúcares no alimento.

\section{Roteiro Experimental}

Material e reagentes

- 1 Suporte universal 
- 2 Garras

- Açúcar (sacarose, frutose)

- Água destilada

- Fonte de luz monocromática.

- Proveta de $100 \mathrm{~mL}$ com base de vidro (se possível com fundo bem plano), ou com base plástica removível.

- Dois filtros polarizadores, de diâmetro de $55 \mathrm{~mm}$.

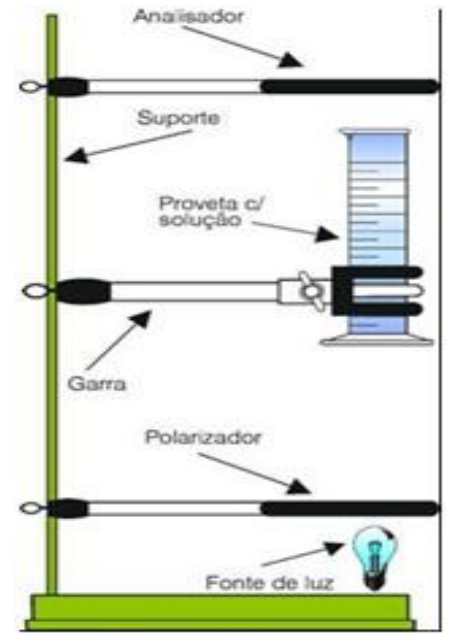

\section{Montagem}

Monte o arranjo óptico conforme mostrado na figura ao lado, mantendo os filtros polarizadores inferior e superior perpendiculares ao eixo da proveta e ao feixe de luz. Eles devem ser presos com o uso das garras fixando-se seu anel, mas permitindo sua livre rotação.

\section{Procedimento}

1. Com a proveta inicialmente vazia e a lâmpada acesa, mantenha o filtro inferior em posição fixa e gire o filtro superior em torno de seu eixo perpendicular.

2. Observe. Ajuste o polarizador superior para que o brilho observado seja máximo.

3. A seguir, acrescente água destilada.

4. Observe se ocorre algum efeito.

5. Substitua por solução de açúcar.

6. Lave a proveta com água destilada entre cada solução.

7. Em todos os casos, gire o filtro superior e observe o que acontece.

8. Procure observar em especial se o ângulo de rotação necessário para manter o brilho máximo depende da substância em estudo.

\section{Interpretando os resultados}

O que acontece com brilho do feixe de luz quando este passa pela água destilada e pela solução de açúcar? 


\section{APÊNDICE VI - Folha de Atividade 2}

Nome Data:

O papel da História da Ciência no ensino de Química

Leia o texto: "A história da ciência e o ensino de Química", retirado da Proposta Curricular para o Ensino de Química, CENP/SEESP (São Paulo, 1990).

Após a leitura do texto responda as seguintes questões:

1. Segundo a visão da proposta curricular (CENP/SEESP), qual justificativa em termos de formação do aluno do ensino médio, da introdução da História da Ciência nas aulas de Química?

2. Essas ideias parecem plausíveis para você?

3. Quais seriam, para você, as maiores dificuldades em se trabalhar com a História da Ciência, no ensino médio?

Leia um dos seguintes textos:

a) "Transformações das ideias" (texto extraído: GEPEQ. Interações e transformações - Química para o $2^{\circ}$. Grau. Livro do aluno: guia do professor. São Paulo, EDUSP,1993).

b) "Átomos e a sua combinação. A primeira ideia de átomo" de Hartwig, Souza e Mota (Química Geral e Inorgânica, Scipione.1999, p.45-48)

1. Para você qual o papel da história na abordagem do autor?

2. Tendo em vista as ideias defendidas pelo documento da CENP, você considera que a atividade desenvolvida (ou texto) está de acordo com tais ideias? 


\section{APÊNDICE VII - Instrumento 2: IDENTIFICAÇÃO DAS IDÉIAS SOBRE A CIÊNCIA (adaptado INPECIP)}

Nome:

Data:

Analise as afirmativas abaixo e marque, com um $x$, aquelas que mais se aproximam de sua visão sobre a ciência:

\section{O conhecimento científico é o conhecimento provado.}

2. A ciência tem evoluído historicamente mediante a acumulação sucessiva das teorias verdadeiras.

3. O conhecimento é construído com base em teorias que orientam a observação, em outras palavras, uma observação depende da teoria.

4. A eficácia e a objetividade do trabalho científico consistem em seguir fielmente as fases ordenadas do método científico: observação, hipótese, experimentação e elaboração de teorias.

5. Os cientistas explicam os fatos por meio de teorias que já estavam em suas cabeças antes da observação dos fatos.

6. Toda investigação científica começa pela observação rigorosa do fenômeno que se estuda.

7. O conhecimento científico se gera graças à capacidade que os seres humanos possuem para propor problemas e imaginar possíveis soluções aos mesmos.

8. Através do experimento, o investigador comprova se sua hipótese de trabalho é verdadeira ou falsa.

9. Ao realizar uma observação o cientista não deve sofrer a influência de teorias prévias sobre o problema investigado.

10.O método científico é um conjunto de etapas de atividades práticas e mentais que sem duvida alguma levara a um conhecimento verdadeiro.

11.As hipóteses dirigem o processo de investigação científica.

12. Teorias científicas são derivadas, de um modo rigoroso, de fatos adquiridos pela observação e pela experimentação.

13. As teorias determinam quais experimentos são considerados legítimos e como eles devem ser conduzidos. Em outras palavras, não existem experimentos independentes de teorias. 


\section{APÊNDICE VIII - Folha de Atividade 3}

\section{Leitura e análise de artigo}

\section{Leitura base:}

DOURADO, Luís; SEQUEIRA, Manuel. Uma análise da relação entre os conceitos de método científico e de investigação. Instituto de Educação e Psicologia, Universidade do Ninho, Braga, Portugal. 2002. Disponível em: http://webpages.ull.es/users/apice/pdf/351-076.pdf

Objetivo: Leitura e analise de um texto que aborda o método científico.

\section{Atividade:}

Leia o texto assinalando as idéias que você considera como sendo importantes para apresentar para a classe, assim como as duvidas surgidas na leitura.

$\checkmark$ A partir da leitura do texto elabore três questões para o grupo. Estas questões deverão ser entregues em uma folha separada com a sua identificação. 


\section{APÊNDICE IX - Folha de Atividade 4 - Mapa conceitual}

Nome:

Data

Considerando

$\checkmark$ As ideias sobre ciência que você considera importante que seu aluno construa durante as suas aulas de química,

elabore um mapa conceitual que relacione essas ideias e suas implicações no ensino de ciências. 


\section{APÊNDICE X - Folha de Atividade 5}

\section{Leitura e análise de artigo}

\section{Leitura base:}

CHAGAS, Aécio Pereira. 100 anos de Nobel - Jacobus Henricus van't Hoff. Química nova na escola. $n^{\circ} 14$, novembro. 2001.

Objetivo: Leitura e analise de um texto que aborda a vida e produção de um cientista.

\section{Atividade:}

A partir da leitura do texto responda as seguintes questões:

- É possível determinar, pela leitura do texto, qual era o "método científico" que van't Hoff utilizava nas suas pesquisas?

- Quais foram as contribuições de van't Hoff para o desenvolvimento da cinética química? 
Nome:

Data:

\section{Le mémoire de BERTHELOT et PEAN DE SAINT-GILLES sur les réactions d'estérification et d'hydrolyse (1861)}

A seguir se descreve os experimentos realizados por Berthelot e Péan de Saint-Gilles: as reações de esterificação e hidrólise:

" Les expériences consistent en général à introduire les substances que l'on fait réagir dans des vases scellés, à les chauffer à une température déterminée pendant un temps plus ou moins long, à analyser les produits, enfin à calculer les résultats de l'analyse... Dans tous les cas de ce genre, le produit final se compose des mêmes corps... Mais ces corps sont dans des proportions telles qu'il suffit de déterminer exactement la masse d'un seul d'entre eux, à un moment quelconque des expériences, pour en déduire toutes les autres, pourvu que l'on connaisse les masses des matières primitivement mélangées.

C'est évidemment l'acide qu'il faut déterminer, car l'acide se prête à des dosages plus rapides et plus précis qu'aucun autre composant... On transvase le produit final dans un vase à fond plat, on ajoute quelques gouttes de teinture de tournesol, et l'on verse l'eau de baryte (solution d'hydroxyde de baryum: $\mathrm{Ba}^{2+}+2 \mathrm{OH}$ ) avec une burette graduée jusqu'à ce que la teinte rose ou violacée du tournesol ait viré au bleu franc...

Si l'on élimine l'eau, la réaction d'un acide sur un alcool, à quantités de matière égales, peut atteindre un rendement de $100 \%$.»

\section{Tradução:}

"Os experimentos envolvem a introdução de substâncias para reagir em frascos fechados, aquecê-los a uma determinada temperatura, durante um tempo longo ou mais curto, para analisar os produtos e, finalmente, para calcular os resultados da análise ... Em todos esses casos, o produto final consiste de um mesmo corpo ... Mas esses corpos são de tal proporção que é suficiente para determinar com precisão a massa de um deles, em qualquer momento dos experimentos, deduzir todas as outras, desde que sabemos as massas dos materiais originalmente misturados.

Obviamente, o ácido deve ser determinado porque o ácido é adequado testes mais rápidos e precisos do que qualquer outro componente ... O produto final é colocado em um recipiente com fundo plano, adicione algumas gotas de tintura de tornassol, e derrame a água de barita (hidróxido de bário: $\mathrm{Ba}_{2}{ }^{+}+2 \mathrm{OH}^{-}$), com uma bureta graduada até "que o tornassol rosa ou roxo vire azul ...

.... Se a áqua é retirada, a reação de um ácido sobre um álcool em quantidades iguais de matéria, pode atingir um rendimento de 100\%. " 
Tabela XIX do artigo: ácido etanóico e etanol em mistura equimolar à $100^{\circ} \mathrm{C}$.

\begin{tabular}{|c|c|}
\hline Duração da experiência & $\begin{array}{c}\text { Porcentagem inicial de } \\
\text { ácido esterificado }\end{array}$ \\
\hline 15 dias (maio 1861) & 10,0 \\
22 dias & 14,0 \\
70 dias (julho) & 37,3 \\
72 dias & 38,3 \\
128 dias (setembro) & 46,8 \\
154 dias (outubro) & 48,1 \\
277 dias (janeiro) & 53,7 \\
368 dias (junho) & 55,0 \\
\hline
\end{tabular}

\begin{tabular}{|c|c|}
$\begin{array}{l}\text { Uuraçao da experıencıa } \\
\text { (horas) }\end{array}$ & $\begin{array}{c}\text { rorcentagem Inıcıaı } \\
\text { de ácido esterificado }\end{array}$ \\
\hline 4 & 25,8 \\
5 & 31,0 \\
9 & 41,2 \\
15 & 47,4 \\
32 & 55,7 \\
60 & 59,0 \\
83 & 60,6 \\
150 & 65,0 \\
\hline
\end{tabular}

Reação:

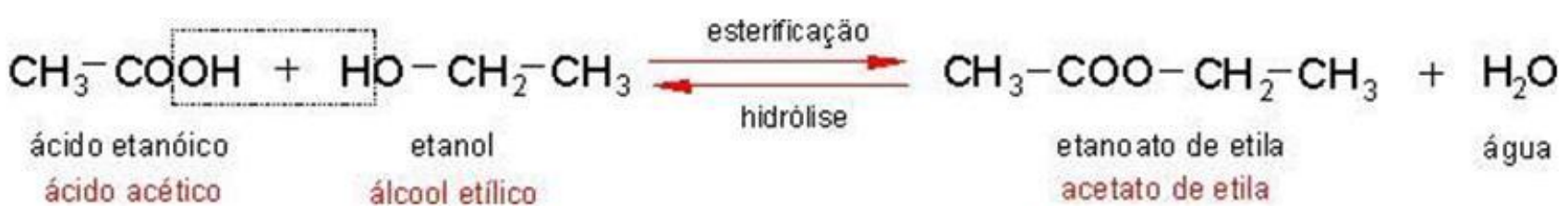

\section{Estudo das velocidades de transformação:}

1. Traçar a curva que representa a percentagem de ácido esterificado com o tempo durante o ensaio realizado a uma temperatura de $100^{\circ} \mathrm{C}$.

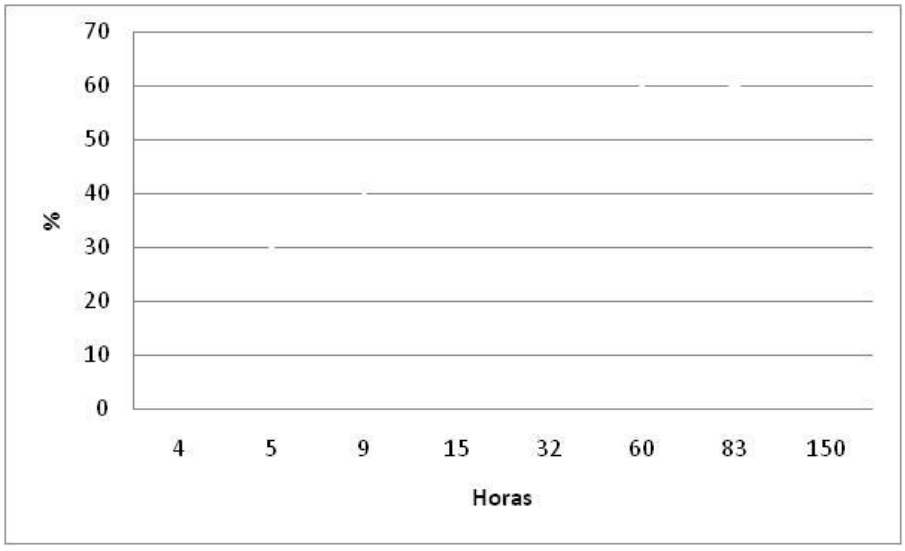

2. Como evolui a velocidade de formação de éster com o tempo? Dê uma justificativa.

3. Compare os resultados obtidos nos dois experimentos que são mostrados em ambas as tabelas. O que podemos concluir?

4. Explique a última frase do texto: "Se a água é retirada, a reação de um ácido sobre um álcool em quantidades iguais de matéria, pode atingir um rendimento de $100 \%$

\section{"APÊNDICE XII - Experimento 3}


Nome:

Data:

TíTULO: Influência da Temperatura e da Superfície de Contato na Velocidade de reação de comprimidos efervescentes com a água

Certos comprimidos antiácidos contem bicarbonato de sódio e ácido cítrico que reagem entre si quando colocados na água. Essa transformação pode ser assim representada:

$$
\mathrm{HCO}_{3}{ }^{-}(\mathrm{aq})+\mathrm{H}^{+}(\mathrm{aq}) \rightarrow \mathrm{H}_{2} \mathrm{O}(\mathrm{l})+\mathrm{CO}_{2}(\mathrm{~g})
$$

Objetivo: Neste experimento será observado o que ocorre com a rapidez das transformações químicas quando são variados dois fatores, a temperatura e a superfície de contato. Para isto, serão medidos os tempos de reação para seis sistemas formados pelos mesmos componentes, em situações distintas.

\section{Atividade:}

Antes de realizar o experimento formule um problema, dirigido ao aluno, para que essa atividade experimental passe a ter um caráter investigativo:

\section{ROTEIRO EXPERIMENTAL:}

\section{Materiais e Reagentes}

- 6 béqueres de $250 \mathrm{~mL}$ (ou copo de vidro transparente);

- cronômetro;

- termômetro

- água gelada, água quente e água em temperatura ambiente;

- 6 comprimidos de antiácido efervescente.

\section{Procedimento}

O experimento deve ser realizado em duas séries: uma com os comprimidos inteiros e outra com os comprimidos pulverizados (triturados).

1. Encha um béquer com água gelada, meça e anote a temperatura da água.

2. Coloque um comprimido efervescente no béquer e anote o tempo que decorre até a dissolução completa dele.

3. Repita as mesmas operações com água à temperatura ambiente $\left(25^{\circ} \mathrm{C}\right)$ e com a água quente. Tome $\mathrm{o}$ cuidado de usar as mesmas quantidades de reagentes e o mesmo 
critério para assinalar os tempos, inicial e final. (Obs.: o controle do volume é muito importante).

4. Complete a tabela, em seu caderno, com os dados obtidos.

\begin{tabular}{|c|l|l|l|l|l|}
\hline $\begin{array}{l}\text { Compri - } \\
\text { midos }\end{array}$ & $\begin{array}{l}\text { Evidências do } \\
\text { início da } \\
\text { Transformaçã } \\
0\end{array}$ & $\begin{array}{l}\text { Evidências do } \\
\text { final da } \\
\text { Transformaçã } \\
0\end{array}$ & $\begin{array}{l}\text { Tempo de } \\
\text { Transformaçãa } \\
\text { o com água } \\
\text { gelada }\end{array}$ & $\begin{array}{l}\text { Tempo de } \\
\text { Transformaçã } \\
\text { o com água à } \\
25^{\circ} \text { C }\end{array}$ & $\begin{array}{l}\text { Tempo de } \\
\text { Transformaçã } \\
\text { o com água } \\
\text { quente }\end{array}$ \\
\hline 1 & & & & & \\
\hline 2 & & & & & \\
\hline 4 & & & & & \\
\hline 5 & & & & & \\
\hline 6 & & & & & \\
\hline
\end{tabular}

\section{Interpretando os Resultados}

1. Compare os dados nas três temperaturas. Há regularidades? Qual reagiu mais rapidamente?

2. Procure explicar por que a transformação a baixa temperatura é mais lenta tanto para o comprimido inteiro como para o pulverizado?

3. Como a temperatura em que os reagentes se encontram pode influenciar a rapidez dessa transformação?

4. Como a superfície de contato pode influenciar a rapidez dessa transformação?

5. Utilizando o modelo de partículas para os materiais, explique por que a transformação é mais lenta quando realizada em água gelada. 


\section{Elaboração de um plano de ensino}

Nome:

Data:

\section{O plano de ensino deve considerar:}

$>\quad$ Duração 2 a 4 aulas (aproximadamente)

$>\quad$ Conteúdos relativos ao tema cinética química

$>\quad$ Conteúdo da História da cinética química.

> Conteúdos relativos a construção de uma visão de ciência.

$>\quad$ Estratégias de ensino (experimentação investigativa, textos, filmes, outros)

> Atividade de avaliação (questionário, mapa conceitual, pesquisa, elaboração ou interpretação de um texto, entre outros)

Definindo:

* Público alvo

* Número de aulas previstas

* Objetivos

* Conteúdos

* Estratégias de ensino

* $\quad$ Atividade de avaliação 


\section{APÊNDICE XIV - Instrumento 3: IDENTIFICAÇÃO DAS IDÉIAS SOBRE A CIÊNCIA (2)}

Nome:

Data:

Analise as afirmativas abaixo e identifique se elas pertencem a uma visão de ciência da perspectiva Empirista/Indutivista (E/I) ou da Racionalista (R)

\begin{tabular}{|l|l|l|}
\hline Afirmativas & E/I & R \\
\hline 1. O conhecimento científico é o conhecimento provado. & \\
\hline $\begin{array}{l}\text { 2. A ciência tem evoluído historicamente mediante a acumulação sucessiva das teorias } \\
\text { verdadeiras. }\end{array}$ & \\
\hline $\begin{array}{l}\text { 3. O conhecimento é construído com base em teorias que orientam a observação, em } \\
\text { outras palavras, uma observação depende da teoria. }\end{array}$ & \\
\hline $\begin{array}{l}\text { 4. A eficácia e a objetividade do trabalho científico consistem em seguir fielmente as } \\
\text { fases ordenadas do método científico: observação, hipótese, experimentação e } \\
\text { elaboração de teorias. }\end{array}$ & \\
\hline $\begin{array}{l}\text { 5. Os cientistas explicam os fatos por meio de teorias que já estavam em suas cabeças } \\
\text { antes da observação dos fatos. }\end{array}$ & \\
\hline $\begin{array}{l}\text { 6. Toda investigação científica começa pela observação rigorosa do fenômeno que se } \\
\text { estuda. }\end{array}$ & \\
\hline $\begin{array}{l}\text { 7. O conhecimento científico se gera graças à capacidade que os seres humanos } \\
\text { possuem para propor problemas e imaginar possíveis soluções aos mesmos. }\end{array}$ & \\
\hline $\begin{array}{l}\text { 8. Através do experimento, o investigador comprova se sua hipótese de trabalho é } \\
\text { verdadeira ou falsa. }\end{array}$ & \\
\hline $\begin{array}{l}\text { 9. Ao realizar uma observação o cientista não deve sofrer a influência de teorias prévias } \\
\text { sobre o problema investigado. }\end{array}$ & \\
\hline $\begin{array}{l}\text { 10.O método científico é um conjunto de etapas de atividades práticas e mentais que } \\
\text { sem duvida alguma levara a um conhecimento verdadeiro. }\end{array}$ & \\
\hline $\begin{array}{l}\text { 11.As hipóteses dirigem o processo de investigação científica. } \\
\text { observação e pela experimentação. }\end{array}$ & \\
\hline $\begin{array}{l}\text { 13.As teorias determinam quais experimentos são considerados legítimos e como eles } \\
\text { tevem ser conduzidos. Em outras palavras, não existem experimentos independentes de }\end{array}$ & \\
\hline
\end{tabular}

Após essa análise escreva um pequeno texto que resuma a ideia que você possui sobre o que é ciência, como ela se desenvolve e como o conhecimento científico é construído. 


\section{APÊNDICE XV - Exercício 1}

Nome:

data:

Considere a transformação química entre os reagentes " $A$ " e " $B$ " dando o produto "C".

$$
A(a q)+B(a q) \rightarrow C(a q)
$$

O professor desenhou um gráfico mostrando como a concentração de A muda com o tempo.

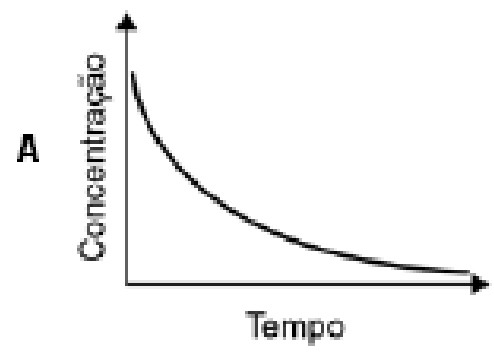

a) Desenhe um gráfico que mostre a variação da velocidade dessa reação com o tempo.

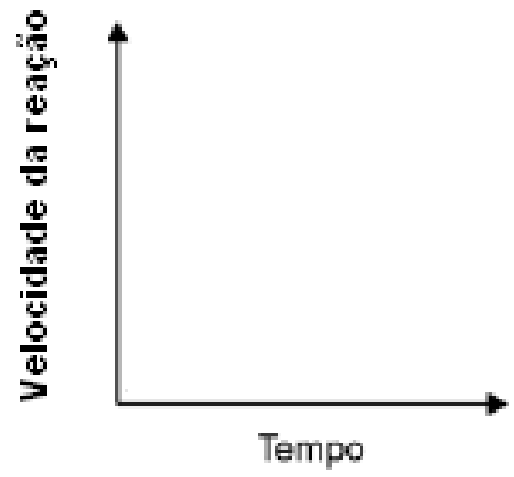

b) Como você pode provar que seu gráfico está correto? Tente explicar com o maior número de detalhes. 


\section{APÊNDICE XVI - Fontes de Pesquisa na Internet}

\section{Simulações:}

\section{Cinética química:}

http://phet.colorado.edu/en/simulation/reactions-and-rates

http://stc-mditr.org/thepoint/Interactive/

http://www.chem.uci.edu/undergrad/applets/sim/simulation.htm

Tratamentos estatísticos de Maxwell e Boltzmann:

http://www.chm.davidson.edu/vce/kineticmoleculartheory/Maxwell.html

\section{Experimentos virtuais:}

http://www.chm.davidson.edu/vce/index.html

Quiralidade: http://www.pucrs.br/quimica/professores/arigony/pasteur_final.swf

Físicoquímica: http://www.molecularium.net/

Reação de esterificação:

http://www.absorblearning.com/media/item.action?quick=11v\#

\section{História da Química:}

- Química Nova na Escola -SBQ: http://anesc.sbq.org.br/online/

- Química Nova - SBQ: http://quimicanova.sbq.org.br/

- História da Ciência e Ensino - PUC:

http://revistas.pucsp.br/index.php/hcensino/login

- Revista Brasileira de História da Ciência:

http://www.sbhc.org.br/revistas atual.php

- Grupo de História e Teoria da Ciência- UNICAMP:

http://www.ifi.unicamp.br/ ghtc/index.htm

- Textos Selecionados por Carmen Giunta- Fontes primárias (em inglês):

http://web.lemoyne.edu/ giunta/index.html

- Society for the History of Alchemy and Chemistry (em

inglês):http://www.ambix.org/

- Premio Nobel: http://nobelprize.org/ 


\section{APÊNDICE XVII - Folha de atividade 8}

Nome: Data

OBJETIVO: Análise do plano de ensino

1. Analisando os objetivos que você pretende alcançar em seu plano de ensino, sobre cinética química, tente colocar em cada vértice do triangulo abaixo, as competências e habilidades que você pretende que seu aluno desenvolva:

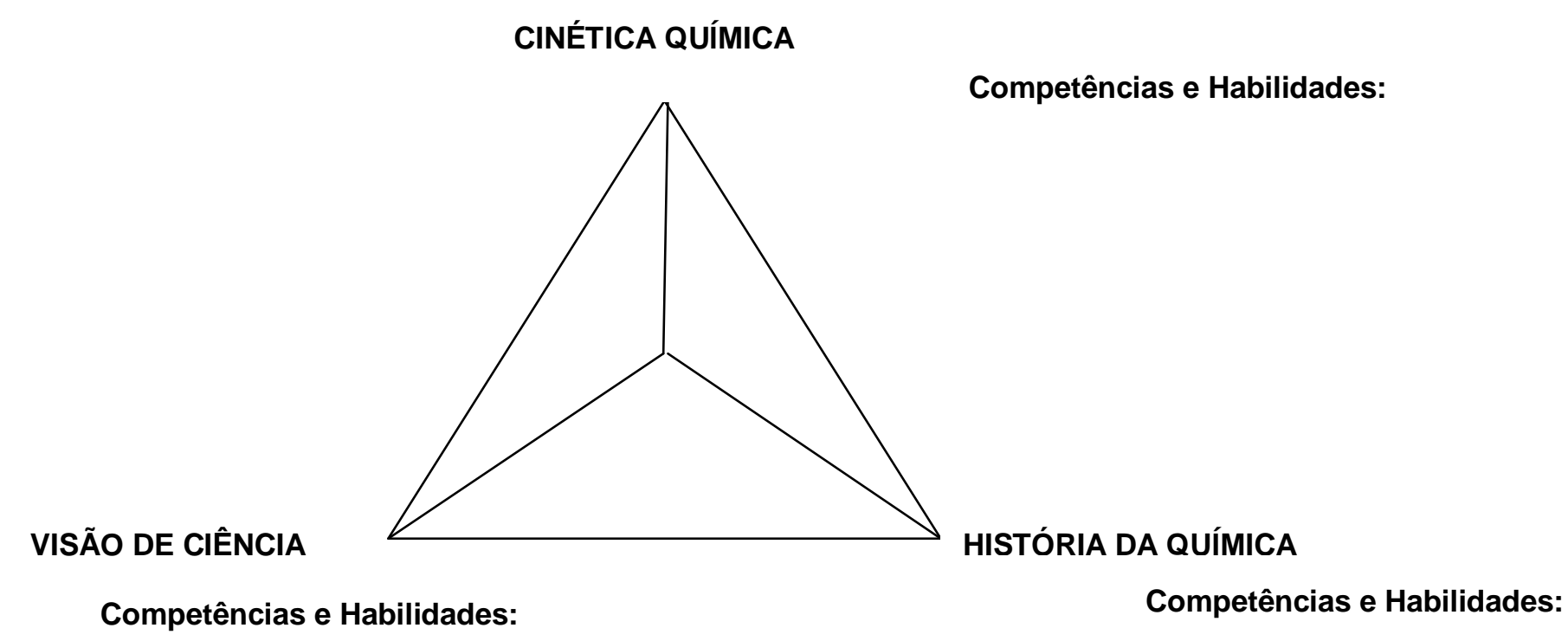




\section{APÊNDICE XVIII- Folha de atividade 9}

Nome:

Data

1. Tente classificar as idéias sobre cinética química, que se encontram no quadro a segui, em quatro Programas de Investigação Científica, considerando que esses programas são constituídos pelos seguintes elementos:

Núcleo duro: modelo que explica a velocidade de uma reação química. Cinturão protetor: dois atributos que influenciam a velocidade de uma reação química. São eles: a concentração das substâncias reagentes e a temperatura.

Heurística positiva (questões que orientam o desenvolvimento do programa):

1-De que modo a velocidade de uma reação química depende das concentrações das substâncias reagentes?

2-Como a temperatura pode influenciar a velocidade de uma reação química?

Mudança de PIC: um programa de investigação suplanta o anterior, quando apresenta explicações mais amplas sobre as velocidades das reações químicas (núcleo do programa). 


\section{Programas de Investigação Científica:}

Núcleo: Como você explicaria, em termos microscópicos, a velocidade de uma reação química?

A velocidade de uma reação depende do número de moléculas que possuem um determinado valor de energia necessário para que a reação ocorra.

A velocidade de uma reação química depende da freqüência com que o complexo ativado, formado durante a quebra e a formação de novas ligações, são convertidos em produtos.

A velocidade de uma reação química depende do número de colisões por segundo que acontecem entre as moléculas reagentes que possuem um determinado valor de energia.

A velocidade de uma reação química é proporcional a quantidade de substâncias que estão reagindo num determinado tempo.

\section{Cinturão protetor:}

\section{Qual é a relação entre a velocidade de uma reação química e as} concentrações das substâncias que estão reagindo?

Quanto maior a concentração das moléculas que possuem um valor inicial necessário de energia, maior a velocidade desta reação.

Quanto maior a quantidade de substâncias, maior é chance de ocorrer interação entre as elas, o que pode acarretar um aumento de velocidade desta reação.

Quanto maior a concentração do complexo ativado, maior a velocidade desta reação.

Quanto maior a concentração de moléculas que conseguem transpor a barreira de energia dessa reação química, maior a velocidade desta reação.

\section{Como a temperatura pode influenciar a velocidade de uma reação} química?

As variações de temperatura exercem grande influência sobre a velocidade das reações químicas. Geralmente as reações ocorrem mais rápido quando aquecidas.

A elevação da temperatura causa um aumento do número de moléculas com energia necessária para a formação do complexo ativado de uma determinada reação química.

A elevação da temperatura causa um aumento do número de moléculas com energia necessária para participarem da reação química.

A elevação da temperatura causa um aumento do número de moléculas com energia necessária para transpor a barreira de energia de uma determinada reação química. 


\section{APÊNDICE XIX - Avaliação do Curso}

Nome:

Data:

Para que possamos melhorar nosso trabalho, pedimos sua colaboração, respondendo as questões a seguir e adicionando os comentários que desejar. (Se necessário utilize o verso da folha para a sua resposta)

1. No inicio do curso foram levantadas algumas dificuldades em relação à inclusão da História da Ciência no ensino de cinética química:

- Falta de materiais, estratégias, experimentos que incluam a história da ciência;

- Falta de textos e fontes de consulta sobre a história da ciência.

Você acha que, após o curso, algumas dessas dificuldades foram superadas? Justifique.

2. No inicio do curso foram levantadas algumas dificuldades em relação ao ensino de cinética química:

- Dificuldade no entendimento dos fatores que afetam a velocidade de uma transformação química (por exemplo, temperatura e concentração);

- Dificuldade no entendimento dos modelos explicativos (teoria da colisão e teoria do complexo ativado).

Você acha que, após o curso algumas dessas dificuldades foram superadas? Justifique.

3. Sobre quais aspectos relacionados à sua prática você refletiu através do curso? Justifique.

4. Para você quais foram os pontos positivos do curso?

5. Para você quais foram os pontos negativos do curso?

Faça outros comentários sobre o curso e sugestões se achar necessário: 
ANEXOS 


\section{ANEXO I - Prática 01 - Decomposição da Matéria Orgânica}

Materiais e Reagentes: fígado cru; óleo de soja; polpa de tomate; papel alumínio ; açúcar; 10 copinhos de plástico ; sal .

\section{Procedimento:}

O experimento deve ser realizado em duas séries: uma com os copinhos de plástico abertos e outra com os copinhos de plástico tampados com papel alumínio.

- Numere os copinhos de 1 a 10.

- Colocar as amostras de acordo com o indicado na tabela 1.

Tabela 1. Organização das Amostras.

\begin{tabular}{|c|c|c|}
\hline \multirow{2}{*}{ Amostras } & \multicolumn{2}{|c|}{ Recipientes } \\
\cline { 2 - 3 } & Aberto & Fechado \\
\hline polpa de tomate & 1 & 2 \\
\hline polpa de tomate com açúcar & 3 & 4 \\
\hline fígado cru & 5 & 6 \\
\hline fígado cru com bastante sal & 7 & 8 \\
\hline fígado cru com bastante óleo & 9 & 10 \\
\hline
\end{tabular}

Deixe os copinhos em repouso, longe da exposição ao sol, por 3 dias.

Observe e anote a cor, cheiro, consistência, etc., de cada um dos sistemas.

Atenção: Nas amostras 3 e 4, o açúcar deve ser colocado sobre a poupa de tomate, formando uma camada protetora. Nas amostras 7, 8, 9 e 10 o sal e o óleo devem envolver o fígado completamente.

\section{2a. Aula:}

\section{Resultados Obtidos:}

- Copos abertos 


\begin{tabular}{|c|c|c|}
\hline Amostras & Recipientes & Analises \\
\hline $\begin{array}{l}\text { Polpa de } \\
\text { tomate }\end{array}$ & 01 & $\begin{array}{l}\text { O tomate ficou seco totalmente. } \\
\text { Pontos brancos na superfície. }\end{array}$ \\
\hline $\begin{array}{l}\text { Polpa de } \\
\text { tomate com } \\
\text { açúcar }\end{array}$ & 03 & O tomate permaneceu com a mesma cor, endureceu \\
\hline Fígado cru & 05 & $\begin{array}{l}\text { O fígado está com cor amarronzada e aparentemente } \\
\text { endurecido com manchinhas brancas por cima. }\end{array}$ \\
\hline $\begin{array}{l}\text { Fígado cru com } \\
\text { sal }\end{array}$ & 07 & $\begin{array}{l}\text { O fígado está com uma cor marrom esverdeada e } \\
\text { com um pouco de líquido, aparentemente mole. }\end{array}$ \\
\hline $\begin{array}{l}\text { Fígado cru com } \\
\text { óleo }\end{array}$ & 09 & O fígado ficou marrom e mole. \\
\hline
\end{tabular}

- Copos fechados

\begin{tabular}{|l|c|l|}
\hline Amostras & Recipientes & Analises \\
\hline Polpa de tomate & 02 & $\begin{array}{l}\text { O tomate parece estar desidratado. } \\
\text { Ficou branco (fungos),ficou com tom rosado. }\end{array}$ \\
\hline $\begin{array}{l}\text { Polpa de tomate } \\
\text { com açúcar }\end{array}$ & 04 & $\begin{array}{l}\text { Coloração igual, presença de água. Presença de } \\
\text { bolhas. }\end{array}$ \\
\hline Fígado cru & 06 & $\begin{array}{l}\text { Mudou de cor, parece estar esverdeado. } \\
\text { Com nuances de marrom. Parece estar duro. }\end{array}$ \\
\hline $\begin{array}{l}\text { Fígado cru com } \\
\text { sal }\end{array}$ & 08 & Ficou esverdeado e marrom, com água ao redor. \\
\hline $\begin{array}{l}\text { Fígado cru com } \\
\text { óleo }\end{array}$ & 10 & $\begin{array}{l}\text { Manchas brancas e mudou a coloração para } \\
\text { marrom muito escuro. Ficou com uma cor preta, } \\
\text { parece que está com bolinhas. Criou fungos. }\end{array}$ \\
\hline
\end{tabular}

Observação:

- A decomposição da matéria orgânica é feita por bactérias e microorganismos na presença de oxigênio e umidade.

- Em recipientes abertos a decomposição é mais rápida por causa da maior concentração de gás oxigênio.

- Quando colocamos a matéria orgânica na geladeira, diminuímos a proliferação da colônia de bactérias, por isso a decomposição é retardada.

- A polpa de tomate entra em decomposição mais rapidamente do que a polpa de tomate com açúcar.

- O açúcar, colocado na superfície da carne, funciona como uma barreira, diminuindo o contato do oxigênio com a polpa de tomate.

- O fígado cru se decompõe mais rapidamente do que o fígado com sal.

- O sal e o óleo funcionam como bactericidas, impedindo que as bactérias ataquem a carne e promovam sua decomposição. 


\section{ANEXO II - Prática 02 - Influencia da Temperatura e da Superfície de Contato na Velocidade de Dissolução de Comprimidos Efervescentes}

Objetivo: Neste experimento será observado o que ocorre com a velocidade das reações quando se varia a temperatura e a superfície de contato. Para isto, serão medidos os tempos de reação para seis sistemas formados pelos mesmos componentes, em situações distintas.

Materiais e Reagentes

- 6 béqueres de $250 \mathrm{~mL}$ (ou copo de vidro transparente);- cronômetro;- água gelada, água quente e água em temperatura ambiente;

- termômetro até $100^{\circ} \mathrm{C}$;- 6 comprimidos de anti - ácido efervescente.

Procedimento

O experimento deve ser realizado em duas séries: uma com os comprimidos inteiros e outra com os comprimidos pulverizados (triturados).

2. Evidências e Tempo de Reação.

- Encha um béquer com água gelada, meça e anote a temperatura da água.

- Coloque um comprimido efervescente no béquer e anote o tempo que decorre até a dissolução completa dele.

- Repita as mesmas operações com água à temperatura ambiente $\left(25^{\circ} \mathrm{C}\right)$ e com a água quente. Tome o cuidado de usar as mesmas quantidades de reagentes e o mesmo critério para assinalar os tempos inicial e final.

Comentários: Esse experimento explora dois fatores que influenciam a velocidade de uma reação química, a superfície de contato e a temperatura. Ao final do experimento o aluno poderá verificar que as reações feitas com água quente foram mais rápidas, e dentre elas, a feita com comprimido pulverizado foi a de maior velocidade. O ideal é que inicialmente os alunos discutam em pequenos grupos os resultados e que depois as ideias sejam discutidas no grande grupo (professor e alunos) para sistematizar os conteúdos trabalhados.

A reação de dissolução dos comprimidos ocorre mais rapidamente em água quente, e mais lentamente em água fria. Quanto maior a temperatura do sistema, maior a energia cinética, maior o número de colisões entre as moléculas dos reagentes, e por isso, maior a velocidade da reação. 


\section{ANEXO III - Prática 3- Por que alimentos estragam?}

(Ponto ciência- http://pontociencia.org.br/experimentos-interna.php?experimento=531)

Problema: Quando deixamos um alimento aberto ou fora da geladeira por alguns dias, ele estraga. Aparece mofo, bolor e, dependendo da quantidade de tempo, pode aparecer até larvas.

\section{Materiais Necessários}

- Placas de Petri (de plástico ou de vidro), Ração de cachorro, Pão de forma, Sal de cozinha ou tempero pronto que contenha alho, Água, Alimentos (biscoito, farinha, cereal), Canetas marcadoras de texto.

\section{Roteiro:}

1. Identifique as placas de Petri com as seguintes marcações:

Placa 1- Ração molhada

Placa 2- Ração seca

Placa 3- Molhada com tempero

Placa 4- Molhada sem tempero

Placa 5- Pão seco

Placa 6- Pão seco com tempero

Placa 7- Pão molhado com tempero

Placa 8- Pão molhado

2. Distribua a ração, o pão, o tempero ou sal e a água, de acordo com as indicações escritas nas placas.

3. Tampe as placas e guarde em abrigo seguro. Embale com plástico filme as seguintes placas: ração molhada sem tempero, ração molhada sem tempero, pão molhado sem tempero e pão molhado com tempero.

4. Aguarde uma semana e observe os resultados.

\section{$O$ que acontece:}

- Desenvolveram colônias de fungos e até larvas de insetos.

- Na placa ração seca e sem sal e na placa ração seca e com sal não houve proliferação visível de nenhum organismo.

- Nas placas ração molhada e ração molhada e sal cresceram fungos e até mesmo larvas.

- Percebemos claramente, com esse experimento, que a água influencia no desenvolvimento dos fungos.

- As placas com pão apresentaram resultados semelhantes aos daquelas com ração.

- Alguns seres vivos não conseguem sobreviver em altas concentrações de sal. Altas concentrações de sal provocam desequilíbrio osmótico, levam à desidratação.

- A conclusão que podemos chegar ao observamos esses resultados é que a presença de água promove a proliferação de bolor e larvas e a presença de sal dificulta o desenvolvimento de fungos e larvas. MICROORGANISMOS. 


\section{ANEXO IV- Linha do tempo elaborada pela professora P11}

\begin{tabular}{|c|c|c|c|c|c|c|c|}
\hline 1808 & 1812 & 1850 & 1865 & 1884 & 1889 & 1918 & 1935 \\
\hline $\begin{array}{l}\text { Dalton: } \\
\text { Modelo } \\
\text { atômico }\end{array}$ & $\begin{array}{c}\text { Biot: } \\
\text { Polarímetro }\end{array}$ & $\begin{array}{l}\text { Wilhelmy: Efeito da } \\
\text { concentração na } \\
\text { velocidade da } \\
\text { transformação química } \\
\text { (primeiro estudo } \\
\text { quantitativo). }\end{array}$ & $\begin{array}{l}\text { Harcourt e Esson: } \\
\text { Estudo da influência da } \\
\text { concentração; estudo } \\
\text { cinético com o foco no } \\
\text { caminho de uma } \\
\text { transformação química. }\end{array}$ & $\begin{array}{l}\text { Van't Hoff: estudo } \\
\text { da influência da } \\
\text { temperatura na } \\
\text { velocidade de uma } \\
\text { transformação } \\
\text { química; } \\
\text { determinação da lei } \\
\text { da velocidade de } \\
\text { uma transformação } \\
\text { química, } v=k C^{n}\end{array}$ & $\begin{array}{l}\text { Arrhenius: } \\
\text { energia de } \\
\text { ativação (ideia de } \\
\text { barreira que as } \\
\text { moléculas dos } \\
\text { reagentes devem } \\
\text { transpor para que } \\
\text { consigam reagir e } \\
\text { formar produtos) }\end{array}$ & $\begin{array}{l}\text { Lewis e } \\
\text { Trautz: } \\
\text { Teoria das } \\
\text { colisões. }\end{array}$ & $\begin{array}{l}\text { Eyring, Polanyi e } \\
\text { Evans : Teoria do } \\
\text { Estado de } \\
\text { Transição(Complexo } \\
\text { ativado). }\end{array}$ \\
\hline
\end{tabular}




\section{ANEXO V - Texto 1 professora P15 \\ "Um breve histórico sobre Cinética Química"}

Um dos objetivos da Química é o de compreender os fatores e leis que influem na velocidade ou "rapidez" das transformações químicas, assim como os eventos microscópicos que se desenrolam durante essas transformações.

Através desse conhecimento, é possível hoje controlarmos a velocidade das transformações químicas tornando-as rápidas quando o objetivo for obter maior rendimento num processo, ou lentas quando oferecem riscos de acidentes, por exemplo.

O ramo da Química dedicado a este estudo denomina-se Cinética Química (do grego kinetiké, que significa "movimento"), o qual se desenvolveu a partir de meados do sec. XIX, graças ao trabalho árduo de vários cientistas que em meio a tantos erros e acertos, ajudaram a construir esta tão importante área da ciência.

Ludwig Wilhemy (1850) foi o primeiro cientista a investigar a rapidez de uma reação ao estudar a hidrólise da sacarose em meio ácido e acompanhando o progresso da mesma por meio de um polarímetro. Nesse estudo, ele utilizou diversos ácidos em diferentes concentrações, variando as quantidades de açúcar e trabalhando em diversas temperaturas e chegou a uma expressão matemática que representa a rapidez de uma transformação química, hoje interpretada como: V = K[reagentes], em que $\mathrm{K}$ é uma constante. Em 1860, Williamsom veio contribuir ainda mais nesse sentido, afirmando: "Se uma transformação química se realizar em um determinado intervalo de tempo, no sentido de formação dos produtos e estes, por sua vez, interagirem reconstituindo os reagentes, haverá um momento em que as duas transformações ocorrerão com a mesma rapidez, estabelecendo entre elas um equilíbrio".

Berthelot e Péan de Saint-Gilles (1862-1863) estudando a esterificação entre um ácido e um álcool, observaram que essa transformação "parava" em um dado instante e que por esta razão nunca se completava pois aproximava-se de um "limite' que correspondia ao "equilíbrio".

Em 1884, o químico holandês Jacobus Henricus van't Hoff (1852-1911) publicou o livro "Études de dynamique chimique" que foi considerado uma das mais importantes obras de química de todos os tempos. Neste livro ele aborda vários temas e os correlaciona com dados experimentais que já existiam na literatura. Devemos a van't Hoff a introdução dos conceitos de ordem de reação, constante de velocidade, constante de equilíbrio, as duas setas opostas, natureza dinâmica do equilíbrio, efeito da temperatura e pressão no equilíbrio, e com relação ao efeito da concentração na velocidade de uma transformação química, van't Hoff estendeu e generalizou a análise matemática feita por Wilhemy. Criou também, juntamente com F.W. Ostwald (1853-1932; Prêmio Nobel de Química em 1909) e S.A. Arrhenius (1859-1927; Prêmio Nobel de Química em 1903), uma nova disciplina: a Físico-Química. Os três e seus estudantes encarregaram-se em divulgar a importância e a utilidade dessa área, que graças a eles cresceu e prosperou.

Jacobus Henricus van't Hoff foi o primeiro cientista a receber o Prêmio Nobel de Química, em 1901. Uma merecida homenagem a um dos químicos mais influentes do seu tempo.

Após a leitura do texto o professor deve organizar a sala em grupos para que sejam debatidas as seguintes questões:

1. Podemos atribuir apenas a van't Hoff (Prêmio Nobel de Química-1901) os conhecimentos de cinética química que temos hoje? Por quê? 
2. É correto afirmar que a ciência é um conjunto de conhecimentos isolados e acabados? Explique.

3. Ao investigar a rapidez da hidrolise da sacarose, Wilhemy alterou alguns fatores como concentração do ácido, quantidade de açúcar e temperatura. De que maneira você acredita que esses fatores foram alterados: todos de uma vez ou cada um de forma isolada? Explique.

4. No segundo parágrafo do texto lemos que hoje é possível controlarmos a velocidade das reações químicas. Cite exemplos que mostram que as vezes é conveniente torná-las "rápidas" e outras vezes, torná-las "lentas".

Obs. As respostas podem ser discutidas entre os grupos e o professor deve atuar como mediador na construção de argumentações consistentes.

\section{Comentários:}

Ao responder a $1^{\text {a }}$ questão, espera-se que os alunos tenham compreendido a importante contribuição dada por outros cientistas, contemporâneos a van't Hoff ou que o antecederam, na construção dos conceitos por ele elaborados.

$\mathrm{Na} 2^{\underline{a}}$ questão, deve ser reforçada a ideia de que o conhecimento científico está em contínua evolução e que depende do contexto sociocultural em que se desenrola. (É importante ressaltar que na época citada no texto, não se trabalhava nem com o modelo atômico de Dalton, pois este só foi aceito pela comunidade científica no final do sec. $X I X !)$

Talvez os alunos tenham dificuldade em responder a $3^{\text {a }}$ questão. Se isto ocorrer, podemos pedir que reflitam sobre a seguinte situação: "Imagine que toda vez que almoçamos arroz, feijão e batata frita sentimos azia. Se quisermos descobrir qual dos três alimentos nos provoca esse desconforto, eliminamos um de cada vez até descobrirmos qual deles nos faz mal".

A 4⿳亠丷a questão aborda a importância em se conhecer as leis que regem um fenômeno a ponto de podermos manipulá-lo. O ideal é que o aluno busque exemplos ligados ao seu cotidiano, como congelar um alimento para que ele demore mais tempo para estragar, ou produzir algo em escala industrial no menor tempo possível, para economizar energia e diminuir o custo final do processo. 


\title{
ANEXO VI - Texto complementar do plano de ensino da professora P15
}

\author{
Um breve histórico sobre cinética química" ( $2^{\mathrm{a}}$ Parte)
}

(texto de apoio)

$\mathrm{Na}$ aula anterior, ao estudarmos o primeiro texto e a evolução dos eventos que permitiram o desenvolvimento da cinética química, vimos que o primeiro polarímetro foi construído por Biot em 1812 e que em 1850, Wilhemy utilizou um polarímetro para investigar pela primeira vez a velocidade de uma transformação química, no caso, a hidrólise da sacarose. Este episódio consagrou a cinética como campo de estudo da química, pois até então, ela era estudada apenas em física.

Wilhemy estudou como a concentração do açúcar e a temperatura, na qual ocorria a reação, podiam interferir na sua velocidade e o enfoque da sua pesquisa, como de todas as pesquisas de sua época, era empírico-matemático (ou empírico-indutivista), ou seja, a partir da observação o cientista induzia uma comprovação experimental e a partir dos dados experimentais obtidos elaboravam-se hipóteses que depois se tornavam teorias ou leis, dependendo do número de provas por detrás da idéia. Tais teorias ou leis eram descritas matematicamente e desta forma o desenvolvimento da ciência acontecia de forma contínua, acumulativa, as conclusões eram definitivas e o homem construía o próprio conhecimento.

Hoje sabemos que a ciência progride por dedução (método racionalista) e está voltada para a identificação, investigação e resolução de problemas. O progresso é caracterizado como uma "problemática progressiva" de uma tentativa teórica para outra.

A experimentação serve apenas de suporte a favor ou contra as hipóteses formuladas e nem toda investigação permite a realização de experiências devido ao custo, perigo, ética ou outras implicações.

Em 1867, Pfaunder sugere pela primeira vez uma explicação da velocidade em nível molecular, alegando que apenas as moléculas com maior energia, poderiam sofrer algum tipo de transformação.

A partir do séc. $X X$ os estudos de cinética passaram a enfocar as transformações químicas em nível microscópico a fim de explicar o comportamento das moléculas durante essas transformações.

Questões:

1) Qual é a importância do estudo da cinética química?

2) O trabalho de Wilhemy foi empírico-matemático, como era o enfoque das pesquisas em sua época. Qual era o papel da "experimentação" no trabalho de Wilhemy e no de outros cientistas de sua época? 


\section{ANEXO VII - Roteiro da atividade experimental P15}

\section{Atividade Experimental: "Rapidez ou Velocidade"}

I) OBJETIVO:

Construir o conceito de rapidez de uma transformação química a partir do estudo da velocidade de deslocamento de uma partícula.

I) INTRODUÇÃO:

Quando falamos em "velocidade", logo lembramos o conceito relacionado à física que a define como o deslocamento de um corpo na unidade de tempo. Em química, esse conceito tem um significado muito diferente, por esta razão, adotaremos o termo "rapidez" ao invés de velocidade quando estivermos tratando de transformações químicas.

\section{II) CONSIDERAÇÕES TEÓRICAS:}

Em 1829, Thomas Graham, um químico inglês, relatou os resultados de suas observações das velocidades de difusão de vários gases. Difusão é o termo dado à passagem de uma substância através de um outro meio. (Por exemplo, quando alguns alimentos são cozidos, eles libertam gases que logo se difundem através do ar e são detectados pelas nossas narinas.) Graham concluiu que a velocidade de difusão de um gás através de outro é inversamente proporcional à raiz quadrada da densidade do gás. Se representarmos por $\boldsymbol{d}$ a densidade, podemos escrever:

$$
\text { Velocidade }=\text { constante } \times \frac{1}{\sqrt{d}}
$$

Ou, para os gases A e B,

$$
\frac{\text { Velocidade de } A}{\text { Velocidade de } B}=\frac{\sqrt{d B}}{\sqrt{d A}}, \quad \text { onde } \quad d=\frac{M}{\text { Volume Molar }(22,4 L)}
$$

Modernamente, podemos expressar esta lei através das massas molares,

$$
\frac{\text { Velocidade de } A}{\text { Velocidade de } B}=\sqrt{\frac{d B}{d A}}=\sqrt{\frac{M B}{M A}}
$$

III) PROCEDIMENTO: 
Em um tubo de vidro de mais ou menos $60 \mathrm{~cm}$, introduzimos dois chumaços de algodão, um embebido em ácido clorídrico $(\mathrm{HCl})$ e o outro em solução aquosa de amônia $\left(\mathrm{NH}_{3}\right)$, ambos concentrados. Logo em seguida, fecham-se os extremos com rolhas, ligase o cronômetro e mede-se o tempo necessário para o surgimento de um anel de fumaça de cloreto de amônio que se forma de acordo com a equação:

$$
\mathrm{NH}_{3}(\mathrm{~g})+\mathrm{HCl}_{(\mathrm{g})} \longrightarrow \mathrm{NH}_{4} \mathrm{Cl}_{(\mathrm{s})}
$$

Medir com uma régua a distância entre o anel e as duas extremidades do tubo e sabendo-se que a expressão da velocidade de deslocamento de uma partícula é dada por:

$$
\text { Velocidade da partícula de gás }=\frac{\text { distância percorrida pela partícula de gás }}{\text { tempo de deslocamento }}
$$

Complete o quadro abaixo:

\begin{tabular}{|l|l|}
\hline Tempo de formação do anel $(\mathrm{s})$ & \\
\hline Distância entre $\mathrm{HCl}$ e o anel $(\mathrm{m})$ & \\
\hline Distância entre $\mathrm{NH}_{3}$ e o anel $(\mathrm{m})$ & \\
\hline Velocidade da partícula de $\mathrm{HCl}(\mathrm{m} / \mathrm{s})$ & \\
\hline Velocidade da partícula de $\mathrm{NH}_{3}(\mathrm{~m} / \mathrm{s})$ & \\
\hline
\end{tabular}

IV) INTERPRETAÇÃO DOS RESULTADOS:

1) Sugira uma explicação para a diferença das velocidades dos dois gases levando-se em conta as diferenças entre as partículas de $\mathrm{HCl}$ e $\mathrm{NH}_{3}$ e suas diferentes velocidades de difusão.

2) Analise os dados da tabela abaixo para a reação genérica: $\mathbf{A} \longrightarrow \mathbf{B}$

\begin{tabular}{|c|c|c|c|c|c|}
\hline [ A ] mol/L & 1 & 0,625 & 0,375 & 0,200 & 0,120 \\
\hline Tempo (min) & 0 & 10 & 20 & 30 & 40 \\
\hline
\end{tabular}

A seguir, resolva os itens abaixo:

I. Construa o gráfico da Concentração de A em função do Tempo

II. Responda:

a. A $[A]$ aumenta ou diminui com o passar do tempo?

b. A velocidade desta reação tende a aumentar ou diminuir com o tempo?

c. Utilizando o mesmo modelo da expressão de velocidade de deslocamento de uma partícula, como você expressaria a "rapidez" desta transformação química? 


\section{ANEXO VIII - Roteiro atividade (plano de ensino, P15)}

Atividade: O modelo submicroscópico representado abaixo foi elaborado com base no experimento estudado na aula anterior. Analise-o e responda às questões:

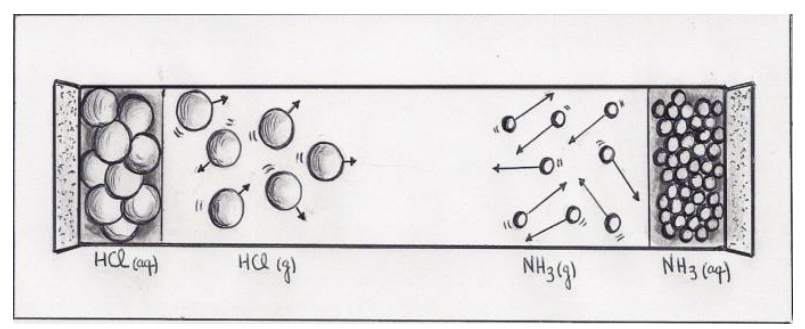

1. O que foi preciso ocorrer para que as substâncias reagentes se convertessem em produto?

2. Das situações representadas abaixo, qual delas sugere a possibilidade de formação de produto? Justifique sua resposta.

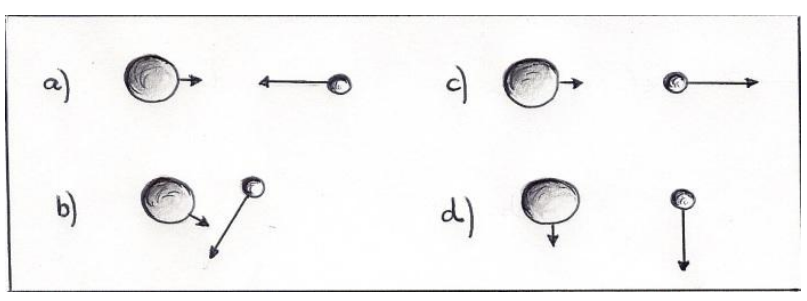

3.Reelabore o modelo submicroscópico apresentado, considerando o instante em que a transformação química torna-se evidente. A quais conclusões podemos chegar com relação à rapidez desta transformação química?

Em relação a essa atividade a professora esperava que:

As questões (1) e (2) dessa atividade deverão auxiliar na construção dos conceitos relacionados à Teoria das Colisões e o professor deverá mediar esta construção fornecendo elementos necessários e explorando a ideia de que as colisões que originam os produtos só ocorrem quando as partículas possuem energia suficiente e orientação certa.

$\mathrm{Na}$ questão (3), espera-se que o aluno elabore um modelo no qual houve algumas colisões efetivas, portanto, formação de algumas moléculas de produto.

A diminuição na quantidade de moléculas reagentes deve também ser destacada no modelo com o intuito de explicar que a rapidez da transformação química tende a diminuir, uma vez que a probabilidade de ocorrerem colisões efetivas diminui. 